Protección

social en

América Latina

La desigualdad en el banquillo

\title{
ANA SOJO
}
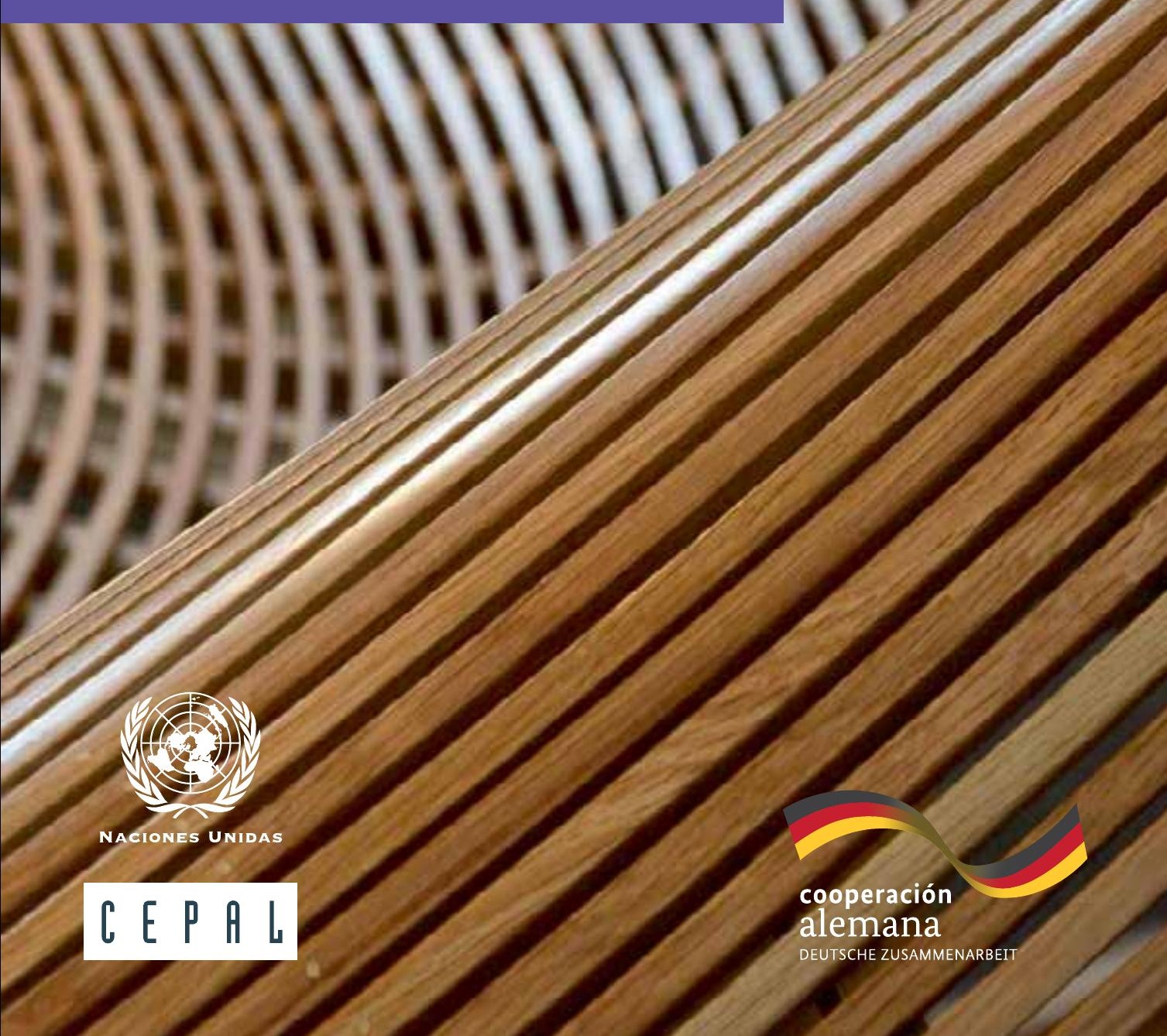


\section{Gracias por su interés en esta}

\section{publicación de la CEPAL}

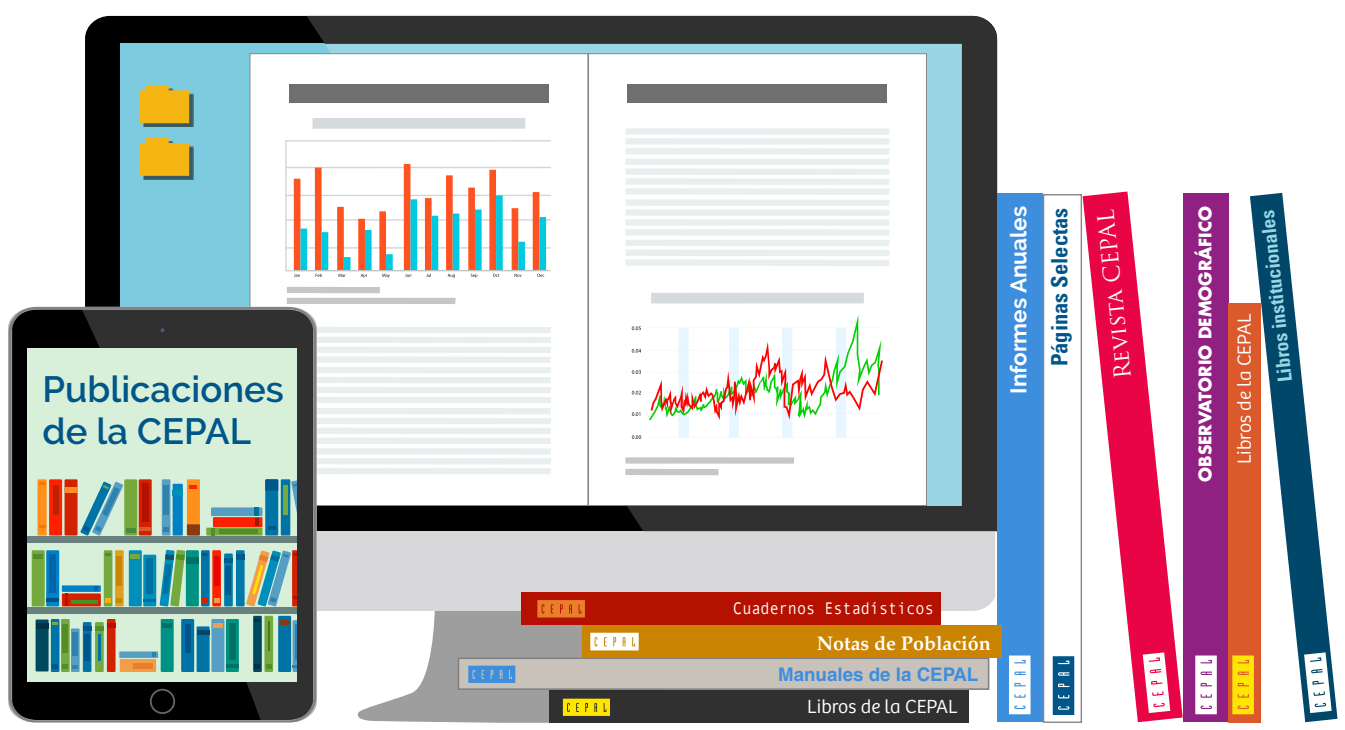

Si desea recibir información oportuna sobre nuestros productos editoriales y actividades, le invitamos a registrarse. Podrá definir sus áreas de interés y acceder a nuestros productos en otros formatos.

\section{Deseo registrarme}

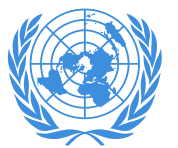

NACIONES UNIDAS

C E P \& L

\section{www.cepal.org/es/suscripciones}




\section{Protección social en América Latina}

\section{La desigualdad en el banquillo}

Ana Sojo
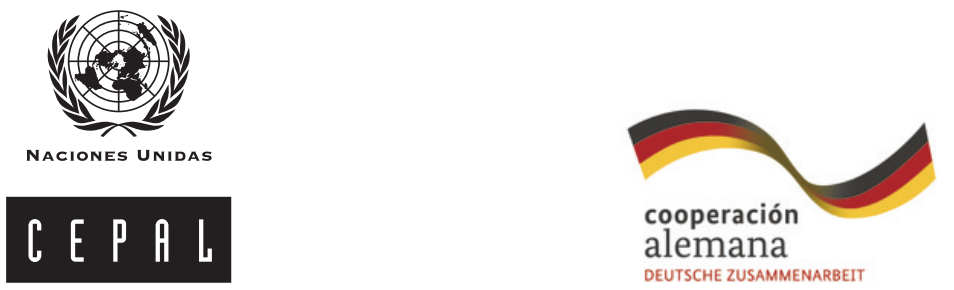

Comisión Económica para América Latina y el Caribe (CEPAL) Santiago, abril de 2017 


\title{
Libros de la CEPAL
}

\section{3}

\section{Alicia Bárcena}

Secretaria Ejecutiva

\section{Antonio Prado}

Secretario Ejecutivo Adjunto

\section{Laís Abramo}

Directora de la División de Desarrollo Social

\section{Ricardo Pérez}

Director de la División de Publicaciones y Servicios Web

Esta publicación fue preparada por Ana Sojo en el marco del proyecto "Protección social, enfoque de derechos y desigualdad en América Latina" del programa Cambio Estructural para un Desarrollo Sostenible e Inclusivo en América Latina y el Caribe, ejecutado por la CEPAL en conjunto con la Agencia Alemana de Cooperación Internacional (GIZ) y financiado por el Ministerio Federal de Cooperación Económica y Desarrollo (BMZ) de Alemania.

La autora agradece la lectura detallada y los valiosos comentarios de Olga Lucía Acosta y José Antonio Ocampo, el apoyo de Laís Abramo para su realización y el enriquecedor diálogo mantenido a lo largo de muchos años.

Las opiniones expresadas en este libro son de exclusiva responsabilidad de la autora y pueden no coincidir con las de la Organización.

\author{
Diseño de portada: María Luisa Avaria \\ Publicación de las Naciones Unidas \\ ISBN: 978-92-1-121946-3 (versión impresa) \\ ISBN: 978-92-1-058583-5 (versión pdf) \\ ISBN: 978-92-1-358053-0 (versión ePub) \\ Número de venta: S.17.II.G.10 \\ LC/PUB.2017/7-P \\ Distr.: General \\ Copyright (C) Naciones Unidas, 2017 \\ Todos los derechos reservados \\ Impreso en Naciones Unidas, Santiago \\ S.16-00819
}

Esta publicación debe citarse como: Ana Sojo, Protección social en América Latina: la desigualdad en el banquillo, Libros de la CEPAL, Nº 143 (LC/PUB.2017/7-P), Santiago, Comisión Económica para América Latina y el Caribe (CEPAL), 2017.

La autorización para reproducir total o parcialmente esta obra debe solicitarse a la Comisión Económica para América Latina y el Caribe (CEPAL), División de Publicaciones y Servicios Web, publicaciones@cepal.org. Los Estados Miembros de las Naciones Unidas y sus instituciones gubernamentales pueden reproducir esta obra sin autorización previa. Solo se les solicita que mencionen la fuente e informen a la CEPAL de tal reproducción. 


\section{Índice}

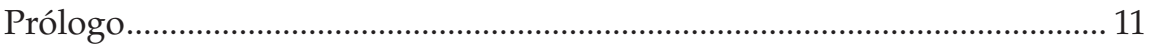

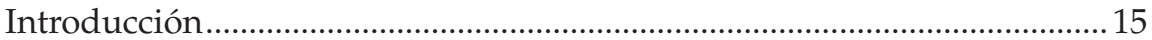

Capítulo I

Las disputas sobre protección social en América Latina:

del reduccionismo a una mayor heterodoxia....

A. Algunos hitos discursivos sobre protección social.....................19

1. La focalización reduccionista y sus implicaciones para la política social y la protección social

2. La universalidad como conjunto limitado de prestaciones y la polémica en torno a la impugnación dicotómica del financiamiento contributivo

3. Evolución del planteamiento sobre el piso de protección social y la cobertura universal de salud

4. La CEPAL y la protección social como derecho ciudadano.... 33

B. Oposiciones y confluencias de las perspectivas sobre protección social y sus virtuales interacciones

o resonancias.

Bibliografía.

\section{Capítulo II}

La razón de ser del aseguramiento: fundamentos para la convergencia en torno a una protección social universal y solidaria

A. La protección social desde la perspectiva de derechos.............. 44

B. La diversificación de los riesgos: el mercado versus la protección social

C. La naturaleza del bien a proteger como determinante del carácter del aseguramiento 
D. Aseguramiento, bienes públicos y externalidades ......................58

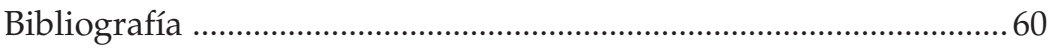

Capítulo III

La protección social en América Latina: desigualdades de afiliación,

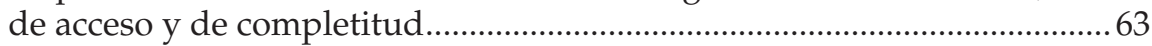

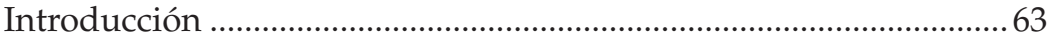

A. La afiliación a la protección social .................................................64

1. Tendencias de la afiliación a los sistemas

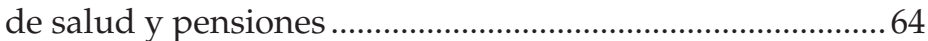

2. Análisis multivariado de los determinantes de la afiliación al sistema de pensiones en la región ............79

3. La evasión contributiva .......................................................... 87

B. Una aproximación a las prestaciones de la protección social.....89

1. Acceso a pensiones y suficiencia .............................................. 89

2. Inserción laboral y cobertura de salud de las personas mayores de 65 años ................................................................. 95

3. La segmentación del aseguramiento y del acceso a prestaciones de salud en el Brasil..........................................97

4. Gastos de bolsillo en salud y desigualdad............................100

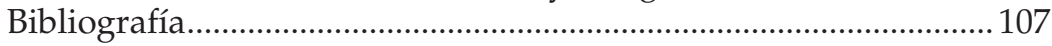

Capítulo IV

El aseguramiento guiado por el lucro: ¿la hora de la verdad? ...................109

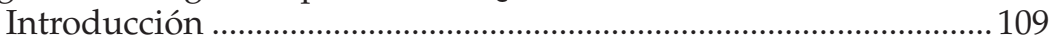

A. Las combinaciones público-privadas dualistas

en la protección social y el menoscabo de la equidad

y el aseguramiento debido al lucro...

B. Competencia y capacidad de elección en

la protección social: argumentos teóricos

y lecciones prácticas

C. La legitimidad de los sistemas de protección social y el cambio institucional: una breve introducción conceptual

D. Las disputas en torno a la reforma del sistema contributivo de pensiones en Chile

1. El sistema de pensiones chileno y algunos hitos de la creciente deslegitimación del sistema contributivo.......123

2. Las tasas de reemplazo y sus múltiples causalidades sistémicas: un punto álgido de la actual disputa

3. La AFP estatal como estrategia de cambio gradual por superposición y de transición hacia un sistema contributivo de cuentas individuales sin fines de lucro

4. Las propuestas de la Comisión Asesora Presidencial sobre el Sistema de Pensiones. 
E. Individualización del riesgo en un sistema de salud dual con reaseguro público: el caso chileno

1. Breve caracterización de algunos rasgos de la lógica dual del sistema de salud y sus efectos

2. La discusión contemporánea en torno a la reforma del aseguramiento privado y sus impactos globales en el sistema de salud

F. Conflictividad y altos costos de transacción:

las trampas de la complejidad del sistema de salud colombiano

Bibliografía

Capítulo V

Claroscuros de la judicialización del derecho a la salud

Introducción

A. Derechos sociales y judicialización ..........................................175

B. Raíces y bases del litigio en América Latina ............................... 180

1. Disposiciones jurídicas sobre la satisfacción de los derechos sociales

2. Arquitectura de los sistemas de protección social en materia de salud y la judicialización

3. La priorización

4. Litigio y acceso a medicamentos

Bibliografía.

\section{Capítulo VI}

El fundamento del cuidado como pilar de la protección social

Introducción

A. Algunas aristas del cuidado y de la interdependencia entre la familia, el Estado y el mercado en su provisión

B. El cuidado desde la perspectiva de la equidad de género y sus conexidades con el bienestar.

1. Los radicales cambios de las estructuras familiares en la región

2. Los cambios de la fecundidad, ¿revelarán maternidades y paternidades constreñidas?

3. Empleo femenino, asimetrías de género e incidencia de la pobreza

4. Otra arista de la transición demográfica y su interrelación con el género y el cuidado: el financiamiento sostenible de la educación y de la protección social 228

C. La polarización cognitiva y el cuidado en la primera infancia: ¿tiempo ganado, perdido o recuperado? 
D. El cuidado de las personas mayores

E. El financiamiento del cuidado desde la perspectiva de la protección social y el aseguramiento

Bibliografía.

\section{Cuadros}

III.1 América Latina (18 países): afiliación a sistemas de pensiones y de salud entre los asalariados de 15 años y más, según sexo.

III.2 América Latina (18 países): afiliación a sistemas de pensiones y de salud entre los asalariados de 15 años y más, según quintiles de ingresos per cápita.

III.3 América Latina (18 países): índices de concentración de la afiliación a sistemas de pensiones y de salud entre los asalariados, no asalariados y ocupados de 15 años y más

III.4 América Latina (18 países): variación de la afiliación a sistemas de pensiones y de salud entre los asalariados de 15 años y más, según inserción laboral

III.5 América Latina (14 países): afiliación a sistemas de pensiones y de salud entre los no asalariados de 15 años y más, según sexo.

III.6 América Latina (13 países): afiliación a sistemas de pensiones y de salud entre los no asalariados de 15 años y más, según quintiles de ingresos per cápita.

III.7 América Latina (17 países): efectos marginales de la rama de actividad sobre la probabilidad de afiliación a sistemas de pensiones, alrededor de 2013.

III.8 Argentina, Colombia y Perú: estimaciones sobre incumplimiento contributivo de los trabajadores asalariados, 2007 y 2010

III.9 América Latina (16 países): personas de 65 años pensionadas y monto medio mensual de sus pensiones, según sexo y tipo de pensiones

III.10 América Latina (16 países): personas de 65 años pensionadas y monto promedio mensual de sus pensiones, según quintiles de ingresos per cápita y tipo de pensiones

III.11 Brasil: tipo de aseguramiento y de prestador de las personas atendidas por razones de salud en las dos semanas previas a la Encuesta Nacional de Hogares, por sexo, 2008.

III.12 América Latina (18 países): indicadores generales relacionados con el gasto de bolsillo en salud, realizado en un mes.

III.13 América Latina (18 países): indicadores de empobrecimiento relacionados con el gasto de bolsillo en salud, realizado en un mes 
IV.1 Tipos de cambio gradual

IV.2 Chile: simulación de las tasas de reemplazo del sistema de pensiones de capitalización individual, considerando diferentes escenarios

IV.3 Chile: modelación de las tasas brutas de reemplazo, por sexo e ingresos individuales

IV.4 Chile: tasas brutas de reemplazo de pensiones, por ingresos individuales, según sistemas de pensiones público, obligatorio privado y voluntario privado, en múltiplos de la media, por sexo

IV.5 Chile: rentabilidad de los fondos de pensiones, promedio anual de los últimos 36 meses a la fecha indicada.

IV.6 Chile: tasas de interés medias (implícitas) de rentas vitalicias contratadas en el mercado, a agosto de cada año

IV.7 Chile: rentabilidad anual de las Administradoras de Fondos de Pensiones (AFP), al 31 de diciembre de cada año.

IV.8 Chile: rentabilidad anual media del sistema de Instituciones de Salud Previsional (ISAPRE) sobre capital y reservas, al 31 de diciembre de cada año

\section{Gráficos}

III.1 América Latina: afiliación a sistemas de pensiones y de salud entre los asalariados de 15 años y más, según sexo, quintil de ingreso per cápita, nivel educativo y grupo de edad, alrededor de 2002 y 2013

III.2 América Latina: puntaje del índice de protección social, alrededor de 2002 y 2012

III.3 América Latina (17 países): efecto marginal de la inserción en el sector informal sobre la probabilidad de afiliación a sistemas de pensiones, alrededor de 2002 y de 2013

III.4 América Latina (17 países): efecto marginal del trabajo a tiempo parcial sobre la probabilidad de afiliación a sistemas de pensiones, alrededor de 2002 y 2013

III.5 América Latina (17 países): efecto marginal de la categoría ocupacional sobre la probabilidad de afiliación a sistemas de pensiones, alrededor de 2013

III.6 América Latina (17 países): efecto marginal del quintil de ingresos del trabajo sobre la probabilidad de afiliación a sistemas de pensiones, alrededor de 2013.

III.7 América Latina (17 países): efecto marginal del sexo sobre la probabilidad de afiliación a sistemas de pensiones, alrededor de 2002 y de 2013

III.8 América Latina (17 países): efecto marginal del tramo etario sobre la probabilidad de afiliación a sistemas de pensiones, alrededor de 2013. 
III.9 América Latina (17 países): efecto marginal del nivel educativo sobre la probabilidad de afiliación a sistemas de pensiones, alrededor de 2002.

III.10 América Latina (17 países): efecto marginal de la jefatura de hogar sobre la probabilidad de afiliación a sistemas de pensiones, alrededor de 2002 y 2013

III.11 América Latina (18 países): vínculo con el sistema de pensiones, personas ocupadas de 65 años y más, 2013

III.12 Brasil: asalariados de 15 años y más cubiertos por planes privados de salud, por sexo y quintiles de ingreso per cápita, 2003 y 2008

III.13 Brasil: aseguramiento público y privado de las personas atendidas por razones de salud en las dos semanas previas a la Encuesta Nacional de Hogares, por sexo y quintiles de ingreso per cápita, 2008

III.14 América Latina: monto medio del gasto de bolsillo en salud por hogar, y gasto en medicamentos y en especialidades como porcentaje del gasto de bolsillo en salud, por quintiles de ingreso, realizado en un mes, alrededor de 2006.

III.15 América Latina (18 países): incremento de la pobreza relativa como efecto de los gastos de bolsillo en salud, realizados en un mes

III.16 América Latina (promedio simple de 18 países): hogares que efectúan gastos de bolsillo en salud, por quintiles de ingreso, alrededor de 2006

III.17 América Latina (18 países): incidencia de la pobreza en los hogares con y sin gasto de bolsillo en salud.....

IV.1 Chile: número de afiliados y cotizantes al sistema contributivo de pensiones, total y por sexo, 1985-2015.

VI.1 Bolivia (Estado Plurinacional de), México, Nicaragua y Perú: gasto en cuidado como proporción del gasto total de los hogares y como monto promedio, hogares pobres y no pobres, por sexo del jefe de hogar, alrededor de 2005.

VI.2 América Latina (14 países): gasto en cuidado como proporción del gasto total de los hogares y como monto promedio, por quintiles de ingreso per cápita de los hogares, alrededor de 2005. 
VI.3 América Latina (14 países): gasto en cuidado como proporción del gasto total de los hogares y como monto medio en el mes de referencia de cada encuesta según presencia de adultos de 75 años o más, alrededor de 2005.

VI.4 Ecuador, Guatemala, México y Uruguay: horas diarias de trabajo no remunerado, por sexo y tipo de familia .

VI.5 América Latina y el Caribe: unidades de demanda de cuidado en los países conforme al avance de su transición demográfica, 2011

\section{Diagramas}

I.1 América Latina: las dicotomías analíticas no reflejan la complejidad de la protección social.

I.2 América Latina: tensiones discursivas sobre la protección social. 36

II.1 Modelo tetradimensional de la democracia según Ferrajoli ............. 45

IV.1 Contexto y cambio institucional .......................................................120

IV.2 Chile: coordenadas de la reforma del sistema dual de salud..........153

IV.3 Salud-Mía: fuentes de los recursos y destinación ..............................167

V.1 Litigación para acceder a beneficios de salud .................................. 192

VI.1 Caracterización de los modelos de cuidado según la cobertura pública y el reparto de la carga doméstica.

VI.2 Principios y criterios para fundamentar un modelo de atención centrado en la persona mayor 



\section{Prólogo}

La Comisión Económica para América Latina y el Caribe (CEPAL) señaló en el conjunto de documentos que constituyen la "trilogía de la igualdad" que, en el complejo y cambiante escenario económico y social actual, América Latina y el Caribe debe reorientar el paradigma del desarrollo para lograr la igualdad y la sostenibilidad ambiental. La igualdad, estructurada a partir de un enfoque de derechos, debe ser el objetivo central y el horizonte del desarrollo, y es crucial para el concepto de desarrollo sostenible. La noción de igualdad no se refiere únicamente a la distribución de los ingresos monetarios. Sin desconocer la importancia fundamental de esta dimensión, la CEPAL ha ampliado su alcance, destacando su carácter multidimensional: se trata de la redistribución de ingresos, activos y recursos, pero también de la autonomía, del reconocimiento de los sujetos y de su dignidad. Afirmar que el desarrollo social es uno de los pilares del desarrollo sostenible significa, por un lado, que su logro depende de las estructuras productivas y de una mayor capacidad inclusiva del mercado de trabajo, del desarrollo económico y de las condiciones políticas y medioambientales; por otra parte, significa también que es condición indispensable para el desarrollo económico y la sostenibilidad ambiental.

En ese sentido, la persistencia de la pobreza y de altos niveles de desigualdad no solo es dramática para quienes la sufren, sino que también afecta a la sociedad como un todo, y el progreso en las condiciones sociales

La "trilogía de la igualdad" comprende los siguientes documentos de la CEPAL: La hora de la igualdad: brechas por cerrar, caminos por abrir (LC/G.2432(SES.33/3)), Santiago, 2010; Cambio estructural para la igualdad: una visión integrada del desarrollo (LC/G.2524(SES.34/3)), Santiago, 2012, y Pactos para la igualdad: hacia un futuro sostenible (LC/G.2586(SES.35/3)), Santiago, 2014. 
de la población es indispensable para lograr el cambio estructural y el desarrollo económico sostenible. En el marco de una coyuntura económica favorable, y gracias a tendencias positivas registradas en el campo laboral y a políticas implementadas por los países en diversas áreas, el bienestar de millones de personas en América Latina y el Caribe se elevó significativamente desde inicios de la década de 2000. Sin embargo, estos avances del desarrollo social siguen siendo volátiles y son variables, insuficientes y especialmente esquivos para determinados grupos sociales.

En el documento elaborado para la Primera Conferencia Regional sobre Desarrollo Social de América Latina y el Caribe realizada en Lima en noviembre de $2015^{2}$, la CEPAL sostuvo que, pese a las dificultades de la actual coyuntura y a que el camino por recorrer para alcanzar sociedades libres de pobreza, más justas y menos desiguales es aún muy largo, debe profundizarse el compromiso de avanzar en la superación de las diversas formas de exclusión que están en la raíz de la desigualdad característica de las sociedades latinoamericanas y caribeñas.

Para ello es indispensable infundir sentido de pertenencia y de justicia distributiva en los ciudadanos, así como confianza en el futuro, en la democracia y en la institucionalidad. Para fortalecer el desarrollo social inclusivo es fundamental avanzar también hacia una protección social universal y solidaria de la población. Este postulado se hace eco de los principios de política social formulados en 2000 en el documento Equidad, desarrollo y ciudadanía ${ }^{3}$, de los desarrollos planteados en 2006 en el documento La protección social de cara al futuro ${ }^{4}$, y de una prolífica línea de trabajo que ha ganado fuerza en la institución y que se traduce en numerosos estudios sobre protección social realizados durante el último decenio.

El presente libro, desde una perspectiva conceptual, histórica y empírica, se adentra en el desarrollo de la protección social en los países de América Latina de una manera sinóptica y comparativa, y profundiza en algunos casos paradigmáticos, con una mirada de largo plazo. Se trata de revelar los desafíos pendientes que derivan de sistemas fragmentados y poco equitativos, que requieren de sólidas coaliciones políticas para ampliar las coberturas, encarar la fragmentación y dar un salto en la calidad.

La autora revisa los paradigmas que han impregnado el debate acerca de la protección social en la región, aborda la discusión conceptual que ha circundado la construcción de fundamentos sobre la necesidad del aseguramiento solidario y de la universalidad, así como las limitaciones

CEPAL, Desarrollo social inclusivo: una nueva generación de políticas para superar la pobreza y reducir la desigualdad en América Latina y el Caribe (LC.L/4056(CDS.1/3)), Santiago, 2015.

CEPAL, Equidad, desarrollo y ciudadanía (LC/G.2071(SES.28/3)), Santiago, 2000.

CEPAL, La protección social de cara al futuro: acceso, financiamiento y solidaridad (LC/G.2294 (SES.31/3)), Santiago, 2006. 
que tiene la competencia de aseguradores privados en este ámbito debido a las restricciones al ejercicio de decisiones fundadas por parte de los asegurados. De la mano de la evidencia empírica y de una amplia documentación, se tratan complejas aristas del aseguramiento, como la relevancia de las políticas del mercado laboral para hacer frente a la desprotección y la segmentación, la judicialización del derecho a la salud, las combinaciones público-privadas articuladas por el principio del lucro en materia de salud y pensiones, y la pertinencia del cuidado como un pilar de la protección social.

Desprotección, insuficiencia de las prestaciones y estratificación son los principales nodos desde los cuales la desigualdad en la protección social se coloca en el banquillo para examinar los conflictos implícitos y explícitos sobre derechos, recursos, formas de distribución, impacto redistributivo y diseño institucional; analizar los escenarios de reforma por venir, y formular algunas recomendaciones y llamados de atención. Todo ello a la luz de la solidaridad y la universalidad como principios rectores.

\author{
Alicia Bárcena \\ Secretaria Ejecutiva \\ Comisión Económica para \\ América Latina y el Caribe (CEPAL)
}





\section{Introducción}

Como explica el filósofo Emilio Lledó, el lenguaje no entraña un estar sino un ser: las palabras nos forjan y estructuran idealmente un conglomerado de sentidos e interpretaciones, por lo que el uso del lenguaje constituye el resultado de la memoria existencial, de lo que hemos aprendido a hacer, de lo que hemos sabido y de lo que hemos podido ver del mundo. La democracia permite cuestionar la preeminencia de la palabra en términos de una interpretación dogmática y exclusiva de la realidad y del mundo atada a las diversas estructuras de poder. Así, la verdad se transforma en una estructura metodológica y en la búsqueda de una verdad compartida y dialogada; el río de las palabras, en un surco móvil; y la vida, en una renovadora y crítica incitación al diálogo, que implica responsabilidad en el aprendizaje de las palabras y de sus sentidos mediante el ejercicio de la especulación, la interpretación y la reflexión'1.

El espíritu del tiempo contemporáneo está marcado por un desasosiego social profundo, manifiesto o larvado - que se expresa de muy distintas formas en los más diversos países, hasta en los más ricos, ante las profundas disparidades en el acceso a los frutos del desarrollo y en la concentración de la riqueza en manos del 1\% más rico de la población-, agudizado al socaire de las recientes crisis económicas, de ciertas tendencias de la globalización y de brechas de legitimidad que la política no logra colmar.

Incluso organismos y entidades que mostraban una relativa indiferencia ante la desigualdad o que confiaban en que esta se reduciría de la mano del progreso económico, reconocen hoy la necesidad de hacerle

Emilio Lledó, Palabra y humanidad, Oviedo, KRK Ediciones, 2015, págs. 11, 119-121 y 181-191. 
frente y muestran un mayor interés por las políticas inclusivas. Por su parte, desde hace largos años, y remando contra la corriente en numerosas ocasiones, la Comisión Económica para América Latina y el Caribe (CEPAL) busca contribuir al establecimiento de consensos en torno a la agenda de la igualdad y, dentro de ella, al logro de una protección social universal y solidaria para la población de América Latina y el Caribe.

En este contexto es imperioso colocar en el banquillo a la desigualdad en materia de protección social $\mathrm{y}$, a tal efecto, este libro representa, en palabras que parafrasean los postulados de Lledó, un ejercicio especulativo de interpretación y reflexión. En la época actual, se demanda más Estado que mercado en los sistemas de protección, se cuestiona el lucro como criterio primordial, y emerge la relevancia del aseguramiento solidario y de la universalidad. Ello se debe a que numerosos sistemas de protección social de la región experimentan una crisis de legitimidad ante las promesas incumplidas de las reformas emprendidas en las décadas de 1980 y 1990, y se enfrenta el reto de emprender políticas orientadas por un compromiso explícito a favor de la igualdad, pero sin que pueda pretenderse hacer tabula rasa de la complejidad de lo existente. Por sus objetivos redistributivos y solidarios, el aseguramiento permite articular beneficios económicos y sociales, y en América Latina y el Caribe es indispensable construir coaliciones políticas amplias para superar la fragmentación y la segmentación propias de los sistemas de protección social vigentes, para fortalecer su ethos redistributivo y solidario, y para mejorar la calidad de los servicios, empresas imposibles cuando los sistemas están destinados solamente a los más pobres. Para forjar tales coaliciones, es menester adentrarse en el plano del discurso, en el río semántico de la protección social y en el análisis empírico de las experiencias. De allí, la pertinencia de analizar la construcción de los sistemas de protección social en la región con una mirada de largo plazo, y de considerar diversas opciones y alternativas futuras. Por tanto, cobra sentido realizar una lectura de los avances y desafíos de las reformas de los sistemas de pensiones y salud en la región, y advertir también acerca de las consecuencias negativas que acarrea no encarar el cuidado como un nuevo pilar de la protección social².

En el primer capítulo se emprende una revisión histórica de los postulados relativos al concepto de protección social en la región. Se devela el reduccionismo de las perspectivas centradas en brindar un conjunto limitado de prestaciones a poblaciones focalizadas, o bien de los anquilosados postulados dicotómicos que contraponen el financiamiento contributivo o con recursos fiscales, y se muestran los avances hacia perspectivas más heterodoxas. En este contexto, se sitúa el discurso de la CEPAL acerca de

No son objeto de este análisis empírico otras dimensiones de la protección social, como los riesgos de accidentes de trabajo y los riesgos profesionales, los seguros de desempleo y los programas de transferencias monetarias. 
la protección social como un derecho ciudadano, donde más que de una estructura institucional se trata de un acuerdo político que debe resolver los conflictos sobre los derechos, los recursos, las formas de distribución y el diseño institucional, y el reto de la solidaridad como elemento crucial para avanzar hacia coberturas universales. Si bien este constituye el meollo del primer capítulo, los diversos enfoques sobre protección social y sus efectos se abordan e hilvanan de manera recurrente a lo largo del libro, al indagar en sistemas fragmentados y poco equitativos.

En el segundo capítulo, se plantean los principios de universalidad y solidaridad desde una perspectiva de derechos, se analiza la racionalidad del aseguramiento de mercado frente al aseguramiento solidario, y se consideran sus matices según la naturaleza y la singularidad de los riesgos y el valor intrínseco e instrumental de la protección de riesgos y sus externalidades. En el caso de las pensiones y la salud, el aseguramiento reviste diferencias marcadas. En el primero, como su fin primordial es proveer protección en la vejez, tiene la función de optimizar los recursos ahorrados a lo largo de la vida y las tasas de reemplazo que estos permitan, con la misma regla de esfuerzo para los afiliados a los sistemas contributivos, mientras que los mecanismos destinados a reducir la pobreza en la vejez y realizar una redistribución deben financiarse sobre todo con recursos fiscales. En el caso de la salud, el financiamiento solidario en sí mismo persigue fines redistributivos, entre otros instrumentos, mediante subsidios cruzados intra- e intergeneracionales, entre ricos y pobres, enfermos y sanos, personas mayores y jóvenes.

En el tercer capítulo se mide el alcance y la profundidad de la protección social, lo que permite elaborar un mosaico de las desigualdades en este terreno mediante indicadores que dan cuenta, entre otros aspectos, de la equidad de los sistemas, de la profundidad y el alcance del aseguramiento en los distintos países de la región, así como de variables asociadas con el mercado laboral. La numerosa evidencia estadística constituye una advertencia sobre los efectos del ciclo económico favorable que se reflejó en el mercado de trabajo y que, junto con las políticas a favor de la formalización, aumentaron la afiliación a los planes de salud y a pensiones, en especial por parte de los asalariados, situación que posibilitó reducir brechas de género en algunos países. Asimismo, se analiza cómo la inserción en el mercado de trabajo repercute en la posibilidad de estar afiliado, y se examina la magnitud y los efectos de la evasión contributiva. Se considera también el acceso a las pensiones tanto contributivas como solidarias y su valor promedio, lo que, junto con la vinculación al mercado laboral de personas de edades avanzadas en la región, permite inferir su suficiencia. Por último, en cuanto al acceso a la salud, se analiza la estratificación del sistema brasileño sobre la base de la dinámica del Sistema Único de Salud (SUS) y del aseguramiento mediante planes privados. Se cierra este capítulo con un análisis del efecto de los gastos de bolsillo en la capacidad de gasto de los hogares. 
En el cuarto capítulo se reflexiona sobre el aseguramiento guiado por el lucro a la luz de diversos tipos de combinaciones público-privadas de la región que han tenido un efecto negativo en la equidad, al incumplirse las promesas de suficiencia, eficiencia y maximización de beneficios para los asegurados, así como la promesa de reducción de los costos fiscales esgrimida como fundamento de las reformas privatizadoras. Se advierte que el logro de mayor equidad es función de los principios y características de los Estados de bienestar que condicionan las articulaciones públicoprivadas, y no de la mera propiedad pública o privada de las entidades que conforman los sistemas. En segundo término, argumentos conceptuales y enseñanzas prácticas evidencian restricciones a la competencia, principio al que le fueron confiados no pocos resultados de algunas reformas. Las asimetrías en materia de información, la complejidad de los problemas (racionalidad restringida) y las limitaciones al poder de decisión impiden que se cumpla el postulado del consumidor bien informado. En este marco se analizan los problemas de los sistemas de pensiones y de salud adoptados por Chile y el sistema de salud vigente en Colombia.

En el quinto capítulo se analiza el papel del litigio o la judicialización como forma de hacer realidad la garantía de los derechos sociales en varios países de la región, recurso que ha tenido mayor incidencia en Colombia en comparación con otros países. En primer lugar, se aborda la relevancia de los derechos sociales, los desafíos para su cumplimiento y la posibilidad del uso de instrumentos jurídicos. En segundo término, se examina la racionalidad del litigio en el ámbito de la salud en América Latina, tomando en consideración cuatro aspectos: las disposiciones legales sobre la satisfacción de los derechos sociales, la arquitectura de los sistemas de salud, las políticas de priorización en salud, y el acceso a medicamentos mediante acciones judiciales. Las diversas aristas muestran que la judicialización abarca una vasta zona de claroscuros, dado que puede contribuir al ejercicio de los derechos, pero también alimentar conductas de riesgo moral por parte de una serie de actores. Se evidencia la necesidad de fortalecer la institucionalidad de los sistemas de salud en torno a la satisfacción de este derecho, para que el recurso a la judicialización no se sobredimensione, el derecho se ejerza con mayor igualdad, se mejore el uso de los recursos y se encaren actos de colusión en esta materia.

En el sexto y último capítulo se tratan las políticas de cuidado como pilar de la protección social y se plantean las distintas racionalidades e interacciones que pueden subyacer tras las políticas de cuidado de la infancia y las personas mayores, con el objeto de mostrar cuán beneficioso resulta que el cuidado constituya el marco de políticas públicas que permita articular y potenciar desde otra óptica varias agendas de las recientes décadas: el acceso universal a determinados servicios con ciertos estándares de calidad, y los derechos de la mujer, de la niñez y de las personas mayores, sin dejar de lado la pertinencia de los contenidos del cuidado y de la calidad de los servicios. 
Capítulo I

\section{Las disputas sobre protección social en América Latina: del reduccionismo a una mayor heterodoxia}

En este capítulo se analizan algunos hitos discursivos sobre la protección social que han sido relevantes en el debate latinoamericano de las últimas tres décadas, a saber, las propuestas del Banco Mundial, el Banco Interamericano de Desarrollo (BID), la Organización Internacional del Trabajo (OIT) y la Comisión Económica para América Latina y el Caribe (CEPAL).

Se muestra cómo la discusión ha transitado de un influyente reduccionismo en materia de política social - propio de una focalización reduccionista y antagonista de la universalidad - a una mayor presencia de perspectivas más heterodoxas, tanto respecto de las formas de financiamiento como del ámbito considerado propio de la protección social.

Los planteamientos sobre cobertura y financiamiento han sido ejes fundamentales de la contienda y la fuerza de las tensiones en torno a ellos ha subsumido otros temas. Se visibilizan oposiciones y confluencias de las distintas perspectivas y sus virtuales interacciones o resonancias, deseadas o no deseadas, explícitas o implícitas.

\section{A. Algunos hitos discursivos sobre protección social}

En la región son necesarios esfuerzos de diversa magnitud para expandir la protección social, tanto en lo concerniente a la cobertura como a la calidad y la solidaridad de su financiamiento. Como revelan distintas 
aristas, la estrategia de universalización de la protección social no puede centrarse exclusivamente en un incremento de los recursos, sino que debe actuarse sobre la morfología de la protección social: el cambio institucional forma parte crucial del locus de la innovación, ya que la fragmentación y la segmentación están establecidas en los propios sistemas de protección social y en la acción política y discursiva en torno a ellos. Respecto de las políticas de bienestar vigentes en otras latitudes, se ha afirmado que los patrones interpretativos propuestos y debatidos se han transformado notablemente en las últimas décadas. Los temas tratados, las preferencias, los valores y los símbolos son elementos que inciden tanto en la forma en que se definen las políticas como en las soluciones que se alcanzan (Bonoli y Natali, 2012, págs. 12-13). Esa transformación también fue relevante en América Latina, por lo que a lo largo de este libro, nos detendremos en una gama de experiencias.

Se sistematizan seguidamente algunos planteamientos que han conformado hitos en la manera en que se conceptualiza y discute la protección social, y mediante los cuales se ha intentado incidir en la política pública ${ }^{1}$. El orden en que se exponen no se ajusta a una sucesión cronológica del momento en que se pusieron en el tapete las diversas ideas; la óptica de la CEPAL se expone al final, dado que permite abordar varias dicotomías, cuya plena comprensión se facilita al haber sido expuestas previamente. De hecho, las diversas posturas interactúan entre sí, aspecto que se abordará después, aunque de forma esquemática² .

\section{La focalización reduccionista y sus implicaciones para la política social y la protección social}

La dicotomía entre focalización y universalidad se condensó en los años ochenta, tanto en términos conceptuales como políticos. Sistemáticamente, este enfoque identificaba determinados elementos negativos de los programas universales, para postular el reemplazo del principio de universalidad por la focalización, esgrimido como un principio articulador general que, a la vez, designaba un orden más simple y acotado para la política social: ser subsidiaria en materia de pobreza. En el marco de propuestas privatizadoras de las políticas sociales que constreñían la solidaridad de su financiamiento, se abogó por desmantelar los servicios sociales universales - evaluados muy negativamente mediante un giro analítico que calificaba la generalidad de los programas universales como

\footnotetext{
Esta sistematización fue elaborada inicialmente por la autora para la CEPAL (2013), y aquí se la presenta con algunos complementos.

2 Por ejemplo, en una conversación reciente con la autora de este trabajo, José Antonio Ocampo planteó que, a su juicio, los lineamentos sobre universalismo básico del BID constituyeron un intento por parte de esta institución de "absorber", desde su punto de vista, las ideas que la CEPAL (2000) había sometido a debate previamente.
} 
regresivos-y por concentrar la inversión pública social en los grupos más vulnerables mediante los llamados "programas focalizados". Se postuló que, a diferencia de la provisión universal, caracterizada como muy costosa e ineficiente, la focalización podía permitir a los gobiernos reducir la pobreza de manera más efectiva y a menor costo (Sojo, 1990).

Esta falsa dicotomía entre focalización y universalismo, propugnada por algunos gobiernos de la región y por el Banco Mundial, era funcional a una propuesta global sobre política social y protección social que se articulaba en torno a los siguientes objetivos: i) contribuir a solucionar la crisis fiscal del Estado con recortes al gasto social; ii) concentrar el gasto público social en los grupos más vulnerables de la población, y restringir la acción del Estado en materia de política social, cuestionando y evaluando negativamente el principio de universalidad y proponiendo el desmantelamiento relativo de las políticas universalistas; iii) preconizar la privatización relativa de los servicios sociales, incluso para los programas focalizados, y iv) postular que la distribución primaria del ingreso y la elevación del nivel de vida, producto del derrame y de la reactivación económica, garantizarían a los grupos ajenos a la focalización la capacidad de pago para utilizar los servicios privados (Sojo, 1990 y 2007). Todo ello se planteaba sin prestar atención a la selección de riesgos propia del mercado, aspecto que se abordará en el próximo capítulo.

En la región se registraron algunas experiencias paradigmáticas en Chile y en el Estado Plurinacional de Bolivia. En Chile, las reformas neoliberales emprendidas durante la dictadura apuntaron a desmantelar la solidaridad del financiamiento; acotar la prestación de servicios universales; lograr que la población no clasificada como pobre adquiriese servicios de mercado en las áreas de la salud, las pensiones y la educación; establecer subsidios a la demanda para que las personas que vivían en condición de pobreza tuvieran acceso a prestaciones de mercado, y traspasar importantes funciones a los entes municipales en materia de salud primaria y educación. Gran cantidad de recursos se destinaron a privatizar el sistema de pensiones y a consolidar las instituciones de salud previsional. Por tanto, la focalización fue de la mano de profundos cambios en la dinámica de los sectores sociales y de la protección social. En el Estado Plurinacional de Bolivia, las relaciones competitivas de los fondos sociales con lo sectorial, más que garantizar agilidad o eficiencia, incrementaron la fragmentación administrativa y la debilidad de las políticas sociales, pues se añadieron superposiciones y duplicidades, o se provocaron discontinuidades con la dinámica sectorial (Sojo, 2007).

Esa visión reduccionista de la política social se vio gradualmente erosionada por diversas razones y consideraciones, entre las que se destacan: i) la limitada viabilidad de establecer programas focalizados 
aislados, ya que, de hecho, la mayoría de los programas selectivos de la región suponía una relación con servicios sociales básicos como los de salud y educación, y ii) el creciente reconocimiento de que el énfasis en políticas macro, sectoriales y focalizadas debe ser función de la profundidad y naturaleza específica de la pobreza en cada país. La focalización es más importante cuando la pobreza está muy concentrada y la capacidad de ejecución es buena, pero cuando la pobreza está muy difundida y la capacidad de ejecución es débil, el crecimiento económico, los factores relacionados con el mercado de trabajo y el apoyo de los servicios sociales básicos son las vías más efectivas para enfrentarla (Sojo, 1999).

En ese contexto, se fortalecieron en la región visiones más abiertas respecto de la vinculación de programas selectivos con las políticas sectoriales, eminentemente de carácter universal. Entre otros aspectos, esto se expresó en la introducción paulatina de condicionalidades para acceder a ciertos beneficios (por lo general monetarios) de los programas de transferencias condicionadas que, al estar generalmente relacionadas con la salud, la nutrición y la educación, se satisfacían en el marco de políticas sectoriales. Se acotó el sentido de la selectividad, al fortalecerse la visión de que la complejidad de los objetivos de la política social trasciende la lucha contra la pobreza, que la propia lucha contra la pobreza es una tarea ingente que sobrepasa ampliamente a la focalización, que el carácter multifacético de la pobreza impone políticas integrales y heterogéneas e intervenciones diferenciadas, y que se debe incidir en las causas de la pobreza, haciendo hincapié en la adquisición de capacidades, destrezas y habilidades que permitan superarla, mediante la inserción social, económica y política. Las prestaciones universales -inmersas por su naturaleza en la dinámica sectorial y de la protección social- constituyen una bisagra entre obligaciones y derechos, que actúa en un amplio espectro temporal e invierte en capacidades humanas (Sojo, 2007).

Por su parte, a inicios del milenio emergió desde el Banco Mundial la propuesta del manejo social del riesgo (social risk management) que, vista en perspectiva, constituyó la principal rémora en términos conceptuales del reduccionismo en política social, pero que por el relativo hermetismo de su jerga no tuvo la influencia de la focalización reduccionista. A partir de definiciones del riesgo y del aseguramiento, se realizaba una propuesta global de política social, basada en una combinación públicoprivada que resultaba funcional: se circunscribían las responsabilidades del Estado en materia de bienestar social al combate contra la pobreza, se establecía el aseguramiento contra los riesgos como una responsabilidad individual, y se desestimaba la solidaridad en la diversificación de riesgos. En esos términos, el aseguramiento individual en el mercado, la provisión de servicios para los pobres mediante redes de protección y la focalización contrapuesta a la universalidad conformaban una estrategia 
de política social que disponía una responsabilidad pública mínima en materia de protección social, depositaba el financiamiento y la prestación de los demás servicios relacionados con el bienestar social en manos privadas, y reiteraba la desestimación del principio de solidaridad del financiamiento (Sojo, 2003).

\section{La universalidad como conjunto limitado de prestaciones y la polémica en torno a la impugnación dicotómica del financiamiento contributivo}

En América Latina, algunas visiones restrictivas acerca del papel que le cabe cumplir al Estado en la protección social y en la diversificación de riesgos han ido de la mano de propuestas restrictivas de coberturas - que se propone financiar con recursos fiscales-y de la impugnación del financiamiento contributivo. Tales visiones no cuestionan la segmentación y estratificación de la protección social ni indagan mayormente en el carácter regresivo o progresivo de los recursos fiscales en juego. Dentro de esta perspectiva, la formalización del empleo tampoco juega un papel importante, porque precisamente está ligada a lo contributivo (Sojo, 2015b y 2016).

En el caso del BID, desde el Instituto Interamericano para el Desarrollo Social (INDES) se propugnó hace algunos años la idea del universalismo básico. Esta se basaba, por una parte, en una crítica al "falso universalismo", cuya retórica escondería una oferta y un acceso segmentados a bienes y servicios de calidad diferencial que beneficiarían más a quienes se encontraran en mejores condiciones para acceder a estos. Por otra parte, también criticaba el "universalismo ineficaz", cuya oferta carecería de calidad y no reflejaría preocupación por su incidencia (Filgueira y otros, 2006, pág. 47).

El universalismo básico propone "acciones de cobertura universal" y "prestaciones seleccionadas", que constituyan verdaderos pisos de protección que se deberán fortalecer gradualmente. Se trata de brindar una cobertura universal de un "conjunto limitado de prestaciones esenciales para categorías de población definidas a partir de ciertos atributos", o bien de "un conjunto limitado de prestaciones básicas" que variaría de acuerdo con las posibilidades y definiciones propias de cada país (Filgueira y otros, 2006, pág. 46).

Debe destacarse que las fallas específicas de los mercados de aseguramiento no se consideran; en cuanto al mercado, se afirma simplemente que "carece de la fuerza necesaria (y a veces de los marcos e instrumentos de regulación) para que amplios sectores de la población accedan a los bienes y servicios necesarios para su plena inserción social". Son los mercados laborales los que reciben mayor atención por 
cuanto estratifican sistemas corporativos de base laboral. Al Estado se le asigna el papel de garantizar el acceso y usufructo de bienes, rentas y servicios de calidad homogénea (Filgueira y otros, 2006, págs. 26, 37-40).

Una lectura atenta de las alusiones a la viabilidad de establecer diversas prestaciones evidencia que se considera eminentemente el uso de recursos fiscales no contributivos, e incluso emerge el uso del término "universalismo básico no contributivo" (Rezk, 2006, pág. 350). Ante ese planteamiento, se advirtió ya entonces sobre la previsible restricción de recursos fiscales destinados a tales fines y sobre la necesidad de reorientar la protección social mejorando los diseños de los sistemas contributivos, para hacer converger las lógicas y evitar que se profundice la segmentación existente (Tokman, 2006, pág. 163).

También desde un ámbito cercano al BID ha emergido recientemente en la región otra posición taxativa contraria al financiamiento contributivo. Acuñada esta vez para México, le endilga al financiamiento contributivo un papel crucial respecto de los niveles de informalidad: "la informalidad se genera por distorsiones del régimen fiscal y de seguridad social" (Levy, 2012). Entre otros aspectos, se propone sustituir los impuestos a la nómina por incrementos del IVA, lo que "implica un cambio de la seguridad social: de impuestos al trabajo a impuestos al consumo" (Levy, 2012); sin embargo, se conserva el financiamiento de ciertos beneficios para los asalariados con impuestos sobre la nómina ${ }^{3}$. Para atenuar el impacto que tendría en las familias pobres el pago de impuestos al consumo del que se beneficiaría el sistema, se contemplan transferencias compensatorias canalizadas mediante el programa Oportunidades.

Por otra parte, cabe recordar que el sistema de protección social mexicano continúa siendo uno de los más estratificados de América Latina. En ese marco se propone una "seguridad social universal" que procure una convergencia de beneficios para todos los trabajadores, junto con otros beneficios específicos para los asalariados. Para esa concurrencia de prestaciones, la actual cobertura del Instituto Mexicano de Seguridad Social (IMSS) desempeña un papel importante (Levy, 2012).

Tales visiones dicotómicas del financiamiento de la protección social - que contraponen el financiamiento contributivo y no contributivo con miras a favorecer el no contributivo- no son muy conducentes para comprender los sistemas de protección social. En el capítulo III se

Cabe reflexionar sobre el contexto específico de la propuesta en un país en que se tiende a recurrir a los impuestos indirectos: si los ingresos resultantes de gravar la producción de hidrocarburos se clasifican como no tributarios, México tiene actualmente una de las cargas tributarias más reducidas de América Latina e incluso ha retrocedido en los últimos tiempos. Si se contabilizan esos ingresos, la carga se sitúa levemente por debajo del promedio regional y refleja un aumento moderado desde los años ochenta; en ese caso la orientación a favor de la imposición indirecta, que se observa a escala latinoamericana, sería muy marcada en este país (Gómez-Sabaini y Morán, 2013, pág. 16). 
analizan los niveles de afiliación a los sistemas de pensiones y salud de la región. Sin embargo, tales niveles no son función de la forma en que los sistemas se financian: hay sistemas contributivos con coberturas amplias y otros con coberturas muy limitadas según las trayectorias específicas de los países. Si se observan las coberturas de la protección social y se considera el financiamiento de los sistemas, resalta que las coberturas y sus desigualdades no dependen de esta variable: los países ubicados en las antípodas en cuanto al grado de cobertura de pensiones y de salud, en cuanto a las desigualdades en su acceso por ingreso o inserción laboral, o en cuanto a los montos que brindan sus sistemas de pensiones, no podrían clasificarse conforme al tipo de financiamiento. Por ejemplo, existen sistemas contributivos muy estratificados, como el mexicano, disociados de un seguro popular financiado con recursos fiscales, pero con coberturas muy limitadas. Pero otros sistemas contributivos tienen características diferentes: un ejemplo es el de Costa Rica, donde se ha buscado una convergencia de beneficios de la cobertura contributiva y no contributiva, que además están incorporadas dentro de la misma institucionalidad (Sáenz, 2015). Otro ejemplo de esta convergencia es el sistema colombiano de salud, que ha sido muy difícil de lograr dada la compleja arquitectura del aseguramiento y de la prestación (véanse los capítulos IV y V). Existe también un sistema no contributivo como el Sistema Único de Salud (SUS) del Brasil, que a pesar de su amplia cobertura y de ser financiado con recursos fiscales, se inserta dentro de una estratificación sistémica por los incentivos fiscales y otros beneficios que reciben los planes privados de salud (véase el capítulo III).

En las antípodas de ese razonamiento puede argumentarse que para desarrollar los mercados laborales e incrementar la formalidad, más que considerar el carácter contributivo o fiscal del financiamiento que sustenta el aseguramiento, es indispensable centrarse en la calidad de este. Según esa perspectiva, dado que en un contexto de salarios flexibles el costo de los beneficios provistos por el empleador se traslada parcialmente al trabajador mediante una reducción de los salarios, si los trabajadores no valoran tanto aquellos beneficios como el ingreso que dejan de percibir, pueden en el sector formal acceder a la elusión en acuerdo con el empleador o bajo su coerción, o buscar trabajo en el sector informal, donde la remuneración es totalmente monetaria. Es posible que esto ocurra cuando la provisión de las pensiones o de los beneficios de salud sean muy ineficientes, los vínculos entre beneficios y contribuciones muy débiles, o algún miembro de la familia ya inserto en el sector formal provea una cobertura familiar que no difiera de la alcanzable por aseguramiento propio. De allí la necesidad de velar por la eficiencia y calidad de los sistemas de seguridad social. Las carencias en materia de pensiones o los beneficios de salud precarios 
son externalidades negativas que no crean incentivos adecuados para profundizar los mercados laborales (Sojo, 2003).

Respecto de la equidad del financiamiento, cabe destacar que en el caso del obtenido por medio de impuestos generales, depende de la equidad general del sistema tributario del país, mientras que en el sistema contributivo está determinada en gran medida por los detalles de su diseño y por las bases sobre las cuales se cobra la contribución obligatoria. Para evaluar reformas del financiamiento no deben perderse de vista los objetivos del sistema: cómo afecta la calidad de los servicios, la mancomunación de riesgos y la trayectoria de los costos administrativos (Gutiérrez, Acosta y Alfonso-Sierra, 2012, págs. 84-86).

Respecto del financiamiento de la inversión social basado en impuestos al consumo, el caso chileno evidencia de manera fehaciente que el gasto social progresivo no basta para modificar la estructura desigual del ingreso, para lo que es clave una recaudación progresiva (Rivera, 2013). Recurrir a impuestos indirectos para financiar la protección social acentúa la regresividad tributaria, mientras que eliminar las contribuciones de las empresas a la protección social y financiarla mediante impuestos indirectos en términos netos puede redundar en una rebaja adicional del aporte empresarial al gasto público y social. Además, es pertinente recordar que la equidad no está asociada únicamente a las fuentes de financiamiento, sino también a la combinación de recursos de distintas fuentes, los métodos de recolección, las transferencias centrales a entidades subnacionales ajustadas por niveles de desarrollo social, y la modalidad de la compra de servicios en el marco de diversas combinaciones público-privadas. Ninguno de estos aspectos puede ser captado adecuadamente desde una visión dicotómica del financiamiento contributivo (CEPAL, 2016).

En este contexto cabe advertir sobre la importancia de dar seguimiento a un proceso que se enmarca dentro de la amplia reforma de la salud que se está realizando en Colombia. En 2013 se cambió la participación en las contribuciones de los empresarios, pero mediante impuestos progresivos: con la reforma tributaria plasmada en la Ley 1.607 se modificó la estructura de financiamiento del sector al incrementarse la participación de los recursos fiscales por medio del impuesto sobre la renta para la equidad (CREE), con el fin de que a partir de 2014 más de un $60 \%$ del financiamiento del sector de la salud proviniera de recursos fiscales. Por otra parte, esta modificación de la combinación de ingresos contributivos y fiscales fue de la mano de la creación de una entidad que concentrara las fuentes y que afiliara, recaudara, administrara y girara los recursos destinados al pago de los servicios de salud, reforma que será analizada en el capítulo cuarto. 
En cuanto a la dicotomía entre formas de financiamiento, cabe resaltar que en recientes estudios realizados en el seno del propio Banco Mundial se ha advertido sobre la complejidad y los problemas que acarrea impugnar el financiamiento contributivo en la región para proponer paquetes básicos de beneficios sufragados por impuestos generales o específicos, junto con planes complementarios y voluntarios manejados por el sector público o privado. Se señala que hay pocos casos de financiamiento basado exclusivamente en estas fuentes y se acusan las restricciones fiscales, legales y administrativas que se encararían en América Latina. A ello se sumaría el bajo nivel de recaudación fiscal de muchos países y el hecho de que en varios existen instituciones de protección social sólidas que ya ofrecen beneficios de salud, pensiones y, a veces, de desempleo, los cuales pueden ser incluso mayores que los que se incluirían en los paquetes básicos (Ribe, Robalino y Walker, 2012, pág. 46).

Como giro fundamental sobre esta materia dentro del ideario afín al Banco Mundial, se destaca el planteamiento de que el objetivo principal consista en proporcionar a todos los ciudadanos o residentes el mismo aseguramiento social, según las mismas reglas y condiciones, independientemente de dónde trabajen (Ribe, Robalino y Walker, 2010). Se señala que, si bien los sistemas contributivos que cubren el sector formal son insuficientes, tener sistemas contributivos y no contributivos que funcionen de manera paralela tampoco es eficiente, por lo que se proponen sistemas integrados (Ribe, Robalino y Walker, 2012, pág. 106).

Además, se manifiestan preocupaciones en cuanto a la suficiencia de los programas no contributivos de la región, dado que en muchos casos los beneficios son muy reducidos, especialmente en el sector de la salud, y a que no se integran satisfactoriamente con los programas contributivos. Por otra parte, se considera que los seguros sociales adolecen de fragmentación institucional, caracterizada por planes múltiples con baja coordinación, que afectan la movilidad laboral, crean desigualdad horizontal entre trabajadores y aumentan los costos administrativos. La visión de largo plazo para las políticas de protección social y de mercado laboral, entre otras, implica ofrecer acceso a un mismo seguro social contributivo a todos, independientemente de dónde se trabaje, lo que supone no solo mantener el aseguramiento obligatorio del sector formal, sino incluir también a los trabajadores informales mediante incentivos financieros e institucionales (Rashid, 2012; Ribe, Robalino y Walker, 2010, pág. 60).

Para avanzar hacia la cobertura universal en materia de pensiones, el BID ha propuesto recientemente que el ciudadano sea objeto de un aseguramiento previsional, lo que implica una pensión universal para adultos mayores sustentable en términos fiscales e institucionales, así como la imperiosa necesidad de fortalecer los sistemas contributivos para 
garantizar en el largo plazo el nivel de las pensiones. Se propone además procurar la incorporación paulatina de los no asalariados que han estado excluidos tradicionalmente de la seguridad social, de modo que tengan los mismos costos y beneficios que los trabajadores asalariados, con una modalidad de implementación más flexible con respecto a los pagos e innovando en las maneras de forzar el ahorro para colectivos que están desligados de la seguridad social, pero sin generar sistemas paralelos ni proporcionar incentivos para reasignar trabajadores a unidades de producción pequeñas y poco productivas. Para fomentar el crecimiento del empleo formal, se plantean subsidios a los aportes previsionales para reducir el costo de la formalidad y aumentar las densidades de cotización presentes y futuras para todos los trabajadores, independientemente de su categoría ocupacional. En cuanto al financiamiento de la ampliación de cobertura, se recomienda reducir la gran cantidad de gravámenes impuestos al trabajo formal o, al menos, no sumarle más cargas, por sus efectos negativos sobre la formalidad laboral, y explorar vías alternativas de financiamiento, como los impuestos al consumo y los ingresos públicos por materias primas (Bosch, Melguizo y Pagés, 2013). Respecto del financiamiento mediante impuestos al consumo, cabe reiterar los problemas antes expuestos en relación con otra propuesta cercana al ideario del BID en esta materia.

Interesa destacar que en la región está emergiendo un reconocimiento creciente de que el financiamiento contributivo no tiene que estar asociado únicamente al estatus laboral de las personas, de que los pobres pueden contribuir mediante esquemas familiares y tasas diferenciales según su nivel de ingresos y de que deben flexibilizarse los mecanismos de formalización, como se plantea en el capítulo IV. Este hecho se había demostrado en estudios sobre diversos países de la región, que han evidenciado la capacidad de cotización en esquemas subsidiados de los trabajadores informales, o incluso de no ocupados receptores de remesas (Gutiérrez, Acosta y Alfonso-Sierra, 2012; Carrera, Castro y Sojo, 2010). En países con esquemas muy poco desarrollados, no solo es indispensable ampliar la cobertura, sino también mejorar la calidad del aseguramiento en los mercados laborales e incrementar el impacto redistributivo. En tal sentido, además del uso de recursos fiscales, es imprescindible la ruptura de los techos contributivos (Carrera, Castro y Sojo, 2010).

También en la literatura sobre economía de la salud se advierte una impugnación de las visiones dicotómicas respecto del financiamiento mediante contribuciones o recursos fiscales. En ese sentido resulta interesante el llamado de atención de que hay un reconocimiento creciente de que la fuente de los recursos no determina la estructura organizacional del sector, los mecanismos por los cuales esos recursos son asignados, ni la precisión con que se especifican los beneficios. Así, términos como sistema de financiamiento por impuestos generales 
o sistemas de seguridad social no son descriptores adecuados de los sistemas actuales. La forma tradicional de pensar en la seguridad social impone restricciones innecesarias al rango de opciones de políticas abiertas a los países (Kutzin, 2013).

En América Latina, a partir de lógicas de una presunta racionalidad técnica, en la discusión acerca del financiamiento de la protección social se escamotean en ocasiones los determinantes estrictamente políticos de la arquitectura de esa protección ${ }^{4}$. La vasta literatura contemporánea sobre el Estado de bienestar que trata sobre su genealogía y transformaciones a lo largo del tiempo en varias latitudes permite conocer en profundidad los condicionantes históricos y políticos que subyacen tras las opciones de financiamiento ${ }^{5}$.

La fragmentación y la segmentación están establecidas en los sistemas de protección social y en su acción política y discursiva; es decir, no son exógenas (no emanan únicamente de dinámicas propias del mercado laboral, por ejemplo). Por ello, la estrategia de universalización de la protección social en la región no puede centrarse exclusivamente en un incremento de recursos, sino que debe actuar sobre la morfología de la protección social: el cambio institucional forma parte crucial del "locus" de la innovación (Sojo, 2013).

La fuente de los recursos por sí sola no determina la estructura organizacional del sector, los mecanismos mediante los cuales se asignan los recursos, ni la precisión con que se determinan los beneficios (Kutzin, 2008; Gutiérrez, Acosta y Alfonso-Sierra, 2012). Avanzar contra la segmentación y hacia la equidad no exime, evidentemente, de la necesidad de combinar los recursos contributivos con los no contributivos, pero en cuanto a la equidad, es la arquitectura de los sistemas de protección social la que determina sus fragmentaciones, segmentaciones y estratificaciones, que no dependen directamente del carácter contributivo o no contributivo de los recursos. También resulta crucial la manera específica en que ellos se combinan, que depende del andamiaje de esta arquitectura, que incluye, entre otros aspectos la progresividad del financiamiento, la asignación de los recursos, la especificación de los beneficios, la calidad de las prestaciones, la eficacia y eficiencia del uso de los recursos, la regulación de las combinaciones público-privadas y la protección jurídica de los derechos. En el caso de la salud, resulta crucial velar por una convergencia de los beneficios por encima de las fuentes de financiamiento que estén en juego: cuanto mayor sea la fragmentación institucional, más complejo resultará avanzar hacia esa convergencia (véase el diagrama I.1).

4 Según la acepción de "escamotear" en el Diccionario de la Real Academia Española: "hacer desaparecer, quitar de en medio de un modo arbitrario o ilusorio algún asunto o dificultad".

5 Véanse Schmidt y Thatcher (2013); Palier (2010); Barr y Diamond (2008); Hemerijck (2013); Bonoli y Natali (2012), y Porter (1999). 


\section{Diagrama I.1 \\ América Latina: las dicotomías analíticas no reflejan la complejidad de la protección social}

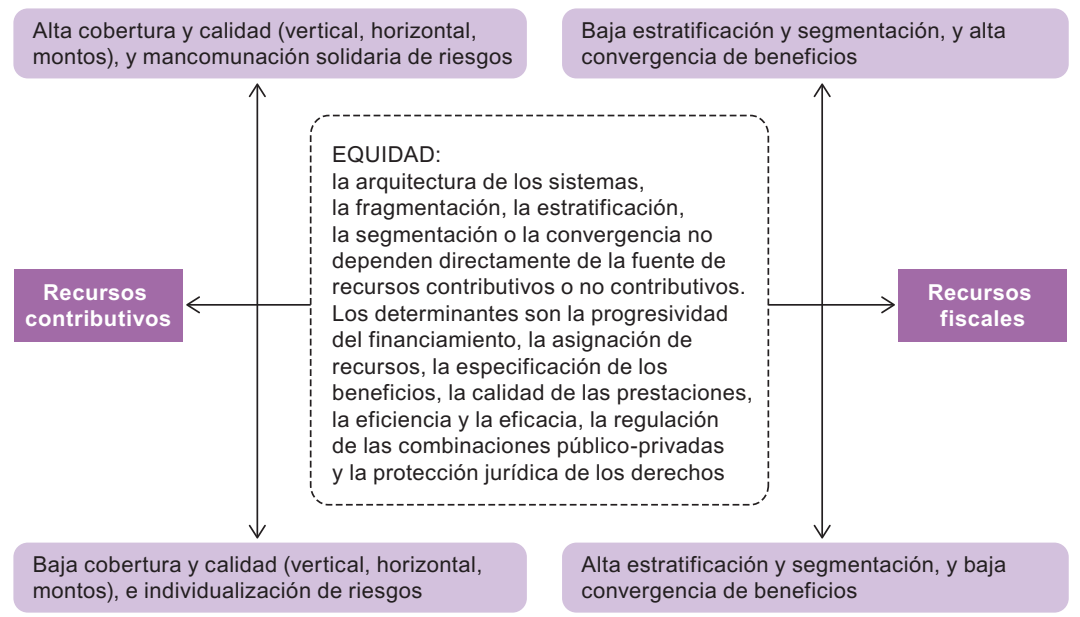

Fuente: A. Sojo, "Desigualdade e proteção social em saúde e previdência na América Latina", Gestão e políticas públicas no cenário contemporâneo: tendências nacionais e internacionais, T. Menicucci y J. G. Leandro (eds.), Brasilia, Editorial Fiocruz, 2016.

Como se ha visto, la impugnación dicotómica del financiamiento contributivo ha ido de la mano de diversas propuestas que cifran la universalidad de la protección social de manera reduccionista en diversos conjuntos limitados de prestaciones. De allí que sea crucial impugnar postulados dicotómicos sobre el financiamiento de la protección social y sus coberturas, así como reconocer el papel que cumple en la protección social el financiamiento contributivo y avanzar hacia una convergencia y una menor estratificación de las prestaciones en los ámbitos de la protección social, donde estén presentes tanto recursos contributivos como no contributivos (Sojo, 2015a).

\section{Evolución del planteamiento sobre el piso de protección social y la cobertura universal de salud}

La noción de piso de protección social, desarrollada por la Organización Internacional del Trabajo (OIT) conjuntamente con la Organización Mundial de la Salud (OMS), constituye otro hito importante en la discusión sobre protección social, concepto que ha sufrido transformaciones considerables.

Inicialmente prevaleció el planteamiento de un paquete esencial de prestaciones. El piso básico de protección social, promovido en primer lugar por la Comisión Mundial de la Dimensión Social de la Globalización 
en 2002, se definió como un conjunto básico y modesto de garantías de seguridad social, que debían implementarse mediante transferencias monetarias y prestaciones (OIT, 2008).

Se afirmaba que, más que un conjunto de beneficios, constituirían un conjunto de garantías de acceso a transferencias esenciales. Asimismo, por su monto - se trataba de asegurar a niños y niñas, adultos mayores y personas con discapacidad ingresos suficientes para que no estuvieran por debajo de la línea de pobreza, así como de brindar algún apoyo focalizado a desempleados y pobres en edad activa - tendrían características de beneficios de asistencia social, más que de seguridad social, a diferencia de los beneficios de la seguridad social adquiridos sobre la base del pago de contribuciones o impuestos, que generalmente representan un reemplazo alto del ingreso (OIT, 2008, pág. 3).

Más adelante se definió como la interrelación entre garantías básicas, a la que se sumaba un segundo nivel con prestaciones garantizadas como derecho y un piso superior con seguros voluntarios regulados (Cichon, Behrendt y Wodsak, 2011, pág. 9).

Destacan esas transformaciones de la propuesta, junto con otras que siguieron a lo largo del tiempo (Sojo, 2012). Debido a la presión sindical en las discusiones tripartitas en el seno de la OIT, el término "básico" fue eliminado. El "piso de protección social" se deslinda de las "redes de protección" (safety nets), por cuanto estas consideraban a las políticas sociales de manera residual y pretendían suavizar los efectos del ajuste con medidas temporales, fragmentadas y focalizadas en las personas pobres y vulnerables según ciertos criterios (Grupo Consultivo sobre el Piso de Protección Social, 2011, págs. 12-13). Se concibe el piso como un complemento y no como una alternativa a las instituciones de seguridad social existentes; es decir, un componente de un sistema de protección social pluralista y comprehensivo. En países con sistemas de protección social comprehensivos pero segmentados, la función del piso sería reducir las brechas de cobertura y mejorar la coherencia de las políticas sociales (Grupo Consultivo sobre el Piso de Protección Social, 2011, pág. xxxii).

En el marco de la Comisión Asesora del Piso de Protección Social, presidida por Michelle Bachelet, ex Directora Ejecutiva de la Entidad de las Naciones Unidas para la Igualdad de Género y el Empoderamiento de las Mujeres (ONU-Mujeres), la universalidad de la protección social se plantea como una búsqueda progresiva en el marco de una pluralidad institucional y dentro de una estrategia que comprende una dimensión horizontal (conjunto de garantías básicas para todos) y otra vertical, que se refiere a la implementación gradual de estándares más elevados (Grupo Consultivo sobre el Piso de Protección Social, 2011, pág. xxv). La dimensión horizontal guarda relación con servicios esenciales financiables de salud, 
educación, saneamiento, seguridad alimentaria, vivienda, seguridad básica de ingresos o medidas de nivel básico (o muy básico) conforme a un mínimo establecido a escala nacional y cuya amplitud está en función del espacio fiscal y financiero. Debe aspirarse a su expansión conforme a los niveles de desarrollo económico y la ampliación del espacio fiscal, ya que el piso debe entenderse como un primer paso hacia una expansión de los niveles de protección (Grupo Consultivo sobre el Piso de Protección Social, 2011, pág. 12).

En 2012, de las recomendaciones de la Conferencia General de la OIT sobre la materia (OIT, 2012) destaca lo que puede denominarse "pluralismo institucional inherente" (Sojo, 2012), por cuanto se afirma que la concreción del piso abarca regímenes universales de prestaciones, de seguro social, de asistencia social, impositivos y relacionados con el empleo. Ante el gran desafío de evitar que la escalera interdependiente del piso en sus dimensiones vertical y horizontal origine una fragmentación adicional de la protección social existente (Sojo, 2012 y 2013), en el seno de la OIT se ha planteado la necesidad de desarrollar en forma simultánea ambas dimensiones (Schwarzer, 2013).

Por su parte, en el Informe sobre la salud en el mundo 2010 (OMS, 2010) se resaltan algunos compromisos necesarios para el diseño de beneficios que deben asumirse para avanzar hacia la cobertura universal en salud. Se consideran tres dimensiones: quién se beneficia de los recursos, a qué servicios se tiene acceso y cuál es su costo. El avance hacia la cobertura universal y sus mecanismos se representan mediante un cubo que debe ser colmado, y en el que se ponen en relación la población, los costos y los servicios. En las dimensiones horizontales, empezando por las personas pobres y vulnerables, el objetivo es ir abarcando a la población no cubierta; en cuanto a los servicios, deben ser de calidad y estar basados en la distribución de la carga de la enfermedad, priorizando las necesidades de los más vulnerables y progresando hacia la inclusión de otros servicios. En la dimensión vertical, se avanza al reducir los gastos de bolsillo en salud, considerando las necesidades específicas de los grupos más desaventajados, mediante la rebaja de copagos y cuotas.

Para cerrar esta sección cabe señalar que en la discusión internacional en torno a la protección social se ha evolucionado hacia visiones más pluralistas sobre cómo avanzar hacia mayores niveles de protección social. Se trata de planteamientos heterodoxos y probablemente tendrán impacto en la región. En lo referente a la seguridad social, el avance hacia este tipo de interpretaciones se expresa en advertencias acerca de que no existe un modelo único a escala internacional para proveer protección social en materia de salud, ni un solo camino para expandir la cobertura, dada las diferencias entre países en cuanto a estructuras de gobernanza, 
mecanismos de financiamiento y fuentes de recursos, diversificación de riesgo y asignación de recursos y beneficios cubiertos. Se subraya cómo se está transformando la protección social —en el marco de sistemas de financiamiento que cubren de manera independiente o traslapada a grupos de población muy diversos-, entre otras razones debido al desarrollo económico, a valores culturales, a determinantes institucionales y al compromiso y liderazgo políticos (Scheil-Adlung, 2013).

\section{La CEPAL y la protección social como derecho ciudadano}

Tal como lo ha planteado la CEPAL (2006), un sistema de protección es más que una estructura institucional; es un acuerdo político al que concurre la sociedad para establecer las bases sobre las que desea construir y regular su convivencia. Este acuerdo, que está en construcción permanente, determina qué derechos se aplican a toda la población, cómo se garantizan y en qué forma se hacen viables. Por lo tanto, se requiere un cierto nivel de cohesión para construir consensos que se plasmen en instituciones, normas, programas y recursos. Asimismo, para transitar de un conjunto de políticas sociales a un sistema integral de protección social se precisa cohesión social. Esta debe promoverse e implica encarar conflictos entre derechos, recursos, patrones distributivos y diseños institucionales. Un modelo de protección social basado en derechos y orientado a la cohesión exige pronunciarse en torno a cuatro elementos esenciales: la determinación de los niveles y las fuentes de financiamiento contributivo y no contributivo; la magnitud de la solidaridad en el financiamiento; el desarrollo de la institucionalidad social para una gestión eficiente de la política de oferta de prestaciones, y la identificación de derechos explícitos que se pueden garantizar y exigir en términos de acceso a prestaciones sociales (CEPAL, 2007).

A partir de 2000, con el fin de encarar discursivamente la visión reduccionista de la política social, la CEPAL ha formulado principios sobre esa política y, con ello, de la protección social, desde un escenario de reconocimiento de los derechos ciudadanos.

El principio de universalidad consiste en garantizar a todos los miembros de la sociedad determinadas protecciones o beneficios en forma de derechos, con la calidad y en la cantidad que se consideran necesarios para una participación plena en la sociedad. Con este principio se pretende que todos los individuos cuenten con la certeza de que se les asegura el máximo bienestar permitido por el desarrollo económico en un momento dado. Ello no significa que todo beneficio sea universalizable, sino que la sociedad establece, a partir de acuerdos, los 
estándares de calidad y de cobertura que deben garantizarse a todos sus miembros (CEPAL, 2000 y 2006).

La universalidad está íntimamente vinculada con el principio de solidaridad, que postula a su vez la participación en el financiamiento de la política social de acuerdo con la capacidad económica individual. Así, la solidaridad debe coadyuvar a asegurar la universalidad y la equidad en el acceso a las prestaciones sociales, considerando las asimetrías de las condiciones económicas y de la exposición a riesgos, particularmente en materia de salud y empleo. Según el principio de solidaridad se asume también que, dadas las externalidades del bienestar individual, existe una estrecha interrelación entre este y el bienestar social. En la vida de las personas y en el desarrollo de las sociedades influyen la amplitud y calidad de los servicios y las protecciones sociales (CEPAL, 2000 y 2006).

Los principales obstáculos para el avance hacia la universalidad de las políticas sociales y de sus beneficios han sido la restricción de recursos y la falta de acuerdos sociales sobre su prioridad, así como dificultades instrumentales para su ejecución. La universalidad no es contraria a la posibilidad de establecer criterios de selectividad, que se imponen ante la escasez de recursos como forma de asegurar que los servicios sociales lleguen a la población más pobre. Así pues, debe existir una interacción benéfica entre las políticas universales e integrales y las selectivas y diferenciadas si se desea atender el carácter multifacético y heterogéneo de la pobreza. Como las barreras afectan principalmente a las personas más pobres, la selectividad debe entenderse como el instrumento o conjunto de instrumentos que permiten orientar la acción, particularmente la asignación de subsidios, para que la población carente de recursos económicos pueda acceder a los servicios y garantías sociales. De ese modo, la focalización tiene por objeto hacer más eficaz la universalización de las políticas sociales (CEPAL, 2000 y 2006).

Para que la equidad sea sustantiva, el uso de los recursos públicos debe ser eficiente. El principio de eficiencia en la utilización de los recursos públicos destinados a la política social resulta también intrínseco a la equidad, en la medida en que permite potenciar los principios de universalidad y solidaridad sin contraponerlos. No debe entenderse exclusivamente en términos de efectos macro- y microeconómicos, sino, en última instancia, como la capacidad para maximizar con recursos escasos los objetivos sociales definidos (CEPAL, 2000 y 2006). Además, las reformas dirigidas a insertar los subsistemas en un sistema integrado de protección social deben también regular las opciones de mercado y particulares, con normas que velen por adecuadas combinaciones público-privadas, a fin de lograr los objetivos sociales y públicos deseados (CEPAL, 2007, pág. 137). 
Como el mercado de trabajo no ha mostrado una adecuada capacidad incluyente en términos de creación de empleo de calidad ni de cobertura contributiva, no puede ser el único mecanismo para proteger a la mayoría de la población frente a riesgos relacionados con las fluctuaciones de ingresos, la salud y el envejecimiento, entre otros. Por eso la protección social no debe quedar restringida a los mecanismos que ofrece el mundo laboral: el gran desafío es replantearla en el marco de una solidaridad integral, en que se combinen mecanismos contributivos y no contributivos (CEPAL, 2006).

Para ampliar la cobertura y la calidad de la protección social es indispensable actuar en las materias postergadas e incumplidas respecto del mercado laboral y debe nivelarse el campo de juego en el ámbito productivo, que durante décadas ha agudizado la gran heterogeneidad de la estructura productiva. De no corregirse esas disparidades - al menos parcialmente- es difícil que las políticas sociales puedan contribuir a generar un modelo social más inclusivo. Para avanzar, debe repensarse la dinámica subyacente del mercado laboral, ya que el desarrollo histórico de la protección social está vinculado con la legislación laboral, las regulaciones de las condiciones de trabajo y de los despidos, los convenios colectivos, las políticas de capacitación y educación, y las capacidades de supervisión del cumplimiento de las normativas (CEPAL, 2013).

La CEPAL (2016) ha planteado que es fundamental superar la visión reduccionista y dicotómica de la relación entre la protección social contributiva y no contributiva porque resulta inconducente. Reviste entonces gran importancia reconocer el papel que cumple en la protección social el financiamiento contributivo y avanzar hacia una convergencia y menor estratificación de las prestaciones en los ámbitos de la protección social - en especial el aseguramiento de salud y de las pensiones asociadas con el mercado de trabajo y con el trabajo no remunerado-, donde estén presentes tanto los recursos contributivos como los no contributivos.

\section{B. Oposiciones y confluencias de las perspectivas sobre protección social y sus virtuales interacciones o resonancias}

En América Latina los planteamientos relativos a la cobertura y el financiamiento de la protección social han sido los ejes fundamentales de la discusión en las últimas décadas, y la fuerza de las tensiones en torno a ellos ha subsumido otros temas. De allí que su intersección permita trazar espacialmente la inserción de posturas cruciales sobre protección social (Sojo, 2016 y 2015b). 
En el diagrama I.2 se presentan las propuestas en un espacio bidimensional, donde se las ordena en torno a los planteamientos de cobertura y al financiamiento. Aunque de una manera inicial y sin atribuir valores numéricos a variables estandarizadas que podrían determinar su posición en los puntos del plano o del espacio, al esbozar este territorio discursivo es posible visibilizar las oposiciones y confluencias de las distintas perspectivas y sus virtuales interacciones o resonancias - deseadas o no deseadas; explícitas o implícitas-, al igual que algunas evoluciones en el seno de algunos organismos internacionales (Sojo, 2015b y 2016). Como se observa, en el marco de instituciones como el Banco Mundial o la OIT se han elaborado postulados disímiles, que se sitúan, por tanto, en varias coordenadas.

\section{Diagrama I.2 \\ América Latina: tensiones discursivas sobre la protección social}

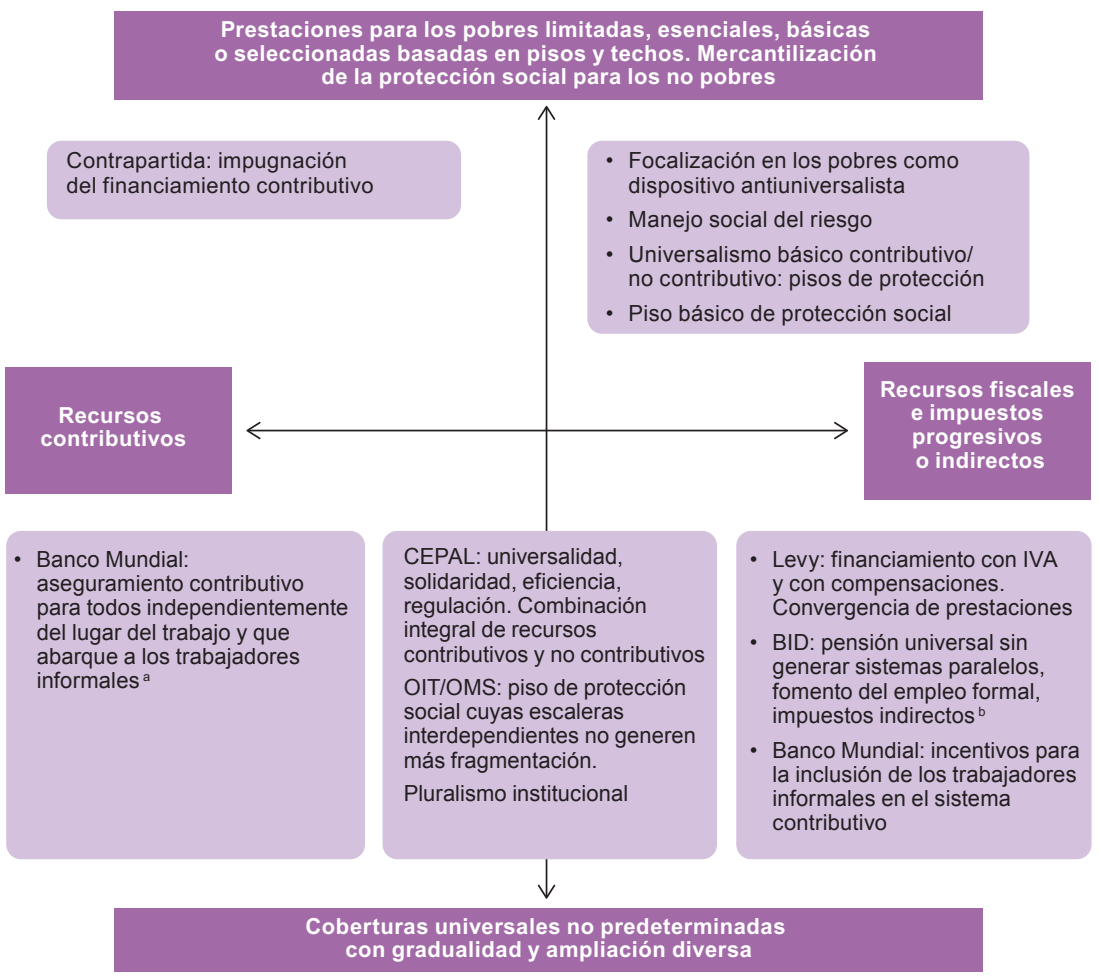

Fuente: A. Sojo, "Desigualdade e proteção social em saúde e previdência na América Latina”, Gestão e políticas públicas no cenário contemporâneo: tendências nacionais e internacionais, T. Menicucci y J.G. Leandro (eds.), Brasilia, Editorial Fiocruz, 2016.

a Ribe, H., D.A. Robalino e I. Walker (2012), From Right to Reality. Incentives, Labor Markets, and the Challenge of Universal Social Protection in Latin America and the Caribbean, Washington, D.C., Banco Mundial.

b Bosch, M., Á. Melguizo y C. Pagés (2013), Mejores pensiones, mejores trabajos. Hacia la cobertura universal en América Latina y el Caribe, Washington, D.C, Banco Interamericano de Desarrollo (BID). 
En el cuadrante II se reúnen las posiciones más restrictivas sobre el papel que le cabe desempeñar al Estado en materia de protección social y de diversificación de riesgos, que propugnan bajas coberturas, políticas destinadas eminentemente a los pobres y una escasa diferenciación de los riesgos en términos de la protección social. Al no tener como objetivos la diferenciación de riesgos ni los efectos redistributivos de la protección social, tales propuestas impugnan el financiamiento contributivo y proponen el uso de recursos fiscales para financiar coberturas limitadas, denominadas, según el caso, limitadas, esenciales, básicas, mínimas o seleccionadas, con una gran abundancia de metáforas relativas a pisos y techos (en que los pisos arriesgan convertirse en techos), dentro de una protección social segmentada, sin indagar mayormente en el carácter regresivo o progresivo de los recursos fiscales que estarían destinados a dichos fines (por ejemplo, si son impuestos progresivos o indirectos). Por ello, en términos del financiamiento, se sitúan en el cuadrante I. A esta conjunción subyace una protección social eminentemente mercantilizada para los no pobres y de cobertura muy restringida para los pobres y, con ello, segmentada, lo que cuestiona tanto la universalidad como la solidaridad del financiamiento. En estos términos coinciden la focalización reduccionista y el manejo social del riesgo del Banco Mundial, el universalismo básico del BID, y el planteamiento inicial del piso de protección social denominado básico de la OIT, que más tarde evoluciona, elimina la calificación de "básico" y se preocupa por superar la fragmentación.

En el cuadrante IV se sitúan las propuestas que revelan una mayor preocupación por la estratificación de la protección social y por avanzar hacia una mayor convergencia de las prestaciones, aunque sin mayores referencias a lo que ella implica en cuanto a las instituciones a cargo. Coinciden allí las posturas recientes de Levy sobre el financiamiento de la salud en México y las propuestas del BID sobre pensión universal sin sistemas paralelos, de allí que no sean tan restrictivas en términos de la cobertura como las del cuadrante II. Pero ambas propugnan el financiamiento mediante impuestos indirectos y con ello coartan la vocación redistributiva del financiamiento de la protección social que debe actuar también sobre lo contributivo para impugnar la segmentación.

En cuanto al financiamiento, en el cuadrante IV también aparecen las ideas del Banco Mundial que propugnan el uso de incentivos fiscales, pero que discrepan profundamente de las posturas del BID en el mismo cuadrante, ya que estos incentivos son un instrumento para la inserción de los trabajadores informales dentro del aseguramiento contributivo. Por ende, sus propuestas en materia de cobertura se ubican en el cuadrante III, dado que plantean un aseguramiento para todos, por encima del tipo de inserción laboral y que abarca el trabajo informal, mediante el aseguramiento contributivo, lo que implica un serio cuestionamiento de 
la segmentación de la protección social en el marco de una propuesta que tiene implicaciones para la formalización del mercado laboral. Resulta interesante reflexionar sobre las implicaciones institucionales en el ámbito de la protección social que ella acarrea y que no se han explicitado.

Por otra parte, se deben situar aquellas propuestas de vocación universalista que no predeterminan o encorsetan los contenidos de estas coberturas universales y que endosan el carácter gradual de la ampliación, debido a la complejidad política, institucional y financiera que les es inherente, y que comparten una visión pluralista sobre las instituciones de la protección social que pueden estar involucradas. Dado que impugnan la segmentación de las coberturas, figuran en la parte inferior del eje $y$; por otra parte, como plantean una combinación de recursos contributivos y no contributivos, se ubican en una posición equidistante en el eje $x$ (entre los cuadrantes III y IV) en cuanto a la tensión relativa al financiamiento. Considerando las proporciones reales del financiamiento contributivo y no contributivo, dado el peso real que tienen los recursos contributivos en la actualidad y el peso que pueden adquirir en el marco de estrategias de formalización del mercado laboral, ciertamente puede ser debatible asignarles tal posición. No obstante, en esos términos cabe aclarar que la equidistancia recoge más cierta ecuanimidad sobre los tipos de financiamiento que la forma empírica en que se combinan en cada país. Así, se observan coincidencias parciales entre las propuestas de la CEPAL y el planteamiento remozado de la OIT y la OMS acerca del piso de protección social desarrollado a partir de 2011.

\section{Bibliografía}

Auerbach, P., M.E. Genoni y C. Pagés (2007), "Social security coverage and the labor market in developing countries", IZA Discussion Papers, N 2979, Bonn, Institute for the Study of Labour (IZA).

Barr, N. y P. Diamond (2008), Reforming Pensions. Principles and Policy Choices, Nueva York, Oxford University Press

Bonoli, G. y D. Natali (2012), The Politics of the New Welfare State, Nueva York, Oxford University Press.

Bosch, M., Á. Melguizo y C. Pagés (2013), Mejores pensiones, mejores trabajos. Hacia la cobertura universal en América Latina y el Caribe, Washington, D.C, Banco Interamericano de Desarrollo (BID).

Carrera, F., M. Castro y A. Sojo (2010), “Progresar hacia la equidad: sinopsis de algunos retos del financiamiento de la salud y las pensiones en Guatemala, Honduras y Nicaragua", Envejecimiento en América Latina. Sistemas de pensiones y protección social integral, Antonio Prado y Ana Sojo (eds.), Libros de la CEPAL, No 110 (LC/G.2475-P), Santiago, Comisión Económica para América Latina y el Caribe (CEPAL).

CEPAL (Comisión Económica para América Latina y el Caribe) (2016), Desarrollo social inclusivo. Una nueva generación de políticas para superar la pobreza y reducir la desigualdad en América Latina y el Caribe (LC/L.4056/Rev.1), Santiago. 
(2013), Panorama Social de América Latina 2013 (LC/G.2580), Santiago.

(2010), La hora de la igualdad: brechas por cerrar, caminos por abrir (LC/G.2432 (SES.33/3)), Santiago.

(2007), Cohesión social. Inclusión y sentido de pertenencia en América Latina y el Caribe (LC/G.2335/Rev.1), Santiago.

(2006), La protección social de cara al futuro: acceso, financiamiento y solidaridad, (LC/G.2294(SES.31/3)), Santiago.

(2000), Equidad, desarrollo y ciudadanía (LC/G.2071/Rev.1-P), Santiago.

Cichon, M., C. Behrendt y V. Wodsak (2011), "La iniciativa del piso de protección social de las Naciones Unidas. Cambiando la tendencia en la Conferencia de la OIT de 2011", Análisis de politicas internacionales, Fundación Friedrich Ebert.

Filgueira, F. y otros (2006), “Universalismo básico: una nueva política social para América Latina", Universalismo básico: una alternativa posible y necesaria para mejorar las condiciones de vida, Carlos Gerardo Molina (ed.), Ciudad de México, Banco Interamericano de Desarrollo (BID)/Editorial Planeta.

Gómez Sabaini, J.C. y D. Morán (2013), "Política tributaria en América Latina: agenda para una segunda generación de reformas", serie Macroeconomía del Desarrollo, No 133 (LC/L.3632), Santiago, Comisión Económica para América Latina y el Caribe (CEPAL).

Grupo Consultivo sobre el Piso de Protección Social (2011), Piso de protección social para una globalización equitativa e inclusiva, Ginebra.

Gutiérrez, C., O.L. Acosta y E.A. Alfonso-Sierra (2012), "Financiación de la seguridad social en salud: fuentes de recursos y su administración. Problemas y alternativas", La salud en Colombia: logros, retos y recomendaciones, Óscar Bernal y Catalina Gutiérrez (comps.), Bogotá, Universidad de los Andes.

Hemerijck, A. (2013), Changing Welfare States, Londres, Oxford University Press

Holzmann, R., E. Palmer y A. Uthoff (eds.) (2008), Fortalecer los sistemas de pensiones latinoamericanos, Bogotá, Comisión Económica para América Latina y el Caribe (CEPAL)/Mayol Ediciones.

Kutzin, J. (2013), "La financiación sanitaria para una cobertura universal y el funcionamiento de los sistemas sanitarios: conceptos e implicaciones de las estrategias", Boletín de la Organización Mundial de la Salud, N 91, Washington, D.C. (2008), "Health financing policy: a guide for decision-makers", Health Financing Policy Paper, $N^{\circ}$ 2008/1, Oficina Regional de la OMS para Europa.

Levy, S. (2012), "Seguridad social universal: un camino para México", NEXOS en línea [en línea] http: / / www.nexos.com.mx/?P=leerarticulo\&Article=2103001.

Ministerio deSalud de Colombia (2013), "Proyecto de Ley por el cual se redefine el Sistema General de Seguridad Social en Salud y se dictan otras disposiciones", Bogotá.

OIT (Organización Internacional del Trabajo) (2012), "Texto de la recomendación relativaalospisosnacionales deprotección social" [enlínea]http:/ /www.ilo.org/ wcmsp5/groups / public/---ed_norm/---relconf/documents / meeting document/wcms_183322.pdf.

(2008), "Can low-income countries afford basic social security?", Social Security Policy Briefings Paper, No 3, Ginebra.

OMS (Organización Mundial de la Salud) (2010), Informe sobre la salud en el mundo 2010, Ginebra.

Palier, B. (ed.) (2010), A Long Goodbye to Bismarck? The Politics of Welfare Reform in Continental Europe, Amsterdam, Amsterdam University Press. 
Porter, D. (1999), Health, Civilization and the State, Londres, Routledge.

Rashid, M. (2012), "La protección social y el empleo en América Latina y el Caribe", presentación en la reunión del Grupo de Trabajo Conjunto del Consejo Permanente y el Consejo Interamericano para el Desarrollo Integral (CIDI) de la Organización de los Estados Americanos (OEA) sobre el proyecto de plan de acción de la Carta Social de las Américas, Washington, D.C., octubre.

Rezk, E. (2006), "Desafíos de la viabilidad financiera", Universalismo básico: una alternativa posible y necesaria para mejorar las condiciones de vida, Carlos Gerardo Molina (ed.), Ciudad de México, Banco Interamericano de Desarrollo (BID)/ Editorial Planeta.

Ribe, H., D.A. Robalino e I. Walker (2012), From Right to Reality. Incentives, Labor Markets, and the Challenge of Universal Social Protection in Latin America and the Caribbean, Washington, D.C., Banco Mundial.

(2010), Achieving Effective Social Protection for all in Latin America and the Caribbean. From Right to Reality, Washington, D.C., Banco Mundial.

Rivera, E. (2013), "Treinta años de política tributaria en Chile: una reorientación necesaria”. Radiografía crítica al "modelo chileno". Balance y propuestas, Gonzalo Martner y Eugenio Rivera (eds.), Santiago, LOM Ediciones.

Sáenz, R. (2015), "Articulación solidaria de los regímenes contributivos y no contributivos de salud y pensiones en Costa Rica, exposición en Seminario técnico CEPAL-GIZ sobre institucionalidad social en el desarrollo de una protección social bajo el enfoque de derechos", Santiago [en línea] http:// conferencias.cepal.org/cepal_giz/Martes\%2011/Camtasia\%20editado/R\%20 Saenz/R\%20Saenz.html.

Scheil-Adlung, X. (2013), "Health protection. More than financial protection", Scaling Up Affordable Health Insurance. Staying the Course, A. Preker y otros (eds.), Washington, D.C., Banco Mundial.

Schmidt, V. y M. Thatcher (2013), "Resilient liberalism: European political economy through boom and bust", Resilient Liberalism in Europe's Political Economy, V. Schmidt y M. Thatcher (eds.), Cambridge, Cambridge University Press.

Schwarzer, H. (2013), "El piso de protección social", presentación en el Seminario de formación e intercambio sobre la situación social, económica y de derechos de los trabajadores en la economía informal, organizado por la Oficina de Actividades para los Trabajadores (ACTRAV) de la Organización Internacional del Trabajo (OIT), Lima, agosto.

Sojo, A. (2016), "Desigualdade e proteção social em saúde e previdência na América Latina", Gestão e políticas públicas no cenário contemporâneo: tendências nacionais e internacionais, T. Menicucci y J.G. Leandro (eds.), Brasilia, Editorial Fiocruz. (2015a), "Las imprecisas distinciones entre protección social contributiva y no contributiva en la discusión latinoamericana", presentación en el Seminario "Los desafíos de la institucionalidad social en el desarrollo de una protección social universal bajo el enfoque de derechos", Santiago, Comisión Económica para América Latina y el Caribe (CEPAL)/Agencia Alemana de Cooperación Internacional (GIZ), agosto.

(2015b), "Including informal economy workers in contributory social protection: Current challenges in Latin America", International Social Security Review, vol. $68, \mathrm{~N}^{\circ} 4$. 
(2013), “La propuesta del piso de protección social y la extensión de la cobertura en la región, vista desde la CEPAL", presentación en el Seminario de formación e intercambio sobre la situación social, económica y de derechos de los trabajadores en la economía informal, organizado por la Oficina de Actividades para los Trabajadores (ACTRAV) de la Organización Internacional del Trabajo (OIT), Lima, agosto.

(2012), “El piso de protección social: una perspectiva sobre sus potenciales lecturas en la región", presentación en el taller "Seguridad social para todos: el piso de protección social", organizado por la Organización Internacional del Trabajo (OIT) y la Organización Panamericana de la Salud (OPS), Lima, agosto. (2007), "La trayectoria del vínculo entre políticas selectivas contra la pobreza y políticas sectoriales", Revista de la CEPAL, N 91 (LC/G.2333-P), Santiago, Comisión Económica para América Latina y el Caribe (CEPAL). (2003), "Vulnerabilidad social, aseguramiento y diversificación de riesgos en América Latina y el Caribe", Revista de la CEPAL, No 80 (LC/G.2204-P), Santiago, Comisión Económica para América Latina y el Caribe (CEPAL). (1999), "La política social en la encrucijada: opciones o disyuntivas", De igual a igual: el desafío del Estado ante los nuevos problemas sociales, J. Carpio e I. Novacovsky (eds.), Buenos Aires, Fondo de Cultura Económica (FCE). (1990), "Naturaleza y selectividad de la política social", Revista de la CEPAL, N 41 (LC/G.1631-P), Santiago, Comisión Económica para América Latina y el Caribe (CEPAL).

Tokman, Víctor (2006), "Empleo y protección: una vinculación necesaria", Universalismo básico: una alternativa posible y necesaria para mejorar las condiciones de vida, Carlos Gerardo Molina (ed.), Ciudad de México, Banco Interamericano de Desarrollo (BID)/Editorial Planeta. 

Capítulo II

\section{La razón de ser del aseguramiento: fundamentos para la convergencia en torno a una protección social universal y solidaria}

Para encarar la desigualdad en América Latina e incrementar el bienestar de los ciudadanos, es fundamental forjar coaliciones políticas amplias que tengan como objetivo superar la fragmentación y estratificación propias de los sistemas de protección social vigentes.

En este capítulo, en primer lugar se aborda la protección social desde una perspectiva de derechos y se analiza cómo el mercado limita la diversificación de riesgos que requieren las personas. Con el propósito de brindar argumentos para la convergencia de intereses en torno a la protección social solidaria y universal, también se enfatiza la naturaleza impredecible de los riesgos, su magnitud y su carácter, como fundamento de un interés común por la diferenciación de los riesgos y la indispensable reciprocidad del aseguramiento.

También se distingue el sentido de los sistemas contributivos de pensiones, que deben reflejar el esfuerzo del ahorro personal y el del pilar solidario y redistributivo de las pensiones, respecto del fundamento de la protección social de la salud, que enfrenta desafíos distintos derivados de la singularidad y excepcionalidad de la salud como un bien sui géneris, tanto por su valor intrínseco como instrumental. Por último, se esbozan algunas externalidades del aseguramiento. 


\section{A. La protección social desde la perspectiva de derechos}

Pese al transcurso del tiempo, la definición de ciudadanía como un principio de igualdad y como una institución en desarrollo, postulada por Marshall en 1949, conserva una enorme lozanía para pensar en los contenidos y en los linderos de las trayectorias de la protección social en diversos países: la ciudadanía es un estatus conferido a quienes son miembros plenos de la comunidad. Todos los que lo poseen son iguales respecto de los derechos y obligaciones con que está investido este estatus. No hay un principio universal que determine cuáles deben ser estos derechos y estas obligaciones, pero las sociedades en las cuales la ciudadanía es una institución que evoluciona crean una imagen de una ciudadanía ideal, respecto de la cual pueden medirse los logros, y hacia la cual pueden dirigirse las aspiraciones. El impulso así planeado a lo largo del sendero es un impulso hacia una igualdad más plena, hacia un enriquecimiento de la materia que constituye la ciudadanía, y hacia un incremento del número de personas a quienes se les confiere este estatus (Marshall, 1992).

En esos términos, analizar la protección social desde una perspectiva de derechos permite visualizar los logros y restricciones de la igualdad en esta materia. A tal fin, es útil el modelo tetradimensional de democracia propuesto por el jurista italiano Ferrajoli, que se articula en torno a cuatro dimensiones de los derechos: los políticos, los civiles, los sociales y los derechos de libertad. Aunque insuficiente por sí sola, la dimensión política resulta indispensable, ya que en su ausencia no puede hablarse de democracia en ningún sentido del término: las otras tres dimensiones presuponen el goce de los derechos políticos. Los derechos políticos y civiles fundamentan la legitimidad formal de la democracia; los de libertad y los sociales fundan la legitimidad sustancial, en el sentido negativo y positivo de la democracia, ya que prescriben aquello que está prohibido, o bien, lo que es obligatorio hacer. En este sentido, los derechos fundamentales democráticos pueden analizarse conforme al tipo de expectativas que generan. Por una parte, los derechos de libertad - tanto civil como política- encarnan expectativas negativas, es decir que imponen límites o prohibiciones a su lesión. Por otra parte, los derechos sociales generan expectativas positivas: imponen vínculos y obligaciones de prestación, cuya inobservancia da lugar a lagunas (Ferrajoli, 2008, págs. 80-82) (véase el diagrama II.1).

La protección social es un ámbito de concreción de los derechos sociales. En tal sentido, es pertinente subrayar que los derechos sociales estipulan estándares imperativos para la sociedad y definen situaciones de privación de sus miembros que son inadmisibles (Abramovich y Courtis, 2002; 
Courtis, 2007; CEPAL, 2007). Los sistemas de protección social en América Latina, por ser muy estratificados y excluyentes, conculcan con frecuencia el disfrute de estos derechos y - en los términos de Ferrajoli-generan lagunas respecto de su observancia.

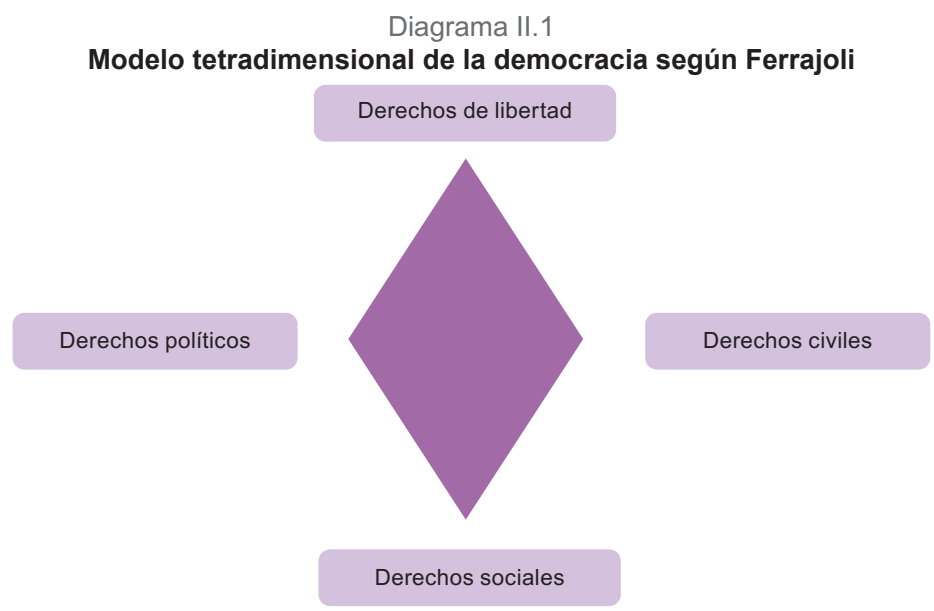

Fuente: L. Ferrajoli, Democracia y garantismo, Madrid, Editorial Trotta, 2008.

De allí que sea relevante reflexionar acerca de las condiciones políticas y económicas que han posibilitado un mayor avance de la solidaridad y de la universalidad de la protección social y, en esos términos, las alianzas que subyacen tras los singulares Estados de bienestar, así como los intereses en juego. Por ejemplo, se revela que la consolidación histórica de los Estados de bienestar europeos fue de la mano de amplias coaliciones políticas que - entre otros actores-incluyeron a las élites, las clases medias y los obreros industriales. Por el contrario, cuando no se forjaron tales coaliciones, como en el caso de los Estados Unidos, se privilegió la combinación de seguros privados con la protección brindada a quienes carecían de recursos (Porter, 1999, pág. 219).

Para evaluar la viabilidad de nuevas reformas en América Latina, resultan sugerentes algunas investigaciones del desarrollo histórico de los Estados de bienestar en algunos países de Europa Occidental, que concluyen que la política social trascendió los mínimos política y económicamente funcionales cuando las clases medias desempeñaron un papel importante, y que la redistribución real de la carga de riesgo fue posible cuando grupos por lo demás privilegiados descubrieron que compartían con los desfavorecidos un mismo interés por la reasignación del riesgo. Como las presiones "desde abajo" resultan insuficientes para alcanzar reformas solidarias, los desafortunados han podido beneficiarse 
de reformas redistributivas en la medida en que grupos de las élites, que eran decisivos en términos políticos, también podían verse beneficiados. Incluso sin un cambio o incremento de la incidencia del riesgo, grupos que no son necesariamente solidarios pueden llegar a adquirir un interés por la redistribución al experimentar una menguada capacidad para soportar cargas sin ayuda. Si bien la experiencia histórica muestra que la identidad de los actores favorables a la redistribución del riesgo puede variar mucho según las circunstancias, resulta innegable el papel desempeñado por los sectores medios para que la política social -en términos económicos y políticos - trascienda los umbrales mínimos (Baldwin, 2003, págs. 9, 10, 15 y 292). Es decir que los acuerdos destinados a redistribuir el riesgo más allá de cualquier nivel mínimo funcional han sido posibles gracias a la concurrencia de coaliciones de ganadores redistributivos que llegaron a ser lo suficientemente fuertes en términos políticos como para traspasar la carga a los perdedores (ibídem, pág. 36).

En ese sentido, si en América Latina se desea avanzar hacia reformas con efectos redistributivos más globales y que cuestionen la estratificación y la exclusión propias de los sistemas de protección social, parece también indispensable forjar nuevas "alianzas redistributivas". Conforme a las categorías de Baldwin (2003), es pertinente forjar coaliciones en el plano de la protección social que se basen en la transversalidad de las categorías de riesgos y que, al estar por encima de la distribución primaria del ingreso, puedan introducir fisuras en la estructuración previsible de actores que se daría a partir de la lógica económica, por ejemplo, en la confrontación política con las empresas privadas que administran los fondos de pensiones: desde esta óptica, las clases medias e, incluso, los sectores de altos ingresos descontentos con las tasas de reemplazo brindadas por los sistemas contributivos de pensiones guiados por el lucro (Sojo, 2014) o con la selección del riesgo en materia de salud de los sistemas contributivos también guiados por el lucro, pueden llegar a constituir sujetos políticos relevantes para las alianzas reformistas.

De allí, la relevancia de construir coaliciones políticas amplias en América Latina que tengan como objetivo superar la fragmentación y estratificación propias de los sistemas de protección social vigentes en un momento más propicio, dado que las ilusiones individualistas sobre el aseguramiento se han erosionado conforme maduraron los sistemas con esta orientación. Desde dicha perspectiva, en este capítulo se procura fundamentar una posible convergencia de intereses en torno a la cobertura universal de riesgos y su financiamiento solidario: se propone que la naturaleza impredecible de los riesgos, su magnitud y su carácter pueden ser la base de un interés compartido por diferenciar los riesgos mediante el aseguramiento y por la reciprocidad inherente a tal diferenciación, expresada mediante el aseguramiento solidario. Como se verá en los dos 
capítulos siguientes, en la medida que la desigualdad de la protección social afecta a diversos sectores sociales, en determinadas circunstancias ello podría sustentar pactos en torno al fortalecimiento de políticas universales y con financiamiento solidario que permitan enfrentar en condiciones menos desiguales a las poderosas coaliciones que, en sus antípodas, se articulan en torno al lucro y a la individuación de los riesgos.

\section{B. La diversificación de los riesgos: el mercado versus la protección social}

Riesgos tales como las enfermedades, las restricciones para satisfacer necesidades de cuidado de niños y de personas frágiles o con discapacidad, los episodios de desempleo y subempleo, y la pérdida o la radical disminución de ingresos en la vejez son factores determinantes del bienestar presente y futuro de todos los individuos. Aunque estas circunstancias están determinadas crucialmente por las asimetrías de las condiciones socioeconómicas de que gozan las personas, escapan en diversa medida a su control: resultan inciertos tanto el momento en que acontecen como el acceso que se tendrá a la protección necesaria, e indeterminados el tiempo durante el que se requieren las prestaciones, los costos involucrados y el grado de afectación de la integridad personal y de los ingresos así originados. En consecuencia, por su naturaleza, la demanda de servicios también suele ser irregular e impredecible, especialmente en el caso de la salud.

De allí, la relevancia de poder lidiar con lo que se ha denominado "economía del bienestar de la incertidumbre". El conjunto de riesgos al que está expuesto un individuo constituye su riesgo agregado; el aseguramiento debe permitir reducir este riesgo a escala individual mediante el pago de un monto determinado a una entidad que tiene capacidad para diversificar estos riesgos (Arrow, 2000, págs. 220-229). Tanto en términos individuales como sociales, es deseable reducir la brecha entre la dotación de ingresos y los niveles deseados de aseguramiento.

A continuación, se examinan las características del aseguramiento de mercado y del aseguramiento solidario que constriñen o posibilitan la diversificación del riesgo: se verá que el aseguramiento de mercado adolece de una serie de limitaciones que fundamentan la necesidad del aseguramiento solidario.

La variedad de riesgos en el mundo es asombrosa, pero el mercado para cubrirlos es muy limitado debido a la prevalencia de la incertidumbre y la orientación al lucro (Arrow, 1963). Como el sistema de precios es incapaz de manejar adecuadamente algunos riesgos, su uso es limitado; por ende, 
el aseguramiento de mercado se restringe tanto por su cobertura como por su monto. Por ejemplo, los límites en el aseguramiento privado de la salud acarrean desprotección ante gastos médicos elevados, precisamente aquellos contra los cuales resultaría muy atractivo asegurarse (Arrow, 2000, págs. 220-229).

En un mercado de aseguramiento competitivo, si las pólizas se ajustan plenamente a los riesgos individuales, los seguros de salud pueden resultar inasequibles para muchos individuos de alto riesgo. En ausencia de regulación y de restricciones a las primas de las pólizas, la norma en los mercados es que los planes de salud establezcan primas ajustadas a los riesgos individuales: esto es lo que se denomina el principio de equivalencia, y a tal fin pueden adoptarse diversas estrategias (Van de Ven y Schut, 2011, págs. 381 y 382). Es posible variar los planes conforme a la evaluación del riesgo (risk rating) y diseñar paquetes de beneficios orientados, tanto por su cobertura como por el tipo de beneficios y precios, a atraer determinados tipos de riesgos: es lo que se denomina segmentación por riesgo (risk segmentation). En cuanto a los riesgos que resultan muy costosos, las empresas pueden excluir de los planes la cobertura de algunas condiciones médicas preexistentes o negarse a celebrar contratos con individuos de alto riesgo (Van de Ven y Ellis, 2000, pág. 759; Van de Ven y Schut, 2011, pág. 382). También pueden emplear contratos anuales cuyas primas varían según el estado de salud observable: por ejemplo, mediante la denominada calificación de la experiencia (experience rating) - que toma en cuenta nuevos cuadros de morbilidad o enfermedades preexistentes- se efectúa una selección de riesgos (risk selection) que impide el aseguramiento intertemporal, es decir, el derecho a comprar coberturas futuras de salud a costos medios, pese a que la enfermedad sobrevenga hoy mismo (Cutler y Zeckhauser, 2000, pág. 564).

La segmentación por riesgo y la selección de riesgos limitan la oferta de coberturas para riesgos altos, mientras que la evaluación del riesgo disminuye la asequibilidad de las coberturas. Ambas estrategias ponen en peligro el acceso a coberturas adecuadas en el caso de riesgos altos y pueden causar impactos en el ingreso de los afectados (Van de Ven

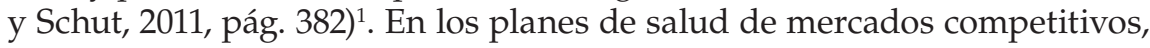
las imperfecciones de tales mecanismos originan incentivos a la selección de riesgos: cuanto mejores sean los subsidios explícitos para riesgos relevantes, menor será la transacción entre los objetivos de eficiencia y de justicia. Los sistemas de subsidios ajustados al riesgo pretenden dar subsidios explícitos a individuos de alto riesgo; por su parte, la regulación del diseño de planes y las restricciones a la variación de las contribuciones

En el capítulo III se analizan dentro de los gastos de bolsillo en materia de salud, los llamados gastos catastróficos, que se refieren precisamente a esos impactos. 
individuales pretenden que los individuos de bajo riesgo implícitamente subsidien a los de alto riesgo (Van de Ven y Ellis, 2000, págs. 762-763; Van de Ven y Schut, 2011, pág. 382). Debido a las asimetrías de información, los costos de entrada o de transacción son elevados y pueden conducir a que los aseguradores fijen pólizas altas (Belli, 2001, pág. 21). En sus antípodas, para conciliar la eficiencia con los criterios de justicia y equidad, revisten crucial importancia los mecanismos de ajuste que permiten una amplia diversificación de los riesgos.

La esencia del aseguramiento radica en la diversificación de los riesgos mediante una transferencia parcial efectiva del riesgo individual al asegurador para lo cual se está dispuesto a pagar un porcentaje de la prima bruta destinada a cubrir gastos y margen de lucro (loading fee), es decir, aquella parte del precio de la póliza que cubre los costos de operación del asegurador (por ejemplo, los gastos de administración y publicidad), los costos asociados al pago de riesgos impredecibles (que exceden el pago efectivo de aquellos relativamente predecibles), las inversiones del asegurador y su ganancia (Van de Ven, 2013, págs. 52 y 53). Ahora bien, el nivel de aseguramiento deseado depende de la transacción (trade-off) entre la ganancia de bienestar atribuible a la reducción del riesgo y al acceso a una atención que no podría financiarse de otra forma, por un lado, y la reducción del bienestar que trae aparejada el riesgo moral y los costos de la prima, por el otro. En ese sentido, los elevados costos de la prima en términos absolutos o del porcentaje de la prima bruta destinada a cubrir gastos y margen de lucro pueden disminuir la predisposición al aseguramiento (Van de Ven, 2013, págs. 52 y 53). De allí que los individuos adversos al riesgo demanden aseguramiento de la salud, incluso en caso de sufrimiento, siempre y cuando la póliza no represente un costo excesivo que sea imputable a gastos administrativos y a ganancias, bajo el signo del riesgo moral (Zweifel, 2013, pág. 565).

Por tanto, no debe sobredimensionarse la capacidad de enfrentar riesgos idiosincráticos mediante instrumentos de riesgo informales o de mercado: sin una adecuada diversificación del riesgo, ocurren exclusiones y desigualdades. El subconsumo en materia de aseguramiento puede afectar a amplios sectores sociales y no solo a los pobres, sobre todo en América Latina, donde los mercados de aseguramiento a veces no existen o no están desarrollados adecuadamente. Además, por la relación entre precios e ingresos en países con una concentración de ingresos particularmente alta, cuando las remuneraciones son bajas o se sufren episodios de desempleo, la necesidad de aseguramiento de la población no puede traducirse en una demanda efectiva, factores que llevan a este subconsumo de aseguramiento. En tales términos, la acción del Estado o la participación obligatoria en una mancomunación de riesgos (pooling of risks) es pertinente no solo cuando los mecanismos de mercado no existen, 
colapsan o son disfuncionales, puesto que las asimetrías de información y las fallas de mercado son inherentes a los mercados de aseguramiento, y no situaciones excepcionales ${ }^{2}$.

La acción pública regulatoria, el aseguramiento público o el aseguramiento social con aseguradores privados, pero con mecanismos de financiamiento obligatorio y regulaciones que garanticen la diversificación del riesgo y, por tanto, la solidaridad, constituyen mecanismos diversos que permiten enfrentar la selección del riesgo y el desarrollo de la protección social y que, en el caso de los mercados, pueden incrementar su eficiencia, al propiciar la estabilidad del aseguramiento.

Además, cuando se opta por el financiamiento solidario, los objetivos son redistributivos y es posible establecer subsidios cruzados entre distintos estratos de ingreso, grupos etarios, niveles de riesgo, entre otros. El principio de solidaridad destinado a hacer efectiva la universalidad del aseguramiento permite tomar en cuenta diferentes aspectos que los sistemas de precios no encaran adecuadamente, entre los que se cuentan los siguientes: el individuo no debe cubrir la totalidad de los costos vinculados con su estructura presente de riesgos; es preciso proteger contra riesgos relacionados con bienes que no tienen un buen sustituto de mercado (por ejemplo, la buena salud); los precios de mercado no reflejan los costos sociales de oportunidad ni las externalidades del consumo privado y las dimensiones de bien público que este consumo podría tener; es menester encarar el subconsumo asociado con bajos ingresos o con un alto riesgo individual, en cuyo caso no se tiene acceso al aseguramiento aunque exista el mercado; y a lo largo de la vida las personas suelen tener una estructura de riesgos diversa y en las etapas de altos riesgos deberían poder beneficiarse intertemporalmente de los aportes que realizaron cuando sus riesgos eran bajos. Estas situaciones permiten corregir las externalidades, dado que no solo se beneficia del aseguramiento la persona que adquiere una póliza, sino también la sociedad, pues se ve favorecida

\footnotetext{
Este razonamiento está en las antípodas del ideario neoliberal en materia de política social, que se expresó en Chile sin ambages durante la dictadura de Pinochet y que tuvo sendos efectos en las respectivas reformas emprendidas en Chile y que se constituyeron en paradigmas para otros actores en diversos países latinoamericanos. Por ejemplo, José Piñera, artífice del nuevo sistema de pensiones, lo expresaba como la importancia de ir más allá para "extender la disciplina del mercado al sector social: el sistema de pensiones, las prestaciones de salud y el resto [...] Preveíamos que dejar estas actividades en las manos del Estado solo aumentaría su poder conforme la economía fuese más próspera, revirtiendo mucho de lo que habíamos alcanzado para recortar las ataduras del Estado. Por tanto, argumentábamos, si la empresa privada y el mercado son buenos para producir acero, ¿por qué no son buenos para producir pensiones?" (Piñera, 1991, p. 229); o como lo planteaba en una entrevista anónima realizada el 16 de abril de 1998 uno de los cuadros influyentes durante la dictadura militar: "Pensábamos que la única regulación eficaz era la ejercida por el consumidor informado" (González y otros, 2000, p. 71, traducción propia). En el capítulo V ahondaremos en una crítica al postulado del consumidor informado.
} 
por las externalidades en diversos planos, como contar con una población sana o sufrir menos convulsiones sociales (Arrow, 1963 y 2000; Sojo, 2003).

El aseguramiento social basado en el principio de solidaridad permite velar por la eficiencia en la asignación de los recursos, el financiamiento y la provisión, es decir, por la eficiencia para alcanzar objetivos tanto microeconómicos como sociales, y también velar por la equidad (CEPAL, 2000).

Cuando el seguro es voluntario y de mercado, en general conlleva exclusiones, dada la aplicación del principio de equivalencia. Las condiciones de un seguro privado no regulado y guiado por el lucro inevitablemente implican exclusiones explícitas que afectan, por ejemplo, a quienes sufren enfermedades crónicas o congénitas, o entrañan primas elevadas, deducibles o copagos que representan barreras de entrada o impiden y coartan la permanencia de los asegurados. Por el contrario, al incluir y retener personas con diferentes grados de riesgo y al no estar orientados por el lucro, los seguros obligatorios permiten operar con una lógica distinta y lograr una diferenciación estable de los riesgos. El seguro social articulado de manera solidaria puede estar en manos de aseguradores públicos o privados, y su financiamiento puede provenir de primas obligatorias de los trabajadores y los empleadores o solo de los trabajadores, o bien de impuestos generales. Pero en ambos casos, su lógica difiere de manera sustancial de la del seguro privado, pues se rompe la identidad entre prima y riesgo individual y se establece la cobertura de riesgos en términos más genéricos, por lo que pueden incluirse personas que normalmente no estarían cubiertas por los seguros individuales de mercado (Barr, 1993, págs. 123-128 y 308).

De allí, el valor heurístico de la definición de Barr, que considera al Estado de bienestar un contrato de seguro celebrado voluntariamente entre individuos con aversión al riesgo tras el "velo de la ignorancia", en los términos de Rawls; desde esa perspectiva, no solo el seguro social definido en términos estrechos es una forma de aseguramiento, sino que también lo son los beneficios universales y la asistencia social (Barr, 2001). Así, el "velo de la ignorancia" es el polo opuesto de la individualización del riesgo propia del aseguramiento privado guiado por el lucro.

Por lo general, los seguros obligatorios operan con una perspectiva de largo plazo, ya que al establecerse garantías generales en lugar de garantías según subgrupos de riesgo, los individuos no son reclasificados si sus riesgos se incrementan (Arrow, 1963, pág. 904). La diferenciación estable de los riesgos, que tiene efectos evidentes en la equidad, también los tiene en la eficiencia: los fenómenos de selección adversa reducen esta última e, incluso en casos extremos, pueden conducir a la liquidación de 
las aseguradoras (death spiral) (Cutler y Zeckhauser, 2000, págs. 606-625; Cutler, 2002, págs. 83-86).

Desde la perspectiva individual, los subsidios son dinámicos, pues a lo largo de la vida las personas proveerán o recibirán subsidios según las variaciones de su nivel de riesgo. Así, la equivalencia entre el precio del seguro y el grado de riesgo se establece a escala del sistema y no de la prima individual, y puede darse en el marco de combinaciones público-privadas muy diversas. Desde una perspectiva dinámica, los beneficios intergeneracionales o entre personas con condiciones diversas de salud representan también beneficios individuales de diversa magnitud, que se obtienen en diferentes momentos. Además, el ahorro obligatorio durante períodos de buena salud que permite al sistema cubrir estados de enfermedad aguda o crónica trae aparejados efectos micro- y macroeconómicos positivos, ya que acrecienta el ahorro de los hogares y empareja su consumo.

En este sentido, el aseguramiento también guarda una analogía con el ahorro, que disminuye la brecha entre los niveles de dotación y de consumo a lo largo de diferentes momentos (Ehrlich y Becker, 2000, pág. 171). Por ejemplo, los jóvenes o quienes tienen un bajo riesgo de salud aceptan pagar más de lo que consumen, ya que a su vez podrán beneficiarse en el futuro de una cobertura subsidiada. Incluso en un contexto estático y no de ciclo de vida, podrán estar anuentes al subsidio, como un medio para acercarse a un grado de cobertura más cercano a su preferencia que un contrato con cobertura total (Belli, 2001, pág. 18; Sojo, 2003).

Cuando el seguro no está orientado por el lucro en el caso de la salud, los aportes de los contribuyentes se ahorran a escala del sistema, y los beneficios se tornan efectivos cuando las reglas así lo disponen. Por el contrario, un sistema basado en el lucro no brinda capacidad de ahorro a las personas ni al sistema, porque los considerables montos de las contribuciones o aportes que se recaudan y que temporalmente no se traducen en demanda se canalizan sustancialmente a la ganancia privada de las compañías aseguradoras y prestadoras involucradas. Por su parte, en el caso de los sistemas de pensiones, el lucro se traduce en bajas tasas de reemplazo y en pingües ganancias para las administradoras de los fondos de pensiones y las empresas conexas (Sojo, 2014). En el capítulo $\mathrm{V}$ se profundizan estos razonamientos a la luz de algunas experiencias latinoamericanas de privatización del aseguramiento de la salud y de los sistemas de pensiones.

En esta temática es importante matizar el argumento acerca del lucro mediante la consideración de "umbrales de lucro", porque naturalmente diversos agentes involucrados — por ejemplo, los médicos en el ejercicio de 
su profesión- buscan obtener una adecuada retribución a su trabajo ${ }^{3}$. Sin embargo, el argumento se refiere a la proporcionalidad, la razonabilidad y la magnitud de la ganancia en términos sistémicos y en relación con los recursos disponibles para la protección social efectiva. Como se verá más adelante, al estar articuladas por la maximización del beneficio privado -en detrimento de las funciones de aseguramiento-, las combinaciones público-privadas dualistas rompen con los principios de la seguridad social. El término dual subraya el uso conforme a la racionalidad del lucro de los recursos contributivos o fiscales para el aseguramiento, a diferencia del pago procedente del bolsillo individual que sufraga, por ejemplo, una póliza de seguro de mercado. Dentro de este marco dual, el avance hacia la universalidad, la solidaridad y la eficiencia no es viable. En el caso de las pensiones, en lugar de cumplir el objetivo esencial de maximizar la protección de los ingresos tras la vida activa mediante las mejores tasas de reemplazo viables en un contexto de optimización de las inversiones de los fondos, los recursos se destinan a obtener pingües ganancias por parte de las administradoras de los fondos y los organismos conexos, debido a la racionalidad dual del sistema. Si la racionalidad no fuese el lucro, las ganancias que obtengan los fondos deberían destinarse al supremo objetivo de maximizar las tasas de reemplazo de las pensiones (Sojo, 2014).

Algunos autores han buscado fundamentar la protección social solidaria en el altruismo. Por ejemplo, como marco normativo para lograr un relativo consenso sobre el uso redistributivo de los recursos sociales, se propone que se internalicen la norma moral pública y el imperativo ético relativos a la necesidad de hacer "sacrificios financieros", para ampliar el aseguramiento y fortalecer la "disposición para pagar por la cobertura de salud de otros". Desde esta perspectiva, cuando se rechaza esa norma, se obstaculiza el logro de acuerdos a partir de la invocación de principios abstractos tales como la igualdad o la cobertura universal, y proliferan los desacuerdos (Ruger, 2009, págs. xiii, 14 y 119). Como se ve, la argumentación está sesgada hacia el "sacrificio" y la cobertura "de otros".

Si bien el altruismo puede desempeñar un papel crucial en cuanto a velar por las necesidades de otros y no solo por las propias - como bien lo planteó Titmus-, la racionalidad del aseguramiento expuesta en este trabajo encuentra en la magnitud de los riesgos, en su carácter impredecible y en el sentido intertemporal del aseguramiento un fundamento de carácter material que es objetivo e, incluso, instrumental en términos individuales en lo relativo a la necesidad de compartir riesgos y la aspiración a la reciprocidad, aun para las personas de altos ingresos. Como se postula a lo

La autora agradece a Olga Lucía Acosta por haberle sugerido la idea del "umbral de lucro" durante una conversación. En el capítulo IV se amplía esta idea. 
largo del libro, la desigualdad de la protección social afecta a muy diversos sectores en la región, situación que proporciona una base argumentativa para apelar al fortalecimiento de políticas universales mediante un financiamiento solidario. Esta perspectiva pone sobre el tapete la necesidad de velar por la eficiencia y la calidad de los sistemas de seguridad social y por vínculos adecuados entre los beneficios y las contribuciones en el caso de los sistemas contributivos, para que los beneficios sean atractivos y valorados. Ya que no existe un automatismo en cuanto a la formación de coaliciones políticas proclives a la universalidad y la solidaridad de la protección social a partir de las exclusiones y estratificaciones y que, a tal fin, resultan cruciales las intervenciones discursivas, la calidad es una dimensión que puede jugar un papel movilizador destacado y que es imposible lograr con pocos recursos. Se trata de configurar un círculo virtuoso en términos de equidad: resulta difícil brindar servicios de calidad cuando están exclusivamente destinados a los pobres (Sen, 1995; Sojo, 1990, págs. 187-198), mientras que la universalidad y la solidaridad potencian los recursos económicos y políticos con que impulsarlos ${ }^{4}$.

\section{La naturaleza del bien a proteger como determinante del carácter del aseguramiento}

Una vez establecido el sentido del aseguramiento, cabe distinguir la forma en que su carácter se relaciona con la especificidad del bien que se asegura y se protege. A continuación se abordan ciertas distinciones indispensables respecto de la protección social en materia de salud y pensiones.

En el caso de los sistemas de pensiones que no están guiados por el lucro, el objetivo consiste en proveer seguridad del ingreso en la vejez, objetivo que reúne al menos cuatro elementos: homogeneización del consumo, aseguramiento, auxilio a la pobreza y redistribución. Al ser usual que estos objetivos no puedan alcanzarse cabalmente al mismo tiempo, la política debe tratar de optimizarlos de manera transversal, es decir, ni minimizarlos ni maximizarlos de manera aislada (Barr y Diamond, 2008, pág. 21).

El objetivo de homogeneizar o nivelar el ingreso mediante la maximización y la protección de los ingresos tras la vida activa implica alcanzar las mejores tasas de reemplazo que resulten viables en un contexto de optimización de las inversiones cuando están organizadas por fondos o bien en un contexto de garantía de los recursos destinados a tal fin cuando el sistema de pensiones no se organiza mediante fondos, como en el caso del sistema de reparto.

Como incisivamente expresó hace años Sen, los beneficios otorgados solo a los pobres terminan siendo beneficios pobres (Sen, 1995, pág. 5). 
Las pensiones deben reflejar los esfuerzos de ahorro realizados a lo largo de la vida del asegurado: el criterio de equivalencia debe garantizar que, a niveles semejantes de esfuerzo, se obtendrán protecciones similares o proporcionales (CEPAL, 2000, pág. 78). En un sistema contributivo, la equivalencia se da entre la historia de contribuciones y las tasas de reemplazo. Por lo general, las contribuciones son pagadas, en proporciones variables, por los empleados y los empleadores, ya sean privados o públicos ${ }^{5}$. Por ello, puede hablarse de una razonabilidad de los beneficios que brindan los sistemas de pensiones, conforme a la proporcionalidad del vínculo entre el ahorro realizado a lo largo de la vida activa y las pensiones (Sojo, 2014).

Además, cuando existen mecanismos de aseguramiento, la equivalencia no se da estrictamente a escala individual, sino que pueden crearse mecanismos de solidaridad o de diferenciación de riesgos, por ejemplo, ante los riesgos financieros. Estos mecanismos pueden introducirse incluso en sistemas de capitalización individual de carácter nocional (Barr, 2013). Cuando los sistemas carecen de mecanismos de aseguramiento, como en el caso chileno, la equivalencia se da estrictamente a escala individual, sin mecanismos de solidaridad o de diferenciación de riesgos, lo que puede derivar en discriminaciones de las mujeres en los cálculos actuariales debido a su mayor expectativa de vida, como acontece en Chile.

Respecto de las pensiones, los elementos de auxilio a la pobreza y de redistribución deben financiarse sobre todo con recursos no contributivos, es decir, fiscales. Por tanto, los pilares solidarios tienen una función esencialmente redistributiva. En este ámbito, el grado de progresividad depende tanto de la distribución socioeconómica de las pensiones no contributivas, como, indirectamente, del sistema impositivo del cual se nutren.

Por su parte, la protección social de la salud enfrenta desafíos distintos, que se derivan de la singularidad y la excepcionalidad de la salud como un bien sui géneris, tanto por su valor intrínseco como instrumental: la salud es crítica, porque afecta el bienestar de las personas y constituye un prerrequisito básico de lo que Sen denomina capacidad de agencia. Es decir, que las desigualdades en este ámbito afectan las libertades y oportunidades fundamentales de las personas, porque coartan la capacidad de realizar los proyectos y lograr los objetivos alternativos en la vida que las personas valoran. La capacidad de realizarse y llevar a cabo actividades depende crucialmente de la propia salud, por lo que la mala salud reduce el alcance de la capacidad de agencia. Desde este punto de vista, la mala salud sin duda reduce el pleno alcance de la agencia

El sistema chileno de cuentas individuales constituye una excepción, pues la reforma introducida durante la dictadura eliminó el aporte contributivo de los empleadores a las pensiones. 
humana, pues limita la libertad positiva y la igualdad de oportunidades. En tales términos, el disfrute de la salud debe ser "excluido" de los precios que conforman los incentivos para la actividad económica, en aras de lo que Tobin denomina un "igualitarismo específico", que permita distribuir la salud de manera menos desigual de lo que las personas obtendrían en razón de su capacidad de pago. Por ende, el objetivo es que la distribución de la salud sea menos inequitativa que la del ingreso general y de la que haría el mercado en función del ingreso (Anand, 2004, págs. 16 y 17).

Sen llama la atención sobre el hecho de que - más allá de los factores socioeconómicos- la salud que una persona disfruta está influida por una compleja serie de consideraciones y factores, como las discapacidades, las susceptibilidades individuales a la enfermedad, los peligros epidemiológicos de ciertas regiones o los factores climáticos, que deben ser abordados por una teoría y disciplina apropiadas de la equidad en materia de salud. Propone que la teoría de la equidad en salud distinga la igualdad en los logros en este ámbito y en sus correspondientes capacidades y libertades, por un lado, y la igualdad en la distribución de lo que en términos generales pueden denominarse recursos de salud y la atención de salud, por el otro. Aunque esto último es importante e indispensable, la igualdad en materia de salud no debe reducirse solo a ello o al enfoque más estrecho respecto de la distribución de los recursos. La primera postura debe ocupar un lugar central en la equidad, en general, $\mathrm{y}$ en la equidad en materia de salud, en particular, porque representa una de las condiciones más importantes y un componente críticamente significativo de la vida humana y de las oportunidades que cabe valorar. Por consiguiente, resulta crucial encarar las enfermedades evitables, las aflicciones eludibles y la mortalidad prematura. De allí que el logro de la igualdad deba estar incorporado e inserto en un concepto más amplio de la justicia: lo que es particularmente grave de la injusticia en este ámbito es la falta de oportunidades para gozar de buena salud debido a instituciones o disposiciones sociales inadecuadas. En esos términos, la asignación económica debe dar una atención apropiada al rol de la salud en la vida y la libertad humanas (Sen, 2004, págs. 23 y 29).

A diferencia de los sistemas contributivos de pensiones que deben reflejar el esfuerzo del ahorro personal, y el pilar solidario y redistributivo destinado a garantizar un ingreso a quienes han tenido una inserción laboral desafortunada, la solidaridad en materia de salud se refiere a un ámbito consustancial al desarrollo de la naturaleza humana en cuanto a las libertades y las oportunidades a que se puede aspirar. El financiamiento solidario del aseguramiento tiene objetivos redistributivos, ya que permite establecer subsidios cruzados entre diferentes estratos de ingreso, de edad y de riesgo. Se puede dar en el marco del aseguramiento mediante cotizaciones obligatorias o con cargo al presupuesto nacional. 
Además, cabe tener presente la singularidad de algunos bienes en relación con el aseguramiento. Es posible suponer que todos los productos sujetos a pérdida pueden ser valorados en los mercados pertinentes y que los seguros permiten reemplazarlos parcial o totalmente mediante compensaciones monetarias (por ejemplo, un automóvil que sufre un accidente de tránsito). Sin embargo, hay elementos que no tienen sustitutos de mercado adecuados, como la pérdida de la vida o de la buena salud, debido a que abarcan componentes no monetarios, como el dolor, el sufrimiento o la discapacidad (Dionne y Harrington, 2000, pág. 12). Dado que algunas fuentes permanentes de beneficio, como la buena salud, no tienen sustitutos perfectos, tampoco existen en sentido estricto mercados de estos bienes, aunque los individuos puedan imputarles determinados valores monetarios. Tal valoración puede variar, lo que se toma en cuenta en la teoría del comportamiento ante los riesgos, por ejemplo, porque puede conducir a que sea menor la magnitud del aseguramiento que se adquiere en el mercado (Cook y Graham, 2000, págs. 207 y 214) y, por lo tanto, coadyuve a un subaseguramiento que acarrea costos individuales y sociales. Así, cobra sentido el aseguramiento obligatorio frente al comportamiento típico del polizón (free-rider). De allí la importancia de tener en cuenta que las políticas de aseguramiento, los sistemas de salud, las políticas preventivas y la cultura de la salud son factores que pueden impedir o prevenir el deterioro de la salud. El aseguramiento debe permitir el acceso a servicios preventivos y curativos en el momento oportuno a fin de encarar condiciones de morbilidad reversibles y que sí tienen sustitutos de mercado, mientras que la desprotección puede conducir a situaciones de morbilidad irreversibles, cuyos efectos negativos hacen, además, que en general carezcan de tales sustitutos.

Por otra parte, la transformación de riesgos idiosincráticos en riesgos catastróficos también alerta sobre la necesidad de consolidar políticas universales y de financiamiento solidario en materia de salud en la región. Debido a la avanzada etapa de transición epidemiológica en que esta se halla, los desafíos provienen de las enfermedades crónicas y degenerativas, a raíz de sus costos elevados y la necesidad de consolidar políticas preventivas. Estos desafíos deben ser encarados tanto en el ámbito del financiamiento como de la constitución de sistemas de salud cuyos prestadores conformen redes de referencia eficientes mediante diversas combinaciones público-privadas. En la transición epidemiológica polarizada de la región, las personas pobres exhiben altas tasas de morbilidad y mortalidad relacionadas con enfermedades tanto pretransicionales como postransicionales (Bobadilla, Frenk y Lozano, 1990). Pero los riesgos idiosincráticos de salud pueden devenir en catastróficos también para sectores de buenos ingresos por el elevado costo de algunas enfermedades crónicas y degenerativas. Esta situación pone 
de relieve la importancia de diversificar los riesgos, de la solidaridad y la regulación de las exclusiones. A diferencia de lo que planteaba el Banco Mundial en su paradigmático informe de 1993, si bien las inmunizaciones, las campañas de salud pública y la prevención vinculada a la salud maternoinfantil son elementos indispensables, la prevención no puede constituir el foco de largo plazo de los esfuerzos en el sector de la salud, así como la preocupación por los seguros contra riesgos catastróficos tampoco es válida solo cuando estos riesgos afectan a los pobres (Banco Mundial, 1993). Los gastos catastróficos afectan a amplios sectores sociales, tal como se verá en el capítulo III.

\section{Aseguramiento, bienes públicos y externalidades}

Para calibrar la relevancia del aseguramiento, hay que considerar las dimensiones de bien público o la combinación de elementos de bien público y de bien privado que pueda tener, o bien sus externalidades. En el caso de los bienes públicos puros, la teoría ha establecido un criterio exigente: la no rivalidad en el consumo, es decir, la total ausencia de conflicto entre el consumo que realizan diferentes individuos. Dado que resulta indeseable excluir a individuos del acceso a estos bienes mediante los precios, ellos deben ser provistos mediante otras fuentes de ingreso. El desempeño del mercado dependerá, sobre todo, de las características del bien público en cuanto a las posibilidades de exclusión, el número de individuos que disfrutan de él, el otorgamiento de amplios beneficios a los consumidores directos, las economías de escala involucradas en su producción y el marco jurídico e institucional en que tienen lugar las transacciones. Dada esta compleja matriz de factores, se afirma que poco puede generalizarse más allá de aseverar que los mercados privados tienden a subproveer bienes públicos y a sobreproveer males públicos. Muchos de los servicios a cargo de los gobiernos, por el lado de la provisión o del financiamiento, combinan elementos públicos y privados. Las decisiones políticas relativas al suministro y al financiamiento de bienes públicos tienen efectos distributivos y se mezclan con consideraciones de eficiencia económica; de allí que acertadamente se reconozca la importancia de comprender mejor estos procesos y de incorporar variables políticas en los modelos normativos de la oferta de bienes públicos (Oakland, 1987).

El producto social neto se acrecienta cuando otros beneficios exceden los obtenidos en forma directa por las personas mediante una transacción, por lo cual se requiere una subvención que cubra las externalidades no reflejadas en la demanda del mercado. Los instrumentos fiscales son mecanismos que permiten reconocer externalidades (Musgrave, 1985, pág. 11). 
Con este telón de fondo cabe señalar la importancia de los objetivos redistributivos del aseguramiento y de la diversificación estable de los riesgos, sea mediante contribuciones obligatorias o del financiamiento no contributivo en el caso de las personas de escasos recursos. Dos importantes consideraciones relativas a la incidencia social del bienestar individual justifican que la sociedad, mediante el presupuesto público, garantice el acceso de los ciudadanos a determinados servicios sociales en tanto bienes de mérito. Es preciso entender que, dadas las externalidades del bienestar individual, existe una estrecha relación entre el bienestar individual y el bienestar social. También cabe recordar que la sociedad y los individuos no pueden abdicar voluntariamente de los bienes públicos o cuasipúblicos, pues estos tienen la característica singular de que es imposible dejar de consumirlos o, al menos, de consumir sus externalidades, salvo que se abandone la comunidad que los provee (Hirschman, 1977). Esto se expresa en múltiples y diversas dimensiones: la vida privada de los ciudadanos, la seguridad ciudadana y la competitividad de los países en un mundo abierto y globalizado están afectadas, de hecho, por la calidad de la educación y de la salud públicas o por el grado de integración y cohesión social.

También es pertinente aludir tanto al entramado microeconómico de algunas dimensiones del aseguramiento como a las repercusiones macroeconómicas que puede acarrear. En un contexto de salarios flexibles, el costo de los beneficios provistos por el empleador se traslada parcialmente al trabajador mediante salarios menores; luego, si los trabajadores no valoran tanto aquellos beneficios como esta disminución, pueden buscar trabajo en el sector desregulado, donde la remuneración es totalmente monetaria. Esto puede ocurrir cuando la provisión de la seguridad social o de los beneficios de salud es muy ineficiente o poco valorada, cuando los vínculos entre los beneficios y las contribuciones son débiles, o si algún miembro de la familia ya inserto en el sector formal provee una cobertura familiar. Junto a las asimetrías de información y a los débiles derechos de propiedad, la baja eficiencia y calidad de los sistemas de seguridad social se han señalado asimismo como elementos que propician el aislamiento de las microempresas respecto del mercado (De Ferranti y otros, 2002, recuadro 5.5 y pág. 145). En el capítulo IV se analizan las nefastas consecuencias que esta situación puede acarrear respecto de la evasión contributiva, lo que a su vez ejerce efectos adversos en el bienestar individual.

Vistas desde este ángulo, tales conclusiones son sugerentes para argumentar precisamente a favor de reformas en el aseguramiento, si consideramos que las carencias en materia de seguridad social o los beneficios de salud precarios representan externalidades negativas que no crean incentivos adecuados para profundizar los mercados laborales. En el mismo ámbito de las externalidades, cabe también tener en cuenta que 
las estrategias adoptadas por los hogares pobres y de medianos ingresos para amortiguar los choques - cuando la protección social es precaria y los mercados de aseguramiento, poco desarrollados- pueden resultar eficaces en algunos casos para proteger los niveles de consumo, pero no son necesariamente muy productivas. En este sentido, el aseguramiento precario o inexistente afecta tanto la asignación como la disponibilidad de recursos de los hogares. Como complemento, es útil reflexionar en ese contexto sobre las repercusiones positivas que puede tener el aseguramiento en el crecimiento económico: si se supone que el ahorro genera crecimiento y que existe un estrecho vínculo entre el ahorro de los hogares y el ahorro nacional, es interesante considerar el aseguramiento como determinante del ahorro de los hogares, que a su vez trae aparejadas importantes repercusiones macroeconómicas. Si los individuos no son islas, el seguro social es uno de los mecanismos que, al diversificar los riesgos, actúa como emparejador y estabilizador del consumo frente a sus fluctuaciones, en reemplazo de estrategias individuales y autárquicas de ahorro y desahorro que a lo largo del tiempo emprendan los individuos o los hogares (Deaton, 1997, págs. 335-400).

Por otra parte, cabe recordar que, desde un punto de vista económico más general, los sistemas de protección social forman parte de las instituciones donde está enraizada la economía, instituciones cuya construcción y mantención es una actividad eminentemente política. A pesar de que no se originan en el mercado, las intervenciones en materia de política social resultan esenciales para las economías debido a su impacto en la producción, la asignación de recursos, la regulación, el crecimiento económico, los niveles de productividad y de empleo, y la distribución de bienes, servicios, ingresos y bienestar (Hemerijck, 2013, pág. 8).

\section{Bibliografía}

Abramovich, V. y C. Courtis (2006), El umbral de la ciudadanía. El significado de los derechos sociales en el Estado social constitucional, Buenos Aires, Editores del Puerto.

Anand, S. (2004), "The concern for equity in health", Public Health, Ethics, and Equity, S. Anand, F. Peter y A. Sen (eds.), Nueva York, Oxford University Press.

Arrow, K. (2000), "Insurance, risk and resource allocation", Foundations of Insurance Economics. Readings in Economics and Finance, G. Dionne y S.E. Harrington (comps.), Boston, Kluwer Academic Publishers.

(1963), “Uncertainty and the welfare economics of medical care”, American Economic Review, vol. 53, N॰ 5, Nashville, Tennessee, American Economic Association.

Baldwin, P. (2003), The Politics of Social Solidarity. Class Bases of the European Welfare State 1875- 1975, Cambridge, Cambridge University Press.

Banco Mundial (1993), Informe sobre el desarrollo mundial 1993. Invertir en salud, Washington, D.C.

Barr, N. (2013), "The pension system in Sweden. Report to the Expert Group on Public Economics", Estocolmo, Ministerio de Hacienda. 
(2001), Economic Theory and the Welfare State, vols. 1, 2 y 3, Cheltenham, Edward Elgar Publishing.

(1993), The Economics of the Welfare State, Standford, California, Stanford University Press.

Barr, N. y P. Diamond (2010), "Pension Reform in China: Issues, Options and Recommendations" [en línea] https:/ / econ.lse.ac.uk/staff/nb/Barr_Diamond_ China_Pensions_2010.pdf.

(2008), Reforming Pensions. Principles and Policy Choices, Nueva York, Oxford University Press.

Belli, P. (2001), "How adverse selection affects the health insurance market", Policy Research Working Paper, N$^{\circ}$ 2574, Washington, D.C., Banco Mundial.

Bobadilla, J.L., J. Frenk y R. Lozano (1990), "The epidemiologic transition and health priorities", The World Bank/Health Sector Priorities Review, Washington, D.C., inédito.

CEPAL (Comisión Económica para América Latina y el Caribe) (2013), Panorama Social de América Latina 2013 (LC/G.2580), Santiago.

(2007), Cohesión social. Inclusión y sentido de pertenencia en América Latina y el Caribe (LC/G.2335/Rev.1), Santiago.

(2006), La protección social de cara al futuro: acceso, financiamiento y solidaridad, (LC/G.2294(SES.31/3)), Santiago.

(2000), Equidad, desarrollo y ciudadanía (LC/G.2071/Rev.1-P), Santiago.

Cook, Ph. y D. Graham (2000), "The demand for insurance and protection. The case of irreplaceable commodities", Foundations of Insurance Economics. Readings in Economics and Finance, G. Dionne y S.E. Harrington (eds.), Boston, Kluwer Academic Publishers.

Courtis, C. (2007), "Los derechos sociales en perspectiva: la cara jurídica de la política social", Desempeño económico y política social en América Latina y el Caribe: Los retos de la equidad, el desarrollo y la ciudadanía, A. Sojo y A. Uthoff (eds.), Ciudad de México, Editorial Fontamara.

Cutler, D. y R. Zeckhauser (2000), "The anatomy of health insurance", Handbook of Health Economics, A.J. Culyer y J.P. Newhouse, vol. 1A, Amsterdam, Elsevier.

Deaton, A. (1997), The Analysis of Household Surveys. A Microeconomic Approach to Development Policy, Baltimore, Johns Hopkins University Press.

De Ferranti, D. y otros (2000), "Securing our future in a global economy", World Bank Latin American and Caribbean Studies. Viewpoints, Washington, D.C., Banco Mundial.

Dionne, G. y S.E. Harrington (2000), "An introduction to insurance economics", Foundations of Insurance Economics. Readings in Economics and Finance, G. Dionne y S.E. Harrington (eds.), Boston, Kluwer Academic Publishers.

Ehrlich, I. y G. Becker (2000), "Market insurance, self-insurance, and self- protection", Foundations of Insurance Economics. Readings in Economics and Finance, G. Dionne y S.E. Harrington (eds.), Boston, Kluwer Academic Publishers.

Ferrajoli, L. (2008), Democracia y garantismo, Madrid, Editorial Trotta.

Glied, S. y P. Smith (eds.) (2011), The Oxford Handbook of Health Economics, Oxford, Oxford University Press.

González-Rossetti, A., T. Chuaqui y C. Espinosa (2000), “Enhancing the Political Feasibility of Health Reform: the Chile Case" [en línea] http://www.americas. health-sector-reform.org.

Hemerijck, A. (2013), Changing Welfare States, Londres, Oxford University Press. 
Hirschman, A. (1977), Salida, voz y lealtad: respuestas al deterioro de empresas, organizaciones y estados, Ciudad de México, Fondo de Cultura Económica.

Marshall, T.H. (1992), "Citizenship and social class", Citizenship and Social Class, T.H. Marshall y T. Bottomore, Londres, Pluto Press.

Musgrave, R.A. (1985), "A brief history of fiscal doctrine", Handbook of Public Economics, A.J. Auerbach y M. Feldstein, vol. 1, Amsterdam, Elsevier Science Publishers.

Oakland, W. (1987), "Theory of public goods", Handbook of Public Economics, A. Auerbach y M. Feldstein, vol. 2, Amsterdam, Elsevier Science Publishers.

Olsen, J.A. (2011), "Concepts of equity and fairness in health and health care", The Oxford Handbook of Health Economics, G. Sherry y P. Smith (eds.), Oxford, Oxford University Press.

Piñera, J. (s/f), "El cascabel al gato" [en línea] http://www.josepinera.com/jp/ el_cascabel_al_gato.pdf. Publicado también en 1990 por Editorial Zig-Zag.

Porter, D. (1999), Health, Civilization and the State, Londres, Routledge.

Ritter, G. (1998), Soziale Frage und Sozialpolitik in Deutschland seit Beginn des 19. Jahrhunderts, Wiesbaden, Springer.

Ruger, J.P. (2009), Health and Social Justice, Nueva York, Oxford University Press.

Sen, A. (2004), "Why health equity?", Public Health, Ethics, and Equity, S. Anand, F. Peter y A. Sen (eds.), Nueva York, Oxford University Press. (1995), "The political economy of targeting", Public Spending for the Poor. Theory and Evidence, D. Van der Walle y K. Nead (eds.), Baltimore, Banco Mundial/ Johns Hopkins University Press.

Sojo, A. (2014), "El sistema contributivo de pensiones como locus de rivalidad y de un nuevo pacto social en Chile", Serie Politicas Sociales, N 211 (LC/L.3901), Santiago, Comisión Económica para América Latina y el Caribe (CEPAL). (2003), "Vulnerabilidad social, aseguramiento y diversificación de riesgos en América Latina y el Caribe", Revista de la CEPAL, Nº 80 (LC/G.2204-P), Santiago, Comisión Económica para América Latina y el Caribe (CEPAL).

(1990), "Naturaleza y selectividad de la política social", Revista de la CEPAL, No 41 (LC/G.1631-P), Santiago, Comisión Económica para América Latina y el Caribe (CEPAL).

Van de Ven, W. (2013), "Making health insurance affordable: role of risk equalization", Scaling Up Affordable Health Insurance: Staying the Course, A.S. Preker y otros (eds.), Washington, D.C., Banco Mundial.

Van de Ven, W. y F.T. Schut (2011), “Guaranteed access to affordable coverage in individual health insurance markets", The Oxford Handbook of Health Economics, G. Sherry y P. Smith (eds.), Oxford, Oxford University Press.

Van de Ven, W. y R. Ellis (2000), "Risk adjustment in competitive health plan markets", Handbook of Health Economics, A.J. Culyer y J.P. Newhouse, vol. 1A, Amsterdam, Elsevier Science.

Zweifel, P. (2013), "Theory of social health insurance", Scaling Up Affordable Health Insurance: Staying the Course, A.S. Preker y otros (eds.), Washington, D.C., Banco Mundial. 
Capítulo III

\section{La protección social en América Latina: desigualdades de afiliación, de acceso y de completitud}

\section{Introducción}

Con un énfasis cuantitativo, en el presente capítulo se abordan algunas aristas de las desigualdades de la protección social, considerando tanto los avances como los desafíos pendientes. En primer término, con datos de las encuestas de hogares, se analiza la cobertura de pensiones y de salud, que se revela como muy heterogénea y con grados de desigualdad muy diversos entre un país y otro. Para elaborar políticas que mejoren la protección social es necesario encarar la falta de financiamiento y es vital comprender los factores del mercado laboral que son determinantes respecto del acceso a dicha protección. En ese sentido, se profundiza en el análisis de cómo la afiliación a los sistemas de pensiones se relaciona con determinadas características de los puestos de trabajo y de los individuos en el mercado laboral. Además, se estudia la evasión contributiva en cuatro países, como un elemento que compromete el goce efectivo de las prestaciones de salud y pensiones.

En segundo lugar, se aborda el acceso efectivo a la protección social desde tres ámbitos específicos. En cuanto a las pensiones, se analiza la cobertura y el monto de las pensiones contributivas y no contributivas que perciben las personas de más de 65 años. Para brindar indicios acerca de la suficiencia de las pensiones también se considera 
la inserción laboral de este grupo etario, un asunto que tiene relación tanto con las trayectorias laborales como con los respectivos sistemas de pensiones. Por otra parte, se examina la afiliación de los pensionados a sistemas de salud. El estratificado acceso efectivo a prestaciones y aseguramiento de salud se analiza para el caso del Brasil, utilizando los módulos especiales de las encuestas. Finalmente, con encuestas de ingresos y gastos de los hogares, se evalúa la forma en que los gastos de bolsillo en salud reflejan la desigualdad de ingreso y de aseguramiento, y su incidencia en el empobrecimiento o la vulnerabilidad económica de los hogares en la región.

\section{A. La afiliación a la protección social}

\section{Tendencias de la afiliación a los sistemas de salud y pensiones}

Favorecida por la evolución positiva del mercado de trabajo, especialmente por la disminución del desempleo y el aumento de los niveles de ocupación y formalización, que contribuyeron a expandir los mecanismos contributivos, la protección social de salud y pensiones se amplió en los últimos años en numerosos países. El incremento también es consecuencia de la implementación de estrategias para extender la cobertura de los sistemas contributivos de pensiones en algunos países o de ampliaciones del acceso a los sistemas de salud mediante otros mecanismos. En algunos países se expanden pilares no contributivos.

Las encuestas de hogares permiten aproximarse al vínculo efectivo de las personas con la protección social. Por lo general, estas encuestas registran si las personas están afiliadas y, solo en algunos casos, si cotizan (como quien cotiza está afiliado, para medir la cobertura, en el presente análisis se usa la variable de afiliación, que es más abarcadora en términos comparativos, y a ella se asimila la variable de cotización). En el caso de las pensiones, la afiliación indica estrictamente la expectativa futura de recibir una pensión a la edad determinada por ley, cualquiera sea su monto, y por sí sola no da cuenta de si los afiliados están cotizando; de no hacerlo, se originan lagunas de cotización que, según su magnitud, pueden llegar a comprometer seriamente el futuro nivel de las pensiones. También puede ocurrir que los empleadores de trabajadores afiliados sean quienes no efectúen el pago de las contribuciones, a pesar de haber deducido de las planillas las cantidades correspondientes (esta temática de la evasión o elusión contributiva en salud y pensiones se aborda en el capítulo IV). Por 
tanto, la afiliación es una noción bruta de cobertura, que no se refiere al acceso efectivo a prestaciones ni a su calidad.

A escala regional, la afiliación de los asalariados muestra que las diferencias por género que se registran en la actualidad por lo general favorecen a las mujeres: los incrementos de la afiliación en los últimos años las han beneficiado proporcionalmente más en varios países, lo que demuestra la mejor inserción laboral de la mujer asalariada. De manera análoga a las grandes disparidades por quintiles, se registran sendas brechas de acceso a sistemas de pensiones y de salud según niveles educativos, aunque con una tendencia a reducirse, sobre todo en los sistemas de salud. Entre quintiles de ingreso extremos, en el último año de la medición, la brecha de afiliación al sistema de salud es de 36 puntos porcentuales y en el caso del sistema de pensiones es de 49 puntos porcentuales; en el primer caso se redujo 7 puntos porcentuales y en el segundo se incrementó 2 puntos porcentuales. En cuanto a las desigualdades por nivel educativo, las diferencias de acceso entre categorías extremas - asalariados con educación universitaria frente a asalariados con educación primaria incompleta- alcanzan 55 puntos porcentuales en la afiliación a un sistema de pensiones (la desigualdad se eleva 1 punto porcentual respecto del punto de comparación inicial), mientras que en cuanto a la afiliación al seguro de salud, la disparidad entre esos mismos grupos extremos es de 40 puntos porcentuales (disminuye solo 1 punto porcentual). En lo que respecta a las tendencias por grupos de edad, si bien se registró un aumento de la afiliación tanto al sistema de pensiones como al sistema de salud, la mayor afiliación se registra en los rangos intermedios de la vida activa (véase el gráfico III.1).

Vista a escala nacional, la cobertura de los asalariados se revela como muy heterogénea y también es diversa la desigualdad dentro de los países, tanto respecto de la escala de la población cubierta y la población desprotegida, como en cuanto a las disparidades en el seno de la primera.

Como puede observarse en el cuadro III.1, hay países con coberturas altas, bajas e intermedias de afiliación a sistemas de salud y pensiones de los asalariados. El grupo con mayores coberturas está compuesto por la Argentina, el Brasil, Chile, Costa Rica, la República Dominicana y el Uruguay (zonas urbanas), cuyos niveles de afiliación en materia de pensiones fluctúan entre un $68,5 \%$ y un $86,4 \%$. En salud, las mejores coberturas van de un $77,8 \%$ a un $99,1 \%$ en el grupo que abarca a Colombia, México y la República Dominicana por su alta cobertura en salud, que sin embargo en materia de pensiones tienen coberturas menores. 


\section{Gráfico III.1}

América Latina: afiliación a sistemas de pensiones y de salud entre los asalariados de 15 años y más, según sexo, quintil de ingreso per cápita, nivel educativo y grupo de edad, alrededor de 2002 y $2013^{a}$

(En porcentajes)

\section{A. Según sexo}

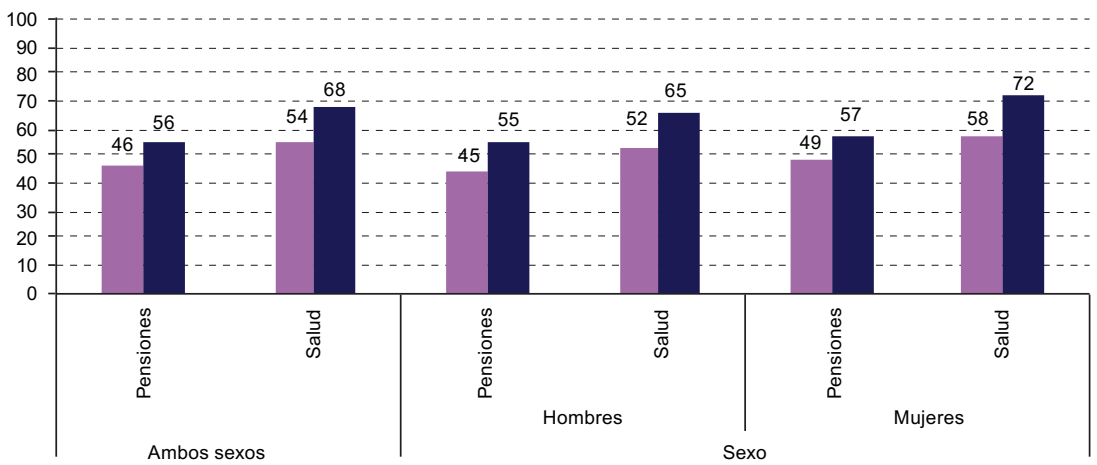

B. Según quintil de ingreso per cápita

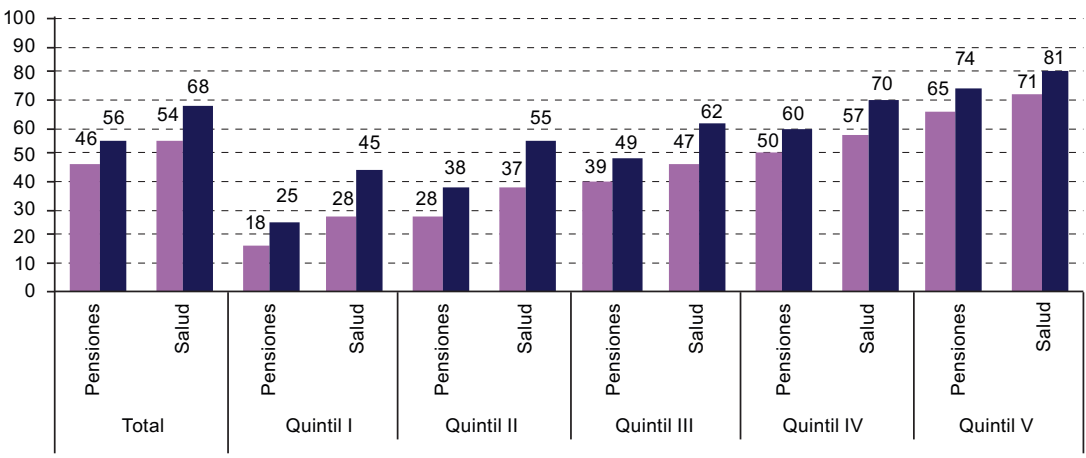

C. Según nivel educativo

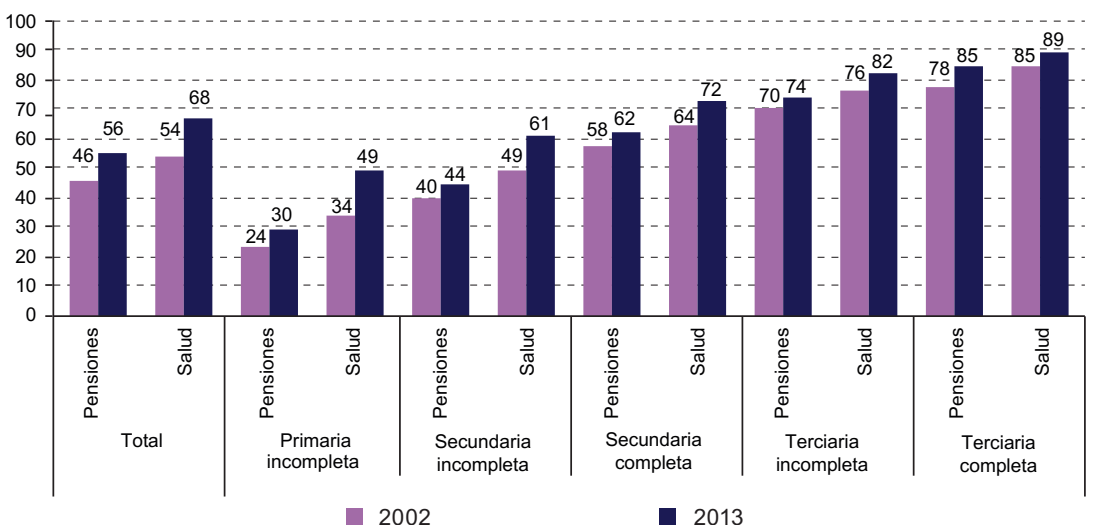


Gráfico III.1 (conclusión)

D. Según grupo de edad

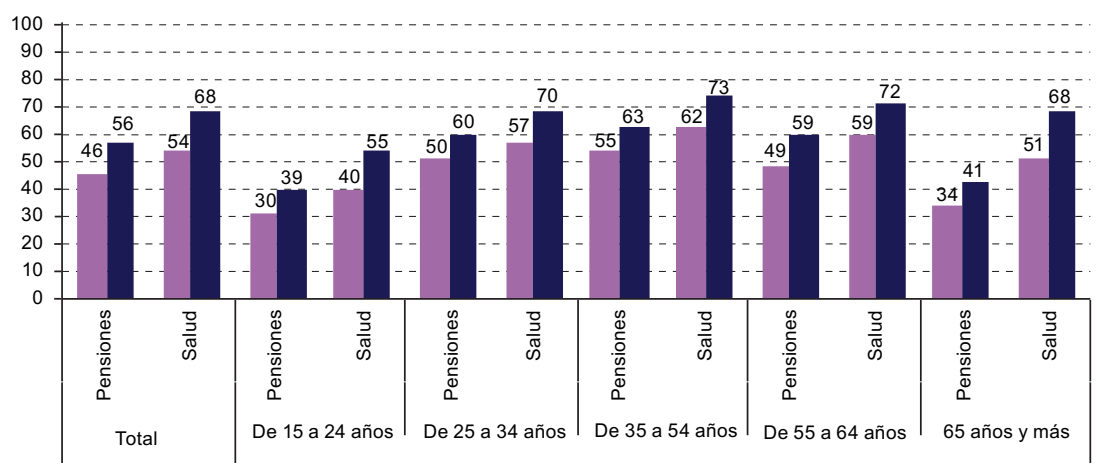

2002

2013

Fuente: Comisión Económica para América Latina y el Caribe (CEPAL), sobre la base de tabulaciones especiales de las encuestas de hogares de los respectivos países.

a Promedio simple de 18 países: Argentina (zonas urbanas), Bolivia (Estado Plurinacional de), Brasil (solo en el caso de las pensiones), Chile, Colombia, Costa Rica (solo en el caso de la salud), Ecuador (zonas urbanas), El Salvador, Guatemala, Honduras, México, Nicaragua, Panamá (solo en el caso de la salud), Paraguay, Perú, República Dominicana, Uruguay (zonas urbanas) y Venezuela (República Bolivariana de) (solo en el caso de las pensiones).

Cuadro III.1

América Latina (18 países): afiliación a sistemas de pensiones y de salud entre los asalariados de 15 años y más, según sexo

(En porcentajes)

\begin{tabular}{|c|c|c|c|c|c|c|c|}
\hline \multirow{3}{*}{ País } & \multirow{3}{*}{ Año } & \multirow{2}{*}{\multicolumn{2}{|c|}{ Ambos sexos }} & \multicolumn{4}{|c|}{ Sexo } \\
\hline & & & & \multicolumn{2}{|c|}{ Hombres } & \multicolumn{2}{|c|}{ Mujeres } \\
\hline & & Pensiones & Salud & Pensiones & Salud & Pensiones & Salud \\
\hline \multirow{2}{*}{$\begin{array}{l}\text { Argentina } \\
\text { (zonas urbanas) }\end{array}$} & 2004 & 54,7 & 65,1 & 59,3 & 66,4 & 49,0 & 63,5 \\
\hline & 2012 & 68,5 & 77,8 & 70,9 & 77,3 & 65,4 & 78,4 \\
\hline \multirow{2}{*}{$\begin{array}{l}\text { Bolivia (Estado } \\
\text { Plurinacional de) }\end{array}$} & 2002 & 26,3 & 29,8 & 25,6 & 27,5 & 27,6 & 34,1 \\
\hline & 2011 & 39,6 & 45,4 & 38,2 & 42,1 & 41,8 & 51,0 \\
\hline \multirow[t]{2}{*}{ Brasila $^{a}$} & 2001 & 68,5 & $\ldots$ & 71,5 & $\ldots$ & 65,0 & $\ldots$ \\
\hline & 2013 & 77,4 & $\ldots$ & 77,6 & $\ldots$ & 77,2 & $\ldots$ \\
\hline \multirow[t]{2}{*}{ Chile } & 2000 & 76,9 & 92,1 & 79,0 & 91,2 & 73,4 & 93,5 \\
\hline & 2013 & 83,5 & 96,0 & 85,3 & 95,3 & 81,1 & 97,0 \\
\hline \multirow[t]{2}{*}{ Colombia } & 1999 & 40,8 & 53,2 & 36,4 & 48,5 & 47,7 & 60,4 \\
\hline & 2013 & 60,1 & 92,8 & 60,5 & 91,6 & 59,4 & 94,4 \\
\hline \multirow[t]{2}{*}{ Costa Ricab } & 2002 & $\ldots$ & 83,7 & $\ldots$ & 81,6 & $\ldots$ & 87,2 \\
\hline & 2013 & 76,9 & 87,8 & 79,5 & 85,9 & 72,8 & 90,7 \\
\hline \multirow{2}{*}{$\begin{array}{l}\text { Ecuador } \\
\text { (zonas urbanas) }\end{array}$} & 2002 & 42,0 & 45,0 & 40,7 & 43,6 & 44,2 & 47,5 \\
\hline & 2013 & 65,6 & 66,0 & 61,9 & 62,3 & 71,5 & 72,1 \\
\hline \multirow[t]{2}{*}{ El Salvador } & 1999 & 48,6 & 50,0 & 45,0 & 45,6 & 54,6 & 57,5 \\
\hline & 2013 & 48,5 & 51,0 & 46,3 & 47,7 & 52,2 & 56,6 \\
\hline \multirow[t]{2}{*}{ Guatemala } & 2002 & 35,1 & 37,8 & 33,5 & 36,2 & 38,6 & 41,4 \\
\hline & 2006 & 38,5 & 44,5 & 36,4 & 42,5 & 42,8 & 48,9 \\
\hline
\end{tabular}


Cuadro III.1 (conclusión)

\begin{tabular}{|c|c|c|c|c|c|c|c|}
\hline \multirow{3}{*}{ País } & \multirow{3}{*}{ Año } & \multirow{2}{*}{\multicolumn{2}{|c|}{ Ambos sexos }} & \multicolumn{4}{|c|}{ Sexo } \\
\hline & & & & \multicolumn{2}{|c|}{ Hombres } & \multicolumn{2}{|c|}{ Mujeres } \\
\hline & & Pensiones & Salud & Pensiones & Salud & Pensiones & Salud \\
\hline \multirow[t]{2}{*}{ Honduras } & 2006 & 38,0 & 36,0 & 30,8 & 30,2 & 51,8 & 47,1 \\
\hline & 2010 & 38,8 & 37,2 & 32,4 & 31,8 & 51,2 & 47,7 \\
\hline \multirow[t]{2}{*}{ México } & 2002 & 41,0 & 53,8 & 39,5 & 52,0 & 44,0 & 57,0 \\
\hline & 2012 & 39,8 & 77,0 & 40,0 & 75,0 & 39,3 & 80,3 \\
\hline \multirow[t]{2}{*}{ Nicaragua } & 2001 & 33,2 & 28,8 & 28,6 & 24,9 & 42,4 & 36,5 \\
\hline & 2005 & 34,0 & 36,3 & 28,0 & 30,2 & 45,6 & 48,3 \\
\hline \multirow[t]{2}{*}{ Panamáb } & 2002 & $\ldots$ & 73,2 & $\ldots$ & 71,6 & $\ldots$ & 75,6 \\
\hline & 2013 & $\ldots$ & 79,0 & $\ldots$ & 76,5 & $\ldots$ & 82,7 \\
\hline \multirow[t]{2}{*}{ Paraguay } & 2000 & 28,1 & 33,2 & 27,2 & 30,9 & 29,6 & 36,9 \\
\hline & 2013 & 38,8 & 45,6 & 38,8 & 43,4 & 38,9 & 48,7 \\
\hline \multirow[t]{2}{*}{ Perú } & 2001 & 27,1 & 39,3 & 27,1 & 38,9 & 26,9 & 40,0 \\
\hline & 2013 & 52,8 & 67,9 & 56,0 & 66,7 & 48,0 & 69,7 \\
\hline \multirow[t]{2}{*}{ República Dominicana } & 2005 & 42,5 & 51,1 & 42,5 & 52,6 & 42,4 & 49,0 \\
\hline & 2013 & 63,0 & 77,7 & 67,2 & 76,6 & 58,0 & 79,1 \\
\hline \multirow{2}{*}{$\begin{array}{l}\text { Uruguay } \\
\text { (zonas urbanas) }\end{array}$} & 2002 & 76,3 & 98,2 & 79,6 & 97,8 & 72,5 & 98,6 \\
\hline & 2013 & 86,4 & 99,1 & 88,3 & 98,8 & 84,3 & 99,4 \\
\hline \multirow{2}{*}{$\begin{array}{l}\text { Venezuela (República } \\
\text { Bolivariana de) }\end{array}$} & 2002 & 61,0 & $\ldots$ & 57,4 & $\ldots$ & 66,5 & $\ldots$ \\
\hline & 2013 & 55,9 & $\ldots$ & 52,9 & $\ldots$ & 59,9 & $\ldots$ \\
\hline \multirow[t]{2}{*}{ América Latina $^{c}$} & 2002 & 46,3 & 54,4 & 45,2 & 52,5 & 48,5 & 57,9 \\
\hline & 2013 & 55,7 & 67,6 & 55,1 & 65,2 & 57,3 & 71,6 \\
\hline
\end{tabular}

Fuente: Comisión Económica para América Latina y el Caribe (CEPAL), sobre la base de tabulaciones especiales de las encuestas de hogares de los respectivos países.

a Las encuestas utilizadas no permiten distinguir la afiliación a sistemas de salud de manera independiente.

b Las encuestas utilizadas no permiten distinguir la afiliación a sistemas de pensiones de manera independiente.

c Promedio simple; se excluye a los países que no cuentan con información para los dos puntos del tiempo tomados como referencia.

El segundo grupo, compuesto por el Ecuador (zonas urbanas), El Salvador, el Perú tiene coberturas en salud que varían entre un 51\% y un $67,9 \%$ de los asalariados y comprende también a Venezuela (República Bolivariana de) en cuanto al nivel de afiliación en pensiones, que decrece en el decenio analizado. En pensiones, la cobertura fluctúa entre el 39,8\% y el $66 \%$. Finalmente, Bolivia (Estado Plurinacional de), Guatemala, Honduras, Nicaragua y el Paraguay exhiben una menor cobertura, con niveles en salud comprendidos entre el $36,3 \%$ y el $45,6 \%$, y en pensiones entre el $34 \%$ y el $39,6 \%$.

Los países con crecimientos más dinámicos difieren notablemente en sus puntos de partida. La ampliación fue más discreta en los países con coberturas más altas, mientras que en algunos que inicialmente tenían una cobertura intermedia se experimenta un interesante dinamismo, e incluso algunos grandes progresos en la afiliación a sistemas de salud y pensiones. 
Este es el caso, por ejemplo, del Estado Plurinacional de Bolivia, un país que estaba muy rezagado, de Colombia, un país de afiliación intermedia que logra un crecimiento récord en materia de afiliación a sistemas de salud, y del Ecuador, el Perú y la República Dominicana. En algunos casos se registran incrementos en pensiones y en salud, mientras que en otros las tendencias divergen, lo que puede denotar diferencias de énfasis o, incluso, una eficacia diversa en términos de cobertura, según el carácter de la protección social sea solidario o individualista ${ }^{1}$. Sin embargo, es muy inquietante el virtual estancamiento en los países que tienen una cobertura muy baja, que no alcanza siquiera a cubrir la mitad de las personas que perciben un salario; en dos países de cobertura intermedia incluso se da una reducción de la afiliación a pensiones.

En muchos países ha crecido la cobertura de salud y pensiones de los asalariados y se han reducido las brechas de género. Sin embargo, en algunos países muy rezagados esta cobertura sigue siendo extremadamente baja y está prácticamente estancada o solo registra leves incrementos, y en tres países la cobertura en pensiones muestra un leve descenso. Por otra parte, la afiliación de los no asalariados, en especial a sistemas de pensiones, es claramente excluyente y perjudica sobre todo a las mujeres; aun así, se registran incrementos, cuyo alcance varía de un país a otro.

Con la excepción de Honduras, la afiliación al seguro de salud entre los asalariados es mayor que la afiliación al sistema de pensiones en todos los países en ambos años. No obstante, dada la alta correlación entre ambas coberturas, los bajos niveles suelen presentarse simultáneamente en las dos dimensiones. Por otro lado, los países con mayor afiliación al sistema de pensiones muestran un porcentaje de afiliación al seguro de salud de alrededor del $90 \%$ y varios de ellos cuentan con un sistema de salud que tiende a la universalización mediante mecanismos contributivos y no contributivos. Los países con una cobertura de pensiones intermedia presentan niveles más variados de afiliación al seguro de salud. En este grupo destaca Colombia, cuya cobertura de salud en 14 años aumentó del $53,2 \%$ al $92,8 \%$, mientras que la de pensiones experimentó un incremento menor, aunque importante, de 19,3 puntos porcentuales.

En algunos países, el ritmo de mejoramiento de la afiliación de las mujeres asalariadas resulta problemático. En la República Bolivariana de Venezuela, el nivel de afiliación disminuye, pero en una proporción que afecta menos a las mujeres. En la Argentina, el Brasil, Chile, Costa Rica, el Perú y el Uruguay las mujeres asalariadas registran menores niveles de

En Colombia, por ejemplo, para la reforma del sistema de salud se incluían diversos componentes solidarios, mientras que la reforma de pensiones derivó hacia la capitalización individual. Las trayectorias de afiliación son diversas en los dos ámbitos. 
afiliación a sistemas de pensiones que los hombres. Además, hay retrocesos en la afiliación de mujeres a pensiones en El Salvador y México. Este aspecto de género se profundizará al analizar los determinantes de la afiliación en el mercado laboral.

En cuanto a la desigualdad de la afiliación medida por quintiles de ingreso, incluso entre los asalariados, cuando la afiliación media es más baja, está más concentrada por ingresos (véase el cuadro III.2). Las brechas por ingreso de la afiliación a sistemas de salud son menores que en la afiliación a pensiones y han tendido a reducirse. Aunque las proporciones de no afiliación se reducen conforme los ingresos se incrementan, una parte de la población -incluso en el quintil de mayores ingresos- no está afiliada a ningún sistema de salud. Si bien en una magnitud algo menor que en el caso de las pensiones y con grandes variaciones de un país a otro, esto puede deberse a cierto tipo de contratos laborales o bien pudiera expresar la autoselección de quienes renuncian voluntariamente a afiliarse porque - al menos en el presente - se aseguran mediante el mercado o incurren en gastos de bolsillo. Si la seguridad social carece de barreras de entrada y actúa como reaseguro de los mercados privados, estas personas pueden tratar de migrar a la seguridad social cuando requieran prestaciones de salud indispensables que sus pólizas no cubran o cuando los gastos de bolsillo se eleven en demasía.

Cuando se mide la desigualdad de la afiliación por ingreso mediante índices de concentración y sus correspondientes curvas, se evidencia un gran mosaico en 18 países de la región (véase el cuadro III.3)². Al comparar ambos puntos del tiempo, se observa que hay países que evidencian mejoras distributivas, como la Argentina en pensiones y salud, Bolivia (Estado Plurinacional de) en salud (en pensiones sigue siendo muy concentrado), el Ecuador en ambos sistemas, Panamá en salud, el Perú en ambos sistemas (con más avance en salud), el Paraguay y la República Dominicana en salud, y el Uruguay en pensiones. El Uruguay, en primer término, seguido por Costa Rica, tienen los sistemas de salud con la afiliación más igualitaria, en tanto que Costa Rica tiene la afiliación al sistema de pensiones más igualitaria de los 18 países. En El Salvador y Nicaragua la concentración de la afiliación a pensiones ha aumentado.

La concentración es mayor conforme se acerca a 1 y menor conforme se acerca a 0. Por motivos de espacio, aquí se incluyen únicamente los índices. 


\section{Cuadro III.2}

\section{América Latina (18 países): afiliación a sistemas de pensiones y de salud entre los asalariados de 15 años y más, según quintiles de ingresos per cápita}

(En porcentajes)

\begin{tabular}{|c|c|c|c|c|c|c|c|c|c|c|c|c|c|}
\hline \multirow{3}{*}{ País } & \multirow{3}{*}{ Año } & \multirow{2}{*}{\multicolumn{2}{|c|}{ Total }} & \multicolumn{10}{|c|}{ Quintil de ingresos per cápita } \\
\hline & & & & \multicolumn{2}{|c|}{ Quintil I } & \multicolumn{2}{|c|}{ Quintil II } & \multicolumn{2}{|c|}{ Quintil III } & \multicolumn{2}{|c|}{ Quintil IV } & \multicolumn{2}{|c|}{ Quintil V } \\
\hline & & Pensiones & Salud & Pensiones & s Salud & Pensiones & $s$ Salud & Pensiones & Salud & Pensiones & $s$ Salud & Pensiones & s Salud \\
\hline \multirow{2}{*}{$\begin{array}{l}\text { Argentina } \\
\text { (zonas } \\
\text { urbanas) }\end{array}$} & 2004 & 54,7 & 65,1 & 13,9 & 20,3 & 36,5 & 45,1 & 52,0 & 63,0 & 64,5 & 77,2 & 79,8 & 90,8 \\
\hline & 2012 & 68,5 & 77,8 & 33,9 & 42,6 & 53,1 & 64,2 & 66,9 & 77,3 & 76,8 & 85,9 & 86,8 & 94,5 \\
\hline \multirow{2}{*}{$\begin{array}{l}\text { Bolivia (Estado } \\
\text { Plurinacional de) }\end{array}$} & 2002 & 26,3 & 29,8 & 9,8 & 9,0 & 6,9 & 9,8 & 15,5 & 18,5 & 20,4 & 26,1 & 43,1 & 45,3 \\
\hline & 2011 & 39,6 & 45,4 & 14,9 & 22,0 & 23,2 & 30,5 & 28,0 & 35,6 & 41,1 & 47,2 & 55,9 & 59,5 \\
\hline \multirow[t]{2}{*}{ Brasila $^{a}$} & 2001 & 68,5 & $\ldots$ & 37,2 & $\ldots$ & 54,0 & $\ldots$ & 64,8 & $\ldots$ & 74,9 & $\ldots$ & 82,2 & \\
\hline & 2013 & 77,4 & $\ldots$ & 46,8 & $\ldots$ & 67,7 & $\ldots$ & 76,9 & $\ldots$ & 84,0 & $\ldots$ & 89,3 & \\
\hline \multirow[t]{2}{*}{ Chile } & 2000 & 76,9 & 92,1 & 54,3 & 89,3 & 69,8 & 90,8 & 77,4 & 91,4 & 82,7 & 92,8 & 87,2 & 94,3 \\
\hline & 2013 & 83,5 & 96,0 & 70,6 & 96,3 & 78,2 & 96,4 & 82,7 & 95,7 & 87,0 & 95,5 & 89,7 & 96,4 \\
\hline \multirow[t]{2}{*}{ Colombia } & 1999 & 40,8 & 53,2 & 10,5 & 17,4 & 21,9 & 33,4 & 27,8 & 41,9 & 39,6 & 53,6 & 62,3 & 73,4 \\
\hline & 2013 & 60,1 & 92,8 & 8,1 & 87,2 & 30,1 & 90,3 & 49,2 & 91,1 & 64,6 & 92,6 & 82,2 & 95,7 \\
\hline \multirow[t]{2}{*}{ Costa Ricab $^{b}$} & 2002 & $\ldots$ & 83,7 & $\ldots$ & 63,3 & $\ldots$ & 73,6 & $\ldots$ & 80,5 & $\ldots$ & 86,5 & $\ldots$ & 92,0 \\
\hline & 2013 & 76,9 & 87,8 & 48,6 & 69,1 & 68,4 & 81,7 & 72,3 & 85,9 & 80,3 & 89,8 & 89,8 & 96,2 \\
\hline \multirow{2}{*}{$\begin{array}{l}\text { Ecuador } \\
\text { (zonas urbanas) }\end{array}$} & 2002 & 42,0 & 45,0 & 17,6 & 18,1 & 24,8 & 26,9 & 34,3 & 36,3 & 45,3 & 48,3 & 64,9 & 70,3 \\
\hline & 2013 & 65,6 & 66,0 & 30,0 & 30,2 & 45,9 & 46,1 & 56,1 & 56,3 & 69,5 & 70,1 & 87,8 & 88,5 \\
\hline \multirow[t]{2}{*}{ EI Salvador } & 1999 & 48,6 & 50,0 & 6,6 & 7,1 & 17,8 & 18,0 & 36,4 & 37,7 & 52,7 & 54,7 & 76,0 & 77,7 \\
\hline & 2013 & 48,5 & 51,0 & 9,1 & 9,3 & 25,2 & 26,4 & 40,1 & 42,7 & 52,1 & 55,3 & 74,0 & 77,2 \\
\hline \multirow[t]{2}{*}{ Guatemala } & 2002 & 35,1 & 37,8 & 7,6 & 7,9 & 16,4 & 17,1 & 27,9 & 31,3 & 41,8 & 43,5 & 58,9 & 64,4 \\
\hline & 2006 & 38,5 & 44,5 & 5,1 & 9,1 & 17,3 & 21,0 & 30,9 & 36,0 & 43,3 & 49,6 & 60,8 & 69,2 \\
\hline \multirow[t]{2}{*}{ Honduras } & 2006 & 38,0 & 36,0 & 0,6 & 0,6 & 5,5 & 5,5 & 21,4 & 21,0 & 41,8 & 40,3 & 61,2 & 57,1 \\
\hline & 2010 & 38,8 & 37,2 & 0,9 & 0,9 & 5,9 & 7,2 & 19,5 & 20,2 & 40,8 & 40,3 & 64,5 & 60,0 \\
\hline \multirow[t]{2}{*}{ México } & 2002 & 41,0 & 53,8 & 7,6 & 16,6 & 23,3 & 35,0 & 38,1 & 53,0 & 49,8 & 63,5 & 66,6 & 79,1 \\
\hline & 2012 & 39,8 & 77,0 & 9,9 & 73,7 & 23,9 & 73,9 & 34,3 & 75,7 & 44,5 & 75,3 & 62,9 & 83,1 \\
\hline \multirow[t]{2}{*}{ Nicaragua } & 2001 & 33,2 & 28,8 & 9,4 & 7,0 & 16,2 & 13,9 & 26,1 & 21,2 & 34,0 & 30,8 & 50,9 & 44,1 \\
\hline & 2005 & 34,0 & 36,3 & 9,4 & 9,4 & 14,7 & 15,9 & 25,4 & 28,0 & 38,7 & 40,4 & 53,3 & 57,3 \\
\hline \multirow[t]{2}{*}{ Panamáb } & 2002 & $\ldots$ & 73,2 & $\ldots$ & 39,1 & $\ldots$ & 62,0 & $\ldots$ & 71,0 & $\ldots$ & 76,3 & $\ldots$ & 78,3 \\
\hline & 2013 & $\ldots$ & 79,0 & $\ldots$ & 35,6 & $\ldots$ & 65,0 & $\ldots$ & 78,2 & $\ldots$ & 83,9 & $\ldots$ & 89,1 \\
\hline Paraguay & 2000 & 28,1 & 33,2 & 2,0 & 2,6 & 8,1 & 9,9 & 16,2 & 19,1 & 32,0 & 33,5 & 43,0 & 54,0 \\
\hline & 2013 & 38,8 & 45,6 & 6,8 & 9,1 & 19,3 & 23,2 & 33,1 & 39,1 & 43,0 & 50,3 & 55,8 & 65,2 \\
\hline Perú & 2001 & 27,1 & 39,3 & 2,5 & 11,5 & 5,9 & 15,1 & 15,2 & 25,6 & 28,9 & 41,8 & 43,3 & 57,5 \\
\hline & 2013 & 52,8 & 67,9 & 13,6 & 64,5 & 30,2 & 62,7 & 43,7 & 61,6 & 56,7 & 65,5 & 73,9 & 77,2 \\
\hline República & 2005 & 42,5 & 51,1 & 26,8 & 34,8 & 35,1 & 43,0 & 41,3 & 48,8 & 44,6 & 52,7 & 53,7 & 64,6 \\
\hline & 2013 & 63,0 & 77,7 & 44,3 & 65,3 & 55,0 & 72,6 & 60,4 & 75,7 & 67,1 & 80,3 & 75,2 & 86,1 \\
\hline Uruguay & 2002 & 76,3 & 98,2 & 40,2 & 98,2 & 64,1 & 97,4 & 76,6 & 97,8 & 85,1 & 98,1 & 91,6 & 99,3 \\
\hline 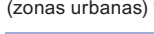 & 2013 & 86,4 & 99,1 & 58,6 & 97,7 & 79,9 & 98,8 & 87,6 & 99,0 & 92,5 & 99,4 & 96,4 & 99,7 \\
\hline Venezuela & 2002 & 61,0 & $\ldots$ & 33,5 & $\ldots$ & 49,4 & $\ldots$ & 57,2 & $\ldots$ & 66,1 & $\ldots$ & 76,8 & $\ldots$ \\
\hline Bolivariana de) & 2013 & 55,9 & $\ldots$ & 30,2 & $\ldots$ & 45,5 & $\ldots$ & 51,0 & $\ldots$ & 59,4 & $\ldots$ & 69,0 & $\ldots$ \\
\hline América Latina $^{c}$ & 2002 & 46,3 & 54,4 & 17,5 & 27,7 & 28,5 & 37,3 & 39,3 & 47,4 & 50,3 & 57,5 & 65,1 & 71,4 \\
\hline & 2013 & 55,7 & 67,6 & 24,5 & 45,1 & 38,4 & 54,7 & 49,1 & 62,4 & 60,1 & 70,1 & 73,6 & 80,9 \\
\hline
\end{tabular}

Fuente: Comisión Económica para América Latina y el Caribe (CEPAL), sobre la base de tabulaciones especiales de las encuestas de hogares de los respectivos países.

a Las encuestas utilizadas no permiten distinguir la afiliación a sistemas de salud de manera independiente.

b Las encuestas utilizadas no permiten distinguir la afiliación a sistemas de pensiones de manera independiente.

c Promedio simple; se excluye a los países que no cuentan con información para los dos puntos del tiempo tomados como referencia. 


\section{Cuadro III.3}

\section{América Latina (18 países): índices de concentración de la afiliación a sistemas de pensiones y de salud entre los asalariados, no asalariados y ocupados de 15 años y más}

\begin{tabular}{|c|c|c|c|c|c|c|c|}
\hline \multirow{2}{*}{ País } & \multirow{2}{*}{ Año } & \multicolumn{2}{|c|}{ Asalariados } & \multicolumn{2}{|c|}{ No asalariados } & \multicolumn{2}{|c|}{ Ocupados } \\
\hline & & Pensiones & Salud & Pensiones & Salud & Pensiones & Salud \\
\hline \multirow{2}{*}{$\begin{array}{l}\text { Argentina } \\
\text { (zonas urbanas) }\end{array}$} & 2004 & 0,227 & 0,204 & $\ldots$ & $\ldots$ & $\ldots$ & \\
\hline & 2012 & 0,143 & 0,120 & $\ldots$ & $\ldots$ & $\ldots$ & $\ldots$ \\
\hline \multirow{2}{*}{$\begin{array}{l}\text { Bolivia (Estado } \\
\text { Plurinacional de) }\end{array}$} & 2002 & 0,313 & 0,278 & 0,601 & 0,450 & 0,548 & 0,457 \\
\hline & 2011 & 0,202 & 0,155 & 0,460 & 0,129 & 0,368 & 0,200 \\
\hline \multirow[t]{2}{*}{ Brasila $^{a}$} & 2001 & 0,108 & $\ldots$ & 0,356 & $\ldots$ & 0,214 & \\
\hline & 2013 & 0,085 & $\ldots$ & 0,311 & $\ldots$ & 0,137 & \\
\hline \multirow[t]{2}{*}{ Chile } & 2000 & 0,075 & 0,010 & 0,286 & $-0,016$ & 0,078 & 0,000 \\
\hline & 2013 & 0,041 & 0,000 & 0,224 & $-0,014$ & 0,038 & $-0,004$ \\
\hline \multirow[t]{2}{*}{ Colombia } & 1999 & 0,248 & 0,188 & 0,500 & 0,390 & 0,364 & 0,300 \\
\hline & 2013 & 0,205 & 0,016 & 0,553 & 0,002 & 0,365 & 0,012 \\
\hline \multirow[t]{2}{*}{ Costa Ricab $^{b}$} & 2002 & $\ldots$ & 0,055 & $\ldots$ & 0,044 & $\ldots$ & 0,062 \\
\hline & 2013 & 0,085 & 0,048 & 0,102 & 0,044 & 0,094 & 0,049 \\
\hline \multirow{2}{*}{$\begin{array}{l}\text { Ecuador } \\
\text { (zonas urbanas) }\end{array}$} & 2002 & 0,228 & 0,236 & 0,356 & 0,411 & 0,260 & 0,279 \\
\hline & 2013 & 0,166 & 0,168 & 0,339 & 0,328 & 0,236 & 0,235 \\
\hline \multirow[t]{2}{*}{ El Salvador } & 1999 & 0,285 & 0,282 & 0,595 & 0,481 & 0,371 & 0,364 \\
\hline & 2013 & 0,253 & 0,251 & 0,667 & 0,495 & 0,345 & 0,341 \\
\hline \multirow[t]{2}{*}{ Guatemala } & 2002 & 0,303 & 0,313 & $\ldots$ & $\ldots$ & $\ldots$ & $\ldots$ \\
\hline & 2006 & 0,272 & 0,259 & $\ldots$ & $\ldots$ & $\ldots$ & \\
\hline \multirow[t]{2}{*}{ Honduras } & 2006 & 0,345 & 0,338 & 0,701 & 0,729 & 0,511 & 0,506 \\
\hline & 2010 & 0,362 & 0,340 & 0,688 & 0,682 & 0,546 & 0,529 \\
\hline \multirow[t]{2}{*}{ México } & 2002 & 0,280 & 0,220 & $\ldots$ & $\ldots$ & $\ldots$ & \\
\hline & 2012 & 0,256 & 0,026 & $\ldots$ & $\ldots$ & $\ldots$ & \\
\hline \multirow[t]{2}{*}{ Nicaragua } & 2001 & 0,246 & 0,256 & 0,232 & 0,491 & 0,306 & 0,332 \\
\hline & 2005 & 0,278 & 0,277 & 0,686 & 0,524 & 0,356 & 0,358 \\
\hline \multirow[t]{2}{*}{ Panamáb } & 2002 & $\ldots$ & 0,050 & $\ldots$ & 0,311 & $\ldots$ & 0,202 \\
\hline & 2013 & $\ldots$ & 0,081 & $\ldots$ & 0,266 & & 0,166 \\
\hline \multirow[t]{2}{*}{ Paraguay } & 2000 & 0,320 & 0,249 & 0,573 & 0,372 & 0,510 & 0,380 \\
\hline & 2013 & 0,205 & 0,053 & 0,365 & $-0,101$ & 0,335 & $-0,009$ \\
\hline \multirow[t]{2}{*}{ Perú } & 2001 & 0,294 & 0,323 & 0,772 & 0,558 & 0,447 & 0,470 \\
\hline & 2013 & 0,223 & 0,222 & 0,738 & 0,417 & 0,340 & 0,326 \\
\hline \multirow{2}{*}{$\begin{array}{l}\text { República } \\
\text { Dominicana }\end{array}$} & 2005 & 0,111 & 0,103 & $\ldots$ & $\ldots$ & $\ldots$ & \\
\hline & 2013 & 0,093 & 0,051 & $\ldots$ & $\ldots$ & $\ldots$ & \\
\hline \multirow{2}{*}{$\begin{array}{l}\text { Uruguay } \\
\text { (zonas urbanas) }\end{array}$} & 2002 & 0,113 & 0,003 & 0,340 & 0,003 & 0,174 & 0,006 \\
\hline & 2013 & 0,069 & 0,003 & 0,247 & 0,007 & 0,118 & 0,006 \\
\hline \multirow{2}{*}{$\begin{array}{l}\text { Venezuela (República } \\
\text { Bolivariana de) }\end{array}$} & 2002 & 0,127 & $\ldots$ & $\ldots$ & $\ldots$ & $\ldots$ & \\
\hline & 2013 & 0,124 & & $\ldots$ & $\ldots$ & & \\
\hline
\end{tabular}

Fuente: Comisión Económica para América Latina y el Caribe (CEPAL), sobre la base de tabulaciones especiales de las encuestas de hogares de los respectivos países.

a Las encuestas utilizadas no permiten distinguir la afiliación a sistemas de salud de manera independiente.

b Las encuestas utilizadas no permiten distinguir la afiliación a sistemas de pensiones de manera independiente. 
Por otra parte, si se considera la inserción laboral de los asalariados, cuanto más baja es la afiliación global, más afectados se ven en términos relativos los trabajadores de microempresas o del servicio doméstico. A lo largo del espectro laboral, la afiliación es mayor entre los empleados públicos que en la empresa privada, lo que remite, entre otras causas, a problemas de evasión y a fallas de supervisión de los mercados laborales. No obstante, cinco países presentan un notable incremento de la afiliación de los empleados de la empresa privada, entre ellos Honduras, que tiene niveles de cobertura muy bajos. Por el contrario, la afiliación a los sistemas de salud y de pensiones entre los profesionales y técnicos de microempresas se redujo en varios países. La afiliación del servicio doméstico a los sistemas de salud es mayor que la afiliación a los sistemas de pensiones y experimentó notables incrementos en Colombia, el Ecuador, México y el Perú, y avances más discretos en varios de los demás países. En materia de pensiones se registran alzas notables en el Ecuador y el Uruguay, aumentos sobre el 10\% en tres países y muy bajos en otros (véase el cuadro III.4).

En los 14 países en que pudo analizarse la afiliación a sistemas de salud de los no asalariados resalta el enorme desfase con respecto a los asalariados. La situación menos desfavorable se da en Chile, Colombia, Costa Rica y el Uruguay. Sin embargo, aun dentro de ese marco global claramente desventajoso - con excepción de los países más rezagados-, la afiliación de los no asalariados ha crecido en los últimos años. Los avances más significativos se registran en Colombia y el Perú. El desfase de las mujeres no asalariadas en la afiliación a sistemas de salud es menor que en el ámbito de las pensiones (véase el cuadro III.5).

Al profundizar en la distribución socioeconómica de la afiliación, emerge nítidamente la desigualdad en la correspondiente a la protección social entre los no asalariados. Tanto en pensiones como en salud son muy notorios los contrastes entre el primer y el quinto quintil de ingresos (véase el cuadro III.6). 


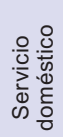

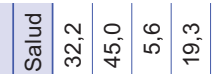

$\mid$

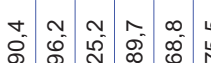

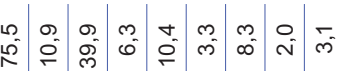

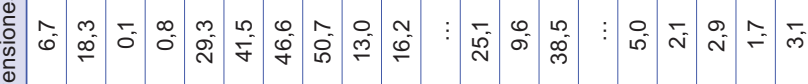

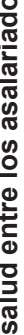

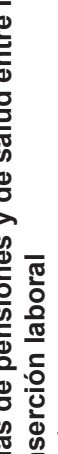

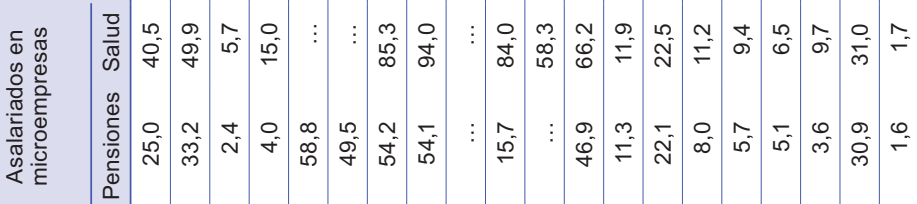

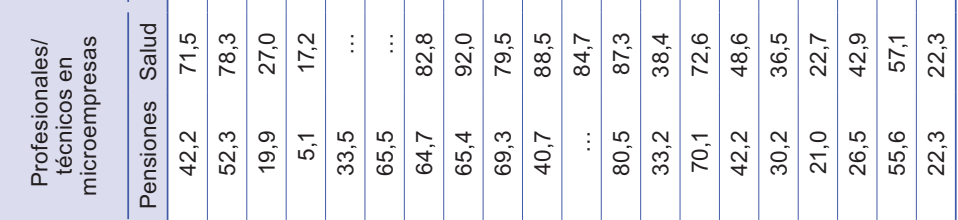

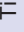

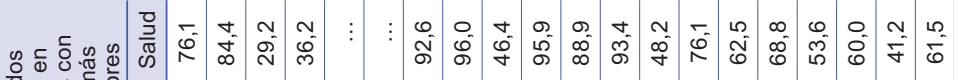

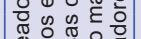

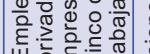

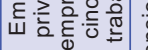

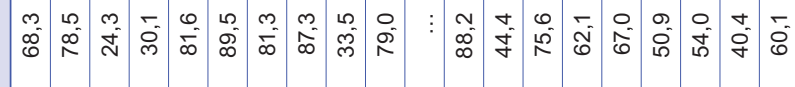

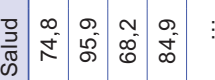

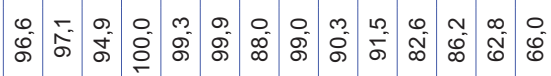
๘ :은 政

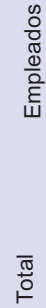

疍

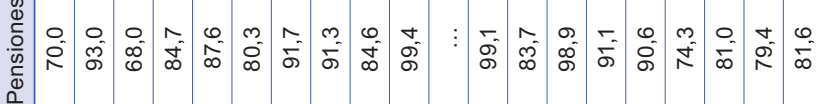

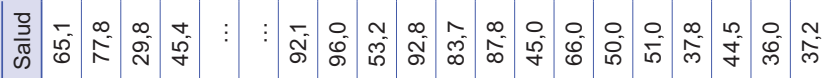
๘ँ

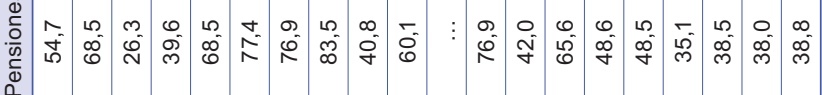

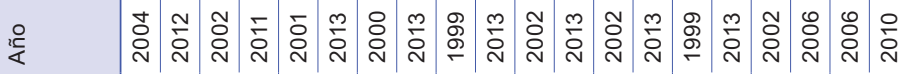
ช્త 


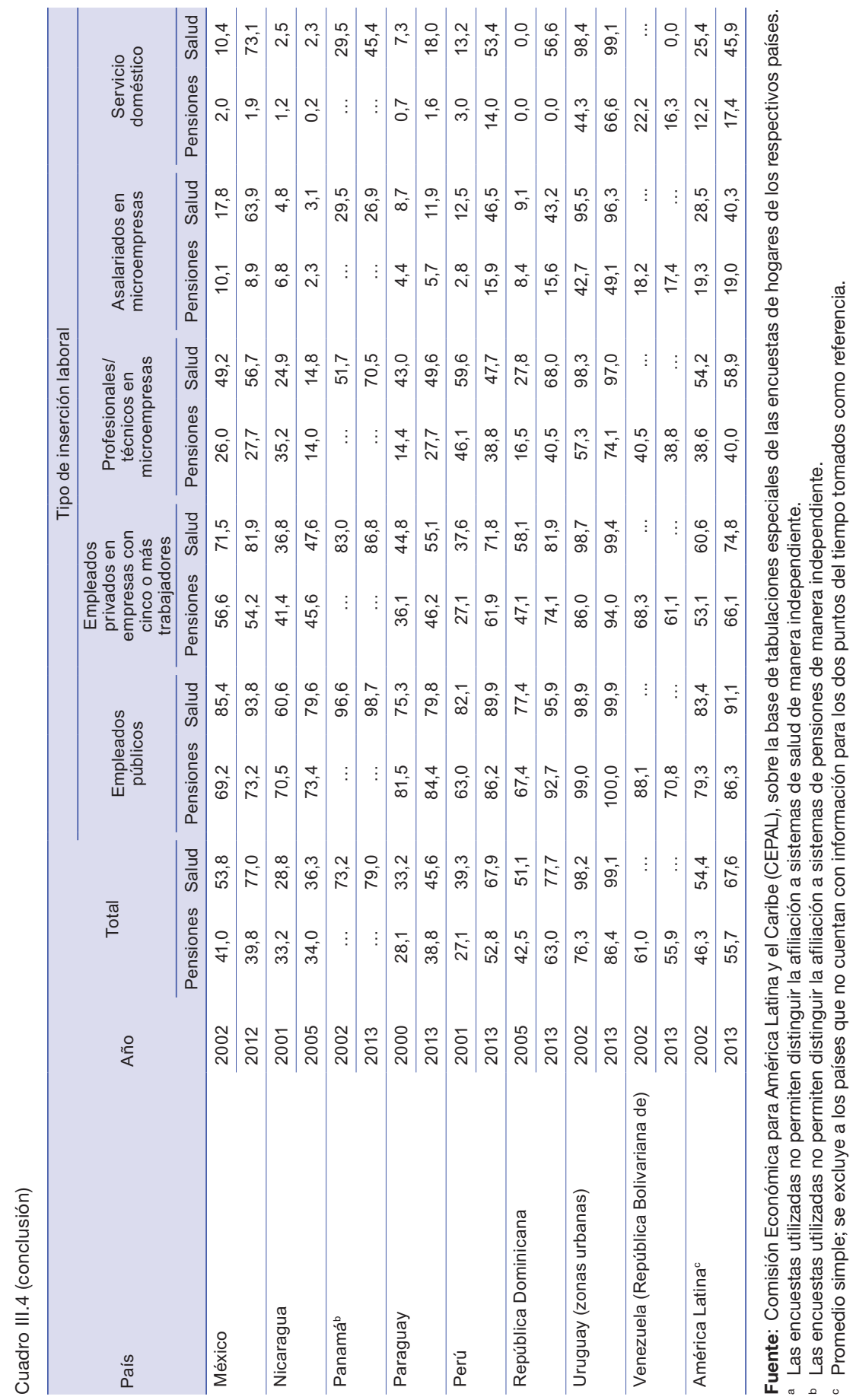


Cuadro III.5

\section{América Latina (14 países): afiliación a sistemas de pensiones y de salud entre los no asalariados de 15 años y más, según sexo}

(En porcentajes)

\begin{tabular}{|c|c|c|c|c|c|c|c|}
\hline \multirow{3}{*}{ País } & \multirow{3}{*}{ Año } & \multirow{2}{*}{\multicolumn{2}{|c|}{ Ambos sexos }} & \multicolumn{4}{|c|}{ Sexo } \\
\hline & & & & \multicolumn{2}{|c|}{ Hombres } & \multicolumn{2}{|c|}{ Mujeres } \\
\hline & & Pensiones & Salud & Pensiones & Salud & Pensiones & Salud \\
\hline \multirow{2}{*}{$\begin{array}{l}\text { Argentina } \\
\text { (zonas urbanas) }\end{array}$} & 2004 & $\ldots$ & 44,0 & $\ldots$ & 42,5 & $\ldots$ & 45,6 \\
\hline & 2012 & $\ldots$ & 53,0 & $\ldots$ & 50,0 & $\ldots$ & 56,3 \\
\hline \multirow{2}{*}{$\begin{array}{l}\text { Bolivia (Estado } \\
\text { Plurinacional de) }\end{array}$} & 2002 & 1,4 & 7,8 & 2,1 & 6,7 & 0,7 & 8,9 \\
\hline & 2011 & 2,9 & 19,3 & 4,4 & 16,7 & 1,5 & 21,9 \\
\hline \multirow[t]{2}{*}{ Brasila $^{a}$} & 2001 & 20,6 & $\ldots$ & 22,4 & $\ldots$ & 18,3 & $\ldots$ \\
\hline & 2013 & 30,2 & $\ldots$ & 29,9 & $\ldots$ & 30,5 & $\ldots$ \\
\hline \multirow[t]{2}{*}{ Chile } & 2000 & 28,0 & 78,3 & 25,6 & 71,8 & 31,0 & 86,3 \\
\hline & 2013 & 26,0 & 91,4 & 25,9 & 87,3 & 26,2 & 95,8 \\
\hline \multirow[t]{2}{*}{ Colombia } & 1999 & 7,0 & 14,3 & 7,0 & 14,1 & 7,0 & 14,6 \\
\hline & 2013 & 11,9 & 88,4 & 12,2 & 86,2 & 11,6 & 91,2 \\
\hline \multirow[t]{2}{*}{ Costa Ricab } & 2002 & $\ldots$ & 65,3 & $\ldots$ & 60,7 & $\ldots$ & 72,1 \\
\hline & 2013 & 40,6 & 77,7 & 54,3 & 75,2 & 24,6 & 80,5 \\
\hline \multirow{2}{*}{$\begin{array}{l}\text { Ecuador } \\
\text { (zonas urbanas) }\end{array}$} & 2002 & 11,0 & 13,4 & 12,8 & 15,5 & 8,9 & 11,0 \\
\hline & 2013 & 21,8 & 23,0 & 22,0 & 23,3 & 21,6 & 22,7 \\
\hline \multirow[t]{2}{*}{ EI Salvador } & 1999 & 3,1 & 10,6 & 4,5 & 7,7 & 1,9 & 13,3 \\
\hline & 2013 & 3,4 & 11,7 & 4,8 & 8,7 & 2,1 & 14,4 \\
\hline \multirow[t]{2}{*}{ Guatemala } & 2002 & 0,5 & 3,1 & 0,6 & 4,3 & 0,3 & 1,7 \\
\hline & 2006 & 0,2 & 7,6 & 0,0 & 7,8 & 0,4 & 7,4 \\
\hline \multirow[t]{2}{*}{ Honduras } & 2006 & 0,8 & 0,9 & 0,9 & 1,0 & 0,6 & 0,8 \\
\hline & 2010 & 0,8 & 1,0 & 0,6 & 0,9 & 1,1 & 1,1 \\
\hline \multirow[t]{2}{*}{ México } & 2002 & 0,2 & 2,0 & 0,3 & 1,9 & 0,1 & 2,1 \\
\hline & 2012 & 1,7 & 71,3 & 2,4 & 66,3 & 1,0 & 76,0 \\
\hline \multirow[t]{2}{*}{ Nicaragua } & 2001 & 1,9 & 2,7 & 1,9 & 2,3 & 1,8 & 3,3 \\
\hline & 2005 & 0,5 & 2,7 & 0,5 & 2,2 & 0,4 & 3,3 \\
\hline \multirow[t]{2}{*}{ Panamáb } & 2002 & $\ldots$ & 21,8 & $\ldots$ & 17,5 & $\ldots$ & 30,5 \\
\hline & 2013 & $\ldots$ & 24,7 & $\ldots$ & 19,6 & $\ldots$ & 31,8 \\
\hline \multirow[t]{2}{*}{ Paraguay } & 2000 & 0,3 & 9,7 & 0,4 & 7,5 & 0,3 & 12,2 \\
\hline & 2013 & 1,3 & 15,5 & 1,7 & 12,1 & 0,9 & 19,1 \\
\hline \multirow[t]{2}{*}{ Perú } & 2001 & 2,9 & 14,2 & 4,6 & 13,4 & 1,4 & 14,9 \\
\hline & 2013 & 14,4 & 57,2 & 21,0 & 52,2 & 8,5 & 61,6 \\
\hline \multirow{2}{*}{$\begin{array}{l}\text { República } \\
\text { Dominicana }\end{array}$} & 2005 & 0,0 & 0,0 & 0,0 & 0,0 & 0,0 & 0,0 \\
\hline & 2013 & 0,0 & 49,4 & 0,0 & 44,9 & 0,0 & 58,8 \\
\hline \multirow{2}{*}{$\begin{array}{l}\text { Uruguay } \\
\text { (zonas urbanas) }\end{array}$} & 2002 & 35,6 & 95,2 & 34,1 & 93,1 & 37,3 & 97,5 \\
\hline & 2013 & 47,9 & 96,1 & 43,0 & 93,8 & 52,5 & 98,3 \\
\hline \multirow{2}{*}{$\begin{array}{l}\text { Venezuela (República } \\
\text { Bolivariana de) }\end{array}$} & 2002 & 1,3 & 0,0 & 0,1 & 0,0 & 2,8 & 0,0 \\
\hline & 2013 & 0,6 & 0,0 & 0,1 & 0,0 & 1,5 & 0,0 \\
\hline \multirow[t]{2}{*}{ América Latina $^{\circ}$} & 2002 & 10,2 & 29,1 & 10,6 & 27,2 & 9,9 & 31,6 \\
\hline & 2013 & 14,7 & 43,2 & 15,1 & 40,6 & 14,3 & 46,0 \\
\hline
\end{tabular}

Fuente: Comisión Económica para América Latina y el Caribe (CEPAL), sobre la base de tabulaciones especiales de las encuestas de hogares de los respectivos países.

a Las encuestas utilizadas no permiten distinguir la afiliación a sistemas de salud de manera independiente.

b Las encuestas utilizadas no permiten distinguir la afiliación a sistemas de pensiones de manera independiente.

c Promedio simple; se excluye a los países que no cuentan con información para los dos puntos del tiempo tomados como referencia. 
Cuadro III.6

\section{América Latina (13 países): afiliación a sistemas de pensiones y de salud entre los no asalariados de 15 años y más, según quintiles de ingresos per cápita}

(En porcentajes)

\begin{tabular}{|c|c|c|c|c|c|c|c|c|c|c|c|c|c|}
\hline \multirow{3}{*}{ País } & \multirow{3}{*}{ Año } & \multirow{2}{*}{\multicolumn{2}{|c|}{ Total }} & \multicolumn{10}{|c|}{ Quintil de ingresos per cápita } \\
\hline & & & & \multicolumn{2}{|c|}{ Quintil I } & \multicolumn{2}{|c|}{ Quintil II } & \multicolumn{2}{|c|}{ Quintil III } & \multicolumn{2}{|c|}{ Quintil IV } & \multicolumn{2}{|c|}{ Quintil V } \\
\hline & & Pensiones & Salud & Pensiones & $s$ Salud & Pensiones & Salud & Pensiones & Salud & Pensiones & Salud & Pensiones & Salud \\
\hline \multirow{2}{*}{$\begin{array}{l}\text { Argentina } \\
\text { (zonas } \\
\text { urbanas) }\end{array}$} & 2004 & $\ldots$ & 44,0 & $\ldots$ & 14,9 & $\ldots$ & 21,3 & $\ldots$ & 30,7 & $\ldots$ & 44,1 & $\ldots$ & 68,5 \\
\hline & 2012 & $\cdots$ & 53,0 & $\cdots$ & 22,0 & $\cdots$ & 35,0 & $\cdots$ & 43,8 & $\cdots$ & 55,6 & $\cdots$ & 73,7 \\
\hline \multirow{2}{*}{$\begin{array}{l}\text { Bolivia (Estado } \\
\text { Plurinacional } \\
\text { de) }\end{array}$} & 2002 & 1,4 & 7,8 & 0,2 & 1,6 & 0,6 & 4,1 & 0,8 & 7,5 & 0,8 & 11,6 & 5,4 & 18,8 \\
\hline & 2011 & 2,9 & 19,3 & 0,4 & 12,5 & 1,3 & 18,6 & 2,2 & 21,2 & 4,3 & 23,6 & 6,8 & 23,3 \\
\hline \multirow[t]{2}{*}{ Brasil $^{a}$} & 2001 & 20,6 & $\ldots$ & 6,3 & $\ldots$ & 12,9 & $\ldots$ & 17,6 & $\ldots$ & 23,1 & $\ldots$ & 44,2 & $\ldots$ \\
\hline & 2013 & 30,2 & $\ldots$ & 8,4 & $\ldots$ & 18,6 & $\ldots$ & 28,1 & $\ldots$ & 34,5 & $\ldots$ & 53,9 & $\ldots$ \\
\hline \multirow[t]{2}{*}{ Chile } & 2000 & 28,0 & 78,3 & 8,8 & 86,2 & 16,6 & 81,3 & 21,4 & 78,9 & 26,4 & 73,9 & 44,9 & 76,9 \\
\hline & 2013 & 26,0 & 91,4 & 13,8 & 95,3 & 16,4 & 93,6 & 20,2 & 93,0 & 23,9 & 90,8 & 38,7 & 88,8 \\
\hline \multirow[t]{2}{*}{ Colombia } & 1999 & 7,0 & 14,3 & 1,5 & 5,2 & 2,3 & 6,9 & 4,4 & 9,9 & 6,5 & 14,7 & 18,7 & 32,4 \\
\hline & 2013 & 11,9 & 88,4 & 1,1 & 88,8 & 3,1 & 88,4 & 6,9 & 87,4 & 13,7 & 87,2 & 33,9 & 90,2 \\
\hline \multirow[t]{2}{*}{ Costa Ricab } & 2002 & $\ldots$ & 65,3 & $\cdots$ & 55,7 & $\ldots$ & 63,0 & $\ldots$ & 68,1 & $\ldots$ & 68,5 & $\ldots$ & 70,4 \\
\hline & 2013 & 40,6 & 77,7 & 32,3 & 67,7 & 36,4 & 74,2 & 36,9 & 79,4 & 40,6 & 80,3 & 54,0 & 84,5 \\
\hline \multirow{2}{*}{$\begin{array}{l}\text { Ecuador } \\
\text { (zonas } \\
\text { urbanas) }\end{array}$} & 2002 & 11,0 & 13,4 & 4,0 & 4,0 & 5,5 & 5,9 & 8,4 & 9,7 & 9,5 & 10,5 & 22,6 & 30,2 \\
\hline & 2013 & 21,8 & 23,0 & 8,2 & 9,7 & 12,3 & 13,0 & 16,8 & 17,1 & 23,3 & 24,6 & 44,3 & 46,2 \\
\hline \multirow[t]{2}{*}{ El Salvador } & 1999 & 3,1 & 10,6 & 0,9 & 1,5 & 0,5 & 3,1 & 1,2 & 7,6 & 2,0 & 13,0 & 10,4 & 26,2 \\
\hline & 2013 & 3,4 & 11,7 & 0,3 & 0,9 & 0,7 & 4,4 & 1,1 & 7,9 & 2,3 & 14,5 & 11,5 & 28,5 \\
\hline \multirow[t]{2}{*}{ Guatemala } & 2002 & 0,5 & 3,1 & 0,0 & 0,5 & 0,0 & 1,4 & 0,0 & 1,2 & 0,3 & 3,6 & 1,8 & 7,7 \\
\hline & 2006 & 0,2 & 7,6 & 0,0 & 2,1 & 0,0 & 3,6 & 0,0 & 5,1 & 0,0 & 7,7 & 0,6 & 15,5 \\
\hline \multirow[t]{2}{*}{ Honduras } & 2006 & 0,8 & 0,9 & 0,1 & 0,0 & 0,1 & 0,1 & 0,4 & 0,4 & 0,5 & 0,6 & 3,2 & 3,7 \\
\hline & 2010 & 0,8 & 1,0 & 0,1 & 0,2 & 0,2 & 0,2 & 0,4 & 0,4 & 0,4 & 0,5 & 3,4 & 4,1 \\
\hline \multirow[t]{2}{*}{ México } & 2002 & 0,2 & 2,0 & 0,0 & 0,6 & 0,1 & 0,6 & 0,4 & 3,0 & 0,1 & 2,2 & 0,5 & 3,1 \\
\hline & 2012 & 1,7 & 71,3 & 0,2 & 76,7 & 0,5 & 73,8 & 0,9 & 73,1 & 2,8 & 71,1 & 4,1 & 61,3 \\
\hline \multirow[t]{2}{*}{ Nicaragua } & 2001 & 1,9 & 2,7 & 1,1 & 0,5 & 1,1 & 1,0 & 2,0 & 1,8 & 1,4 & 2,7 & 3,4 & 6,6 \\
\hline & 2005 & 0,5 & 2,7 & $\ldots$ & 0,4 & 0,3 & 0,6 & 0,1 & 1,9 & 0,3 & 2,9 & 1,6 & 7,0 \\
\hline \multirow[t]{2}{*}{ Panamáb } & 2002 & $\ldots$ & 21,8 & $\ldots$ & 7,0 & $\ldots$ & 17,3 & $\ldots$ & 26,2 & $\ldots$ & 29,7 & $\ldots$ & 39,1 \\
\hline & 2013 & $\ldots$ & 24,7 & $\ldots$ & 7,9 & $\ldots$ & 23,0 & $\ldots$ & 31,5 & $\ldots$ & 34,5 & $\ldots$ & 35,4 \\
\hline Paraguay & 2000 & 0,3 & 9,7 & $\ldots$ & 1,5 & 0,0 & 2,0 & 0,1 & 4,6 & 0,1 & 11,8 & 1,4 & 27,0 \\
\hline & 2013 & 1,3 & 15,5 & $\ldots$ & 3,2 & 0,3 & 7,5 & 0,4 & 14,2 & 0,4 & 19,6 & 5,4 & 35,1 \\
\hline Perú & 2001 & 2,9 & 14,2 & 0,3 & 4,7 & 0,6 & 7,2 & 2,2 & 12,8 & 3,7 & 20,8 & 9,3 & 30,3 \\
\hline & 2013 & 14,4 & 57,2 & 4,3 & 73,1 & 9,8 & 60,6 & 14,0 & 50,1 & 18,9 & 44,9 & 31,4 & 48,8 \\
\hline República & 2005 & 0,0 & 0,0 & 0,0 & 0,0 & 0,0 & 0,0 & 0,0 & 0,0 & 0,0 & 0,0 & 0,0 & 0,0 \\
\hline & 2013 & 0,0 & 49,4 & 0,0 & 49,8 & 0,0 & 50,7 & 0,0 & 46,4 & 0,0 & 47,2 & 0,0 & 52,5 \\
\hline Uruguay & 2002 & 35,6 & 95,2 & 9,6 & 96,2 & 20,5 & 94,3 & 30,5 & 94,1 & 46,9 & 93,5 & 68,6 & 98,0 \\
\hline & 2013 & 47,9 & 96,1 & 17,0 & 94,2 & 39,0 & 96,0 & 46,8 & 95,5 & 60,4 & 96,9 & 76,3 & 97,9 \\
\hline Venezuela & 2002 & 1,3 & 0,0 & 1,6 & 0,0 & 1,0 & 0,0 & 1,2 & 0,0 & 0,9 & 0,0 & 1,6 & 0,0 \\
\hline $\begin{array}{l}\text { (Republica } \\
\text { Bolivariana de) } \\
\end{array}$ & 2013 & 0,6 & 0,0 & 0,3 & 0,0 & 0,7 & 0,0 & 0,5 & 0,0 & 0,6 & 0,0 & 0,9 & 0,0 \\
\hline América & 2002 & 10,2 & 29,1 & 3,3 & 21,5 & 5,5 & 23,7 & 8,1 & 27,1 & 11,0 & 30,4 & 21,1 & 40,6 \\
\hline & 2013 & 14,7 & 43,2 & 6,0 & 36,6 & 9,3 & 39,6 & 12,5 & 41,8 & 16,6 & 44,3 & 27,9 & 51,0 \\
\hline
\end{tabular}

Fuente: Comisión Económica para América Latina y el Caribe (CEPAL), sobre la base de tabulaciones especiales de las encuestas de hogares de los respectivos países.

a Las encuestas utilizadas no permiten distinguir la afiliación a sistemas de salud de manera independiente.

b Las encuestas utilizadas no permiten distinguir la afiliación a sistemas de pensiones de manera independiente.

c Promedio simple; se excluye a los países que no cuentan con información para los dos puntos del tiempo tomados como referencia. 
Ocampo y Gómez-Arteaga (2016) han construido un índice multidimensional de protección social, constituido por la media aritmética de ocho indicadores, que agrupa los países por cobertura amplia, intermedia y limitada, utilizando cifras de la CEPAL (2013 y 2015) y de otras fuentes (véase el gráfico III.2) ${ }^{3}$. Conforme al índice, se muestran avances generales registrados en la cobertura de la afiliación global y de grupos específicos, como los no asalariados, y asignaturas pendientes para reducir la desigualdad de la protección social, en términos que en general coinciden con la trayectoria delineada por la CEPAL (2013 y 2015) y con el análisis que se realiza en este capítulo.

Gráfico III.2

América Latina: puntaje del índice de protección social, alrededor de 2002 y 2012

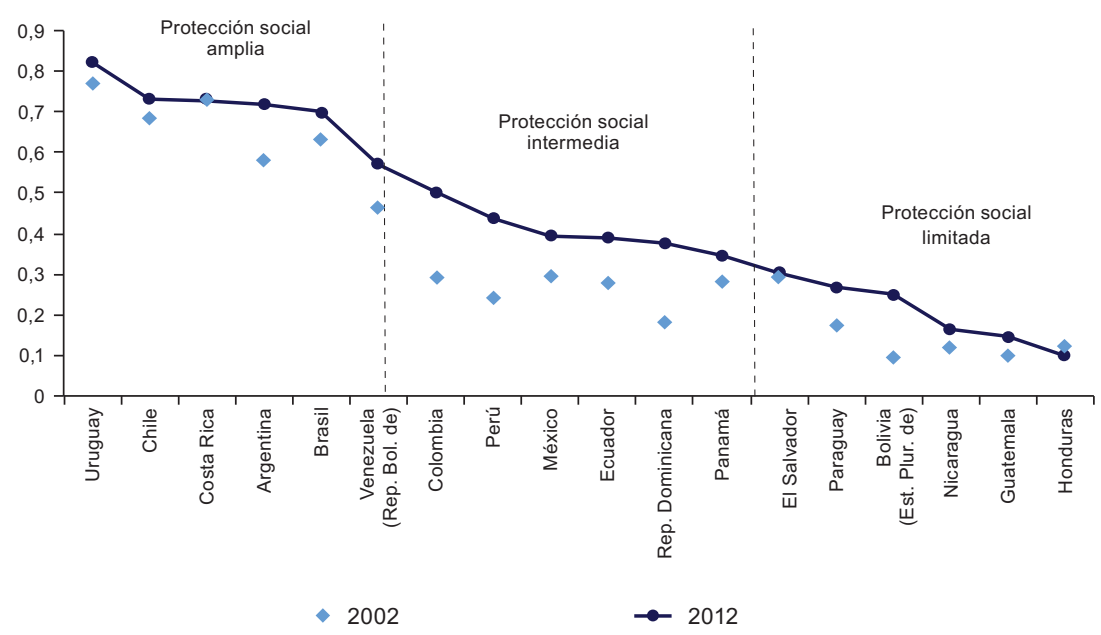

Fuente: J.A. Ocampo y N. Gómez-Arteaga, "Social protection systems in Latin America: an assessment", ESS (Extension of Social Security) Working Paper, N 52, gráfico 1, Ginebra, Oficina Regional de la OIT para América Latina y el Caribe, 2016.

Los indicadores son: cobertura de pensiones contributivas, afiliación de asalariados a sistemas de pensiones y a sistemas de salud, brecha del acceso a pensiones de asalariados y no asalariados, brecha del acceso a sistemas de salud de asalariados y no asalariados, acceso de hogares pobres a algún tipo de programa social, cobertura de asistencia social del quintil más pobre, gasto en protección social como porcentaje del PIB y gasto social en salud como porcentaje del PIB. 


\section{Análisis multivariado de los determinantes de la afiliación al sistema de pensiones en la región}

Para la investigación y las políticas públicas es relevante conocer los factores que determinan la afiliación a los sistemas de pensiones. De manera muy significativa, las disparidades están vinculadas con las características de los puestos de trabajo, no solo con las de las personas. Tal como han demostrado recientes análisis multivariados de los determinantes de la afiliación al sistema de pensiones, en los países emergen patrones comunes, aunque de diversa magnitud (CEPAL, 2013; Amarante y Sojo, 2015). A continuación se presenta una actualización del ejercicio con modelos probit realizado por la CEPAL en 2013 (CEPAL, 2013), con información de encuestas de hogares más recientes (Figueroa, 2015) ${ }^{4}$.

Los efectos marginales de cada variable en la probabilidad de afiliación a los sistemas de pensiones evidencian patrones comunes entre los países, aunque con magnitudes singulares: las características personales tienen una influencia menor en comparación con las variables que caracterizan los puestos de trabajo. Así, los trabajadores formales y con trabajo a tiempo completo tienen mayores probabilidades de afiliación. Por otra parte, se observan importantes diferencias por niveles educativos y también por edades.

La inserción en el sector informal tiene un importante efecto negativo sobre la probabilidad de afiliación al sistema de pensiones (véase el gráfico III.3). Si bien se presenta con diferente magnitud, este es un patrón común a todos los países, que muestra dos tendencias: en la Argentina, el Brasil, Nicaragua, el Uruguay y Venezuela (República Bolivariana de) disminuye la influencia de la variable, mientras que en los demás países aumenta de manera significativa.

\footnotetext{
Mediante modelos probit se estimaron los determinantes para la afiliación de los trabajadores de entre 15 y 64 años. La variable dependiente es la afiliación, las variables independientes abarcan características personales del trabajador (como la edad, el sexo, el nivel educativo y el estado civil), del hogar (tamaño y jefatura) y del puesto de trabajo (como categoría ocupacional, rama de actividad, trabajo a tiempo parcial, tipo de inserción laboral y quintil de ingreso del trabajo). Además, en los países en que se encontraban disponibles, se consideraron variables de raza y zona (urbana o rural) e interacciones entre las variables de nivel educativo y sexo y jefatura del hogar y sexo. Las estimaciones realizadas se corrigieron por el sesgo de selección muestral de Heckman, que consiste en estimar, además de la ecuación principal, una segunda ecuación (denominada de selección) que mide la probabilidad de estar en la muestra para la que se ha estimado la ecuación principal, incluyendo en la ecuación de selección el sexo, la escolaridad, la edad, la cantidad de menores en el hogar (de 0 a 4 años y de 5 a 12 años) y la interacción entre la cantidad de menores de 4 años en el hogar y la presencia de miembros entre 15 y 64 años fuera de la fuerza laboral. En este caso se mide la probabilidad de estar ocupado (o de ser asalariado en los países donde la pregunta por cotización solamente se formula a estos trabajadores) del total de personas económicamente activas.
} 
Gráfico III.3

América Latina (17 países): efecto marginal de la inserción en el sector informal sobre la probabilidad de afiliación a sistemas de pensiones, alrededor de 2002 y de 2013a

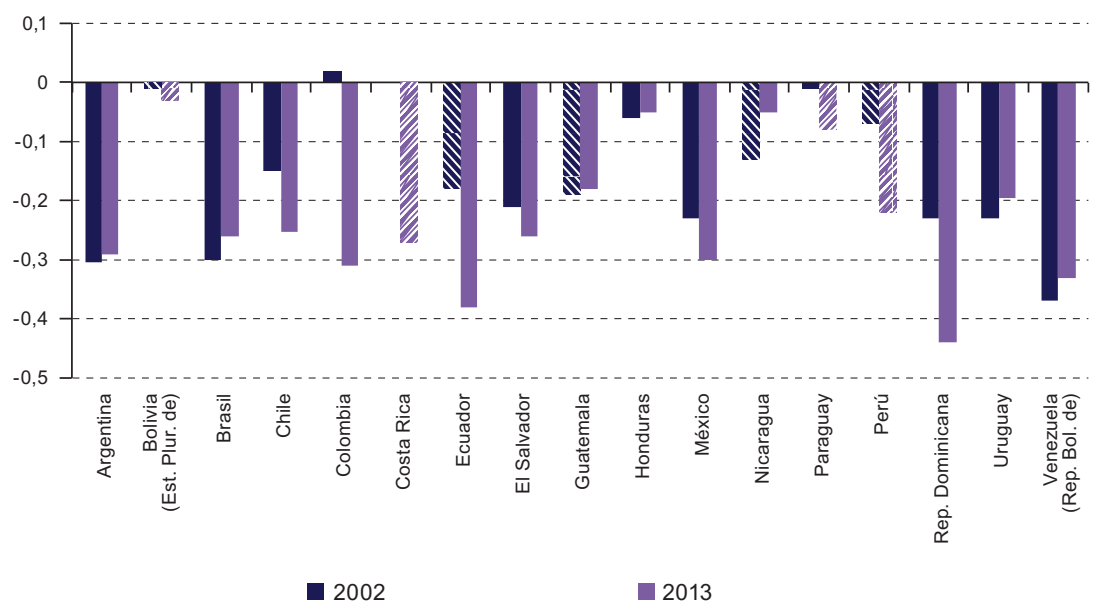

Fuente: Comisión Económica para América Latina y el Caribe (CEPAL), sobre la base de tabulaciones especiales de las encuestas de hogares de los respectivos países.

a Informal=1. Los colores con trama indican los coeficientes no estadísticamente significativos (a un nivel de confianza del 99\%).

La inserción en un trabajo a tiempo parcial también muestra un patrón negativo. En la mayoría de los países, si los individuos trabajan menos de 30 horas a la semana, tienen menos probabilidades de afiliación en comparación con los trabajadores a tiempo completo (véase el gráfico III.4).

La importancia de las características del puesto de trabajo se ve claramente al analizar los efectos marginales por categoría ocupacional (véase el gráfico III.5). En la mayoría de los países, ser asalariado público implica una mayor probabilidad de afiliación en comparación con los asalariados del sector privado. Por otra parte, ser empleador o trabajador por cuenta propia supone menos probabilidades de afiliación en comparación con los asalariados del sector privado. Otro efecto negativo y significativo se evidencia para los trabajadores del servicio doméstico, con la excepción del Uruguay y Venezuela (República Bolivariana de). 


\section{Gráfico III.4}

América Latina (17 países): efecto marginal del trabajo a tiempo parcial sobre la probabilidad de afiliación a sistemas de pensiones, alrededor de 2002 y $2013^{a}$

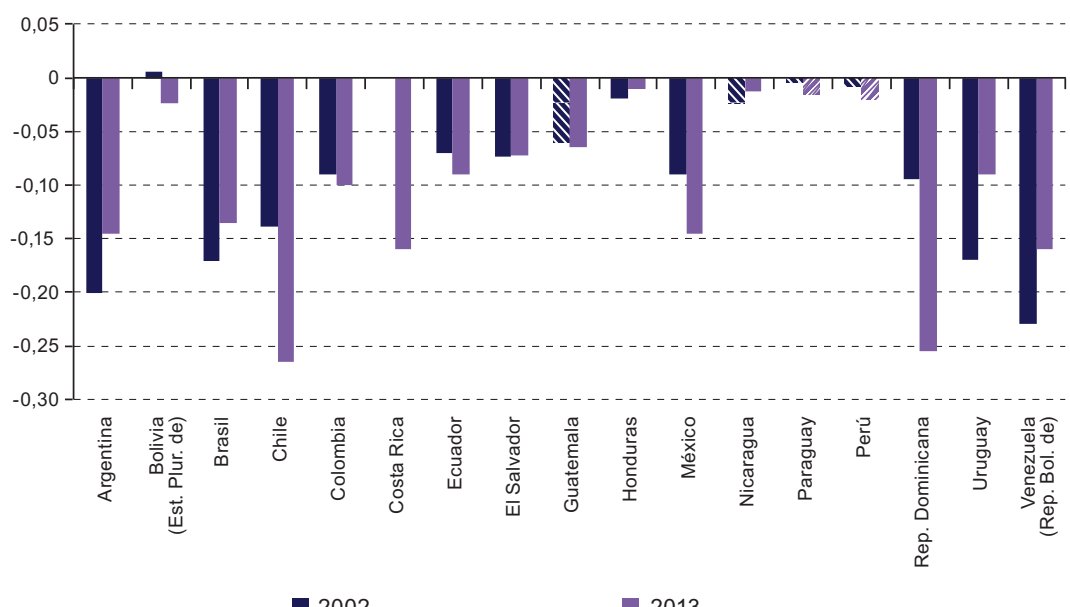

Fuente: Comisión Económica para América Latina y el Caribe (CEPAL), sobre la base de tabulaciones especiales de las encuestas de hogares de los respectivos países.

a Tiempo parcial=1. Los colores con trama indican los coeficientes no estadísticamente significativos (a un nivel de confianza del 99\%).

\section{Gráfico III.5}

América Latina (17 países): efecto marginal de la categoría ocupacional sobre la probabilidad de afiliación a sistemas de pensiones, alrededor de 2013

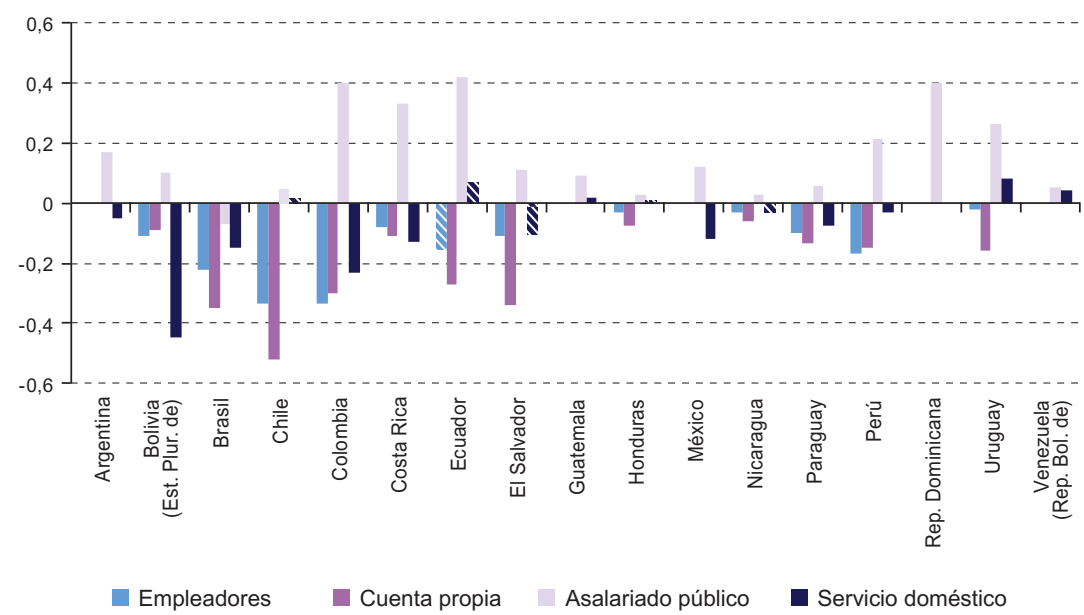

Fuente: Comisión Económica para América Latina y el Caribe (CEPAL), sobre la base de tabulaciones especiales de las encuestas de hogares de los respectivos países.

a Los colores con trama indican los coeficientes no estadísticamente significativos (a un nivel de confianza del 99\%). 
Los efectos marginales de la rama de actividad sobre la probabilidad de afiliación muestran pautas similares en los países. Ser trabajador en los sectores de la agricultura, la construcción, el comercio y el transporte implica tener menos probabilidades de afiliación que se trabaja en la industria. La afiliación en el sector de la minería tiene efectos significativos de diverso signo en la Argentina, Chile, Honduras, Nicaragua y la República Dominicana. En el sector de transporte y el sector financiero se evidencian efectos significativos, pero la influencia es positiva o negativa dependiendo del país (véase el cuadro III.7).

Cuadro III.7

América Latina (17 países): efectos marginales de la rama de actividad sobre la probabilidad de afiliación a sistemas de pensiones, alrededor de 2013 ${ }^{\text {a }}$

\begin{tabular}{|c|c|c|c|c|c|c|c|c|}
\hline & Agricultura & Minería & Electricidad & Construcción & Comercio & Transporte & Finanzas & Servicios \\
\hline Argentina & 0,089 & 0,237 & 0,159 & $-0,160$ & $-0,012$ & $-0,021$ & 0,002 & 0,083 \\
\hline $\begin{array}{l}\text { Bolivia (Estado } \\
\text { Plurinacional de) }\end{array}$ & $-0,056$ & $-0,036$ & $-0,050$ & $-0,117$ & $-0,076$ & $-0,091$ & $-0,012$ & $-0,044$ \\
\hline Brasil & $-0,098$ & $-0,042$ & 0,233 & $-0,149$ & $-0,037$ & $-0,009$ & $-0,012$ & $-0,011$ \\
\hline Chile & $-0,104$ & 0,088 & 0,131 & $-0,054$ & $-0,044$ & $-0,052$ & 0,026 & $-0,036$ \\
\hline Colombia & $-0,092$ & 0,012 & 0,213 & $-0,010$ & $-0,068$ & 0,064 & 0,055 & 0,108 \\
\hline Costa Rica & $-0,013$ & 0,200 & $-0,020$ & $-0,162$ & 0,032 & $-0,020$ & 0,071 & 0,028 \\
\hline Ecuador & $-0,130$ & 0,064 & $-0,027$ & $-0,336$ & $-0,033$ & $-0,015$ & 0,262 & $-0,020$ \\
\hline EI Salvador & $-0,128$ & $-0,048$ & $-0,059$ & $-0,098$ & $-0,063$ & $-0,098$ & 0,018 & $-0,090$ \\
\hline Guatemala & $-0,057$ & 0,060 & $-0,076$ & $-0,128$ & $-0,049$ & $-0,105$ & $-0,039$ & $-0,082$ \\
\hline Honduras & $-0,025$ & $-0,057$ & $-0,008$ & $-0,045$ & $-0,018$ & $-0,034$ & $-0,015$ & $-0,034$ \\
\hline México & $-0,186$ & 0,101 & 0,087 & $-0,207$ & $-0,049$ & $-0,166$ & $-0,038$ & $-0,137$ \\
\hline Nicaragua & $-0,039$ & $-0,040$ & $-0,011$ & $-0,024$ & $-0,025$ & $-0,039$ & $-0,013$ & $-0,024$ \\
\hline Paraguay & $-0,055$ & $\ldots$ & $-0,075$ & $-0,014$ & 0,001 & $-0,008$ & $-0,021$ & $\ldots$ \\
\hline Perú & $-0,024$ & 0,025 & 0,056 & $-0,047$ & $-0,038$ & $-0,014$ & 0,068 & $-0,051$ \\
\hline $\begin{array}{l}\text { República } \\
\text { Dominicana }\end{array}$ & $-0,110$ & $-0,413$ & $-0,114$ & $-0,335$ & $-0,094$ & $-0,076$ & 0,024 & $-0,106$ \\
\hline Uruguay & 0,024 & $-0,002$ & 0,017 & $-0,046$ & 0,004 & 0,032 & 0,051 & $-0,020$ \\
\hline $\begin{array}{l}\text { Venezuela } \\
\text { (República } \\
\text { Bolivariana de) }\end{array}$ & $-0,225$ & $-0,012$ & 0,019 & $-0,215$ & 0,021 & $-0,137$ & 0,055 & $-0,054$ \\
\hline
\end{tabular}

Fuente: Comisión Económica para América Latina y el Caribe (CEPAL), sobre la base de tabulaciones especiales de las encuestas de hogares de los respectivos países.

a Se omite la categoría correspondiente a Industria. Las casillas en gris indican que los efectos son estadísticamente significativos (a un nivel de confianza del 99\%).

Como es previsible, conforme aumentan los ingresos, aumenta la probabilidad de afiliación, con gradientes diversos por país. Las mayores y más significativas diferencias entre los quintiles inferiores y superiores se observan en la Argentina, el Brasil, México, la República Dominicana y Venezuela (República Bolivariana de), mientras que estas son menores en Bolivia (Estado Plurinacional de), Nicaragua y el Paraguay. En Bolivia (Estado Plurinacional de), Colombia y Honduras, la probabilidad de afiliación es menor en el segundo quintil de ingreso (véase el gráfico III.6). 


\section{Gráfico III.6}

América Latina (17 países): efecto marginal del quintil de ingresos del trabajo sobre la probabilidad de afiliación a sistemas de pensiones, alrededor de 2013

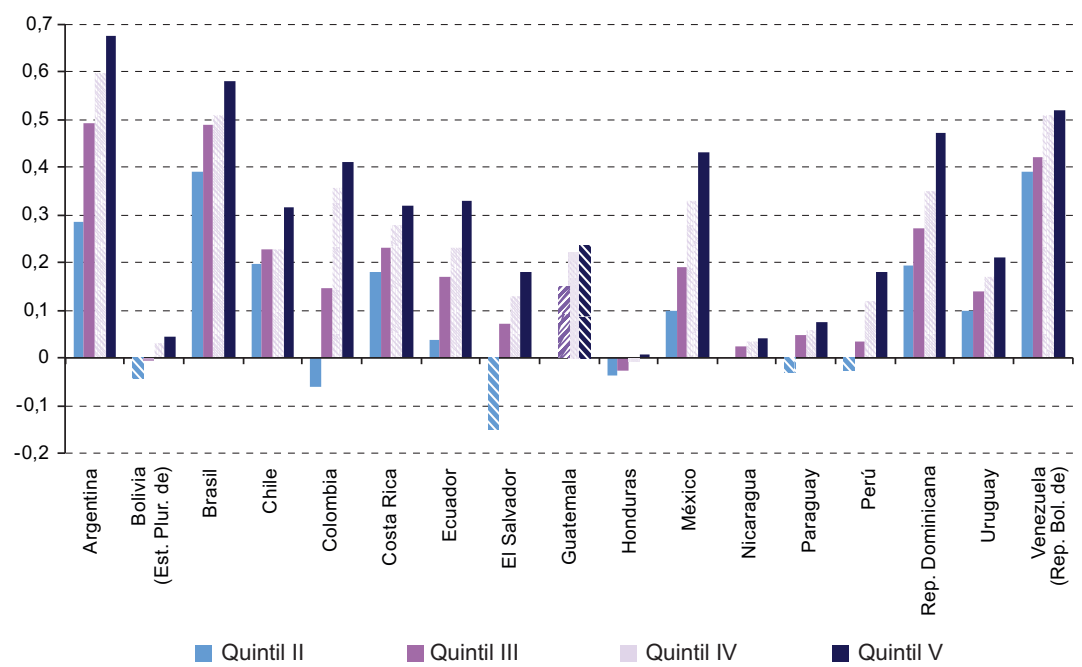

Fuente: Comisión Económica para América Latina y el Caribe (CEPAL), sobre la base de tabulaciones especiales de las encuestas de hogares de los respectivos países.

a Los colores con trama indican los coeficientes no estadísticamente significativos (a un nivel de confianza del 99\%).

Las características personales de los trabajadores tienen efectos significativos en los diferentes países, pero de menor magnitud respecto de las características relativas al puesto del trabajo y de magnitud diversa de un país a otro. En esa línea, ser mujer implica mayores probabilidades de estar afiliada en países como el Brasil, la República Dominicana, el Uruguay y Venezuela (República Bolivariana de). En el Perú, la probabilidad de afiliación es menor y significativa para los hombres (véase el gráfico III.7).

En cuanto a la edad, hay patrones claros. Como se aprecia en el gráfico III.8, la probabilidad de afiliación aumenta conforme aumenta la edad. En casi todos los países, los trabajadores más jóvenes tienen una afiliación menor con respecto al grupo de 55 a 64 años; en Colombia, el Ecuador y el Perú los contrastes son mayores. En los grupos de edad de 25 a 54 años, la probabilidad de afiliación también es significativamente menor. En Guatemala, Nicaragua y la República Dominicana, la edad no es significativa. En Chile, Honduras, México y el Uruguay, la diferencia entre los grupos más jóvenes y el de mayor edad es relevante. Como la suficiencia de las pensiones está relacionada, entre otros aspectos, con los años de cotización y la densidad de los aportes, estos patrones muestran una situación problemática respecto del ahorro previsional. 


\section{Gráfico III.7}

América Latina (17 países): efecto marginal del sexo sobre la probabilidad de afiliación a sistemas de pensiones, alrededor de 2002 y de 2013

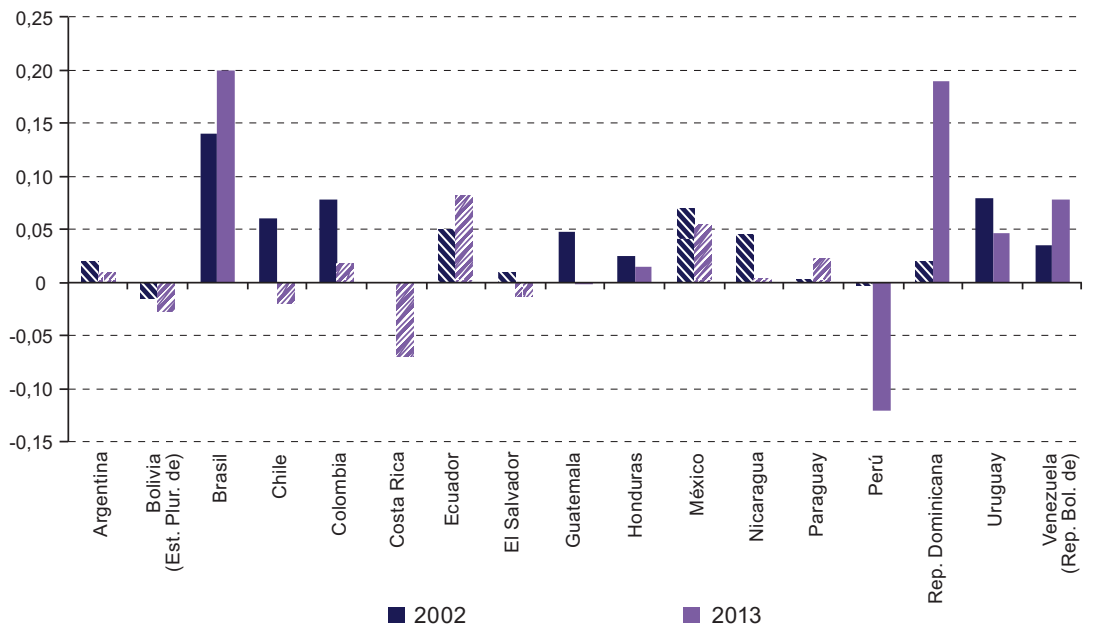

Fuente: Comisión Económica para América Latina y el Caribe (CEPAL), sobre la base de tabulaciones especiales de las encuestas de hogares de los respectivos países.

a Mujer=1. Los colores con trama indican los coeficientes no estadísticamente significativos (a un nivel de confianza del 99\%).

\section{Gráfico III.8}

América Latina (17 países): efecto marginal del tramo etario sobre la probabilidad de afiliación a sistemas de pensiones, alrededor de 2013

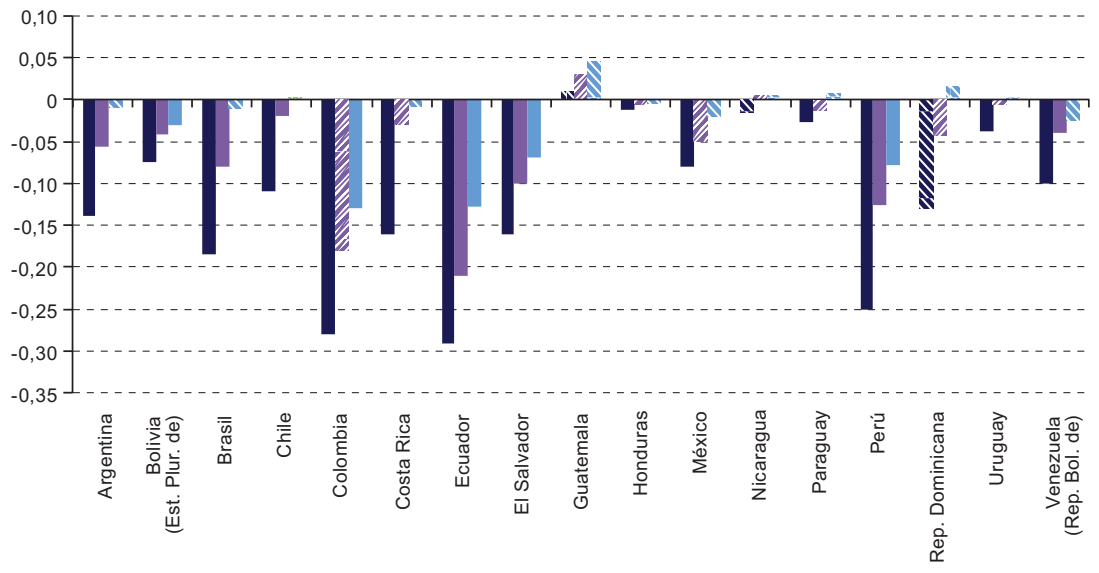

ロ 15 a 24 años $\quad 25$ a 34 años $\quad 35$ a 54 años

Fuente: Comisión Económica para América Latina y el Caribe (CEPAL), sobre la base de tabulaciones especiales de las encuestas de hogares de los respectivos países.

a La categoría de referencia es de 55 a 64 años. Los colores con trama indican los coeficientes no estadísticamente significativos (a un nivel de confianza del 99\%). 
El nivel educativo de los trabajadores influye en la probabilidad de afiliación (véase el gráfico III.9). Los trabajadores de niveles educativos inferiores presentan menores probabilidades de afiliación en todos los países, pero sobre todo en Colombia, el Ecuador, El Salvador y el Perú. En Chile, Guatemala, Honduras, Nicaragua y el Uruguay, las diferencias entre los niveles educativos menores y superiores no son tan claras.

\section{Gráfico III.9}

América Latina (17 países): efecto marginal del nivel educativo sobre la probabilidad de afiliación a sistemas de pensiones, alrededor de 2002

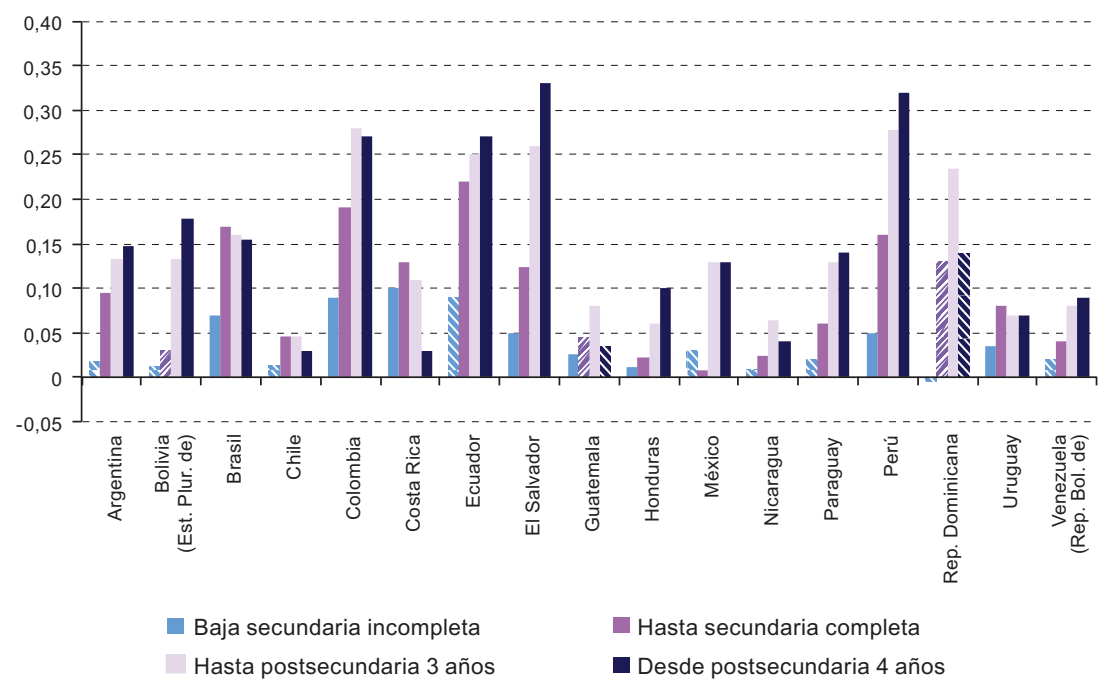

Fuente: Comisión Económica para América Latina y el Caribe (CEPAL), sobre la base de tabulaciones especiales de las encuestas de hogares de los respectivos países.

a Los colores con trama indican los coeficientes no estadísticamente significativos (a un nivel de confianza del 99\%).

Por otra parte, los trabajadores que son jefes de hogar tienen más probabilidades de afiliación en la mayoría de los países, especialmente en el Brasil, Chile, Colombia, Costa Rica, el Perú y Venezuela (República Bolivariana de). Cuando se desglosa por sexo, no obstante, es muy significativo el efecto negativo que tiene ser jefa de hogar para la afiliación de las mujeres, lo que se suma a su vulnerabilidad en términos de ingresos y de mayor incidencia de la pobreza (véase el gráfico III.10). 
Gráfico III.10

América Latina (17 países): efecto marginal de la jefatura de hogar sobre la probabilidad de afiliación a sistemas de pensiones, alrededor de 2002 y $2013^{a}$

A. Jefe de hogar

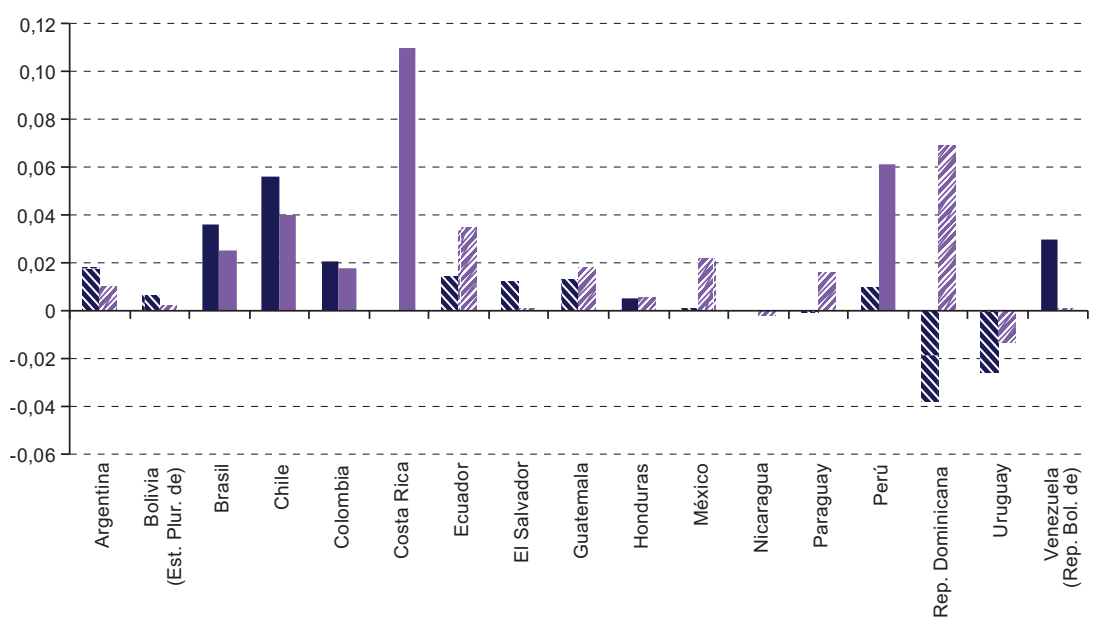

B. Jefa de hogar

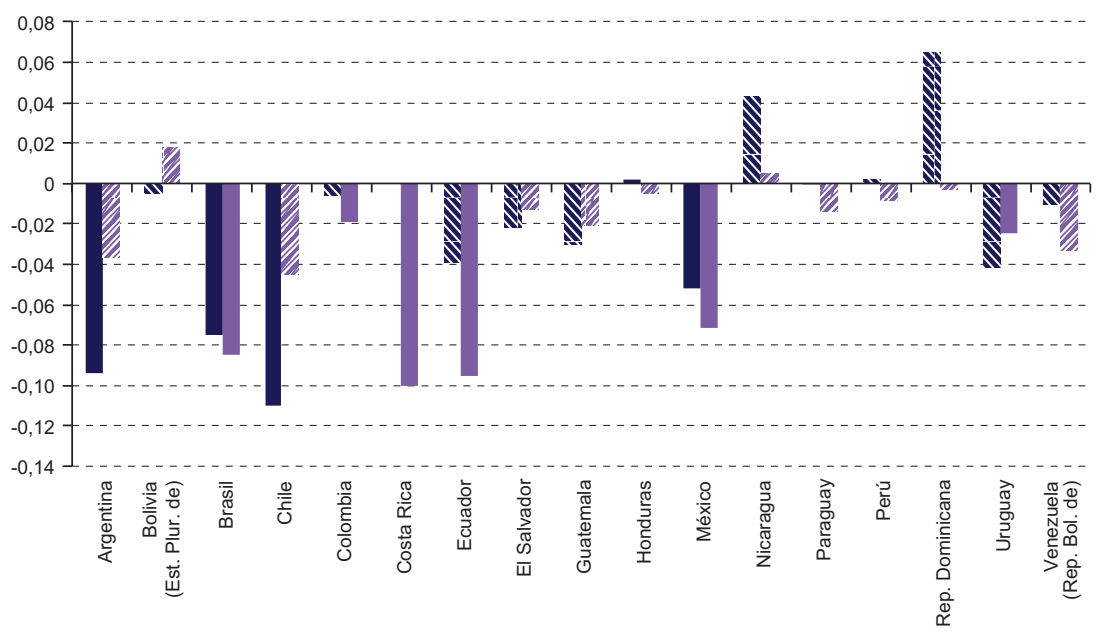

$\mathbf{2 0 0 2}$

2013

Fuente: Comisión Económica para América Latina y el Caribe (CEPAL), sobre la base de tabulaciones especiales de las encuestas de hogares de los respectivos países.

a Los colores con trama indican los coeficientes no estadísticamente significativos (a un nivel de confianza del $99 \%)$. 


\section{La evasión contributiva}

La protección social contributiva se financia con el aporte efectivo de los empleados, los empleadores y los trabajadores por cuenta propia que se encuentren registrados; el caso chileno, en que los empleadores no contribuyen para las pensiones, es excepcional.

El incumplimiento - que puede denominarse "evasión contributiva" es crucial, ya que incide en los beneficios y en la sostenibilidad financiera de los sistemas. No necesariamente lleva a la informalidad, pero generalmente se traduce en una reducción del grado de protección efectiva. Mientras que en el caso de las pensiones esto se debe al vínculo de las tasas de reemplazo con las contribuciones, en el caso de las prestaciones de salud puede conducir a exclusiones. En suma, puede llevar a exclusiones o incidir negativamente en la provisión o en la suficiencia de las prestaciones que reciben las personas.

La evasión o elusión contributivas ocurren cuando empleadores o empleados incumplen el pago de las contribuciones de la seguridad social: los trabajadores al aceptar de manera voluntaria o bajo presión empleos que no están cubiertos por los sistemas de protección social y los empleadores al usar resquicios legales y reestructurar la forma de contratación y remuneración para no registrar a sus empleados. Esto último se hace mediante mecanismos muy diversos, como argumentar que sus empleados son contratistas, extender la jornada laboral de los empleados, reducir los ingresos gravados mediante el aumento de la parte no gravable de las remuneraciones o compensar a los empleados con beneficios en especie o contribuciones especiales. Para que esto ocurra deben darse tres condiciones simultáneas: i) los empleados deben preferir que no se paguen las contribuciones (pese a que dejan de recibir beneficios) o aceptarlo bajo coerción, deben mostrarse reacios a informar situaciones de incumplimiento a las autoridades del Estado o deben, de manera involuntaria, ignorar que sus empleadores incurren en esa evasión cuando reciben información falsa, incompleta o confusa mediante sus sistemas de pago; ii) los empleadores o patrones deben tener la motivación necesaria para evadir o menospreciar el pago de contribuciones de la seguridad social en relación con otros gastos y costos, y iii) el control del gobierno debe tolerar dichas modalidades de evasión o ser inadecuado para prevenirlas, identificarlas y castigarlas (Gómez Sabaini, Cetrángolo y Morán, 2014, págs. 20 y 23).

El incumplimiento contributivo puede adquirir magnitudes importantes, tal como lo demuestra el cálculo realizado por Gómez Sabaini, Cetrángolo y Morán para tres países (la Argentina, Colombia y el Perú). Los autores utilizan información proveniente de cuentas nacionales, con una metodología con la que se busca determinar la brecha de recaudación monetaria que surge de comparar la recaudación teórica estimada y la 
efectivamente ingresada, adaptada a la disponibilidad estadística y a los parámetros de cada sistema contributivo (Gómez Sabaini, Cetrángolo y Morán, 2014, pág. 66) (véase el cuadro III.8).

Cuadro III.8

Argentina, Colombia y Perú: estimaciones sobre incumplimiento contributivo de los trabajadores asalariados, 2007 y 2010

\begin{tabular}{lccc}
\hline & $\begin{array}{c}\text { Argentina } \\
(2007)\end{array}$ & $\begin{array}{c}\text { Colombia } \\
(2010)\end{array}$ & $\begin{array}{c}\text { Perú } \\
(2007)\end{array}$ \\
\hline $\begin{array}{l}\text { Tasas de contribución } \\
\text { (en porcentajes) }\end{array}$ & & & \\
\hline \multicolumn{1}{c}{ Pensiones } & 16,2 & 16,0 & 13,0 \\
\hline Salud & 10,8 & 12,5 & 9,0 \\
\hline$\quad$ Total & 27,0 & 28,5 & 22,0 \\
\hline $\begin{array}{l}\text { Tasa de incumplimiento }{ }^{\text {a }} \\
\text { (en porcentajes) }\end{array}$ & & & 45,5 \\
\hline$\quad$ Pensiones & 21,5 & 46,1 \\
\hline$\quad$ Salud & 21,5 & 30,0 & 45,8 \\
\hline$\quad$ Total & 21,5 & 30,0 & \\
\hline $\begin{array}{l}\text { Tasa de incumplimiento } \\
\text { (en porcentajes del PIB) }\end{array}$ & & 30,0 & 1,63 \\
\hline$\quad$ Pensiones & 0,89 & & 1,13 \\
\hline$\quad$ Salud & 0,59 & 1,67 & 2,76 \\
\hline$\quad$ Total & 1,48 & 1,31 & \\
\hline
\end{tabular}

Fuente: J.C. Gómez Sabaini, O. Cetrángolo y D. Morán, "La evasión contributiva en la protección social de salud y pensiones. Un análisis para la Argentina, Colombia y el Perú", serie Políticas Sociales, № 208 (LC/L.3882), Santiago, Comisión Económica para América Latina y el Caribe (CEPAL), agosto, 2014.

a Como porcentaje de la recaudación teórica para el total de la economía (efectiva más potencial sin evasión).

Es crucial reducir la evasión contributiva para incrementar el financiamiento y la cobertura de la protección social así financiada. Además, se disminuiría la proporción de población que deba ser atendida con recursos de rentas generales, por las presiones que la evasión ejerce sobre la extensión de los pilares solidarios, o de otros mecanismos transitorios que implican erogaciones fiscales.

Hay diversas experiencias de tales presiones fiscales. En la Argentina, a lo largo de los años se han dado moratorias recurrentes a las deudas contributivas. La más reciente fue la moratoria previsional de 2005, una medida de emergencia que dio un acceso "facilitado" a quienes alcanzaron la edad de jubilación (o cumplieron con otros requisitos) sin tener los años de contribución. Esta medida es de carácter provisional, ya que los períodos a incluir deben ser previos al 30 de septiembre de 1993, no forma parte de un pilar solidario y benefició a más de dos millones de personas, con lo que se elevó notablemente la cobertura de pensionados (Bertranou y otros, 2011). 
En el conjunto de medidas para reducir la evasión se incluyen: mejorar la relación entre el aporte de los trabajadores y los beneficios que obtienen de los sistemas de seguro social; realizar campañas de educación y difusión para apreciar los beneficios del sistema; mejorar la administración de los sistemas para identificar rápida y fehacientemente el incumplimiento; simplificar la legislación y facilitar las formas de contribución; evaluar la posibilidad de unificar la administración tributaria con la de seguridad social, e incrementar, actualizar periódicamente y hacer efectiva y ágil la aplicación de penalidades y multas por incumplimiento. Es necesario controlar las modalidades de subcontratación que eluden el pago de las contribuciones y evitar que los propios gobiernos usen esa modalidad, con lo que dan un ejemplo muy negativo (como ocurre con el uso de los denominados contratos "por honorarios") (Gómez Sabaini, Cetrángolo y Morán, 2014, pág. 70).

\section{B. Una aproximación a las prestaciones de la protección social}

\section{Acceso a pensiones y suficiencia}

El acceso de las personas de 65 años y más a pensiones contributivas y su monto medio son indicadores de la suficiencia de estos ingresos, que, a su vez, son el resultado de las trayectorias laborales en términos del nivel de ingresos y la continuidad y densidad de las contribuciones, la capacidad de cotización voluntaria cuando esa modalidad existe y las dimensiones paramétricas aplicadas 5 . Estos mismos factores condicionan la desigualdad de los ingresos por concepto de pensiones.

Resalta, en primer lugar, la heterogeneidad en la región (véase el cuadro III.9). En 7 de los 16 países analizados, la proporción de personas de este tramo de edad con acceso a pensiones es relativamente baja o muy baja, y varía mucho de un país a otro (Honduras es el caso extremo). Con un rango diverso, la Argentina, el Brasil, Chile, Costa Rica, Panamá y el Uruguay son los países donde los adultos mayores están más protegidos. En seis de los países las pensiones registran alzas importantes.

Como edad de jubilación, densidad de cotizaciones requeridas y fórmulas actuariales de cálculo de los beneficios. 


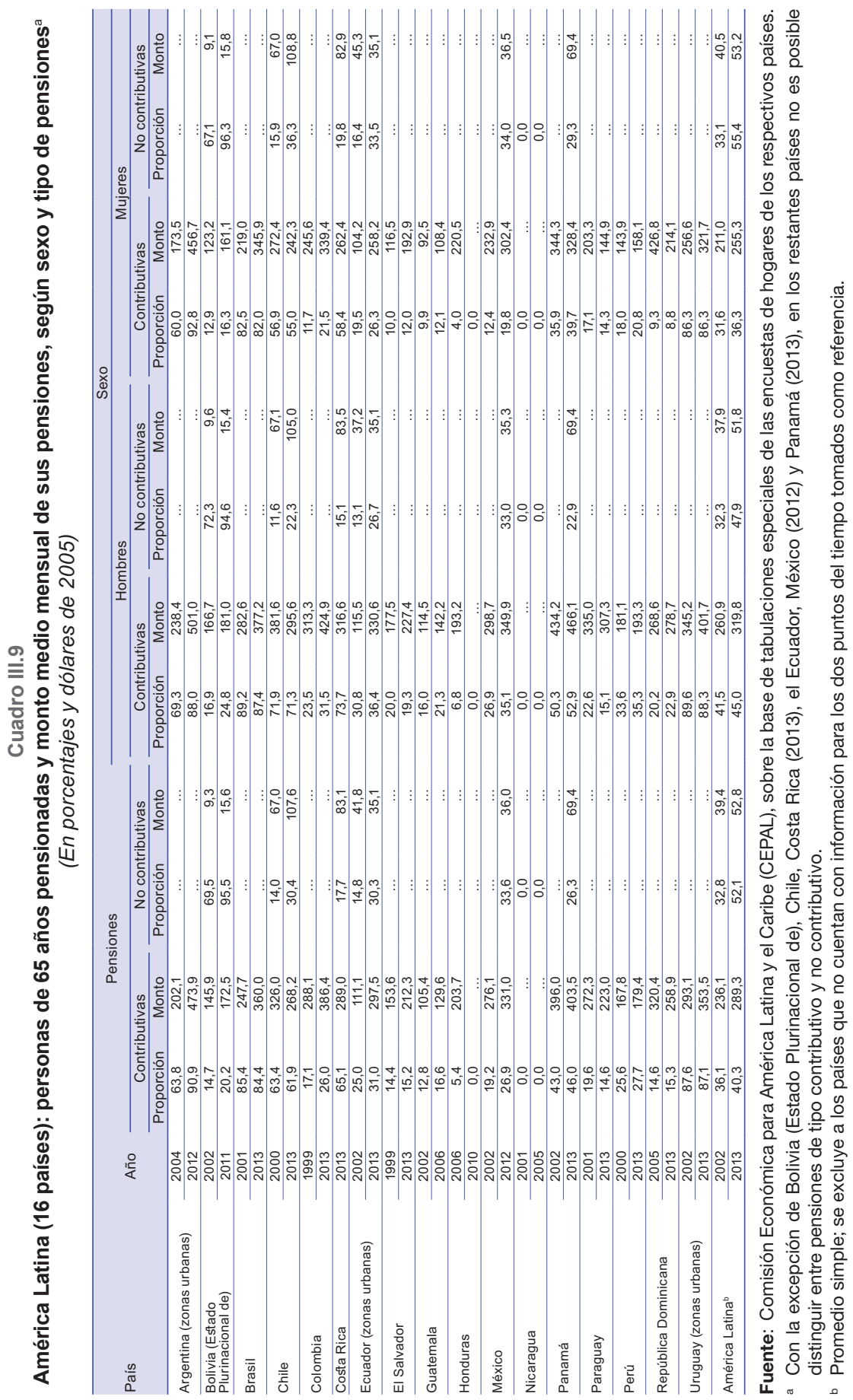


Con excepción de la Argentina en 2012, la proporción de mujeres pensionadas es menor que la de los hombres y el monto de sus pensiones también es sistemáticamente más bajo. Esta dimensión de la desigualdad está asociada a varios factores relacionados con el mercado de trabajo: desigualdades pretéritas de la inserción laboral, en términos de segmentaciones discriminatorias del mercado laboral, discriminaciones en ingresos y trayectorias laborales; discontinuidades en la trayectoria laboral, menor número de horas dedicadas al trabajo remunerado y mayores lagunas contributivas asociadas con ello, y dificultades para conciliar la vida laboral con las responsabilidades de cuidado que las mujeres asumen en el seno familiar debido a la ausencia de sistemas de cuidado y de políticas que permitan esa conciliación En parte también pueden ser producto de discriminaciones de los sistemas de pensiones; en Chile, por ejemplo, se discrimina a las mujeres en el cálculo actuarial de las pensiones debido a su mayor esperanza de vida.

La distribución desigual según quintiles de ingreso es mucho más extrema en los países con las coberturas de pensionados más bajas. En la Argentina, crece mucho la proporción de personas del quintil más pobre que reciben pensiones contributivas. Medido el monto de las pensiones en dólares de 2005, el quintil más pobre experimenta las mayores alzas en la Argentina. Las pensiones también suben en el Brasil, el Ecuador y el Uruguay, mientras que sufren retrocesos en tres países (en el caso de Chile estos afectan a todos los quintiles, excepto el IV) (véase el cuadro III.10).

En la región hay una diversidad de situaciones en lo que respecta al pilar no contributivo (cuadros III.9 y III.10). Como se verá en el capítulo V, la insuficiencia de las pensiones provocada por la privatización de los sistemas de pensiones ha originado presiones en algunos países para que crezca el pilar contributivo para los grupos de menores ingresos, originando cierta instrumentalización por su funcionalidad respecto de los sistemas orientados por el lucro. No obstante, el pilar no contributivo se ha introducido en una amplia gama de países: desde el Estado Plurinacional de Bolivia, que tiene una cobertura muy baja de pensiones contributivas, hasta Costa Rica, que presenta una cobertura contributiva superior.

Al comparar la cobertura de las pensiones no contributivas y su valor medio en seis países de la región, se observa que las pensiones solidarias de Chile son las más altas, seguidas por las de Costa Rica. Por su parte, el Estado Plurinacional de Bolivia presenta las pensiones no contributivas más bajas, pero la cobertura más alta, dado su carácter universal. En general, una proporción algo mayor de mujeres percibe este tipo de pensiones. La diferencia más grande se da en Chile, posiblemente debido al reconocimiento de las labores de cuidado. En valores constantes, los montos de las pensiones solidarias se han incrementado en Bolivia (Estado Plurinacional de) y Chile, mientras que en el Ecuador han decrecido. 


\section{América Latina (16 países): personas de 65 años pensionadas y monto promedio mensual de sus pensiones, según quintiles de ingresos per cápita y tipo de pensiones ${ }^{a}$ \\ (En porcentajes y dólares de 2005)}

\begin{tabular}{|c|c|c|c|c|c|c|c|c|c|}
\hline \multirow{4}{*}{ País } & \multirow{4}{*}{ Año } & \multirow{2}{*}{\multicolumn{4}{|c|}{ Pensiones }} & \multirow{2}{*}{\multicolumn{4}{|c|}{$\begin{array}{c}\text { Quintiles de ingreso per cápita } \\
\text { Quintil I }\end{array}$}} \\
\hline & & & & & & & & & \\
\hline & & \multicolumn{2}{|c|}{ Contributivas } & \multicolumn{2}{|c|}{ No contributivas } & \multicolumn{2}{|c|}{ Contributivas } & \multicolumn{2}{|c|}{ No contributivas } \\
\hline & & Proporción & Monto & Proporción & Monto & Proporción & Monto & Proporción & Monto \\
\hline \multirow{2}{*}{$\begin{array}{l}\text { Argentina } \\
\text { (zonas urbanas) }\end{array}$} & 2004 & 63,8 & 202,1 & $\ldots$ & $\ldots$ & 22,2 & 93,8 & $\ldots$ & $\ldots$ \\
\hline & 2012 & 90,9 & 473,9 & $\ldots$ & $\ldots$ & 72,0 & 291,9 & $\ldots$ & $\ldots$ \\
\hline \multirow{2}{*}{$\begin{array}{l}\text { Bolivia (Estado } \\
\text { Plurinacional de) }\end{array}$} & 2002 & 14,7 & 145,9 & 69,5 & 9,3 & $\ldots$ & $\ldots$ & 58,8 & 9,4 \\
\hline & 2011 & 20,2 & 172,5 & 95,5 & 15,6 & $\ldots$ & $\ldots$ & 93,0 & 16,5 \\
\hline \multirow[t]{2}{*}{ Brasil } & 2001 & 85,4 & 247,7 & $\ldots$ & $\ldots$ & 45,4 & 104,6 & $\ldots$ & $\ldots$ \\
\hline & 2013 & 84,4 & 360,0 & $\ldots$ & $\ldots$ & 27,3 & 188,3 & $\ldots$ & $\ldots$ \\
\hline \multirow[t]{2}{*}{ Chile } & 2000 & 63,4 & 326,0 & 14,0 & 67,0 & 38,4 & 177,3 & 27,0 & 67,0 \\
\hline & 2013 & 61,9 & 268,2 & 30,4 & 107,6 & 43,4 & 156,7 & 41,2 & 107,8 \\
\hline \multirow[t]{2}{*}{ Colombia } & 1999 & 17,1 & 288,1 & $\ldots$ & $\ldots$ & 0,1 & 142,7 & $\ldots$ & $\ldots$ \\
\hline & 2013 & 26,0 & 386,4 & $\ldots$ & $\ldots$ & 0,7 & 162,0 & $\ldots$ & $\ldots$ \\
\hline Costa Rica & 2013 & 65,1 & 289,0 & 17,7 & 83,1 & 45,5 & 59,9 & 29,4 & 82,8 \\
\hline \multirow{2}{*}{$\begin{array}{l}\text { Ecuador } \\
\text { (zonas urbanas) }\end{array}$} & 2002 & 25,0 & 111,1 & 14,8 & 41,8 & 9,6 & 51,3 & 21,7 & 8,8 \\
\hline & 2013 & 31,0 & 297,5 & 30,3 & 35,1 & 2,1 & 109,4 & 54,5 & 35,1 \\
\hline \multirow[t]{2}{*}{ EI Salvador } & 1999 & 14,4 & 153,6 & $\ldots$ & $\ldots$ & 5,3 & 82,8 & $\ldots$ & $\ldots$ \\
\hline & 2013 & 15,2 & 212,3 & $\ldots$ & $\ldots$ & 3,2 & 94,8 & $\ldots$ & $\ldots$ \\
\hline \multirow[t]{2}{*}{ Guatemala } & 2002 & 12,8 & 105,4 & $\ldots$ & $\ldots$ & 3,0 & 92,6 & $\ldots$ & $\ldots$ \\
\hline & 2006 & 16,6 & 129,6 & $\ldots$ & $\ldots$ & 1,6 & 35,8 & $\ldots$ & $\ldots$ \\
\hline \multirow[t]{2}{*}{ Honduras } & 2006 & 5,4 & 203,7 & $\ldots$ & $\ldots$ & 0,0 & $\ldots$ & $\ldots$ & $\ldots$ \\
\hline & 2010 & 0,0 & $\ldots$ & $\ldots$ & $\ldots$ & 0,0 & $\ldots$ & $\ldots$ & $\ldots$ \\
\hline \multirow[t]{2}{*}{ México } & 2002 & 19,2 & 276,1 & $\ldots$ & $\ldots$ & 3,5 & 133,3 & $\ldots$ & $\ldots$ \\
\hline & 2012 & 26,9 & 331,0 & 33,6 & 36,0 & 5,5 & 116,2 & 47,4 & 32,7 \\
\hline \multirow[t]{2}{*}{ Nicaragua } & 2001 & 0,0 & $\ldots$ & 0,0 & $\ldots$ & 0,0 & $\ldots$ & 0,0 & $\ldots$ \\
\hline & 2005 & 0,0 & $\ldots$ & 0,0 & $\ldots$ & 0,0 & $\ldots$ & 0,0 & $\ldots$ \\
\hline \multirow[t]{2}{*}{ Panamá } & 2002 & 43,0 & 396,0 & $\ldots$ & $\ldots$ & 5,4 & 131,2 & $\ldots$ & $\ldots$ \\
\hline & 2013 & 46,0 & 403,5 & 26,3 & 69,4 & 9,6 & 126,5 & 36,1 & 69,4 \\
\hline \multirow[t]{2}{*}{ Paraguay } & 2001 & 19,6 & 272,3 & $\ldots$ & $\ldots$ & 0,9 & 75,7 & $\ldots$ & $\ldots$ \\
\hline & 2013 & 14,6 & 223,0 & $\ldots$ & $\ldots$ & 0,8 & 66,6 & $\ldots$ & $\ldots$ \\
\hline \multirow[t]{2}{*}{ Perú } & 2000 & 25,6 & 167,8 & $\ldots$ & $\ldots$ & 1,6 & 78,1 & $\ldots$ & $\ldots$ \\
\hline & 2013 & 27,7 & 179,4 & $\ldots$ & $\ldots$ & 1,8 & 84,3 & $\ldots$ & $\ldots$ \\
\hline \multirow{2}{*}{$\begin{array}{l}\text { República } \\
\text { Dominicana }\end{array}$} & 2005 & 14,6 & 320,4 & $\ldots$ & $\ldots$ & 3,7 & 76,1 & $\ldots$ & $\ldots$ \\
\hline & 2013 & 15,3 & 258,9 & $\ldots$ & $\ldots$ & 4,8 & 98,9 & $\ldots$ & $\ldots$ \\
\hline \multirow{2}{*}{$\begin{array}{l}\text { Uruguay } \\
\text { (zonas urbanas) }\end{array}$} & 2002 & 87,6 & 293,1 & $\ldots$ & $\ldots$ & 76,4 & 125,7 & $\ldots$ & $\ldots$ \\
\hline & 2013 & 87,1 & 353,5 & $\ldots$ & $\ldots$ & 71,2 & 159,6 & $\ldots$ & $\ldots$ \\
\hline \multirow[t]{2}{*}{ América Latina $^{b}$} & 2002 & 36,1 & 236,1 & 32,8 & 39,4 & 46,5 & 256,5 & 35,9 & 28,4 \\
\hline & 2013 & 40,3 & 289,3 & 52,1 & 52,8 & 54,6 & 291,5 & 62,9 & 53,1 \\
\hline
\end{tabular}


Cuadro III.10 (continuación)

\begin{tabular}{|c|c|c|c|c|c|c|c|c|c|}
\hline \multirow{4}{*}{ País } & \multirow{4}{*}{ Año } & \multicolumn{8}{|c|}{ Quintiles de ingreso per cápita } \\
\hline & & \multicolumn{4}{|c|}{ Quintil II } & \multicolumn{4}{|c|}{ Quintil III } \\
\hline & & \multicolumn{2}{|c|}{ Contributivas } & \multicolumn{2}{|c|}{ No contributivas } & \multicolumn{2}{|c|}{ Contributivas } & \multicolumn{2}{|c|}{ No contributivas } \\
\hline & & Proporción & Monto & Proporción & Monto & Proporción & Monto & Proporción & Monto \\
\hline \multirow{2}{*}{$\begin{array}{l}\text { Argentina } \\
\text { (zonas urbanas) }\end{array}$} & 2004 & 54,5 & 121,7 & $\cdots$ & $\ldots$ & 70,6 & 136,0 & $\ldots$ & $\ldots$ \\
\hline & 2012 & 91,9 & 327,8 & $\ldots$ & $\cdots$ & 95,8 & 384,5 & $\cdots$ & $\cdots$ \\
\hline \multirow{2}{*}{$\begin{array}{l}\text { Bolivia (Estado } \\
\text { Plurinacional de) }\end{array}$} & 2002 & 0,2 & 81,3 & 74,5 & 9,4 & 7,1 & 84,9 & 70,7 & 9,2 \\
\hline & 2011 & 2,5 & 116,6 & 98,3 & 16,4 & 10,5 & 128,3 & 96,5 & 16,0 \\
\hline \multirow[t]{2}{*}{ Brasil } & 2001 & 79,6 & 108,7 & $\cdots$ & $\cdots$ & 84,6 & 115,1 & $\cdots$ & $\cdots$ \\
\hline & 2013 & 71,1 & 194,8 & $\cdots$ & $\ldots$ & 77,2 & 213,7 & $\ldots$ & $\ldots$ \\
\hline \multirow[t]{2}{*}{ Chile } & 2000 & 56,9 & 188,9 & 20,8 & 67,0 & 59,3 & 210,1 & 18,1 & 67,0 \\
\hline & 2013 & 52,3 & 174,9 & 41,9 & 110,3 & 64,0 & 202,3 & 33,8 & 105,0 \\
\hline \multirow[t]{2}{*}{ Colombia } & 1999 & 3,7 & 151,7 & $\cdots$ & $\cdots$ & 9,5 & 166,1 & $\cdots$ & $\cdots$ \\
\hline & 2013 & 5,3 & 181,0 & $\ldots$ & $\ldots$ & 14,7 & 200,1 & $\ldots$ & $\ldots$ \\
\hline Costa Rica & 2013 & 68,0 & 81,1 & 35,9 & 83,7 & 67,4 & 147,4 & 16,4 & 82,9 \\
\hline \multirow{2}{*}{$\begin{array}{l}\text { Ecuador } \\
\text { (zonas urbanas) }\end{array}$} & 2002 & 15,8 & 76,6 & 17,5 & 38,5 & 24,6 & 99,1 & 15,2 & 8,8 \\
\hline & 2013 & 13,1 & 136,3 & 51,7 & 35,1 & 18,8 & 215,5 & 39,1 & 35,1 \\
\hline \multirow[t]{2}{*}{ EI Salvador } & 1999 & 6,9 & 106,6 & $\ldots$ & $\ldots$ & 13,8 & 109,8 & $\ldots$ & $\ldots$ \\
\hline & 2013 & 5,9 & 109,9 & $\ldots$ & $\ldots$ & 8,3 & 131,7 & $\ldots$ & $\ldots$ \\
\hline \multirow[t]{2}{*}{ Guatemala } & 2002 & 3,5 & 55,0 & $\ldots$ & $\ldots$ & 18,8 & 42,1 & $\ldots$ & $\ldots$ \\
\hline & 2006 & 8,0 & 44,4 & $\ldots$ & $\ldots$ & 9,0 & 49,4 & $\ldots$ & $\cdots$ \\
\hline \multirow[t]{2}{*}{ Honduras } & 2006 & 1,2 & 31,7 & $\ldots$ & $\ldots$ & 3,1 & 45,8 & $\ldots$ & $\ldots$ \\
\hline & 2010 & 0,0 & $\ldots$ & $\ldots$ & $\cdots$ & 0,0 & $\ldots$ & $\ldots$ & $\ldots$ \\
\hline \multirow[t]{2}{*}{ México } & 2002 & 11,0 & 135,9 & $\ldots$ & $\ldots$ & 20,9 & 156,5 & $\ldots$ & $\cdots$ \\
\hline & 2012 & 14,5 & 141,3 & 41,4 & 33,5 & 21,9 & 156,2 & 37,0 & 34,2 \\
\hline \multirow[t]{2}{*}{ Nicaragua } & 2001 & 0,0 & $\ldots$ & 0,0 & $\ldots$ & 0,0 & $\ldots$ & 0,0 & $\ldots$ \\
\hline & 2005 & 0,0 & $\ldots$ & 0,0 & $\ldots$ & 0,0 & $\ldots$ & 0,0 & $\ldots$ \\
\hline \multirow[t]{2}{*}{ Panamá } & 2002 & 20,8 & 171,3 & $\ldots$ & $\ldots$ & 40,8 & 238,8 & $\ldots$ & $\ldots$ \\
\hline & 2013 & 27,2 & 154,0 & 46,9 & 69,4 & 46,0 & 207,0 & 28,5 & 69,4 \\
\hline \multirow[t]{2}{*}{ Paraguay } & 2001 & 3,0 & 126,0 & $\cdots$ & $\cdots$ & 10,7 & 142,0 & $\cdots$ & $\cdots$ \\
\hline & 2013 & 7,1 & 106,7 & $\ldots$ & $\cdots$ & 14,5 & 110,7 & $\ldots$ & $\cdots$ \\
\hline \multirow[t]{2}{*}{ Perú } & 2000 & 7,3 & 102,3 & $\ldots$ & $\cdots$ & 17,4 & 106,0 & $\ldots$ & $\ldots$ \\
\hline & 2013 & 10,7 & 105,5 & $\ldots$ & $\ldots$ & 24,0 & 127,3 & $\ldots$ & $\ldots$ \\
\hline \multirow{2}{*}{$\begin{array}{l}\text { República } \\
\text { Dominicana }\end{array}$} & 2005 & 12,4 & 95,9 & $\ldots$ & $\ldots$ & 18,6 & 106,4 & $\ldots$ & $\ldots$ \\
\hline & 2013 & 10,2 & 118,0 & $\ldots$ & $\cdots$ & 21,9 & 125,7 & $\ldots$ & $\cdots$ \\
\hline \multirow{2}{*}{$\begin{array}{l}\text { Uruguay } \\
\text { (zonas urbanas) }\end{array}$} & 2002 & 84,9 & 149,4 & $\ldots$ & $\ldots$ & 86,2 & 172,8 & $\ldots$ & $\cdots$ \\
\hline & 2013 & 84,9 & 181,8 & $\ldots$ & $\cdots$ & 88,1 & 214,4 & $\cdots$ & $\cdots$ \\
\hline América Latina ${ }^{b}$ & 2002 & 32,3 & 73,0 & 37,6 & 38,3 & 31,6 & 211,0 & 34,7 & 28,4 \\
\hline & 2013 & 39,9 & 52,0 & 64,0 & 53,9 & 36,3 & 255,3 & 56,5 & 52,0 \\
\hline
\end{tabular}


Cuadro III.10 (conclusión)

\begin{tabular}{|c|c|c|c|c|c|c|c|c|c|}
\hline \multirow{4}{*}{ País } & \multirow{4}{*}{ Año } & \multicolumn{8}{|c|}{ Quintiles de ingreso per cápita } \\
\hline & & \multicolumn{4}{|c|}{ Quintil IV } & \multicolumn{4}{|c|}{ Quintil V } \\
\hline & & \multicolumn{2}{|c|}{ Contributivas } & \multicolumn{2}{|c|}{ No contributivas } & \multicolumn{2}{|c|}{ Contributivas } & \multicolumn{2}{|c|}{ No contributivas } \\
\hline & & Proporción & Monto & Proporción & Monto & Proporción & Monto & Proporción & Monto \\
\hline \multirow{2}{*}{$\begin{array}{l}\text { Argentina } \\
\text { (zonas urbanas) }\end{array}$} & 2004 & 75,4 & 187,6 & $\ldots$ & $\ldots$ & 70,8 & 351,1 & $\ldots$ & $\ldots$ \\
\hline & 2012 & 92,6 & 505,0 & $\ldots$ & $\ldots$ & 86,2 & 740,5 & $\ldots$ & $\ldots$ \\
\hline \multirow{2}{*}{$\begin{array}{l}\text { Bolivia (Estado } \\
\text { Plurinacional de) }\end{array}$} & 2002 & 15,7 & 107,1 & 70,7 & 9,5 & 41,7 & 164,4 & 72,6 & 9,2 \\
\hline & 2011 & 27,7 & 150,1 & 97,2 & 15,3 & 41,2 & 188,4 & 94,1 & 14,7 \\
\hline \multirow[t]{2}{*}{ Brasil } & 2001 & 90,4 & 132,3 & $\ldots$ & $\ldots$ & 85,9 & 502,1 & $\ldots$ & $\ldots$ \\
\hline & 2013 & 91,8 & 224,6 & $\ldots$ & $\ldots$ & 89,9 & 631,4 & $\ldots$ & $\ldots$ \\
\hline \multirow[t]{2}{*}{ Chile } & 2000 & 70,3 & 255,1 & 13,2 & 67,1 & 67,9 & 556,0 & 5,5 & 67,3 \\
\hline & 2013 & 69,3 & 260,5 & 25,4 & 105,9 & 72,4 & 472,6 & 12,2 & 110,6 \\
\hline \multirow[t]{2}{*}{ Colombia } & 1999 & 19,2 & 189,4 & $\ldots$ & $\ldots$ & 38,8 & 355,8 & $\ldots$ & $\ldots$ \\
\hline & 2013 & 31,0 & 232,9 & $\ldots$ & $\ldots$ & 53,8 & 494,1 & $\ldots$ & $\ldots$ \\
\hline Costa Rica & 2013 & 64,2 & 236,8 & 10,2 & 82,5 & 74,2 & 691,4 & 2,5 & 83,2 \\
\hline \multirow{2}{*}{$\begin{array}{l}\text { Ecuador } \\
\text { (zonas urbanas) }\end{array}$} & 2002 & 31,5 & 96,4 & 12,3 & 45,7 & 40,0 & 148,9 & 8,6 & 161,6 \\
\hline & 2013 & 29,7 & 253,1 & 27,5 & 35,2 & 63,4 & 349,9 & 4,1 & 35,1 \\
\hline \multirow[t]{2}{*}{ EI Salvador } & 1999 & 14,7 & 134,6 & $\ldots$ & $\ldots$ & 29,0 & 203,3 & $\ldots$ & $\ldots$ \\
\hline & 2013 & 14,4 & 166,5 & $\ldots$ & $\ldots$ & 34,8 & 259,1 & $\ldots$ & $\ldots$ \\
\hline \multirow[t]{2}{*}{ Guatemala } & 2002 & 14,0 & 65,8 & $\ldots$ & $\ldots$ & 18,0 & 176,8 & $\ldots$ & $\ldots$ \\
\hline & 2006 & 17,1 & 82,6 & $\ldots$ & $\ldots$ & 33,1 & 176,5 & $\ldots$ & $\ldots$ \\
\hline \multirow[t]{2}{*}{ Honduras } & 2006 & 5,3 & 92,4 & $\ldots$ & $\ldots$ & 15,4 & 281,4 & $\ldots$ & $\ldots$ \\
\hline & 2010 & 0,0 & $\ldots$ & $\ldots$ & $\ldots$ & 0,0 & $\ldots$ & $\ldots$ & $\ldots$ \\
\hline \multirow[t]{2}{*}{ México } & 2002 & 23,2 & 209,3 & $\ldots$ & $\ldots$ & 30,0 & 439,9 & $\ldots$ & $\ldots$ \\
\hline & 2012 & 31,5 & 217,0 & 29,9 & 37,9 & 47,1 & 506,5 & 21,0 & 43,3 \\
\hline \multirow[t]{2}{*}{ Nicaragua } & 2001 & 0,0 & $\ldots$ & 0,0 & $\ldots$ & 0,0 & $\ldots$ & 0,0 & $\ldots$ \\
\hline & 2005 & 0,0 & $\ldots$ & 0,0 & $\ldots$ & 0,0 & $\ldots$ & 0,0 & $\ldots$ \\
\hline \multirow[t]{2}{*}{ Panamá } & 2002 & 55,2 & 307,6 & $\ldots$ & $\ldots$ & 68,4 & 561,9 & $\ldots$ & $\ldots$ \\
\hline & 2013 & 58,5 & 269,9 & 17,8 & 69,4 & 74,8 & 702,4 & 6,5 & 69,4 \\
\hline \multirow[t]{2}{*}{ Paraguay } & 2001 & 25,6 & 179,3 & $\ldots$ & $\ldots$ & 39,8 & 350,9 & $\ldots$ & $\ldots$ \\
\hline & 2013 & 23,6 & 158,2 & $\ldots$ & $\ldots$ & 27,3 & 362,5 & $\ldots$ & $\ldots$ \\
\hline \multirow[t]{2}{*}{ Perú } & 2000 & 30,6 & 139,9 & $\ldots$ & $\ldots$ & 49,0 & 201,0 & $\ldots$ & $\ldots$ \\
\hline & 2013 & 38,4 & 143,1 & $\ldots$ & $\ldots$ & 54,3 & 226,0 & $\ldots$ & $\ldots$ \\
\hline \multirow{2}{*}{$\begin{array}{l}\text { República } \\
\text { Dominicana }\end{array}$} & 2005 & 14,0 & 129,2 & $\ldots$ & $\ldots$ & 29,1 & 696,7 & $\ldots$ & $\ldots$ \\
\hline & 2013 & 16,7 & 192,3 & $\ldots$ & $\ldots$ & 23,0 & 515,2 & $\ldots$ & $\ldots$ \\
\hline \multirow{2}{*}{$\begin{array}{l}\text { Uruguay } \\
\text { (zonas urbanas) }\end{array}$} & 2002 & 89,5 & 229,8 & $\ldots$ & $\ldots$ & 88,9 & 483,8 & $\ldots$ & $\ldots$ \\
\hline & 2013 & 89,8 & 289,3 & $\ldots$ & $\ldots$ & 87,6 & 607,9 & $\ldots$ & $\ldots$ \\
\hline América Latina ${ }^{\mathrm{b}}$ & 2002 & 40,7 & 168,8 & 32,1 & 40,8 & 49,8 & 370,9 & 28,9 & 79,4 \\
\hline & 2013 & 45,1 & 224,7 & 50,0 & 52,1 & 56,4 & 445,2 & 36,8 & 53,5 \\
\hline
\end{tabular}

Fuente: Comisión Económica para América Latina y el Caribe (CEPAL), sobre la base de tabulaciones especiales de las encuestas de hogares de los respectivos países.

a Con la excepción de Bolivia (Estado Plurinacional de), Chile, Costa Rica (2013), Ecuador, México (2012) y Panamá (2013), en los restantes países no es posible distinguir entre pensiones de tipo contributivo y no contributivo.

b Promedio simple; se excluye a los países que no cuentan con información para los dos puntos del tiempo tomados como referencia. 


\section{Inserción laboral y cobertura de salud de las personas mayores de 65 años}

La inserción laboral de las personas de 65 años y más puede ser un indicio de la cobertura y la suficiencia de las pensiones. Aunque pueden estar en juego razones como la autorrealización, la inserción de estas personas en el mercado de trabajo puede evidenciar una insuficiencia de las pensiones o una desprotección de esta franja etaria.

Se observa que un contingente importante de personas trabaja y recibe una pensión en países con niveles medios de pensiones muy diversos. Por otra parte, en varios países, las personas mayores de 65 años que trabajan no reciben pensiones ni están afiliadas a los sistemas de pensiones; el universo que está afiliado es muy reducido. Este perfil evidencia la necesidad de trabajar para obtener ingresos al haber quedado excluidos de los sistemas. La desvinculación de los sistemas de pensiones es un poco mayor entre las mujeres mayores de 65 años que trabajan (véase el gráfico III.11).

Gráfico III.11

América Latina (18 países): vínculo con el sistema de pensiones, personas ocupadas de 65 años y más, 2013

(En porcentajes)

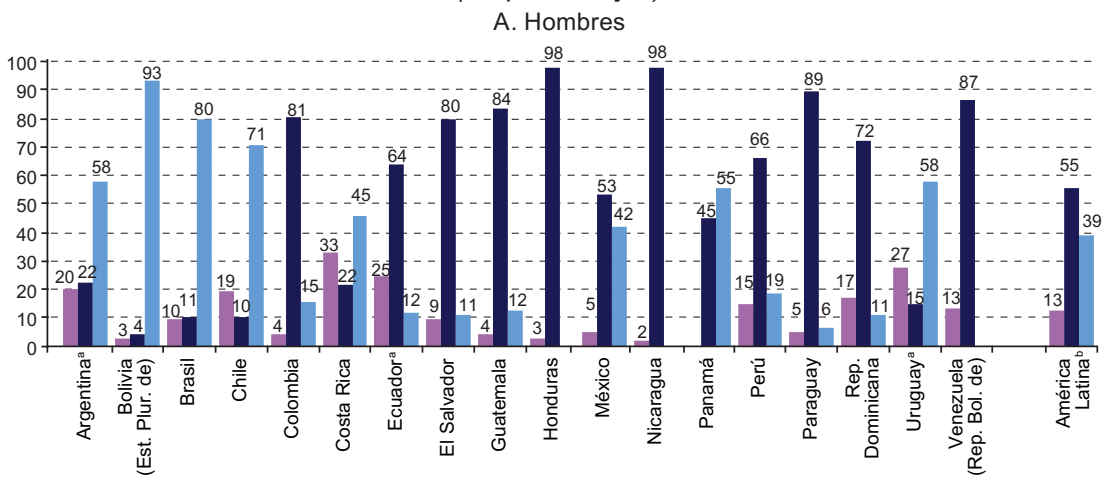

B. Mujeres

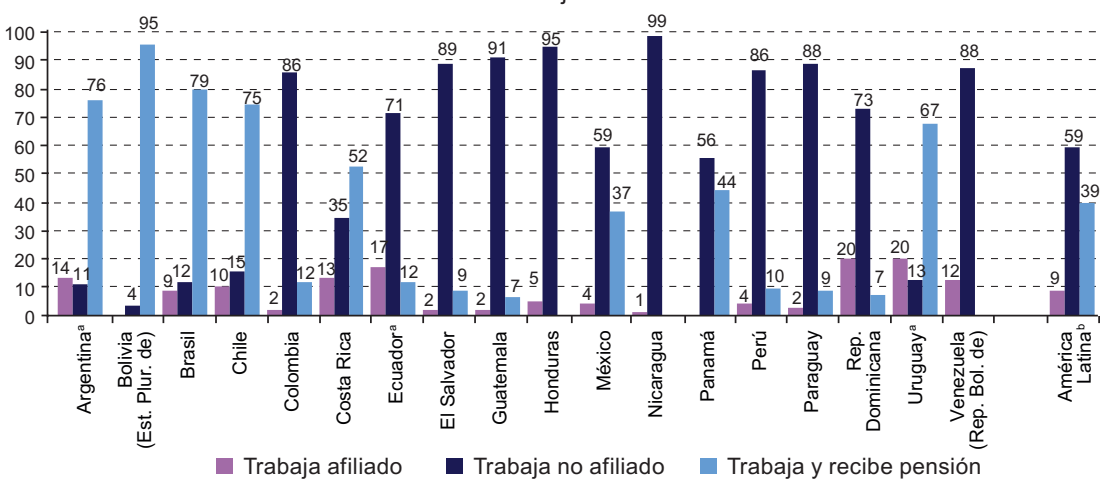

Fuente: Elaboración propia, sobre la base de tabulaciones especiales de las encuestas de hogares de los respectivos países.

a Zonas urbanas.

b Promedio simple de los países. 
Al considerar de manera agregada a las personas pensionadas, sin distinciones entre pensiones contributivas y no contributivas, destaca su alto porcentaje en los países comparados, incluso cuando la cobertura global de la población es más baja. Con solo una excepción, la afiliación a los sistemas de salud se ha incrementado en el período (véase el cuadro III.11).

\section{Cuadro III.11 \\ Brasil: tipo de aseguramiento y de prestador de las personas atendidas por razones de salud en las dos semanas previas a la Encuesta Nacional de Hogares, por sexo, 2008 \\ (En porcentajes)}

A. Población en general

\begin{tabular}{|c|c|c|c|c|c|c|c|c|c|c|}
\hline & \multirow{2}{*}{\multicolumn{2}{|c|}{$\begin{array}{l}\text { Atención } \\
\text { de salud }\end{array}$}} & \multirow{2}{*}{\multicolumn{2}{|c|}{$\begin{array}{l}\text { Cobertura de } \\
\text { plan de salud }\end{array}$}} & \multirow{2}{*}{\multicolumn{2}{|c|}{$\begin{array}{l}\text { Cobertura del } \\
\text { Sistema Único de } \\
\text { Salud (SUS) }\end{array}$}} & \multicolumn{4}{|c|}{ Prestador } \\
\hline & & & & & & & \multicolumn{2}{|c|}{ Público } & \multicolumn{2}{|c|}{ Privado } \\
\hline & 2003 & 2008 & 2003 & 2008 & 2003 & 2008 & 2003 & 2008 & 2003 & 2008 \\
\hline \multicolumn{11}{|l|}{ Sexo } \\
\hline Hombres & 11,4 & 11,8 & 24,8 & 25,7 & 58,1 & 56,2 & 60,2 & 58,4 & 39,8 & 41,6 \\
\hline Mujeres & 17,6 & 17,1 & 26,6 & 26,6 & 58,7 & 56,9 & 60,8 & 58,7 & 39,2 & 41,3 \\
\hline \multicolumn{11}{|l|}{ Quintiles } \\
\hline Quintil I & 11,8 & 11,6 & 2,1 & 4,2 & 89,0 & 87,3 & 91,0 & 88,5 & 9,0 & 11,5 \\
\hline Quintil II & 12,8 & 13,0 & 6,5 & 9,3 & 82,3 & 78,5 & 83,7 & 79,4 & 16,3 & 20,6 \\
\hline Quintil III & 14,0 & 14,2 & 15,3 & 18,3 & 70,4 & 65,3 & 72,0 & 67,0 & 28,0 & 33,0 \\
\hline Quintil IV & 16,0 & 15,6 & 29,0 & 28,6 & 53,2 & 51,9 & 54,7 & 54,0 & 45,3 & 46,0 \\
\hline Quintil V & 18,4 & 18,1 & 60,0 & 55,5 & 19,4 & 20,4 & 21,7 & 23,4 & 78,3 & 76,6 \\
\hline Total & 14,6 & 14,5 & 25,9 & 26,3 & 58,5 & 56,6 & 60,6 & 58,6 & 39,4 & 41,4 \\
\hline
\end{tabular}

B. Asalariados de 15 años y más

\begin{tabular}{|c|c|c|c|c|c|c|c|c|c|c|}
\hline & \multirow{2}{*}{\multicolumn{2}{|c|}{$\begin{array}{l}\text { Atención } \\
\text { de salud }\end{array}$}} & \multirow{2}{*}{\multicolumn{2}{|c|}{$\begin{array}{l}\text { Cobertura de } \\
\text { plan de salud }\end{array}$}} & \multirow{2}{*}{\multicolumn{2}{|c|}{$\begin{array}{l}\text { Cobertura del } \\
\text { Sistema Único de } \\
\text { Salud (SUS) }\end{array}$}} & \multicolumn{4}{|c|}{ Prestador } \\
\hline & & & & & & & \multicolumn{2}{|c|}{ Público } & \multicolumn{2}{|c|}{ Privado } \\
\hline & 2003 & 2008 & 2003 & 2008 & 2003 & 2008 & 2003 & 2008 & 2003 & 2008 \\
\hline \multicolumn{11}{|l|}{ Sexo } \\
\hline Hombres & 9,5 & 10,5 & 34,1 & 34,3 & 45,3 & 44,1 & 47,7 & 47,0 & 52,3 & 53,0 \\
\hline Mujeres & 17,9 & 17,5 & 36,4 & 34,9 & 45,8 & 45,7 & 48,4 & 47,7 & 51,6 & 52,3 \\
\hline \multicolumn{11}{|l|}{ Quintiles } \\
\hline Quintil I & 10,0 & 11,0 & 3,5 & 6,0 & 85,1 & 83,1 & 87,7 & 84,3 & 12,3 & 15,7 \\
\hline Quintil II & 11,2 & 11,8 & 9,4 & 12,6 & 75,0 & 70,6 & 76,9 & 71,7 & 23,1 & 28,3 \\
\hline Quintil III & 11,9 & 12,7 & 19,6 & 21,7 & 61,8 & 58,8 & 64,2 & 60,4 & 35,8 & 39,6 \\
\hline Quintil IV & 13,3 & 13,4 & 35,5 & 35,6 & 44,2 & 42,3 & 45,9 & 44,9 & 54,1 & 55,1 \\
\hline Quintil V & 16,5 & 16,7 & 64,8 & 60,2 & 14,3 & 16,4 & 17,2 & 19,9 & 82,8 & 80,1 \\
\hline Total & 13,1 & 13,6 & 35,5 & 34,6 & 45,6 & 45,0 & 48,1 & 47,4 & 51,9 & 52,6 \\
\hline
\end{tabular}

Fuente: Comisión Económica para América Latina y el Caribe (CEPAL), sobre la base de tabulaciones especiales de la Encuesta Nacional de Hogares (PNAD), Suplemento de salud. 


\section{La segmentación del aseguramiento y del acceso a prestaciones de salud en el Brasil}

La Constitución de 1988 instauró en el Brasil un sistema universal de salud (artículo 196), pero también abrió espacio a la iniciativa privada en el ámbito de la salud (artículo 199). Las políticas han tendido a que el Sistema Único de Salud (SUS) atienda a las personas de menores ingresos. Las personas de mayores ingresos gozan de una doble cobertura que les permite acceder a prestaciones selectas del SUS que serían más caras en la medicina privada. Además, se ha apoyado al sector privado de la salud con cuantiosos subsidios cruzados, con lo cual la presencia subvencionada del sector privado en el sistema de salud se ha "naturalizado" (Ocké-Reis, 2012, págs. 15, 22-24).

Es interesante ver que la estratificación de la salud producto del aseguramiento mediante planes privados ha sido impulsada con el apoyo de los sindicatos, que desde la década de 1960 aceptaron un aseguramiento vinculado con planes corporativos de las empresas, una tendencia que con los años se amplió a sectores más acomodados. Los sindicatos han cumplido un papel crucial: los planes de salud privados se transformaron en parte de la remuneración y de la negociación colectiva y, de hecho, solo pueden obtenerse de manera colectiva. En muchos casos, adolecen de malas coberturas, lo que implica altos gastos de bolsillo, y además la cobertura se pierde en caso de desempleo (Lavinas, 2016, págs. 14-15; Ocké-Reis, 2012, pág. 24).

Cabe resaltar que los pagos por planes privados y pólizas representan un alto porcentaje del gasto total en salud: en 2010 se estimaba que representaron un 40,4\% del gasto total en salud. Los planes privados de salud y el aseguramiento privado reciben diversos subsidios públicos: uso de establecimientos públicos a precios inferiores a los de mercado para asegurados de planes privados; aseguramiento mediante planes privados para los empleados públicos; sendas deducciones de impuestos a individuos y a empresas por gastos en salud, que incluyen pago de planes de salud, y deducciones de impuestos a organizaciones filantrópicas que venden planes de salud privados. Además, el SUS brinda algunos servicios caros que no están incluidos en los planes privados de salud, como algunos tratamientos contra el síndrome de inmunodeficiencia adquirida (SIDA) y el cáncer, cuidados de largo plazo, cirugía cardíaca, hemodiálisis, uso del banco de sangre y trasplantes. Los pacientes de alto riesgo y con dolencias crónicas se ven obligados a salir de los planes privados por las alzas de precios y pasan al SUS, como ocurre en Chile cuando pasan de las Instituciones de Salud Previsional (ISAPRE) al Fondo Nacional de Salud (FONASA) (d'Ávila, da Silva y Yi, 2015, págs. 4, 14 y 15; Ocké-Reis, 2012, pág. 26). Se ha calculado que la denominada "renuncia fiscal", es decir las deducciones fiscales apuntadas, ascendían en 2006 a un monto equivalente al 30,6\% del gasto público federal (Ocké-Reis, 2012, pág. 150). 
Ya se analizó la cobertura de la afiliación a sistemas de salud en países latinoamericanos, variable que no está incluida en la encuesta de hogares del Brasil. Sin embargo, algunos módulos especiales de la Encuesta Nacional de Hogares (Pesquisa Nacional por Amostra de Domicilios Continua o PNAD) permiten analizar el acceso efectivo a la atención de salud y, para indagar en las características socioeconómicas de este acceso, vinculamos los módulos de salud con la encuesta general de hogares y obtuvimos los resultados que se muestran a continuación.

Si se considera la cobertura del aseguramiento privado de la población a lo largo del quinquenio en cuestión, no se advierten cambios sustanciales; los incrementos son menores y hay una leve disminución en el quintil más rico $^{6}$. En el gráfico III.12 se muestra la cobertura de los asalariados, que es superior a la de la población en general.

Gráfico III.12

Brasil: asalariados de 15 años y más cubiertos por planes privados de salud, por sexo y quintiles de ingreso per cápita, 2003 y 2008 (En porcentajes)

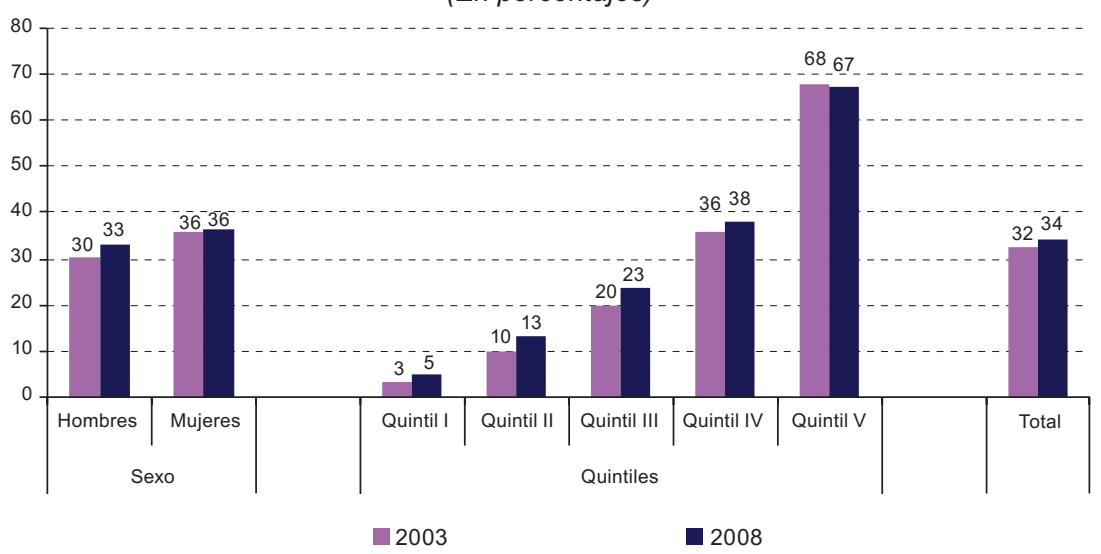

Fuente: Comisión Económica para América Latina y el Caribe (CEPAL), sobre la base de tabulaciones especiales de la Encuesta Nacional de Hogares (PNAD), Suplemento de salud.

Cuando se compara en términos globales el aseguramiento de la población en general y de los asalariados que han sido atendidos por razones de salud, llama la atención que la población en general y los asalariados gocen de coberturas muy semejantes (véase el gráfico III.13). No obstante, es rotunda la estratificación por ingreso del aseguramiento: claramente los estratos más pobres y vulnerables usan el SUS y, conforme aumenta el ingreso, aumenta el uso del aseguramiento privado. Aun así, un contingente muy importante de los estratos medios y un porcentaje

La pregunta utilizada para esta variable fue:¿Tiene usted derecho a algún plan de salud, médico o dental, particular, de empresa o de algún servicio público? 
significativo del quintil de mayores ingresos utilizan el SUS. Puede conjeturarse que esto se debe, en parte, al uso de servicios que serían muy caros en el mercado, como ya se mencionó.

Gráfico III.13

Brasil: aseguramiento público y privado de las personas atendidas por razones de salud en las dos semanas previas a la Encuesta Nacional de Hogares, por sexo y quintiles de ingreso per cápita, 2008 (En porcentajes)

A. Población en general

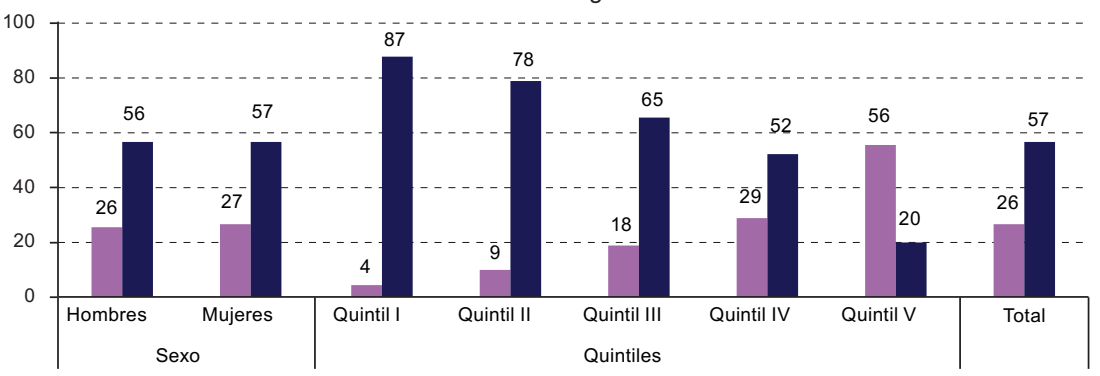

B. Asalariados de 15 años y más

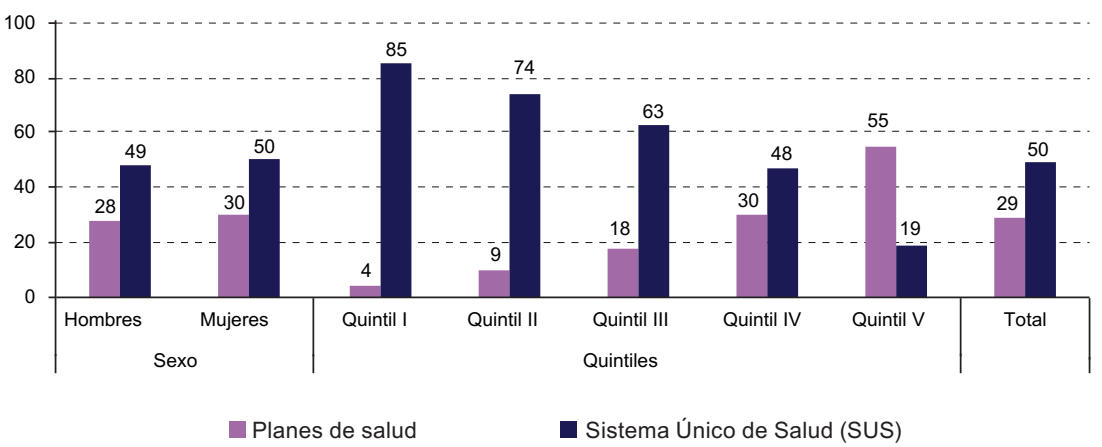

Fuente: Comisión Económica para América Latina y el Caribe (CEPAL), sobre la base de tabulaciones especiales de la Encuesta Nacional de Hogares (PNAD), Suplemento de salud.

En el cuadro III.11 se muestra la singular relevancia que tienen los prestadores públicos y privados para las personas que se atienden. Es claro que hay un mayor uso de prestadores públicos conforme disminuye el ingreso y de prestadores privados conforme este aumenta. Además, destaca que en el caso de los asalariados hay un mayor uso de los prestadores privados en comparación con la población en general. Se observa también que el uso de los servicios de salud es mayor conforme aumenta el ingreso y que las mujeres los utilizan más. 


\section{Gastos de bolsillo en salud y desigualdad ${ }^{7}$}

Los bienes y servicios de salud tienen tres fuentes principales de financiamiento, cuya importancia varía de un país a otro, según las características de cada sistema de salud: i) impuestos generales y específicos; ii) contribuciones a la seguridad social recaudadas mediante impuestos sobre la nómina, otros impuestos o cotizaciones, y iii) desembolsos realizados por los hogares. A continuación se analiza el gasto privado de los hogares latinoamericanos en el ámbito de la salud, particularmente los gastos directos o de bolsillo, derivados del pago o copago de prestaciones.

De acuerdo con la definición de la Organización Panamericana de la Salud (OPS) (2007), el gasto de los hogares en servicios de salud abarca dos tipos de gasto. Los directos, denominados gastos de bolsillo en salud, corresponden a los desembolsos destinados a rubros tales como hospitalizaciones, procedimientos ambulatorios y medicamentos de carácter neto, es decir, una vez deducidos los reembolsos que se reciban del sistema de salud o del seguro al que se esté afiliado. Los gastos indirectos, por su parte, se destinan a planes de atención médica prepagados, seguros médicos privados y contribuciones al seguro público8.

Estos gastos son ajenos a una lógica de solidaridad o de diversificación de riesgos y se efectúan de manera fragmentada, por lo general al prestador del servicio. En algunos casos, su eficacia, eficiencia o pertinencia es incierta (por ejemplo, cuando son consecuencia de los altos precios de los medicamentos o sobreprecios de los servicios en determinados mercados, o de sobreprestaciones). Al reflejar las condiciones socioeconómicas de quienes los efectúan, son una de las formas menos justas de financiar la salud y su reducción supone un complejo desafío que es preciso abordar en el horizonte de una protección social más universal y solidaria. Pero no solo es importante reducir el gasto de bolsillo, sino también la regulación de los rubros relacionados. Cuando determinados ítems son asumidos por el aseguramiento universal y solidario, también debe velarse por sus precios para evitar fenómenos como el acontecido en Colombia, donde la radical reducción del gasto de bolsillo en medicamentos de la población asegurada fue a la par de una explosión del gasto en medicamentos con cargo al sistema de salud y al presupuesto nacional, por los sobreprecios impuestos por las compañías farmacéuticas en el marco de la judicialización del derecho a la salud (véanse los capítulos IV y V).

\footnotetext{
En este apartado se sintetizan planteamientos y cálculos efectuados en CEPAL (2013, cap. V). Conviene señalar que en las encuestas no es posible distinguir si el monto del pago directo ya tiene descontado el monto reembolsado o, en otros casos, cuánto será el reembolso futuro. La carga del gasto de bolsillo expresa la magnitud del gasto respecto de la capacidad de gasto del hogar, que operativamente se define como el gasto total del hogar menos sus gastos de subsistencia (CEPAL, 2013).
} 
La población es vulnerable en distinta medida a incurrir en gastos de bolsillo en salud que afecten sus condiciones socioeconómicas. El grado de vulnerabilidad es función tanto de la magnitud del gasto de bolsillo, como de la capacidad de gasto del hogar (véase el cuadro III.12). La capacidad de gasto se define como el gasto total de los hogares menos el valor de la línea de subsistencia destinada a los gastos en alimentos, que corresponde al promedio de gastos en alimentos del grupo que destina alrededor del 50\% a este rubro. La carga del gasto de bolsillo en salud expresa la proporción que representa respecto de la capacidad disponible de gasto del hogar; pueden establecerse determinados umbrales, alrededor del 30\% al 40\%, para medir los gastos que por su cuantía son catastróficos ${ }^{9}$. En el presente análisis se adopta un umbral del 30\%.

Como es de esperar, la magnitud del gasto de bolsillo varía mucho a lo largo de la distribución del ingreso. El menor gasto de bolsillo que se registra entre los más pobres puede ser un efecto del aseguramiento (variable que no puede medirse estrictamente por los tamaños de las muestras y el diverso detalle con que se registran y codifican los gastos en las encuestas) o, en su defecto, puede indicar la imposibilidad para realizar dicho gasto. La disparidad de los montos medios por quintiles de ingreso a escala de América Latina puede observarse en el gráfico III.14. Si se considera la estructura del gasto, se verifica que los hogares de los quintiles de menores ingresos gastan proporcionalmente más en medicamentos, mientras que conforme se incrementan los ingresos, se gasta más en especialidades (véase el gráfico III.14). Ello puede evidenciar la práctica de la automedicación como salida ante la desprotección en episodios de enfermedad en los hogares más vulnerables y la restricción para gastar en atenciones especializadas.

Xu (2005) y Murray y otros (2003) establecen el umbral en el 40\%, que es el nivel adoptado en el análisis de la CEPAL (2008) y en Perticara (2008). Por su parte, Knaul y otros (2011) lo fijaron recientemente en el 30\%, con lo que aumenta el universo de hogares cuyos gastos caen en esa categoría. En el presente análisis se adopta el umbral del 30\% para mejorar la calidad muestral del universo susceptible de ser analizado con las encuestas; por esta razón, no son cifras comparables con CEPAL (2008) y Perticara (2008). Debe destacarse que la medición por medio de encuestas de ingresos y gastos permite dimensionar estrictamente el impacto de estos gastos en el mes en que se realiza la encuesta, pero no sus efectos más perdurables (por ejemplo, si el empobrecimiento coyuntural por un evento de salud catastrófico se proyecta en el mediano y largo plazo). Tampoco permite captar la recurrencia del gasto ni, por lo tanto, la dimensión temporal de su magnitud e intensidad. No obstante, ofrece una idea acerca de la capacidad desigual con que cuentan los hogares para enfrentar gastos que no están cubiertos por el aseguramiento en eventos de morbilidad agudos o crónicos. Véanse más detalles metodológicos sobre el uso de las encuestas de ingresos y gastos de los hogares para analizar el gasto de bolsillo en salud en CEPAL (2013, recuadro V.2). Para calcular los gastos en dólares de 2005 expresados en paridad del poder adquisitivo (PPA), se usaron los factores de conversión a dólares PPA publicados en World Development Indicators del Banco Mundial; el tipo de cambio utilizado fue la serie rf de 2005. Como no era posible disponer de los tipos de cambio específicos de las submuestras a lo largo del período de referencia para todos los países, se consideraron los promedios de los índices de precios al consumidor del período completo de aplicación de la encuesta para la indexación y el cálculo en moneda local como promedio de 2005. 


\section{Cuadro III.12 \\ América Latina (18 países): indicadores generales relacionados con el gasto de bolsillo en salud, realizado en un mes}

(En porcentajes)

\begin{tabular}{|c|c|c|c|c|c|}
\hline \multirow[b]{2}{*}{ País } & \multirow{2}{*}{$\begin{array}{l}\text { Capacidad } \\
\text { de gasto } \\
\text { como } \\
\text { porcentaje } \\
\text { del gasto } \\
\text { total }^{a}\end{array}$} & \multicolumn{2}{|c|}{$\begin{array}{l}\text { Gasto de bolsillo en } \\
\text { salud }\end{array}$} & \multirow{2}{*}{$\begin{array}{l}\text { Hogares sin } \\
\text { gasto de } \\
\text { bolsillo en } \\
\text { salud }\end{array}$} & \multirow{2}{*}{$\begin{array}{l}\text { Hogares con gasto } \\
\text { de bolsillo en salud: } \\
\text { peso de dicho gasto } \\
\text { en la capacidad } \\
\text { total de gasto }\end{array}$} \\
\hline & & $\begin{array}{l}\text { Como } \\
\text { proporción } \\
\text { del gasto } \\
\text { total }\end{array}$ & $\begin{array}{c}\text { Como } \\
\text { proporción } \\
\text { de la } \\
\text { capacidad } \\
\text { de gasto }^{\text {a }}\end{array}$ & & \\
\hline $\begin{array}{l}\text { Argentina } \\
(2004 / 2005)\end{array}$ & 61,9 & 5,0 & 6,8 & 45,7 & 12,5 \\
\hline $\begin{array}{l}\text { Bolivia (Estado } \\
\text { Plurinacional de) } \\
\text { (2003/2004) }\end{array}$ & 58,8 & 3,1 & 4,5 & 43,2 & 7,9 \\
\hline Brasil (2008/2009) & 85,5 & 5,0 & 5,7 & 14,3 & 6,7 \\
\hline Chile (2006/2007) & 68,3 & 4,3 & 5,6 & 34,5 & 8,6 \\
\hline Colombia (2007) & 59,4 & 1,9 & 2,9 & 36,4 & 4,6 \\
\hline Costa Rica (2004) & 73,2 & 2,1 & 2,6 & 36,5 & 4,1 \\
\hline Ecuador (2003/2004) & 72,9 & 4,7 & 6,2 & 4,0 & 6,5 \\
\hline EI Salvador (2006) & 65,4 & 4,3 & 6,1 & 13,7 & 7,1 \\
\hline Guatemala (2006) & 56,8 & 6,2 & 9,4 & 11,3 & 10,6 \\
\hline Honduras (2004) & 59,2 & 11,2 & 16,4 & 19,4 & 20,3 \\
\hline México (2006) & 75,0 & 4,7 & 6,0 & 19,8 & 7,5 \\
\hline Nicaragua (2005) & 42,7 & 6,6 & 12,6 & 17,2 & 15,2 \\
\hline Panamá (2007) & 72,2 & 2,4 & 3,1 & 10,1 & 3,5 \\
\hline Paraguay (1997) & 43,5 & 3,6 & 7,2 & 7,7 & 7,8 \\
\hline Perú (2008) & 61,7 & 7,0 & 10,4 & 7,5 & 11,2 \\
\hline $\begin{array}{l}\text { República } \\
\text { Dominicana (2007) }\end{array}$ & 42,6 & 6,4 & 11,9 & 18,6 & 14,6 \\
\hline Uruguay (2005/2006) & 77,9 & 2,8 & 3,4 & 25,9 & 4,6 \\
\hline $\begin{array}{l}\text { Venezuela (República } \\
\text { Bolivariana de) } \\
\text { (2008/2009) }\end{array}$ & 53,5 & 3,1 & 4,4 & 60,4 & 11,1 \\
\hline América Latina ${ }^{\mathrm{b}}$ & 62,8 & 4,7 & 7,0 & 23,7 & 9,1 \\
\hline
\end{tabular}

Fuente: Comisión Económica para América Latina y el Caribe (CEPAL), Panorama Social de América Latina, 2013 (LC/G.2580), Santiago, diciembre de 2013.

a La capacidad de gasto se define como el gasto total del hogar menos sus gastos de subsistencia (gastos en alimentos en que incurre el hogar, calculados para cada país). De acuerdo con Xu (2005), se define una línea de subsistencia relativa, estimada como el gasto medio per cápita en alimentos equivalente al gasto que realiza una familia ubicada entre los percentiles 45 y 55 de la distribución de la razón entre gasto en alimentos y gasto total (número de miembros del hogar elevado a 0,56). Véase K. Xu, "Distribución del gasto en salud y gastos catastróficos. Metodología", Discussion Paper, № 2, Ginebra, Organización Mundial de la Salud (OMS), 2005 [en línea] http://www.paho.org/chi/index. php?option=com_docman\&task=doc_view\&gid=149ltemid=.

b Promedio simple de los países. 


\section{Gráfico III.14}

América Latina: monto medio del gasto de bolsillo en salud por hogar, y gasto en medicamentos y en especialidades como porcentaje del gasto de bolsillo en salud, por quintiles de ingreso, realizado en un mes, alrededor de 2006

(En dólares de 2005 en paridad del poder adquisitivo (PPA) y porcentajes)

A. Promedio simple de 18 países: monto del gasto de bolsillo en salud por hogar

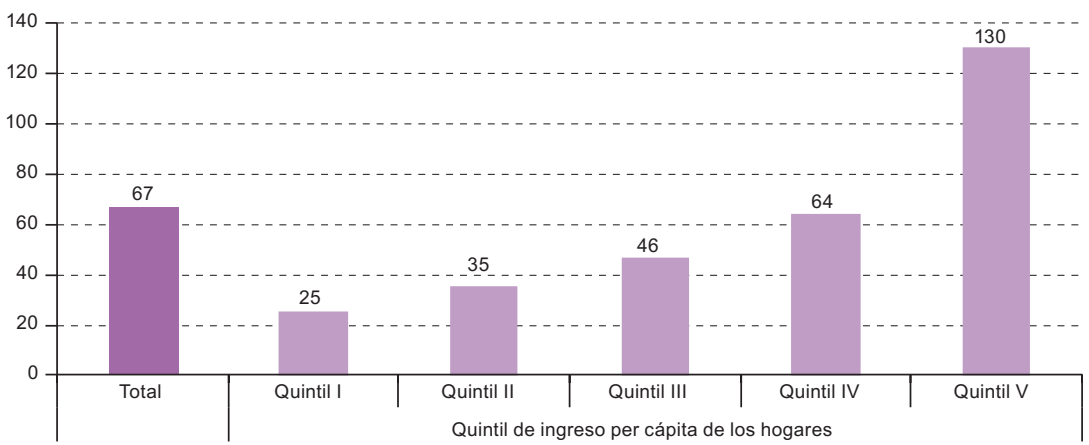

B. Promedio simple de 16 países: gasto en medicamentos como porcentaje del gasto de bolsillo en salud

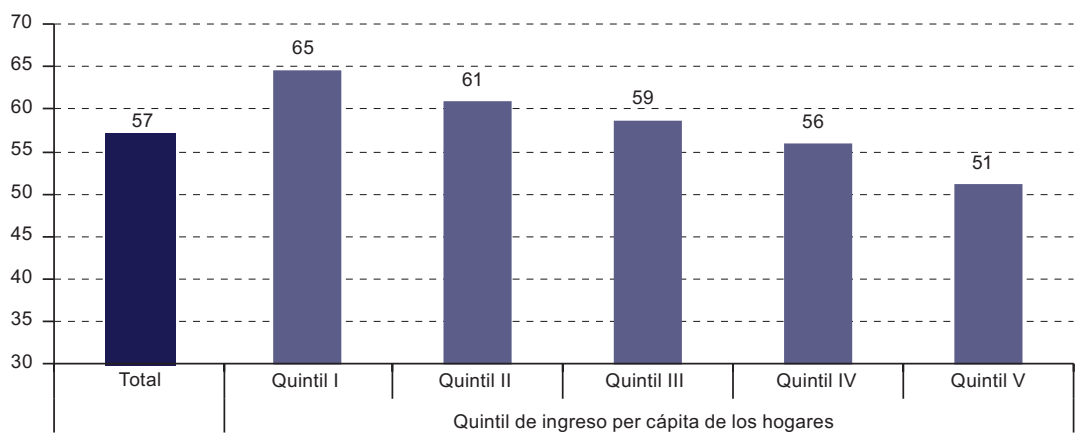

C. Promedio simple de 18 países: gasto en especialidades como porcentaje del gasto de bolsillo en salud

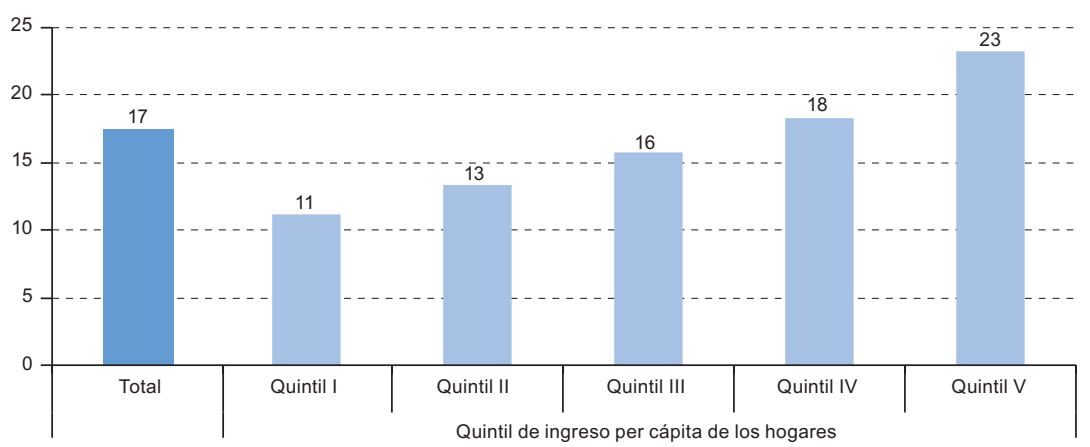

Fuente: Comisión Económica para América Latina y el Caribe (CEPAL), sobre la base de tabulaciones especiales de las encuestas de ingresos y gastos de los respectivos países. 
Debido a altos gastos de bolsillo en salud, los hogares pueden empobrecerse. Para dimensionar este fenómeno, en primer lugar se consigna el porcentaje de hogares que se empobrecen entre los que efectúan gastos de bolsillo en salud. A continuación, esta forma de empobrecimiento se suma a la incidencia de la pobreza calculada estrictamente sobre la base de la línea de subsistencia destinada a alimentos. El ejercicio en 18 países de la región permite observar cómo se incrementa la incidencia de la pobreza en magnitudes que son apreciables en varios países de la región (véanse el cuadro III.13 y el gráfico III.15).

Cuadro III.13

América Latina (18 países): indicadores de empobrecimiento relacionados con el gasto de bolsillo en salud, realizado en un mes

(En porcentajes)

\begin{tabular}{|c|c|c|c|c|c|c|c|}
\hline \multirow[b]{2}{*}{ País } & \multicolumn{3}{|c|}{ Incidencia de la pobreza } & \multirow{2}{*}{$\begin{array}{l}\text { Hogares } \\
\text { empobrecidos } \\
\text { tras afrontar } \\
\text { gastos de } \\
\text { bolsillo }\end{array}$} & \multicolumn{3}{|c|}{$\begin{array}{c}\text { Hogares con gasto de bolsillo en salud } \\
\text { catastrófico (30\% o más de la capacidad } \\
\text { de gasto) }\end{array}$} \\
\hline & $\begin{array}{l}\text { En el } \\
\text { total de } \\
\text { hogares }\end{array}$ & $\begin{array}{c}\text { En los } \\
\text { hogares } \\
\text { sin gasto } \\
\text { de bolsillo }\end{array}$ & $\begin{array}{c}\text { En los } \\
\text { hogares } \\
\text { con gasto } \\
\text { de bolsillo }\end{array}$ & & $\begin{array}{l}\text { Porcentaje } \\
\text { de hogares } \\
\text { con gastos } \\
\text { catastróficos }\end{array}$ & $\begin{array}{l}\text { Incidencia de } \\
\text { la pobreza } \\
\text { en hogares } \\
\text { con gastos } \\
\text { catastróficos }^{\mathrm{a}}\end{array}$ & $\begin{array}{l}\text { Hogares } \\
\text { empobrecidos } \\
\text { tras afrontar } \\
\text { gastos de } \\
\text { bolsillo } \\
\text { catastróficos }\end{array}$ \\
\hline $\begin{array}{l}\text { Argentina } \\
(2004 / 2005)\end{array}$ & 14,3 & 24,2 & 6,0 & 1,2 & 6,7 & 7,7 & 12,7 \\
\hline $\begin{array}{l}\text { Bolivia (Estado } \\
\text { Plurinacional de) } \\
\text { (2003/2004) }\end{array}$ & 15,6 & 22,5 & 10,4 & 0,7 & 3,0 & 14,7 & 12,5 \\
\hline $\begin{array}{l}\text { Brasil } \\
(2008 / 2009)\end{array}$ & 2,8 & 7,9 & 1,9 & 0,6 & 2,5 & 3,9 & 8,8 \\
\hline $\begin{array}{l}\text { Chile } \\
(2006 / 2007)\end{array}$ & 8,2 & 17,7 & 3,2 & 0,5 & 3,7 & 4,8 & 8,6 \\
\hline $\begin{array}{l}\text { Colombia } \\
(2007)\end{array}$ & 14,5 & 20,0 & 11,4 & 0,6 & 1,1 & 24,7 & 21,4 \\
\hline $\begin{array}{l}\text { Costa Rica } \\
(2004)\end{array}$ & 7,6 & 15,4 & 3,1 & 0,3 & 0,5 & 5,4 & 13,3 \\
\hline $\begin{array}{l}\text { Ecuador } \\
(2003 / 2004)\end{array}$ & 2,0 & 7,5 & 1,8 & 0,3 & 2,0 & 3,7 & 4,3 \\
\hline $\begin{array}{l}\text { El Salvador } \\
(2006)\end{array}$ & 11,0 & 24,0 & 9,0 & 0,9 & 2,5 & 5,7 & 8,4 \\
\hline $\begin{array}{l}\text { Guatemala } \\
(2006)\end{array}$ & 10,0 & 16,5 & 9,1 & 1,7 & 8,3 & 4,6 & 9,5 \\
\hline $\begin{array}{l}\text { Honduras } \\
(2004)\end{array}$ & 18,8 & 24,9 & 17,3 & 4,7 & 20,0 & 12,4 & 18,9 \\
\hline México (2006) & 2,8 & 5,6 & 2,1 & 0,5 & 4,1 & 2,8 & 4,1 \\
\hline $\begin{array}{l}\text { Nicaragua } \\
\text { (2005) }\end{array}$ & 22,1 & 28,3 & 20,8 & 3,2 & 12,7 & 21,7 & 15,6 \\
\hline $\begin{array}{l}\text { Panamá } \\
(2007)\end{array}$ & 3,1 & 8,2 & 2,5 & 0,2 & 0,9 & 0,3 & 2,2 \\
\hline $\begin{array}{l}\text { Paraguay } \\
\text { (1997) }\end{array}$ & 20,7 & 34,7 & 19,5 & 1,6 & 4,1 & 38,6 & 12,1 \\
\hline Perú (2008) & 10,8 & 32,0 & 9,0 & 1,5 & 6,4 & 14,3 & 10,7 \\
\hline
\end{tabular}


Cuadro III.13 (conclusión)

\begin{tabular}{|c|c|c|c|c|c|c|c|}
\hline \multirow[b]{2}{*}{ País } & \multicolumn{3}{|c|}{ Incidencia de la pobreza } & \multirow{2}{*}{$\begin{array}{l}\text { Hogares } \\
\text { empobrecidos } \\
\text { tras afrontar } \\
\text { gastos de } \\
\text { bolsillo }\end{array}$} & \multicolumn{3}{|c|}{$\begin{array}{c}\text { Hogares con gasto de bolsillo en salud } \\
\text { catastrófico (30\% o más de la capacidad } \\
\text { de gasto) }\end{array}$} \\
\hline & $\begin{array}{l}\text { En el } \\
\text { total de } \\
\text { hogares }\end{array}$ & $\begin{array}{l}\text { En los } \\
\text { hogares } \\
\text { sin gasto } \\
\text { de bolsillo }\end{array}$ & $\begin{array}{l}\text { En los } \\
\text { hogares } \\
\text { con gasto } \\
\text { de bolsillo }\end{array}$ & & $\begin{array}{l}\text { Porcentaje } \\
\text { de hogares } \\
\text { con gastos } \\
\text { catastróficos }\end{array}$ & $\begin{array}{l}\text { Incidencia de } \\
\text { la pobreza } \\
\text { en hogares } \\
\text { con gastos } \\
\text { catastróficos }^{a}\end{array}$ & $\begin{array}{l}\text { Hogares } \\
\text { empobrecidos } \\
\text { tras afrontar } \\
\text { gastos de } \\
\text { bolsillo } \\
\text { catastróficos }\end{array}$ \\
\hline $\begin{array}{l}\text { República } \\
\text { Dominicana } \\
(2007)\end{array}$ & 16,0 & 23,1 & 14,4 & 3,4 & 11,9 & 26,1 & 19,8 \\
\hline $\begin{array}{l}\text { Uruguay } \\
\text { (2005/2006) }\end{array}$ & 3,7 & 10,3 & 1,4 & 0,1 & 0,5 & 2,6 & 2,1 \\
\hline $\begin{array}{l}\text { Venezuela } \\
\text { (República } \\
\text { Bolivariana de) } \\
(2008 / 2009)\end{array}$ & 16,6 & 23,4 & 6,1 & 1,0 & 4,0 & 10,5 & 17,3 \\
\hline $\begin{array}{l}\text { América } \\
\text { Latina }^{b}\end{array}$ & 11,1 & 19,2 & 8,3 & 1,3 & 5,3 & 11,4 & 11,2 \\
\hline
\end{tabular}

Fuente: Comisión Económica para América Latina y el Caribe (CEPAL), sobre la base de tabulaciones especiales de las encuestas de ingresos y gastos de los respectivos países.

a Hogares en situación de pobreza antes de efectuar el gasto de bolsillo, catastrófico o no.

b Promedio simple de los países.

Gráfico III.15

América Latina (18 países): incremento de la pobreza relativa como efecto de los
gastos de bolsillo en salud, realizados en un mes (En porcentajes)

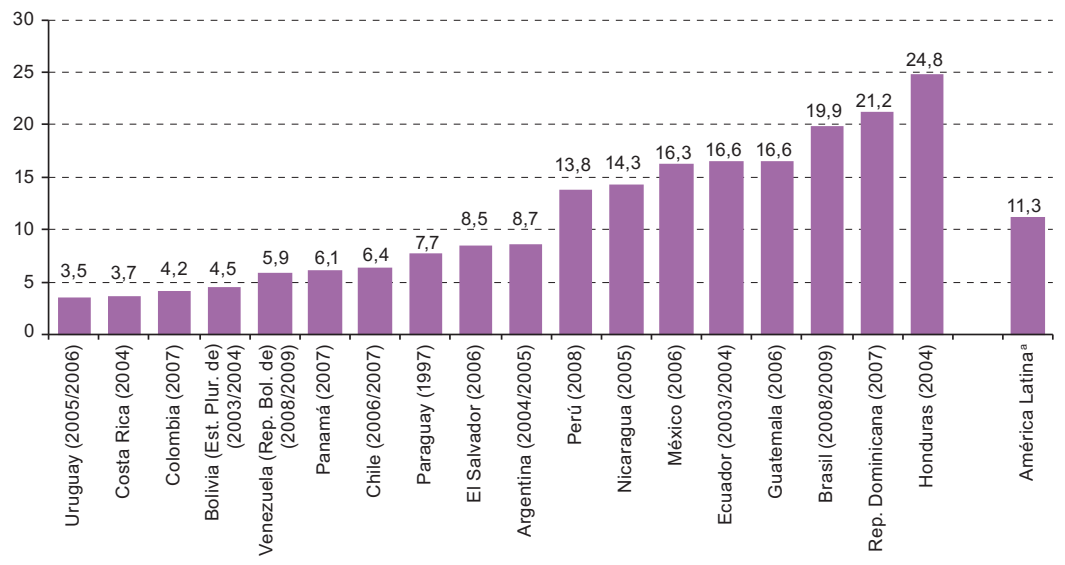

Fuente: Comisión Económica para América Latina y el Caribe (CEPAL), sobre la base de tabulaciones especiales de las encuestas de ingresos y gastos de los respectivos países.

a Promedio simple de los países. 
En el gráfico III.16 puede observarse que la incidencia de la realización de gastos de bolsillo en salud difiere en los distintos quintiles de ingreso. Como un aspecto complementario que evidencia la desigualdad, es importante observar cómo la incidencia también difiere entre hogares no pobres y pobres. En este sentido, llama la atención que la incidencia de la pobreza (medida respecto de la línea de subsistencia) sea notoriamente mayor entre los hogares sin gasto de bolsillo, sobre todo en los países donde existen bajas coberturas de aseguramiento en salud (véase el gráfico III.17) ${ }^{10}$. Teniendo presente que la población que vive en estos hogares, por sus condiciones socioeconómicas adversas, no suele ser muy saludable ni estar provista de buenos niveles de aseguramiento, la ausencia de gastos de bolsillo en salud parece evidenciar que una importante proporción de los pobres ve totalmente coartada su capacidad de incurrir en dichos gastos.

\section{Gráfico III.16 \\ América Latina (promedio simple de 18 países): hogares que efectúan gastos de bolsillo en salud, por quintiles de ingreso, alrededor de 2006 (En porcentajes)}

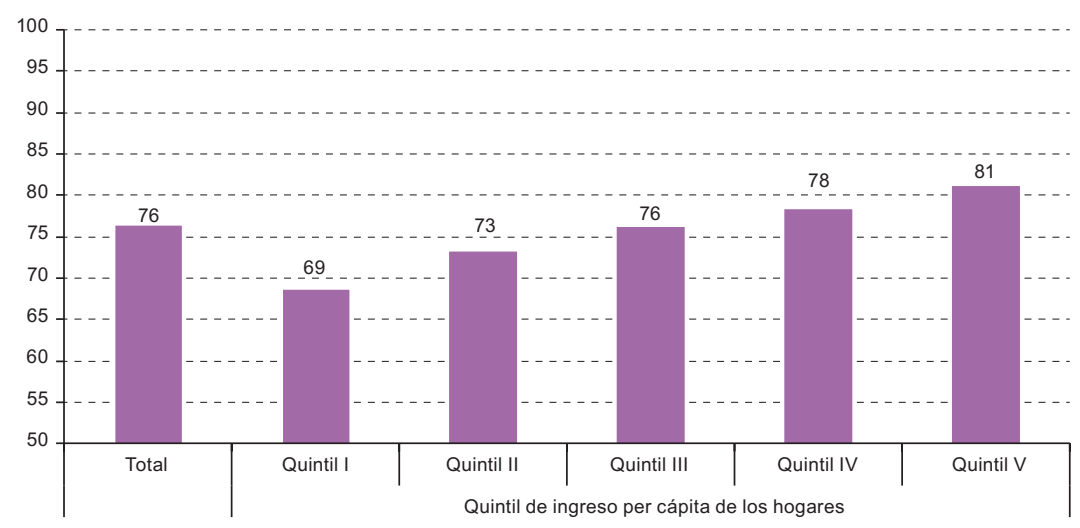

Fuente: Comisión Económica para América Latina y el Caribe (CEPAL), sobre la base de tabulaciones especiales de las encuestas de ingresos y gastos de los respectivos países.

Es decir que mientras el gasto catastrófico se asocia más bien con gastos de bolsillo muy altos que los hogares enfrentan con mucha dificultad, la restricción de los hogares con escasa capacidad de pago se expresa, fundamentalmente, como incapacidad para efectuar gastos de bolsillo en salud, aun cuando no estén asegurados (CEPAL, 2008).

10 Perticara (2008) llamó originalmente la atención sobre este aspecto. 
Gráfico III.17

América Latina (18 países): incidencia de la pobreza en los hogares con y sin gasto de bolsillo en salud

(En porcentajes)

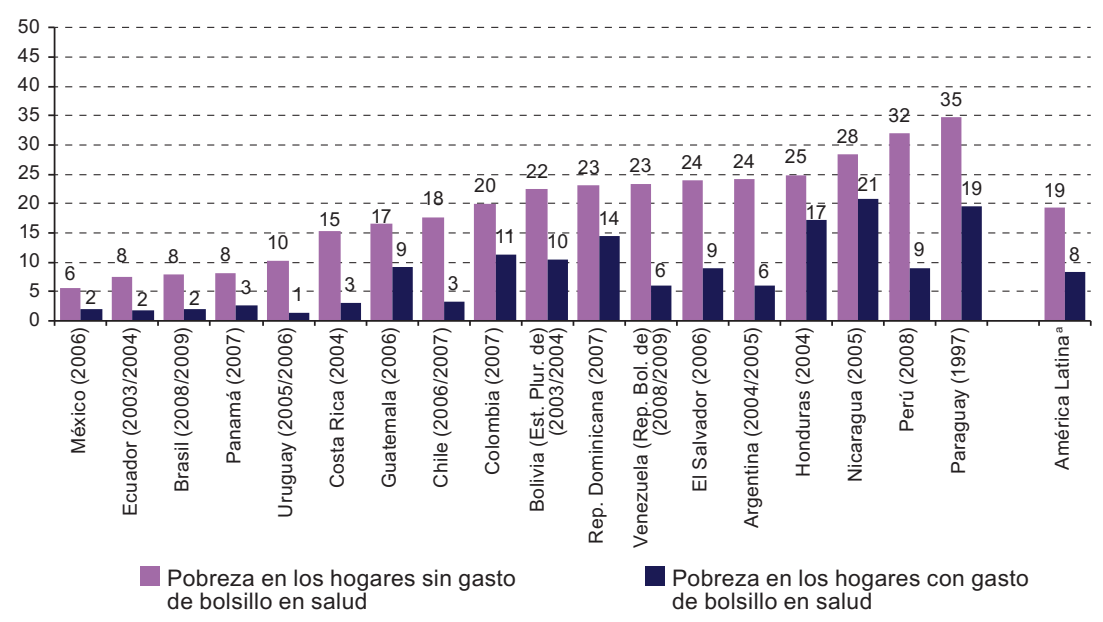

Fuente: Comisión Económica para América Latina y el Caribe (CEPAL), sobre la base de tabulaciones especiales de las encuestas de ingresos y gastos de los respectivos países.

a Promedio simple de los países.

El concepto de gasto catastrófico en salud se refiere a la magnitud de estos gastos de bolsillo respecto de la capacidad general de gasto de los hogares. En razón de este, se constriñe la capacidad de efectuar los demás gastos "normales", se originan deudas o empobrecimiento. Cuando la magnitud de la carga de gastos de bolsillo supera un límite determinado se considera catastrófica; como se dijo, usualmente el umbral se fija en el $40 \%$ de la capacidad de pago (Xu, Evans y Aguilar, 2003) o en el 30\%, como en nuestro análisis. Se trata de un fenómeno que en varios países de la región afecta también a un contingente significativo de hogares que ya eran pobres, independientemente del monto del gasto. Entre los países donde una proporción considerable de los hogares enfrentan gastos de bolsillo en salud catastróficos, Honduras, Nicaragua y la República Dominicana son aquellos en que un mayor porcentaje de hogares se empobrecen por la magnitud de estos gastos.

\section{Bibliografía}

Amarante, V. y A. Sojo (2015), "Protección social y afiliación a los sistemas de pensiones en América Latina", Desigualdad e informalidad: un análisis de cinco experiencias latinoamericanas, Libros de la CEPAL, $\mathrm{N}^{\circ} 133$ (LC/G.2637-P), Santiago, Comisión Económica para América Latina y el Caribe (CEPAL).

Amarante, V. y R. Arim (eds.) (2015), Desigualdad e informalidad: un análisis de cinco experiencias latinoamericanas, Libros de la CEPAL, N 133 (LC/G.2637-P), Santiago, Comisión Económica para América Latina y el Caribe (CEPAL). 
Ávila Viana, A.L, H. P. da Silva e I. Yi (2015), “Universalizing health care in Brazil. Opportunities and challenges", UNRISD Working Paper, N²015-8, abril.

Bertranou, F. y otros (2011), Encrucijadas en la seguridad social argentina: reformas, cobertura y desafíos para el sistema de pensiones, Buenos Aires, Comisión Económica para América Latina y el Caribe (CEPAL)/Organización Internacional del Trabajo (OIT).

CEPAL (Comisión Económica para América Latina y el Caribe) (2015), Desarrollo social inclusivo. Una nueva generación de politicas para superar la pobreza y reducir la desigualdad en América Latina y el Caribe, noviembre, Santiago.

(2013), Panorama Social de América Latina, 2013 (LC/G.2580), Santiago, diciembre. (2008), Objetivos de Desarrollo del Milenio. La progresión hacia el derecho a la salud en América Latina y el Caribe (LC/G.2364/Rev.1), Santiago, noviembre.

Da Costa, R. y otros (2011), The Economy of the Possible: Pensions and Informality in Latin America, París, Organización de Cooperación y Desarrollo Económicos (OCDE), enero.

Figueroa, N. (2015), “Determinantes de la afiliación al sistema de pensiones, 2013", inédito.

Gómez Sabaini, J.C., O. Cetrángolo y D. Morán (2014), “La evasión contributiva en la protección social de salud y pensiones. Un análisis para la Argentina, Colombia y el Perú", serie Políticas Sociales, N 208 (LC/L.3882), Santiago, Comisión Económica para América Latina y el Caribe (CEPAL), agosto.

Knaul, F. M. y otros (2011), "Household catastrophic health expenditures: a comparative analysis of twelve Latin American and Caribbean Countries", Salud Pública de México, N 53, Cuernavaca, Instituto Nacional de Salud Pública.

Lavinas, L. (2016), "How social developmentalism reframed social policy in Brazil", Working Paper Series, N ${ }^{\circ}$ 94, Berlin, desiguALdades.net, Research Network on Interdependent Inequalities in Latin America.

Murray, Ch. y otros (2003), "Assessing the distribution of household financial contributions to the health system: concepts and empirical application", Health Systems Performance Assessment, Ginebra, Organización Mundial de la Salud (OMS), enero.

Ocampo, J.A. y N. Gómez-Arteaga (2016), "Social protection systems in Latin America: an assessment", ESS (Extension of Social Security) Working Paper, No 52, Ginebra, Oficina Regional de la OIT para América Latina y el Caribe.

Ocké-Reis, C. O. (2012), SUS. O desafio de ser único, Río de Janeiro, Editora Fiocruz.

OPS (Organización Panamericana de la Salud) (2007), Salud en las Américas, 2007, Washington, D.C.

Perticara, M. (2008), "Incidencia de los gastos de bolsillo en siete países latinoamericanos", serie Politicas Sociales, $N^{\circ} 141$ (LC/L.2879-P), Santiago, Comisión Económica para América Latina y el Caribe (CEPAL)

Xu, K. (2005), "Distribución del gasto en salud y gastos catastróficos. Metodología", Discussion Paper $N^{\circ}$ 2, Ginebra, Organización Mundial de la Salud (OMS) [en línea] http:/ / www.paho.org/chi/index.php?option=com_docman\&task=doc_ view\&gid=149\&Itemid $=$.

Xu, K., D. Evans y A.M. Aguilar Rivera (2005), “Designing health financing systems to reduce catastrophic health expenditure", Technical Briefs for Policy-Makers, $\mathrm{N}^{\mathrm{o}}$ 2, Ginebra, Organización Mundial de la Salud (OMS). 


\section{Capítulo IV}

\section{El aseguramiento guiado por el lucro: ¿la hora de la verdad?}

Inconmensurabilidad significa que algo es verdadero cuando su significado se sustenta de manera convencional (es decir, de forma consensuada y contextual), y no simplemente empírica. La verdad es una serie de convenciones que se mantienen intersubjetivamente en una comunidad dada y en un momento dado acerca de "la forma en que funciona el mundo" ... Los hechos, ni qué decir los eventos, no son trascendentalmente verdaderos en sí mismos. Lo son más bien en términos de la teoría en la cual se insertan, y son "verdaderos" si la mayoría de los miembros de un grupo o de una sociedad, o los más poderosos, creen tal verdad... el fracaso empírico no es suficiente, los elementos sociopolíticos y discursivos son centrales para la narrativa constructivista. Más aún, si los paradigmas son un corpus inconmensurable de conocimiento, y el keynesianismo y el monetarismo de hecho lo son..., entonces el fracaso empírico no puede ser un criterio suficiente de "verdad", porque lo que para una persona constituye una prueba, para otra es una irrelevancia... (Blyth, 2012)

\section{Introducción}

La maduración de diversos sistemas de salud y pensiones privatizados ha puesto de manifiesto el escaso cumplimiento de las promesas de eficiencia y maximización de beneficios para los asegurados en que se fundamentaron. Además, han acarreado serias consecuencias fiscales debido a la presión que ejercen sobre el crecimiento de los pilares solidarios destinados a las personas que alcanzan coberturas o niveles 
de beneficios muy bajos o que están excluidas de los sistemas debido a los criterios que les sirven de base.

Tras una breve reflexión conceptual sobre la forma en que la orientación al lucro coarta la protección ante los riesgos, sobre las restricciones que enfrentan la competencia y la capacidad de elección en la protección social, y sobre el cambio institucional, se trata el cuestionamiento que enfrentan actualmente el sistema de pensiones en Chile y los sistemas de salud de Chile y Colombia. Se abordan desde diversos ángulos algunos aspectos del éxito o fracaso de las reformas y el cumplimiento de sus objetivos y se analiza quiénes se han visto beneficiados o perjudicados. También se examinan los nuevos problemas que se deben abordar y las oportunidades para nuevas reformas que pueden avizorarse. Se destacan varios aspectos: el nivel extraordinario de las ganancias privadas dado que los riesgos recaen en los individuos, el descreme del mercado ante una desregulación o regulación endeble, y la instrumentalización de los pilares no contributivos en pensiones y salud. Como estos sistemas se encuentran en un momento decisivo, las alianzas políticas que viabilicen o impidan nuevas transformaciones son cruciales, y la disputa discursiva en torno a los criterios de verdad en la evaluación de los sistemas es muy fuerte.

\title{
A. Las combinaciones público-privadas dualistas en la protección social y el menoscabo de la equidad y el aseguramiento debido al lucro
}

\begin{abstract}
El aseguramiento obligatorio es propio de los llamados seguros sociales, públicos o nacionales, que esencialmente tienen como objetivo una diferenciación de riesgos estable y funciones redistributivas del ingreso, lo que puede lograrse en el marco de variadas combinaciones público-privadas.
\end{abstract}

En el capítulo II se analizó la razón de ser del aseguramiento en cuanto a la diversificación de riesgos. El Estado de bienestar, en principio, no debe discriminar y las primas no deben ajustarse a los riesgos individuales de las personas (Barr, 2001). Al quebrarse la identidad entre monto de la prima y riesgo individual y establecerse la cobertura de riesgos en términos más genéricos, se pueden asegurar riesgos que los seguros de mercado normalmente no cubren (Barr, 1993, págs. 123-128 y 308; Arrow, 2000). En el caso de la salud, los seguros obligatorios, aun cuando puedan estar en manos de aseguradores privados, por su naturaleza operan con una lógica distinta a la del seguro privado, al incluir y retener personas de bajo riesgo, no discriminar a las de alto riesgo y permitir una diferenciación de riesgo estable. Su financiamiento puede provenir de primas obligatorias 
de trabajadores y empleadores, o únicamente de los trabajadores, o bien de impuestos generales.

La protección social puede construirse a partir de diversas combinaciones entre lo público y lo privado. El Estado puede reservarse el papel de proveedor único o principal, lo que puede ser deseable para establecer un referente necesario respecto de la prestación privada, para impedir que se conformen posiciones monopólicas y oligopólicas, para evitar escaladas de costos y para promover una mayor simetría en la información que se brinda a los beneficiarios. La provisión puede darse en el marco de diversas combinaciones público-privadas. Para asegurar la eficiencia y eficacia de las prestaciones, la actividad privada debe regirse por una regulación y por procedimientos que garanticen relaciones de competencia. En cuanto al objetivo de equidad - en consonancia con los principios de universalidad y solidaridad-, es fundamental garantizar la calidad, la pertinencia y el acceso a las prestaciones mediante normas $\mathrm{y}$ mecanismos regulatorios y de financiamiento que velen por adecuadas combinaciones público-privadas (CEPAL, 2007, pág. 137; CEPAL, 2013). Independientemente del grado y del tipo de participación privada, el Estado debe mantener responsabilidades indelegables para garantizar los derechos de los ciudadanos, mejorar las condiciones de información y de competencia en los mercados regulados, evitar problemas de selección de riesgos por parte de los oferentes, velar por la cobertura y la calidad, asegurar la protección de los usuarios y ejercer el arbitraje ante eventuales conflictos (CEPAL, 2000, pág. 16).

Por tanto, en sentido estricto, la equidad de la protección social no está dada ni garantizada por el carácter jurídico de la propiedad de las entidades a cargo; es decir, por el carácter público o privado de las entidades que conforman los sistemas de salud, de pensiones o de cuidado. La experiencia histórica de los Estados de bienestar más desarrollados muestra una amplia gama de combinaciones públicoprivadas, en el marco de arquitecturas de la protección social diversas en cuanto a las prestaciones, el financiamiento y los actores intervinientes ${ }^{1}$. En materia de protección social, la equidad está determinada por las características de los Estados de bienestar, por los principios y objetivos que articulan las combinaciones público-privadas dentro de los

\footnotetext{
Véanse, por ejemplo, los interesantes análisis respecto de las vicisitudes de la inserción para el ejercicio de la profesión médica en los distintos Estados de bienestar europeos a lo largo del tiempo (Porter, 1999), o bien, cómo los objetivos y principios de los Estados de bienestar europeos se matizan y transforman de la mano de cambios en el tipo de financiamiento, los nuevos instrumentos y la gestión (Palier, 2010). Entre otros factores, el papel de las entidades estatales y filantrópicas, las regulaciones respecto del ejercicio de la medicina como profesión liberal, la organización de los mercados de trabajo conforme a acuerdos entre las organizaciones empresariales y sindicales, y las profundas transformaciones demográficas han determinado el derrotero de los Estados de bienestar de las democracias occidentales.
} 
sistemas y por las reglas del juego que rigen y regulan sus funciones. En conjunción con las características y el desarrollo de los mercados con los que interactúan los Estados, ello determina una amplia y heterogénea gama de situaciones (Sojo, 1999).

Por ejemplo, como se trató en el capítulo I, la conservadora propuesta del Banco Mundial que se denominó "manejo del riesgo social", a partir del riesgo y del aseguramiento formuló un paradigma global de política social reduccionista en torno a tres planteamientos fundamentales, y propuso una combinación público-privada cuyas delimitaciones y carácter les eran funcionales: las responsabilidades del Estado en materia de bienestar social debían circunscribirse al combate contra la pobreza, el aseguramiento contra los riesgos se establece como un asunto individual a realizarse en el mercado, $y$, en lo fundamental, se desestima la solidaridad en la diversificación de riesgos (Sojo, 2003, pág. 134).

Debido a las complejidades inherentes a la protección social, la aplicación de los principios de universalidad, solidaridad y eficiencia al diseño, el financiamiento, la provisión y la regulación no está exenta de importantes dilemas, cuyas soluciones no son uniformes, sobre todo cuando participan agentes privados.

Cuando se trata de lograr una mancomunación amplia de riesgos con propósitos redistributivos, es indispensable que el aseguramiento tenga un carácter obligatorio. En las antípodas, el aseguramiento privado de mercado orientado por el lucro se ajusta al riesgo individual, tanto en los precios como en la cobertura de las pólizas. De allí que las combinaciones público-privadas dualistas, que se propagaron desde Chile hacia el resto de América Latina con ciertos ajustes, encierren una paradoja: se utilizan contribuciones obligatorias y subsidios cruzados públicos, pero conforme al principio del lucro, al que se subordina el aseguramiento, con lo cual los principios de la seguridad social se abandonan o se restringen de manera contundente (Sojo, 2014a).

Considerando este último aspecto, el sistema de salud chileno es un sistema sui géneris en el plano internacional. Debido a su lógica dual, la cotización obligatoria, que está a cargo exclusivo del trabajador, permite la afiliación al sistema público de salud mediante el Fondo Nacional de Salud (FONASA), cuya forma de reparto favorece la solidaridad, o bien a las Instituciones de Salud Previsional (ISAPRE), que funcionan con una lógica de seguro privado, pese al carácter obligatorio de las contribuciones de que se nutren. El FONASA da acceso a prestaciones públicas en la llamada modalidad institucional o a prestaciones privadas mediante la modalidad de libre elección que está sujeta a diversos copagos, y suma a las contribuciones aportes con cargo al presupuesto público. Las ISAPRE, al contrario de la lógica 
propia del aseguramiento obligatorio, aseguran mediante planes individuales que se renuevan cada año y que plasman una selección de riesgo, al ajustarse su precio y cobertura a la edad, riesgo de salud y sexo del asegurado. El sector público cumple una función de reaseguro global del sistema, ya que, desprovisto de barreras de entrada, cubre a la población de menores ingresos y a la de mayores riesgos (Sojo, 2000). A lo largo de los años, se ha limitado la selección de riesgo de las ISAPRE con medidas paliativas, propiciadas sobre todo por la judicialización del derecho a la salud (véase el capítulo V).

En Chile también destaca el diseño dual del sistema de pensiones, articulado por el lucro, conforme al cual las contribuciones obligatorias al sistema de pensiones de capitalización individual se han traducido en pensiones con bajas tasas de reemplazo y en pingües ganancias de las administradoras de pensiones y de las empresas conexas. En lugar de cumplir el objetivo esencial de maximizar la protección de los ingresos tras la vida activa de la persona mediante las mejores tasas de reemplazo que sean viables en un contexto de optimización de las inversiones de los fondos de pensiones, las administradoras de los fondos y los organismos conexos son los que obtienen y retienen abundantes ganancias.

A diferencia de lo que ocurre con el pago de una póliza individual de seguro de mercado, la dualidad subraya el fin de lucro que tienen estas instituciones, a pesar de que están en juego recursos contributivos o fiscales para el aseguramiento. Por ello, el avance hacia la universalidad, la solidaridad y la eficiencia — cuya definición se abordó en el capítulo IIno es viable dentro de un marco dual. Son esas las razones que hacen indispensable indagar en el fundamento de las combinaciones públicoprivadas en esta materia, y no la caricatura que suele enarbolarse desde el ideario neoliberal ${ }^{2}$.

Ahora bien, el argumento acerca del lucro debe matizarse en esta temática mediante la consideración de "umbrales" de lucro, porque diversos agentes involucrados en la protección social — por ejemplo, los médicos en el ejercicio de su profesión- evidentemente buscan obtener una retribución

\footnotetext{
Piñera, el adalid del sistema de pensiones chileno, plantea lo siguiente: "Creer que la empresa privada era buena para producir refrigeradores y zapatos, pero no para producir servicios de contenido social, tales como educación, salud, pensiones u otros... Nunca pude entender esta incongruencia" (Piñera, 1991, pág. 22). "En Chile la desconfianza ante el interés privado persiste hasta el día de hoy. El estatismo no sembró en vano. Esa resistencia lleva, por ejemplo, a percibir el éxito en el mundo de los negocios casi siempre como una confabulación más o menos fraudulenta en contra de los intereses del cuerpo social; el éxito empresarial, efectivamente, casi nunca es visto como lo que es en una verdadera economía de mercado competitiva, como una recompensa que otorga la comunidad a quien está entregando al mercado algún bien o servicio en términos más convenientes que el resto de la competencia" (Piñera, 1991, pág. 19).
} 
adecuada ${ }^{3}$. El argumento del lucro, no obstante, lo que hace es iluminar, en términos sistémicos, sobre la proporcionalidad, razonabilidad y magnitud de la ganancia de los actores involucrados en relación con los recursos disponibles para la protección social efectiva. Al estar articuladas por la maximización del beneficio privado como principio y objetivo supremos en detrimento de las funciones de aseguramiento, las combinaciones públicoprivadas dualistas, pese al carácter obligatorio de las contribuciones que las distingue de un aseguramiento voluntario de mercado, rompen con los principios de la seguridad social. Debido al uso de recursos contributivos y a las eventuales repercusiones fiscales de su funcionamiento, esta articulación no suele ser reconocida como tal por las empresas administradoras y conexas, aunque asome en la denominación de "industria" con que suelen agruparse las empresas privadas administradoras, prestadoras y aseguradoras de los sistemas dualistas de salud y pensiones; para legitimarse, la oferta de buenos servicios de salud o pensiones se plantea normalmente como el objetivo primordial de su quehacer. Para transparentar el problema, deben contrastarse las ganancias de las entidades empresariales involucradas con las ganancias en bienestar de los afiliados. En este capítulo se develan algunos de los mecanismos y dispositivos mediante los cuales las combinaciones público-privadas en algunos países de la región han puesto en entredicho la diversificación de riesgos (Sojo, 2014).

\section{B. Competencia y capacidad de elección en la protección social: argumentos teóricos y lecciones prácticas}

Ampliar la gama de opciones de los consumidores y su capacidad de elección mediante la competencia ha sido una piedra angular del discurso que ha servido de fundamento a las privatizaciones de la protección social o la participación eminentemente lucrativa de agentes privados en su administración y provisión. Sin embargo, como se verá, la experiencia empírica latinoamericana evidencia que las restricciones a la competencia son muy grandes, que los costos asociados son muy altos, que las conductas de riesgo moral de diversos actores son profusas y que, empíricamente, la mayoría de las personas no ejercen la capacidad de elección o la practican por motivos erróneos (por ejemplo, en razón de campañas publicitarias).

No obstante, como lo señala agudamente Blyth en el planteamiento recogido en el epígrafe de este capítulo, los fracasos empíricos son insuficientes como criterio de verdad, y el relativismo de la verdad vuelve

La autora agradece a Olga Lucía Acosta por haberle sugerido la idea del "umbral de lucro" en una conversación, una idea que luego amplió. 
crucial considerar la teoría en que estos hechos empíricos se insertan y las relaciones de poder en las que operan los criterios de verdad. De allí que sea conducente traer a colación una serie de argumentos que se han planteado en el debate internacional a favor de acotar la elección en los sistemas de protección social.

Los problemas de información y las características de la conducta humana explican una considerable divergencia de los óptimos (first-best) predichos por cierta teoría económica: en la práctica, se observan más bien conductas de indecisión, de inercia y de inmovilización que es indispensable considerar. Debido a que la información imperfecta y asimétrica, los mercados incompletos y el comportamiento "no racional" (conforme a lo que la economía había definido como racional) son omnipresentes, se propone enmarcar el análisis del aseguramiento y el diseño de políticas en un corpus teórico que considera opciones (second-best), desarrollado por una vasta literatura de destacados autores como Stiglitz, Akerloff y Spence, Kahneman, Diamond, Mortensen y Pissarides, Mirrlees y Vickrey. Consecuentemente, el modelo o el postulado del consumidor bien informado no puede sustentarse en muchos ámbitos de la política social, entre otras razones, por las siguientes (Barr, 2013, págs. 73-75; Barr, 2014):

i) Problemas de información: las personas carecen del conocimiento requerido para tomar decisiones fundamentadas y complejas; las asimetrías de información son muy grandes; generalmente se requieren conocimientos especializados (por ejemplo, en finanzas o en medicina) para ejercer una capacidad de elección cabal, aun cuando esta sea de carácter limitado. Mucha gente no tiene conciencia de los riesgos que enfrenta, ni comprende bien las probabilidades de que estos ocurran. Las restricciones en este ámbito se potencian por las desiguales condiciones socioeconómicas. Sin embargo, incluso cuando las decisiones son acertadas, las ganancias pueden ser reducidas o tener efecto solo en lapsos cortos, mientras que los costos de transacción requeridos, medidos en tiempo, pueden ser muy altos (por ejemplo, para manejar cuentas individuales de pensiones). Si la regulación es débil, pueden surgir engaños.

ii) Problemas de racionalidad restringida (bounded rationality): incluso cuando la información pertinente está disponible, los problemas son muy complejos para tomar buenas decisiones. Las restricciones son más grandes cuanto más amplio es el horizonte de tiempo y cuanto mayor es la complejidad de los resultados y de las probabilidades, o la de los productos; es decir, precisamente en aquellas condiciones que son propias de los sistemas de pensiones y de salud. En ese contexto, las 
restricciones conducen, de diversas formas, a tomar decisiones erróneas. Puede darse un comportamiento inercial de las personas, que evitan los cambios - por ejemplo, de afiliación, de pólizas o del grado de exposición al riesgo de sus ahorros de pensiones - sin analizar las bondades o defectos que tiene su elección. Más aún, la complejidad y la información conflictiva llevan a un comportamiento pasivo e incluso a la paralización: las personas reaccionan como conejos cegados por los faros de un automóvil en la noche.

iii) Restricciones al poder de decisión (bounded will power): en ocasiones, las personas enfrentan dificultades para llevar a la práctica la estrategia que se plantean y que, en principio, puede ser la correcta (como reconocer la necesidad de ahorro para obtener una pensión). Sin embargo, la posponen en función de gratificaciones inmediatas, lo que se traduce en una inconsistencia en el tiempo. De este modo, las personas son racionales en cuanto al futuro, pero no en cuanto al presente; cuando el futuro llega, se transforma en el presente y, entonces, prima el corto plazo (Barr, 2014).

Estos argumentos sobre la complejidad de la información y del comportamiento humano permiten extraer importantes conclusiones que se detallan a continuación respecto de la arquitectura de los sistemas de protección social, cruciales especialmente en el ámbito de pensiones y de salud (Barr, 2014).

i) Es insuficiente impulsar la capacidad de elección mediante el voluntarismo o con programas de formación financiera y análogos.

ii) Como la diversidad de opciones puede derivar en una falta de participación y mucha gente no realiza elecciones, es pertinente diseñar una buena opción de afiliación por defecto (default), es decir, automática y obligatoria, que vele por una buena protección contra riesgos, con bajos costos de administración. Como es difícil y complejo optar por un paquete óptimo de aseguramiento y de homogenización del consumo, dado que ello requiere un análisis sofisticado y detallado de los datos y las decisiones, un programa público por defecto puede optimizar las decisiones (Diamond, 2001, pág. 157).

- La política pública debe propugnar que las elecciones que deban o tengan que hacer los individuos sean lo más simples posibles.

- Comola elección tiene costos, es beneficiosa únicamente cuando las ganancias de bienestar compensan con creces los costos. 
iii) A su vez, deben impugnarse las reducciones de bienestar ocasionadas por altos costos administrativos.

iv) Es erróneo promover a secas la competencia y la elección, que además suelen ir de la mano de altos costos administrativos. No se trata de maximizar la elección, sino de optimizarla, y la complejidad excesiva no es sinónimo de una mayor capacidad de elección.

v) En esos términos, la elección excesiva debe restringirse. Por ejemplo, considerar un número acotado de administradores de fondos de pensiones, de aseguradores o de prestadores de salud es un dispositivo deliberado de diseño, que puede mejorar los sistemas de protección social alambicados.

vi) Los costos de administración de los sistemas pueden reducirse (por ejemplo, con una administración centralizada de los recursos, separada de la gestión). La gestión también puede organizarse con economías de escala.

Como se verá más adelante, la capacidad de elección y la competencia son elementos fundamentales de la discusión actual en torno a los sistemas de protección social de la región, cuyas reglas, presuntamente, buscaban promover ambos aspectos y cuyos resultados en esos términos son decepcionantes.

\section{La legitimidad de los sistemas de protección social y el cambio institucional: una breve introducción conceptual}

La viabilidad política y la sostenibilidad a largo plazo de los sistemas de protección social requieren de legitimidad: de allí la importancia de una disposición favorable de la ciudadanía. Las carencias de los beneficios en materia de pensiones o de salud tienen externalidades negativas, ya que no generan incentivos adecuados para fortalecer y profundizar los mercados laborales (Sojo, 2003) ni para afianzar el cumplimiento tributario y contributivo. Esto crea un círculo vicioso porque se ahonda el desfinanciamiento de los sistemas y, con ello, se pone en entredicho su sostenibilidad.

No obstante, por encima de las asimetrías de información inherentes a la complejidad de la protección social que hemos abordado en el capítulo II y en el apartado IV.B, al jubilarse, las personas experimentan las consecuencias de determinadas tasas de reemplazo y pueden contrastar esta experiencia con su esfuerzo personal de ahorro y con las expectativas que en él han cifrado o con las promesas que respecto del sistema habían difundido sus promotores. Ello genera 
percepciones negativas o positivas respecto del sistema de pensiones y la razonabilidad de los beneficios que este brinda, en términos del vínculo entre el ahorro y los beneficios y su proporcionalidad, así como también acerca de si las ganancias privadas que genera el sistema son o no desproporcionadas respecto del bienestar efectivo de los jubilados. Esto también puede darse respecto del sistema de salud, según el bienestar en materia de salud que se experimente en función de determinadas prestaciones preventivas o curativas de salud. Es decir que, por encima de las asimetrías de información, hay una percepción positiva o negativa y una experiencia de ganancia o disminución del bienestar.

Como se vio en el capítulo II, el nivel deseado de aseguramiento depende, entre otros elementos, del bienestar que es atribuible a la reducción del riesgo que así se obtiene y a la percepción que se tenga acerca de sus costos. En el campo de las pensiones, por ejemplo, puede afirmarse que cuando los potenciales cotizantes perciben que el costo que sufraga los gastos administrativos y las ganancias es excesivo, esto opera como un desincentivo para cotizar. La percepción de que las pensiones que se van a obtener son bajas no es un buen incentivo para el cumplimiento. Pese a su carácter obligatorio, este puede eludirse o postergarse cuando ello es viable, como en los contratos por honorarios en Chile. Cuando los sistemas de protección social están afectados en su legitimidad, se incrementa la propensión a incumplir —según sea la forma de financiamiento- el pago de las contribuciones o de los impuestos, asunto que fue tratado en el capítulo III y examinado respecto de tres países de la región.

Como se detalló en el capítulo III, el incumplimiento contributivo, que puede denominarse "evasión contributiva", es un aspecto crucial en el diseño y funcionamiento de los sistemas de pensiones, ya que incide en el futuro nivel de las pensiones, en la sostenibilidad financiera del sistema y en su legitimidad política. Las lagunas de cotización pueden deberse a vicisitudes de la inserción laboral, a comportamientos vinculados a los polizones (free-rider) y a la miopía intertemporal de jóvenes que postergan el cumplimiento, así como a diversas estrategias de evasión de las contribuciones por parte de los sujetos que cotizan, ya sean empleados o empleadores. En materia de protección social, el incumplimiento puede traducirse en la exclusión del sistema o en la subprovisión de prestaciones; en el caso de las pensiones organizadas en cuentas individuales, el monto de las pensiones está asociado, entre otros elementos, con las densidades de cotización. Desde esta perspectiva, la evasión contributiva afecta la sostenibilidad financiera de la protección social y tiene externalidades fiscales negativas, ya que puede requerir mayores esfuerzos económicos del Estado —o tasas de imposición más 
elevadas que las óptimas - para implementar sistemas complementarios y no contributivos que permitan brindar prestaciones básicas en materia de pensiones y salud a la población excluida del régimen contributivo o que alcanza niveles insuficientes de aportes que deben complementarse con recursos fiscales en sistemas solidarios. Así, la evasión contributiva y la mala o volátil inserción laboral en mercados con altos niveles de informalidad incrementan las presiones fiscales sobre los gobiernos para sufragar sistemas no contributivos con financiamiento fiscal (Gómez Sabaini, Cetrángolo y Morán, 2014).

Seguidamente, indagaremos en la crisis de legitimidad de los sistemas contributivos de salud y pensiones en Chile y del sistema de salud de Colombia, y sintetizaremos algunas propuestas de reforma que cuestionan en varias dimensiones la lógica de las combinaciones público-privadas que los han caracterizado. Cabe subrayar que los tres sistemas se implantaron en el marco de reformas radicales que suplantaron a los regímenes previos: en Chile, en el marco de la dictadura militar, y en Colombia, en un contexto democrático en el cual se logró la aprobación parlamentaria.

A manera de introducción al análisis de los aspectos críticos, de las propuestas en juego y su perspectiva, se hará una breve reflexión general sobre algunos aspectos de cambio institucional que se observan en esos casos. A tal efecto, parece útil la tipología desarrollada por Streeck y Thelen (2005) y por Mahoney y Thelen (2009), que considera la interacción entre contexto político y cambio institucional y se adentra en la naturaleza debatible de las reglas institucionales, ya que no es unánime lo que los actores entienden por reglas, la apertura y la flexibilidad en cuanto a cómo estas reglas se interpretan e implementan, y el grado de ambigüedad que pueden explotar los actores (véanse el diagrama IV.1 y el cuadro IV.1). En los tres casos que analizaremos, el cambio de los sistemas opera bajo fuertes posibilidades de veto. El desarrollo de los sistemas ha ido de la mano del fortalecimiento económico y político de actores a cargo de instituciones que son parte integral de los sistemas (ISAPRE, Administradoras de Fondos de Pensiones (AFP), Entidades Promotoras de Salud (EPS), Instituciones Prestadoras de Salud (IPS)) y también de actores externos al sistema que obtienen grandes beneficios de su derrotero, como las compañías farmacéuticas en Colombia o las empresas financieras y los bancos en Chile, que pagan muy bajos dividendos a los fondos de pensiones. En las distintas experiencias, salta a la vista que el proceso de cambio institucional es de ajustes mutuos, influidos por preocupaciones distributivas que están relacionadas con múltiples instituciones y que tienen efectos incrementales en las estrategias de los actores (Hall y Thelen, 2009). 


\section{Diagrama IV.1 \\ Contexto y cambio institucional}

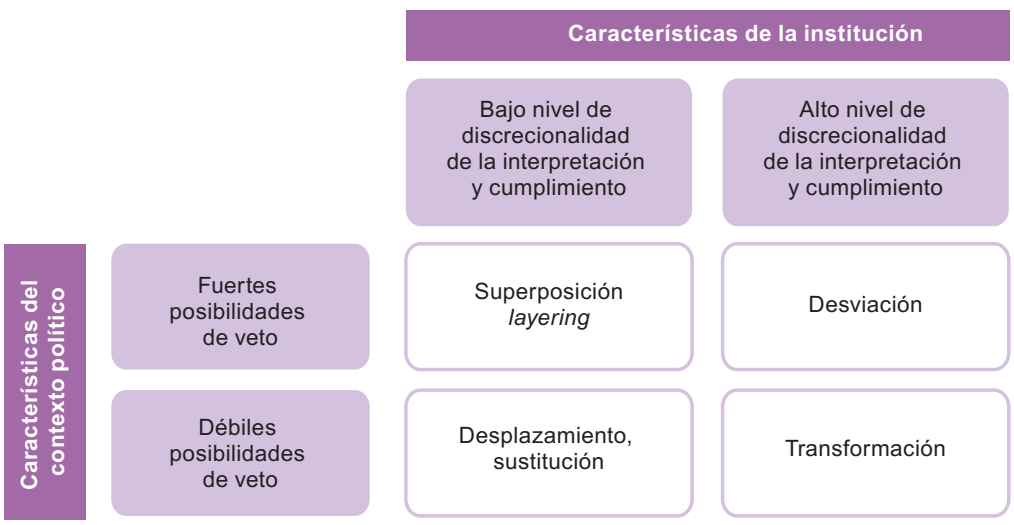

Fuente: J. Mahoney y K. Thelen, "A theory of gradual institutional change", Explaining Institutional Change, Ambiguity, Agency, and Power, J. Mahoney y K. Thelen (eds.), Cambridge University Press, 2009, cuadro I.1 y W. Streeck y K. Thelen, Beyond Continuity. Institutional Change in Advanced Political Economies, Oxford University Press, 2005, cuadro I.1.

Cuadro IV.1

Tipos de cambio gradual

\begin{tabular}{lcccc}
\hline & Sustitución & $\begin{array}{c}\text { Superposición } \\
\text { (layering) }\end{array}$ & Desviación & Transformación \\
\hline Eliminación de viejas reglas & Sí & No & No & No \\
\hline Incumplimiento de viejas reglas & -- & No & Sí & No \\
\hline $\begin{array}{l}\text { Cambio del impacto/aprobación } \\
\text { de viejas reglas }\end{array}$ & -- & No & Sí & Sí \\
\hline Introducción de nuevas reglas & Sí & Sí & No & No \\
\hline
\end{tabular}

Fuente: J. Mahoney y K. Thelen, "A theory of gradual institutional change", Explaining Institutional Change, Ambiguity, Agency, and Power, J. Mahoney y K. Thelen (eds.), Cambridge University Press, 2009, cuadro I.2 y W. Streeck y K. Thelen, Beyond Continuity. Institutional Change in Advanced Political Economies, Oxford University Press, 2005, cuadro I.1.

El poder de los distintos actores -internos y externos- y su capacidad para articular alianzas ha coartado hasta el momento la posibilidad de implementar estrategias transformadoras profundas. Sin embargo, en los tres casos recientemente se han puesto sobre el tapete cambios de gran envergadura, que hubiesen sido impensables hace algún tiempo debido a la hegemonía de las ideas con que habían sido fundadas las reformas. Dada la complejidad de las condiciones políticas, hay un signo de pregunta respecto de cuál será su derrotero. Es que los actores políticos no reflexionan únicamente sobre los problemas de las políticas y sus posibles soluciones, sino también sobre los vínculos de causalidad entre las instituciones y sus posiciones de poder; conforme a las constelaciones de poder, se seleccionan, modifican o ignoran distintos planteamientos e ideas relevantes para las políticas (Hemerijck, 2013, pág. 46). 
En el horizonte más cercano se advierten estrategias de cambio gradual que, al operar bajo la fuerte capacidad de veto de una gama de poderosos actores, podrían tratar de subvertir los sistemas acudiendo a modificaciones de superposición (layering), en que nuevas reglas comienzan a "convivir" con las viejas. Es el caso de la propuesta de una AFP estatal en Chile; en Colombia, es el caso de la regulación de los precios y de la licencia de los medicamentos, o bien de la elaboración de una lista de prestaciones excluidas, en acuerdo con la Corte Constitucional, en un marco de gran litigio sobre el derecho a la salud. En este capítulo y en el capítulo V se observa que también han habido espacios importantes para una alta discrecionalidad en la interpretación de las reglas, como en Colombia en el marco de la judicialización, que dio origen a prestaciones de salud que no estaban consideradas y que, tras muchos años, coadyuvaron a la implantación de nuevas reglas, como la convergencia de los regímenes subsidiado y contributivo que se había ido rezagando.

El momento actual es crucial para una inflexión que recupere los principios de la protección social y, dadas las restricciones políticas al cambio, son indispensables los esfuerzos discursivos extraordinarios que puedan contribuir a cambiar el statu quo de la protección social. En ese sentido, el argumento en torno al lucro puede proveer una ilación transversal a distintos campos, como las pensiones y la salud, y es potente porque encierra la posibilidad de "reinterpretar" lo que los actores asocian con una institución (Streeck y Thelen, 2005). Como idea, además, tiene condiciones de suficiencia, en cuanto a su aplicabilidad, adecuación, pertinencia y resonancia (véase Schmidt, 2008) para coadyuvar al desarrollo de políticas alternativas. Tras el apogeo de la individuación de riesgos, quizá nos encontremos al inicio de una transición en que el rechazo al lucro se constituya en un vehículo, un medio para catalizar transformaciones hacia la solidaridad y la universalidad de la protección social, en un escenario en el cual la maduración de los sistemas ha develado varios de sus problemas estructurales y, con ello, ha creado condiciones favorables para el cambio. La confrontación en torno al lucro puede proveer un marco en el que se expresen conflictos de los actores y fuerzas sociales y se llegue a nuevas formas de resolución 4 .

Sobre la relevancia de los elementos catalizadores de cambios, es muy interesante el análisis que realiza Dorothy Porter del papel que cumplió el cólera en el desarrollo del sistema de salud en Alemania. Porter señala que el cólera actuó como catalizador del cambio. No creó revoluciones sociales ni sistemas de salud pública, pero contribuyó al proceso de transición histórica hacia la sociedad industrial. Quizás el mejor ejemplo de esto sea su papel en la caída del laissez-faire en Hamburgo en 1892. En vez de provocar directamente un levantamiento, sirvió como vehículo, como medio para representar un relato histórico cuyo escenario ya estaba montado. Ofreció un marco en el que los actores y las fuerzas sociales no solo expresaron los conflictos, sino que los resolvieron (Porter, 1999, pág. 96). Algunos de estos argumentos se emplean aquí para destacar el papel que podría jugar la argumentación en torno al lucro. 


\section{Las disputas en torno a la reforma del sistema contributivo de pensiones en Chile ${ }^{5}$}

Las cuentas individuales obligatorias para el retiro como eje del sistema contributivo de pensiones se originaron en América Latina a partir del caso chileno ${ }^{6}$. Aunque en ningún país el Estado se retiró completamente de los sistemas de pensiones, el desencanto con aquellas transformaciones extremas ha inspirado la fase de reformas a lo largo del último decenio en diferentes países y en la que el Estado ha vuelto a hacerse más presente mediante tres modalidades: i) disposiciones que permiten a algunas categorías de trabajadores retornar al sistema de reparto, ii) introducción de mecanismos redistributivos que incorporan solidaridad y iii) creación de nuevos fondos de pensiones. Se combina así una cierta reducción - diversa en su cuantía- de la extensión de las cuentas individuales, con medidas que pretenden mejorar algunos de sus aspectos (Bertranou, Calvo y Bertranou, 2009, págs. 3 y 4). Solo en el caso argentino se reestatizó el sistema de pensiones que había sido privatizado.

Los elementos que se analizan en este apartado no son privativos de la realidad chilena, ya que atañen al sentido y la trayectoria de un sistema que, por paradigmático, tiene especial relevancia para los países donde fue implantado. También tiene relevancia para toda la región, en la medida en que este ideario fue impulsado con singular denuedo en las últimas décadas, como eje de un "poder sobre las ideas" y "poder en las ideas" (Castersen y Schmidt, 2015), por parte de actores que buscaron controlar y dominar el significado de las ideas mediante su imposición y el debilitamiento de otras concepciones, o simplemente su ignorancia o desprecio, y cuya traducción institucional, por medio de las transformaciones radicales de los sistemas de pensiones, socavó durante muchos años la capacidad de otros para hacer propuestas alternativas. Como ya se ha dicho, conforme al eufemismo utilizado por José Piñera, uno de los principales artífices de las reformas de pensiones y de salud en Chile durante la dictadura militar, se trataba de "extender la disciplina del mercado al sector social". Como se verá, el cuestionamiento en Chile ha ganado radicalidad con el transcurso de los años, a la luz de los negativos rendimientos en el bienestar de los pensionados y de transformaciones políticas más globales, lo que se traduce claramente en el cariz de los aspectos abordados y en el tipo de propuestas y polémicas.

Este apartado retoma, con actualizaciones y complementos, algunos planteamientos tratados en Sojo (2014).

6 Se exportaron incluso a El Salvador, país que, como se ha visto en el capítulo III, tiene una cobertura muy baja del sistema de pensiones y un escaso desarrollo del mercado de capitales. En la actualidad, los compromisos fiscales en relación con la privatización del sistema de pensiones y el pago a los beneficiarios del viejo sistema llevan a afirmar que se han constituido en un factor de "insostenibilidad fiscal" (ICEFI, 2013, págs. 13 y 42). 


\section{El sistema de pensiones chileno y algunos hitos de la creciente deslegitimación del sistema contributivo}

El actual sistema contributivo de pensiones en Chile carece de legitimidad de origen, al haber sido establecido cuando los derechos de libertad, políticos y civiles estaban siendo conculcados y al haber sido urdido, con una verticalidad extrema, entre cuatro paredes ${ }^{7}$

A aquella ilegitimidad de origen se suma que la titularidad de los derechos sociales ha ido ganando cada vez más terreno en el mundo y también en Chile, como marco normativo y político de las políticas públicas, lo que determina el perfeccionamiento de las instituciones y la ampliación de recursos para avanzar hacia su satisfacción. En la perspectiva de los derechos sociales, gozar de ingresos dignos tras la vida laboral activa como objetivo primordial del sistema de pensiones tiene carácter de norma democrática sustancial; es decir que su incumplimiento puede afectar la sustancia de las decisiones y su legitimidad (Ferrajoli, 2008). Los demás objetivos o externalidades que pudiera tener un sistema de pensiones no deben reñir con el cumplimiento del objetivo supremo y primordial de los sistemas de pensiones y que, en el caso del pilar contributivo, alude a tasas de reemplazo proporcionales y adecuadas, en consonancia con los esfuerzos de ahorro, como se vio en el capítulo II. A la ilegitimidad de origen se ha agregado otra a lo largo de los años, ya que la maduración

En este marco de análisis, resulta interesante ver cómo José Piñera, en su recapitulación de la reforma, se refocila en la forma en que esta fue aprobada. Al dificultarse el proceso por reticencias de las fuerzas armadas, él amenaza con renunciar como Ministro y Pinochet le pide paciencia. A lo largo de una semana, el equipo forjador de la reforma comienza a desmoralizarse. Finalmente, al exceptuarse a las Fuerzas Armadas de la reforma previsional, se allana la aprobación expedita del proyecto por la Junta de Gobierno: “-Presidente, usted me ha dado su apoyo en el boicot y en el Plan Laboral. Usted ha hecho por Chile más que cualquier presidente. Lo respeto y lo admiro. Pero no puedo seguir de ministro si ahora usted me abandona y no se aprueba la reforma previsional. Entiendo muy bien, Presidente, que usted está presionado por altos oficiales del Ejército. Entiendo que está entre dos fuegos. Pero a mí me parece que usted debiera decidirse por lo que es bueno para Chile. Si no lo puede hacer, lo comprenderé y seguiré siendo partidario suyo, pero desde fuera del gobierno, para poder continuar luchando sin restricciones por mis ideales para Chile. Me miró fijamente a los ojos; le sostuve la mirada, y entonces me dijo: - No se apresure, ministro, no se apresure. Desde luego que no lo hice, aun cuando con el paso de los días, mi inquietud fue en aumento. El equipo comenzaba a desmoralizarse. A diferencia de la derrota que habíamos sufrido tres meses antes, esta sería definitiva. La vez anterior no se habían jugado todas las cartas e influyó un hecho externo a la discusión: el plebiscito constitucional. Ahora, en cambio, sería un revés sin apelación porque el problema iba a radicar en la falta de voluntad del gobierno para seguir adelante. Ahora no perderíamos una batalla sino la guerra. Después de una semana el Presidente me llamó a su oficina. La reunión duró exactamente un minuto. - ¿Cómo está, José? Estoy convocando a la Junta para terminar el análisis del proyecto. Eso fue todo. No hubo referencia alguna a la crisis de la semana anterior. Tampoco quise preguntar nada. ¿Qué ocurrió entre tanto con las posiciones que parecían irreductibles? Nunca lo supe con exactitud y preferí no volver a tocar el tema" (Piñera, 1991, págs. 38 y 39). Evidentemente, fue la exclusión de las fuerzas armadas del nuevo sistema de pensiones lo que permitió superar las reticencias aludidas. 
del sistema ha evidenciado empíricamente que no se satisface adecuadamente este derecho social: el objetivo primordial del sistema de pensiones - proveer seguridad del ingreso en la vejez- no se cumple cabalmente debido al bajo nivel de las pensiones.

El incumplimiento del derecho ciudadano a gozar de una adecuada homogenización del consumo en la vejez y que incluso podría considerar algunas dimensiones de aseguramiento en términos de proteger la exposición individual a los ciclos económicos, lleva a cuestionar la actual articulación del sistema contributivo basado en el lucro, dado que mientras las tasas de reemplazo son bajas, son muy altas las ganancias directas de las administradoras y aseguradoras y las ganancias indirectas de las empresas financieras y los bancos que se benefician de una inversión concentrada de los fondos de pensiones a bajas tasas de interés. En ese sentido, además de su origen espurio, el sistema contributivo de pensiones, que ha mostrado sus alcances y restricciones, no cumple con el objetivo supremo de brindar a los pensionados ingresos dignos tras su vida laboral activa, precisamente debido al fundamento de su arquitectura.

La experiencia empírica permite situar en su justo lugar el cumplimiento de los objetivos con que sus impulsores fundamentaron la privatización del sistema: "El objetivo clave para darle la administración a la empresa privada fue aquel de maximizar el nivel de pensiones que podría dar el sistema de capitalización individual" (Piñera, 1991, pág. 22).

La maximización de las pensiones que se logra en el marco del sistema resulta inadecuada porque se ve impedida por la propia arquitectura del sistema. Los rendimientos del patrimonio que se plasman en las cuentas individuales son inadecuados debido a las bajas tasas de reemplazo, rasgo que tiene un carácter sistémico y endémico porque no puede deslindarse de la maximización del lucro privado con que han operado los administradores directos (AFP) y de los beneficios que entraña para las empresas financieras, bancarias y grandes tiendas minoristas, que concentran cuantiosos recursos de los fondos de pensiones y pagan muy bajos intereses (Rivera, 2009, 2014a y 2014c).

Como se vio en el capítulo II, el objetivo primordial de un sistema de pensiones es proveer seguridad del ingreso en la vejez, lo que reúne, al menos, cuatro elementos: homogenización del consumo, aseguramiento, auxilio a la pobreza y redistribución. Como por lo general estos elementos no pueden lograrse cabalmente al mismo tiempo, la política debe buscar optimizarlos de manera transversal, no minimizarlos ni maximizarlos (Barr y Diamond, 2008, pág. 21). Las pensiones deben reflejar los esfuerzos de ahorro realizados a lo largo de 
la vida del asegurado y el criterio de equivalencia debe garantizar que, a niveles semejantes de esfuerzo, se obtendrán protecciones similares o proporcionales (CEPAL, 2000, pág. 78).

En un sistema contributivo, la equivalencia es entre la historia de contribuciones y las tasas de reemplazo. Por las características del sistema chileno, que carece de mecanismos de aseguramiento y que fue desprovisto del aporte patronal, la equivalencia se da estrictamente a escala individual, sin mecanismos de solidaridad o de diferenciación de riesgos (por ejemplo, ante los riesgos financieros). El pilar solidario, por su parte, representa un auxilio a la pobreza, es redistributivo y coadyuva al aseguramiento mediante ingresos en la vejez que amortiguan la caída tras la vida activa; a tal efecto, los recursos tributarios cumplen un papel crucial. Pero el sistema contributivo de pensiones evidencia fallas graves en cuanto a la nivelación del consumo que brinda, y carece de elementos redistributivos que, por ejemplo, amortigüen los efectos negativos de los ciclos económicos y de la volatilidad financiera. Además, el cálculo actuarial de las pensiones discrimina a las mujeres.

El juicio negativo parece advertirse también en los niveles de incumplimiento contributivo y en la postergación del ahorro previsional. En el sistema contributivo de pensiones se aprecia una amplia brecha entre la afiliación y el cumplimiento contributivo y, con ello, la magnitud de las llamadas "lagunas previsionales", que reducen las expectativas de buenas pensiones, ya que la densidad de cotizaciones es crucial respecto de las futuras tasas de reemplazo y de los potenciales compromisos fiscales relacionados con el pilar solidario para quienes no logran determinados niveles de pensiones. Con la maduración del sistema, la brecha entre afiliados y cotizantes debería haberse reducido, pero ocurrió el fenómeno contrario: en 1985, un 57\% de los afiliados cotizaban sin mayores diferencias por sexo, mientras que en 2014 cotizaban un 53\% de los hombres y un $41 \%$ de las mujeres (véase el gráfico IV.1).

Otras cifras arrojan luces sobre el sistema de pensiones chileno. Como hemos visto en el capítulo III, las cifras de cobertura denotan ciertos rasgos del sistema de pensiones. De acuerdo con los niveles actuales de afiliación de los asalariados a sistemas de pensiones en América Latina, Chile se ubica en el grupo de países con mayor cobertura de pensiones. En Chile las mujeres asalariadas registran menores niveles de afiliación a sistemas de pensiones que los hombres, aunque se observa un incremento de la afiliación entre las mujeres no asalariadas desde su situación de desventaja. En cuanto a la distribución socioeconómica de la afiliación a sistemas de pensiones, se observa una importante mejora relativa de los sectores de menores ingresos: la afiliación es algo menos regresiva. 


\section{Gráfico IV.1}

Chile: número de afiliados y cotizantes al sistema contributivo de pensiones, total y por sexo, 1985-2015

(En miles de personas)

A. total

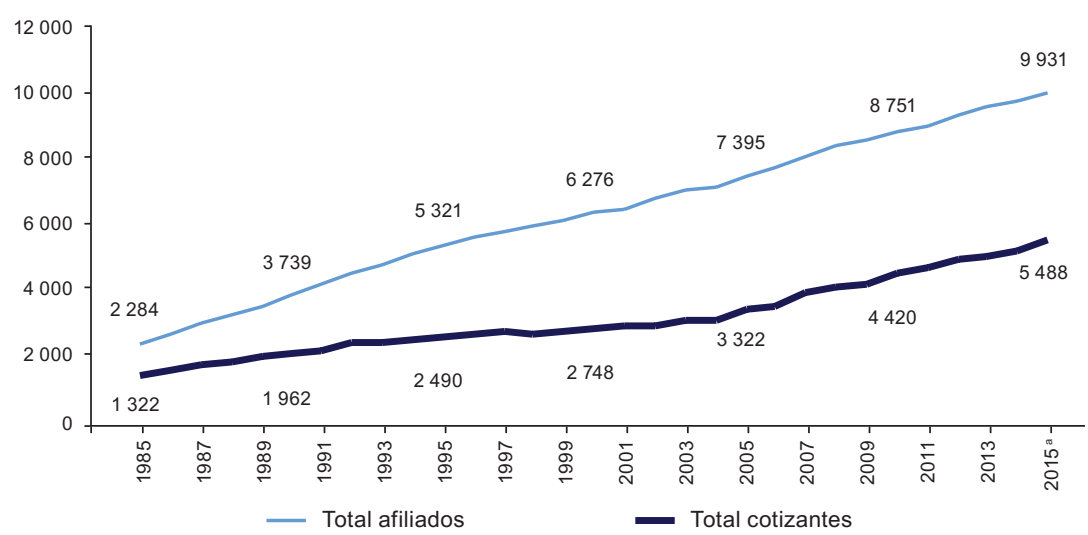

B. Por sexo

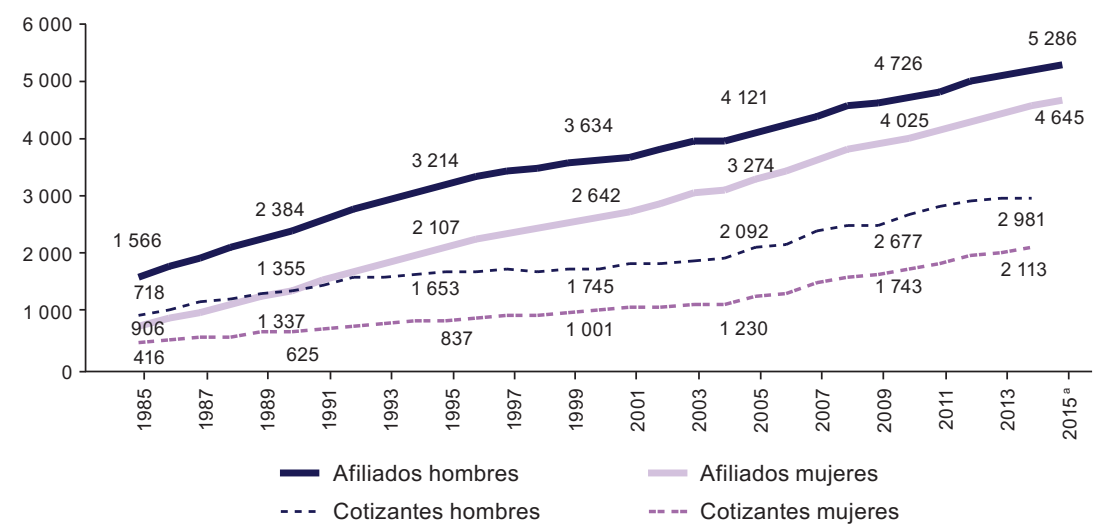

Fuente: Elaboración propia, sobre la base de datos de la Superintendencia de Pensiones.

Nota: Se consideran cotizantes a quienes pagaron contribuciones durante diciembre de cada año por remuneraciones devengadas el mes anterior. Los afiliados son activos y se excluye a los pensionados cotizantes. No se considera la categoría "sin información", por lo que puede haber residuos respecto del total.

a La información para el último año abarca hasta septiembre de 2015 y para los cotizantes no se encuentra desagregada por sexo.

Como vimos en el capítulo III, Chile forma parte del grupo de países con alta cobertura de pensiones en América Latina, pero tiene el nivel medio de pensiones contributivas más bajo del grupo. Por otra parte, en los últimos años estas han experimentado caídas que afectan a todos los quintiles, excepto al IV, tendencia que no se observa en ningún otro país de la región. En cuanto a la inserción laboral, en todos los 
países latinoamericanos, con excepción de Chile, ser asalariado público implica una mayor probabilidad de contribuir en comparación con los asalariados de empresas privadas (ello probablemente denota la cuantía de los contratos por honorarios). La situación de los trabajadores por cuenta propia tiene efectos negativos especialmente elevados en Chile.

En el capítulo III también se analiza la inserción laboral de la población de 65 años. En Chile, de ese contingente de personas, un 71\% de los hombres y un $75 \%$ de las mujeres reciben pensiones, rasgo que difiere de otros países, como Costa Rica, donde los adultos mayores ocupados mayoritariamente carecen de pensiones. Ello pone sobre el tapete la pregunta acerca de las causas: es decir, si estos pensionados chilenos se van obligados a trabajar debido a la insuficiencia de sus pensiones o por otras razones (como la autorrealización) y en qué proporción.

Las principales transformaciones que ha sufrido el sistema desde su origen acontecieron durante el primer gobierno de la Presidenta Bachelet. La reforma previsional entonces emprendida, debido a algunas de sus características, fue promovida activamente por las administradoras y por la comunidad epistémica que giraba en torno al sistema. Entre las propuestas se destacaron las del presidente de la Asociación AFP Chile, Guillermo Arthur, respecto de aumentar la cobertura y generar incentivos al ahorro voluntario de los sectores más pobres, y las promovidas por Solange Berstein, Superintendenta de Administradoras de Fondos de Pensiones hasta marzo de 2014, respecto de liberalizar los topes a la colocación de los fondos de pensiones en el exterior. La creación del pilar solidario, a pesar de su innegable vocación redistributiva, era de interés de las administradoras desde un punto de vista más general: es funcional al sistema de capitalización individual en tanto disminuye las presiones por incumplimiento de los objetivos y por insuficiencia de las pensiones de la mitad de la población que no lograba ingresos mínimos para la vejez; ello sin erogaciones, ya que los costos recaen exclusivamente sobre el Estado, y con el beneficio de seguir administrando los recursos ahorrados por quienes finalmente recibirían el subsidio público, con las comisiones correspondientes. Por otra parte, las AFP comenzaron a poder subcontratar las operaciones básicas de recaudación y de administración de cuentas y de redes de sucursales, así como la gestión de inversiones o administración de fondos. Esto pone sobre el tapete un relativo vaciamiento de las funciones de las AFP (Rivera, 2009, 2010 y 2014b, pág. 91).

El ejercicio de la capacidad de veto de la mal llamada "industria" a ciertos aspectos de la reforma que eran percibidos como adversos trascendió entonces al propio seno del Gobierno ${ }^{8}$ Se traslució, por ejemplo,

El término "industria" para denominar a las empresas que giran en torno al sistema contributivo de pensiones, a pesar de que abarcan eminentemente servicios y finanzas, fue acuñado por su ideólogo, José Piñera (Piñera, 1991). 
a la hora de impugnar la creación de una AFP estatal, idea que antes del inicio de la discusión sobre la reforma previsional ya había sido planteada por diversos actores políticos y expertos en temas de seguridad social identificados con sectores de centroizquierda, como alternativa para estimular la competencia y reducir los costos de administración del sistema contributivo. Aunque no era compartida por todos los parlamentarios del oficialismo, la propuesta contaba con adherentes que abrieron un debate sobre la posibilidad de considerarla desde el Poder Ejecutivo. Ello tensionó la discusión entre las carteras de Hacienda y Trabajo, que mantenían posiciones encontradas, especialmente sus respectivos ministros. Andrés Velasco, entonces Ministro de Hacienda, siempre fue adverso a la AFP estatal y solo se mostró anuente a que se incorporase la banca al negocio de la administración de los fondos y, en ese marco, a posibilitar la participación de una entidad pública, como el Banco Estado. Pero aun esta acotada propuesta abrió primero un frente de debate dentro del sistema financiero, la industria de las AFP, la banca y las compañías de seguros, para enzarzarse posteriormente en la discusión parlamentaria, y quedar fuera de la discusión, haciendo visible la gravitación de las interrelaciones entre actores económicos con intereses en esa industria y actores políticos con capacidad resolutiva (Maldonado y Palma, 2013, págs. 35 y 59).

Es adecuado, por tanto, reflexionar sobre algunas condiciones políticas que podrían desde entonces haber modificado la tenaz capacidad de veto de la diversificada "industria previsional". Si bien la actual capacidad de veto de la "industria" no debe subestimarse, también deben considerarse algunos cambios en la situación política, sobre todo a partir del movimiento estudiantil y de su contundente influencia en términos discursivos, al haber plasmado un discurso comunicativo que cuestiona el lucro en las políticas sociales de educación, cuyos efectos han irradiado hacia el ámbito de la protección social, y que legitima la búsqueda de políticas alternativas.

Claudia Serrano identifica esa inflexión al plantear que en Chile se han allanado caminos para reformas abiertas a una ciudadanía más demandante y se ha transformado la hegemonía acerca de lo que es viable en política social, dentro de un campo de negociación y de persuasión, al haberse debilitado la influencia de los criterios de mercado y de Estado subsidiario y al cuestionarse un afán reformista que había experimentado cierto congelamiento y acomodación: "Hasta que la ciudadanía nos hizo ver en el año 2011 algo que en parte se debe atribuir a los propios resultados de los 20 años anteriores. Claramente, nos dijo 'no va más'. Pero este 'no va más' no apuntó a problemas de acceso, ni siquiera de calidad de los servicios, que fue el segundo tema que comenzó a plantearse.... Se [pusieron] en el tapete... las bases valóricas del sistema y los acuerdos básicos de la sociedad respecto de temas importantes para la ciudadanía. Lo que se puso por delante fue el concepto de ciudadanía y derecho de quienes son 
parte de una misma comunidad cívica, ya no como cobertura o acceso en el sentido técnico de la política, sino en el sentido de ser miembro pleno de la comunidad. Por ejemplo, ¿a qué tengo derecho como chileno de clase media? Sobre este debate muchas respuestas enfatizaron logros: acceso masivo a la universidad, ampliación de matrícula o llegada de primeras generaciones de muchas familias a la educación superior; pero la protesta de la calle hizo ver que las familias quedaban endeudadas, que había un altísimo porcentaje de deserción y, lo que es peor, para aquellos que superaban estos obstáculos en el camino, la formación y el título obtenidos los colocaba en posiciones poco competitivas, porque la formación recibida era claramente deficiente. Por estas razones, la protesta ciudadana desplazó la hegemonía implícita de lo que era aceptable, deseable y responsable en materia de educación pública. Ocho años atrás, afirmar que se ponía fin al lucro de la educación era impensable, pues parecía parte del acuerdo implícito asociado a cierto modelo de gestión de los bienes y servicios públicos. Hoy día decir que se acepta el lucro con recursos públicos es impensable dentro de amplios sectores de centro y de izquierda" (Serrano, 2014, pág. 109).

En Chile se constata que una diversidad de instituciones con objetivos de política social (educación, salud y pensiones) han acarreado desventajas para amplios sectores sociales. La educación, fundamentalmente por los costos que representa para las familias, por los problemas de calidad y de segregación social. La salud, por su financiamiento dual: las ISAPRE, a pesar de alimentarse de contribuciones obligatorias, ejercen el descreme del mercado mediante pólizas cuyas tarifas han originado un alineamiento de la insatisfacción, un malestar social extenso y difuso, que crea condiciones de cambio.

Debido a las complementariedades institucionales (Hall, 2009), la impugnación de otras privatizaciones en materia de política social (educación) y protección social (salud y pensiones) regidas por el lucro crea condiciones potenciales para que las demandas de reformas que se registran en varias esferas puedan fortalecerse recíprocamente. En esos términos, puede afirmarse que se impugnan las propias fronteras que ha tenido la política y la formulación de políticas (Blyth, 2012, pág. 9), al calor de fuertes interacciones discursivas (Schmidt, 2011). Al "reinterpretarse" lo que los actores asocian con una institución - condensado en el rechazo al lucro-, se han generado cambios en la acción de los actores (Streeck y Thelen, 2005), que se potencian por las superposiciones (layers) de instituciones (Hall, 2009, p. 217). En este caso, de instituciones guiadas por el lucro, que proveen un andamiaje para muchos cursos de acción; y es precisamente la superposición de instituciones lo que potencia la movilización (Streeck y Thelen, 2005, pág. 23).

En un contexto de difusión del malestar, el incumplimiento de las promesas de cobertura y de calidad de las pensiones, y la erosión del 
"patrimonio" de las cotizaciones en cuentas individuales cuando no logran traducirse en pensiones adecuadas, muestran rendimientos decrecientes respecto de las expectativas (Streeck y Thelen, 2005). Por otra parte, el viejo sistema público de reparto, de carácter residual, provee tasas de reemplazo más altas y por tanto tiene un efecto de demostración que cuestiona al reformado; es decir que se reactiva una rémora que estaba destinada a sumergirse y desaparecer (Streeck y Thelen, 2005). Además, debe tomarse en cuenta que los resultados negativos que evidencia este proceso de maduración del sistema afectan a sectores sociales muy diversos, entre ellos, sectores medios y de altos ingresos y de inserción pluripartidista, como lo han revelado encuestas demoscópicas (Castiglioni, 2007).

En una encuesta sobre el sistema de pensiones encargada por la Comisión Asesora Presidencial sobre el Sistema de Pensiones en 2015 (CAPSP, 2015c, págs. 37 y 48) se evidencia una evaluación muy desfavorable del sistema: solo un $5 \%$ de los encuestados considera que las pensiones que entrega el sistema de AFP alcanzan a financiar un nivel de vida adecuado, mientras que un $71 \%$ de los pensionados que cotizaron en una AFP dice que la pensión no le alcanza para satisfacer sus necesidades y un $66 \%$ de los afiliados cree que no va a llegar a tener una pensión acorde con sus expectativas 9 .

Sin embargo, el descontento con el sistema no necesariamente parte de un conocimiento razonable acerca de su funcionamiento, que podría operar como un dispositivo para articular mejor la insatisfacción. Anteriormente nos referimos a las restricciones que tiene el postulado del consumidor bien informado en materia de protección social. En el caso de las pensiones en Chile, por ejemplo, la mayoría de las personas no relacionan las tasas de reemplazo que obtendrán con las comisiones que paguen para la administración de las cuentas individuales y, por lo tanto, no toman decisiones basadas en ello, y en muchos casos ni siquiera les resulta transparente o comprensible la respectiva información. Tampoco están al tanto de las ganancias que obtienen las AFP y empresas conexas con sus recursos. En sentido contrario al interés del asegurado, se observan incrementos de los costos administrativos en razón de una falsa y engañosa competencia, y se evidencia la necesidad de iniciativas públicas para que los afiliados lleguen a comprender la relevancia de los precios para sus pensiones (por ejemplo, de las comisiones de administración) (CAPSP, 2015a, 2015b y 2015c). Por las asimetrías de información y la falta de incentivos a la competencia,

\footnotetext{
La encuesta de opinión se realizó para identificar el nivel de conocimiento y la opinión de la ciudadanía sobre los parámetros del sistema y la reforma previsional de 2008. Participaron 3.696 personas, con representatividad de la población mayor de edad a nivel nacional. La muestra estuvo compuesta por personas de 18 años y más, el $20 \%$ de las cuales corresponde a personas de 60 años y más. El ingreso total del hogar informado ascendió, en promedio, a 511.728 pesos chilenos, con una mediana de 350.000 pesos chilenos.
} 
difícilmente sea la reputación de excelencia de las administradoras, en términos de sus logros respecto de las tasas de reemplazo o del monto de las comisiones, lo que determina el comportamiento de los cotizantes; por el contrario, es importante indagar en la incidencia de distintas formas de publicidad para captar cotizantes que rozan el "riesgo moral".

En esos términos, en cuanto a las presuntas ventajas de un sistema competitivo para los contribuyentes del sistema de pensiones, que era uno de los puntos destacados al momento de la privatización del sistema de pensiones y de la creación de las cuentas individuales, también los resultados son decepcionantes.

Véase, en ese sentido, la trayectoria de la competencia entre las AFP, que se esboza en la siguiente periodización:

i) Una fase inicial (1981-1990), en que se registra poco movimiento de entrada y salida de empresas, caracterizada por altas comisiones, altos costos para las AFP y altos niveles de utilidad al final de la fase.

ii) Una fase competitiva (1991-1997), caracterizada por una gran entrada de firmas, fusiones y adquisiciones, y por un nivel de utilidad decreciente. Las comisiones, en términos reales, crecieron sostenidamente. La competencia se libraba mediante una guerra de venta (más de 16.000 vendedores en 1997), que dio lugar a una enorme cantidad de traspasos de afiliados entre AFP y a una disminución de la rentabilidad de la industria. En lugar de originar una disminución de precios o un aumento de la calidad del servicio, crecieron mucho los costos, particularmente en vendedores y fuerza de ventas, lo que afectó sobre todo a las AFP pequeñas y a las que entraron al mercado entre 1990 y 1994, cuya cartera de afiliados estaba compuesta fundamentalmente por clientes que habrían ingresado atraídos por "regalos" y que, por lo tanto, eran más propensos a irse por la misma vía.

iii) Una fase estacionaria (1998-2010), con muy poco movimiento de empresas, altos niveles de utilidad y una mayor concentración.

iv) Una fase de poslicitación (2010-2014). A partir de la licitación introducida por la reforma previsional de 2008, las AFP empezaron a competir en precio por la administración de la cartera de nuevos afiliados, y ello permitió reducir la comisión media cobrada en la industria. Sin embargo, el traspaso de afiliados antiguos a la AFP más barata no ha sido masivo. En 2013 se registraron alrededor de 22.000 traspasos netos voluntarios entre distintas AFP y, de estos, más de 6.000 fueron hacia la AFP que cobra las comisiones más bajas. No obstante, pese a 
que esta AFP es la segunda administradora con mayor número de traspasos netos, la cantidad de afiliados que se cambió de AFP es baja respecto del total de afiliados (aproximadamente 9.500.000 personas). El hecho de que solo un reducido número de afiliados se haya trasladado a la AFP más barata en estos últimos años muestra que no se ha logrado sensibilizar lo suficiente a los afiliados con respecto a la variable precio; el desconocimiento sobre las comisiones y otros parámetros del sistema es generalizado e independiente del nivel educativo, los ingresos o la edad (CAPSP, 2015b y 2015c).

\section{Las tasas de reemplazo y sus múltiples causalidades sistémicas: un punto álgido de la actual disputa}

Las tasas de reemplazo muestran la adecuación de las pensiones respecto de los ingresos en virtud de los que se ha cotizado a lo largo de la vida laboral. Los bajos rendimientos que se evidencian en las tasas de reemplazo son el meollo del cuestionamiento del sistema contributivo en Chile.

En la CEPAL se realizó un estudio sobre los determinantes de las tasas de reemplazo en sistemas de pensiones de capitalización individual para indagar en el perfil de las tasas que los sistemas de pensiones ofrecen al conjunto de la población meta (no sobre las tasas efectivas de reemplazo que, a escala individual, obtendrían quienes reciben o recibirán pensiones) (Durán y Peña, 2011) ${ }^{10}$.

Algunas variables — como la longevidad, la dinámica demográfica y el envejecimiento- que condicionan los sistemas de pensiones de beneficio definido, también afectan los sistemas de capitalización individual. No obstante, dadas las características de los sistemas de capitalización individual, la carga o el riesgo demográfico son asumidos por los afiliados, y con mayor énfasis por las mujeres. La simulación realizada permitió captar la relevancia de los factores determinantes y la magnitud de su incidencia y simular escenarios de interés para el diseño de políticas en distintos países latinoamericanos. Demostró que la tasa de remplazo en estos sistemas es

El análisis de aquel estudio, en ese sentido, no versa sobre las tasas efectivas de reemplazo a escala individual que obtendrían quienes reciben o recibirán beneficios, ya que dichas tasas dependen de las características y trayectorias individuales de las personas seleccionadas. El estudio versa, más bien, sobre las pensiones que brinda el sistema en su conjunto a la población meta establecida en virtud de una ley de seguridad social. Se utilizó como unidad de análisis al individuo por medio de una medición teórica prospectiva de largo plazo que captura datos transversales medios, combina las principales características individuales del grupo cubierto y evalúa la sustitución de los ingresos. A tal fin, se construyó un modelo matemático actuarial que permite capturar un conjunto de características del entorno en el que operan los sistemas: reglamentación de la prestación, densidades de cotización, patrones de evolución de las carreras laborales y salariales según rama de actividad y categoría ocupacional, rentabilidad de las inversiones, comisiones de administración, comisiones de seguros y otras (Durán y Peña, pág. 9). 
una variable dependiente de múltiples factores —de carácter económico, sociodemográfico y programático e institucional- relativos al diseño, la organización financiera y el régimen administrativo de los sistemas (por ejemplo, la tasa de rentabilidad y la tasa de comisión por administración y por compra de la renta vitalicia o programada). Esta plurideterminación hace que los factores generen, en su interacción, resultados muy distintos en cada país (entre otros, por sector económico, edad, sexo, nivel de ingreso, categorías de trabajadores o carreras salariales) (Durán y Peña, 2011).

El nivel de las prestaciones se mostró muy sensible a pequeñas variaciones en la rentabilidad del sistema, que repercuten con mayor intensidad sobre las mujeres. Por su parte, las comisiones tienen un gran efecto sobre las tasas de reemplazo, con mayor intensidad en el caso de los hombres. Ello es relevante dado que el elevado nivel de las comisiones supera ampliamente a varias de las que se cobran en los mercados financieros. En cuanto al análisis por sector de actividad económica, los resultados evidencian una gran dependencia del nivel de formalización y de regulación laboral del sector. El desarrollo de la institucionalidad y la administración del sistema de seguridad social también son elementos determinantes de las tasas de reemplazo, ya que si bien están determinadas, en gran medida, exógenamente por las características del mercado laboral que inciden en el grado de formalización laboral y en las densidades de cotización, también es cierto que el marco jurídico para combatir la evasión contributiva, así como la capacidad administrativa de los sistemas de inspección, afiliación y recaudación, tienen gran incidencia sobre las densidades, y por ende, sobre las tasas de reemplazo (Durán y Peña, 2011). En el cuadro IV.2 se resumen algunas de las conclusiones de las simulaciones de tasas de reemplazo para el caso chileno realizadas en el estudio de la CEPAL.

\section{Cuadro IV.2 \\ Chile: simulación de las tasas de reemplazo del sistema de pensiones de capitalización individual, considerando diferentes escenarios} (En porcentajes)

\begin{tabular}{|c|c|c|c|c|c|c|c|}
\hline & \multirow[t]{2}{*}{ Aporte } & \multicolumn{2}{|c|}{ Salario final } & \multicolumn{2}{|c|}{$\begin{array}{c}\text { Salario medio de } \\
\text { los últimos } 20 \text { años }\end{array}$} & \multicolumn{2}{|c|}{$\begin{array}{l}\text { Salario medio de } \\
\text { carrera completa }\end{array}$} \\
\hline & & Mujer & Hombre & Mujer & Hombre & Mujer & Hombre \\
\hline Salario vigente & 10,0 & 48,6 & 46,3 & 40,1 & 39,5 & 41,5 & 45,3 \\
\hline Rentabilidad del 3,5\% & 10,0 & 58,0 & 54,0 & 48,0 & 46,0 & 50,0 & 53,0 \\
\hline Rentabilidad del 4\% & 10,0 & 69,0 & 63,0 & 57,0 & 54,0 & 59,0 & 62,0 \\
\hline $\begin{array}{l}\text { Considerando hipótesis } \\
\text { de comisiones nulas }\end{array}$ & 10,0 & 51,0 & 57,0 & 42,0 & 49,0 & 44,0 & 56,0 \\
\hline
\end{tabular}

Fuente: F. Durán y H. Peña, "Determinantes de las tasas de reemplazo de pensiones de capitalización individual. Escenarios latinoamericanos comparados", serie Seminarios y Conferencias, N 64 (LC/L.3329-P), Santiago, Comisión Económica para América Latina y el Caribe (CEPAL), 2011.

Nota: El modelo de simulación utiliza microdatos de la Encuesta de Caracterización Socioeconómica Nacional (CASEN) de 2007. 
Del estudio también vale destacar que Chile se reveló como el país latinoamericano donde el pago de comisiones para la administración de las cuentas individuales representaba el mayor número de años de cotización: 7,4 años en el caso de los hombres y 6,3 años en el caso de las mujeres. A su vez, medida como la relación entre los años que representan las comisiones pagadas y los años efectivamente cotizados, esta alcanzaba el $19 \%$ y el $20 \%$ para hombres y mujeres, respectivamente. Otra forma de analizar el costo de las comisiones es respecto del monto total aportado al momento del retiro. En esos términos, estas representaban el 19\% y el $19,7 \%$ por año cotizado, en hombres y mujeres, respectivamente (Durán y Peña, 2011, págs. 43 y 44). La hipótesis de comisión nula del cuadro IV.2, que evidentemente no es viable desde el punto de vista empírico en ningún tipo de escenario, puesto que siempre habrá costos administrativos, se hace para revelar el gran efecto que tienen las comisiones.

Las tasas de reemplazo de las pensiones han sido un punto álgido de las discusiones en los últimos años, y los defensores del sistema han extremado sus recursos para aducir que son adecuadas. Por ejemplo, cuando la Comisión Asesora Presidencial sobre el Sistema de Pensiones realizó audiencias para la elaboración de su diagnóstico y dictamen sobre la reforma del sistema, se trajeron a colación de manera distorsionada cifras de la Organización de Cooperación y Desarrollo Económicos (OCDE) para mostrar que las tasas eran "altas", del orden del 45,5\% (Schmidt-Hebbel, 2014) (véase el cuadro IV.3).

Cuadro IV.3

Chile: modelación de las tasas brutas de reemplazo, por sexo e ingresos individuales (En porcentajes)

\begin{tabular}{|c|c|c|c|c|c|c|c|}
\hline \multirow{2}{*}{\multicolumn{2}{|c|}{ Mediana del ingreso }} & \multicolumn{6}{|c|}{ Ingresos individuales, en múltiplos de la media } \\
\hline & & \multicolumn{2}{|c|}{0,5} & \multicolumn{2}{|c|}{1,0} & \multicolumn{2}{|c|}{1,5} \\
\hline Hombre & Mujer & Hombre & Mujer & Hombre & Mujer & Hombre & Mujer \\
\hline 45,5 & 36,6 & 57,3 & 48,3 & 41,9 & 33,0 & 37,3 & 27,9 \\
\hline
\end{tabular}

Fuente: Organización de Cooperación y Desarrollo Económicos (OCDE), "cuadro 4.1", Pensions at a Glance 2013. OECD and G20 Indicators, París, OECD Publishing, 2013.

Nota: Simulación de tasas calculadas bajo el supuesto de que no hay lagunas previsionales y para trayectorias laborales de 20 años a 65 años en hombres y de 20 años a 60 años en mujeres.

Como ya se advirtió (Sojo, 2014), aquellas cifras correspondían a una lectura inadecuada, por parcial, del informe de 2013 de la OCDE Pensions at a Glance 2013. OECD and G20 Indicators, ya que se tomaban de un cuadro que consideraba conjuntamente el pilar solidario y el sistema contributivo. Por el contrario, si se considera el cuadro 4.4 de la misma publicación, donde se desglosa por regímenes público (correspondiente al pilar solidario), obligatorio privado y voluntario, se evidencia que las tasas del régimen obligatorio privado son sensiblemente menores y que para 
ningún tramo de ingreso llegan al 38\% (véase el cuadro IV.4). Además, este cálculo es una simulación realizada a los efectos comparativos entre países, cuyos supuestos distan mucho de lo observado empíricamente en cuanto a las lagunas previsionales y a la volatilidad de la inserción laboral: es un cálculo de tasas "para una carrera completa", es decir, sin lagunas previsionales, y para trayectorias laborales largas, de 20 años a 65 años en hombres y de 20 años a 60 años en mujeres (véase OCDE, 2013, cuadros 4.1 y 4.4 , págs. 132, 135 y 137).

\section{Cuadro IV.4}

Chile: tasas brutas de reemplazo de pensiones, por ingresos individuales, según sistemas de pensiones público, obligatorio privado y voluntario privado, en múltiplos de la media, por sexo (En porcentajes)

\begin{tabular}{|c|c|c|c|c|c|c|c|c|c|c|c|c|c|c|}
\hline \multicolumn{3}{|c|}{$\begin{array}{l}\text { Público no } \\
\text { contributivo }\end{array}$} & \multicolumn{3}{|c|}{$\begin{array}{l}\text { Obligatorio } \\
\text { privado }\end{array}$} & \multicolumn{3}{|c|}{$\begin{array}{l}\text { Privado voluntario } \\
\text { (contribución definida) }\end{array}$} & \multicolumn{3}{|c|}{$\begin{array}{c}\text { Total } \\
\text { obligatorio }\end{array}$} & \multicolumn{3}{|c|}{$\begin{array}{l}\text { Total incluido } \\
\text { voluntario }\end{array}$} \\
\hline 0,5 & 1,0 & 1,5 & 0,5 & 1,0 & 1,5 & 0,5 & 1 & 1,5 & 0,5 & 1,0 & 1,5 & 0,5 & 1,0 & 1,5 \\
\hline 20,4 & 4,8 & 0,0 & 36,9 & 37,2 & 37,3 & - & - & - & 57,3 & 41,9 & 37,3 & - & - & - \\
\hline
\end{tabular}

Fuente: Organización de Cooperación y Desarrollo Económicos (OCDE), "cuadro 4.4", Pensions at a Glance 2013. OECD and G20 Indicators, París, OECD Publishing, 2013.

Nota: Simulación de tasas calculadas bajo el supuesto de que no hay lagunas previsionales y para trayectorias laborales de 20 años a 65 años en hombres y de 20 años a 60 años en mujeres.

Posteriormente, la Comisión Presidencial solicitó a la OCDE un informe sobre la metodología de cálculo de las tasas de reemplazo que utiliza en sus informes, donde se explicitaron las limitaciones y ventajas del cálculo que permite comparar a Chile con otros países y que es interesante dado que reconoce que las tasas de reemplazo de Chile -que son bajas si se analizan a escala internacional- incluso están sobreestimadas por el informe de la OCDE Pensions at a Glance 2013. $O E C D$ and G20 Indicators. Se plantea que las tasas de reemplazo deben entenderse como la tasa de reemplazo máxima que un individuo puede lograr en cada país, de acuerdo con las reglas vigentes. Se reitera que la metodología asume una carrera completa en el sector privado, desde los 20 años hasta la edad de retiro oficial, y se reconoce que tal supuesto sobre la carrera completa quizá no sea apropiado para el caso de Chile, debido a que se sobreestiman las contribuciones de las mujeres vinculadas con el posnatal, pero, sobre todo, a que las densidades de contribución en Chile, por razones diversas, rondan el 50\%. Por tanto, afirma la OCDE, las tasas de reemplazo máximas para Chile estarían sobreestimadas y deberían considerarse estrictamente como el derecho máximo que podrían alcanzar las personas con una carrera completa, supuesto muy exigente dado que es larga y sin lagunas de cotización. En cuanto al cálculo de las pensiones no contributivas, asumir la metodología de que estas cubren al 100\% de los potenciales beneficiarios, mientras que solo el $43 \%$ las recibe, implica otra fuerte sobreestimación (OCDE, 2015, págs. 12 y 13). 
Considerada la sobreestimación por densidad de cotizaciones, si, por ejemplo, vemos que la tasa bruta de reemplazo de la media de ingreso del régimen obligatorio privado es del 37,2\% según el informe de 2013, y si ello debe leerse como una tasa máxima, si la misma cifra se ajustara a una densidad media de cotizaciones del $50 \%$, esta sería del $18,7 \%$.

Existen diversas maneras de aproximarse a la medición de las tasas de reemplazo. Como expresa Barr, una medida de la adecuación es la tasa de reemplazo, es decir, la proporción de los beneficios de las pensiones respecto de los ingresos mensuales (deducidos impuestos y transferencias) durante el trabajo. Ella puede calcularse de dos formas: i) el beneficio de pensión medio de una persona como porcentaje del salario medio, caso en que la tasa de reemplazo es una medida de los niveles de vida de las personas mayores en relación con los de la población trabajadora, esto es, mide el grado en que las pensiones proveen un alivio contra la pobreza, y ii) el beneficio de quien recibe una pensión en relación con su salario anterior, caso en que la tasa de reemplazo es una medida de la efectividad del suavizamiento del consumo. La medida en que un sistema ofrece una tasa de reemplazo suficiente y amplia en relación con el ingreso anterior, acorde a lo que se prometió, es importante para la legitimidad de un sistema (Barr, 2013, pág. 53)

Si esta segunda medida empírica de la adecuación de las pensiones se aplica a escala del sistema obligatorio privado de Chile, el ejercicio arroja lo siguiente: considerando que el salario medio a febrero de 2016 en Santiago era de 629.100 pesos chilenos, conforme a la Encuesta de Empleo de la Universidad de Chile, y que en el mismo mes, la pensión media de vejez ascendía a 203.425 pesos chilenos, en términos brutos, sin ajustar por localidades, se obtiene una tasa de reemplazo del $32,3 \%$.

En muchas ocasiones las bajas tasas de reemplazo no afectan únicamente al jubilado. En presencia de solidaridad intergeneracional, las malas pensiones tienen efectos intergeneracionales negativos, en términos de los ingresos familiares. Además, estos efectos tienen cierto carácter acumulativo si quienes hoy complementan el bajo ingreso por pensiones de sus parientes mayores también tienen la expectativa de recibir bajas pensiones.

En términos de objetivos de protección de los ingresos tras la vida activa que deben tener los fondos de pensiones, la razón de ser de un sistema de cuentas individuales coordinado por administradoras estribaría en que estas, por encima de las asimetrías de información de las personas y precisamente por haberse delegado en ellas decisiones que requieren una determinada capacidad técnica en materia de finanzas, logren colocar los fondos de manera que se alcancen ganancias adecuadas para este ahorro previsional, beneficiando en primer término a los fondos de pensiones. Pero la trayectoria de las ganancias de los fondos muestra tendencias contrarias, que son inquietantes en varios sentidos. 
Del cuadro IV.5 interesa resaltar los siguientes aspectos. Con excepción de los fondos conservadores, se advierte, en primer término, la gran volatilidad de la rentabilidad a lo largo del tiempo, que evidentemente es muy crítica en los momentos agudos de la crisis financiera. Si se saca un promedio simple de los trienios como una variable sustitutiva cruda de rentabilidad del período de 11 años abarcado, paradójicamente la rentabilidad anual del fondo más conservador supera a la del fondo más riesgoso (un 4,3\% frente a un 3\%). Es grave que la inversión más conservadora resulte ser la más rentable porque ello evidencia el declive de la rentabilidad de la inversión en instrumentos financieros cuyo uso presuntamente justificaría la existencia del oneroso sistema de administración de las cuentas individuales mediante las AFP, e ilumina acerca de la deseabilidad de que las cuentas individuales se administren bajo una lógica posiblemente más conservadora, pero también menos onerosa, en el marco de un sistema que se maneje con otros parámetros: sin lucro y con costos de operación y de transacción sustancialmente menores en la administración de los fondos.

\section{Cuadro IV.5}

Chile: rentabilidad de los fondos de pensiones, promedio anual de los últimos $\mathbf{3 6}$ meses a la fecha indicada

(Deflactada por la unidad de fomento)

\begin{tabular}{lccccc}
\hline & Fondo tipo A & Fondo tipo B & Fondo tipo C & Fondo tipo D & Fondo tipo E \\
\hline Julio de 2008 & 6,98 & 5,56 & 4,45 & 3,45 & 2,45 \\
\hline Julio de 2009 & $-0,90$ & 1,35 & 2,96 & 3,63 & 3,93 \\
\hline Julio de 2010 & $-3,90$ & $-1,13$ & 0,91 & 2,57 & 4,67 \\
\hline Julio de 2011 & 1,26 & 3,18 & 4,07 & 4,41 & 4,85 \\
\hline Julio de 2012 & 3,41 & 3,96 & 3,95 & 4,06 & 4,88 \\
\hline Julio de 2013 & 1,20 & 1,36 & 2,21 & 3,03 & 4,01 \\
\hline Julio de 2014 & 4,37 & 3,83 & 4,56 & 4,90 & 5,30 \\
\hline Julio de 2015 & 9,41 & 7,32 & 7,10 & 6,27 & 4,80 \\
\hline Julio de 2016 & 5,15 & 4,68 & 4,86 & 4,43 & 3,84 \\
\hline
\end{tabular}

Fuente: Superintendencia de Pensiones.

Nota: $\quad$ El fondo tipo A es el más riesgoso, el B es riesgoso, el C es intermedio, el D es conservador y el E es más conservador.

La baja rentabilidad más reciente es representativa de las nuevas condiciones internacionales de regulación menos laxas y de la trayectoria de la economía con posterioridad a la crisis de 2008, que condiciona, además, el horizonte previsible. Esto genera una situación muy grave para el sistema de capitalización individual, ya que los bajos retornos de los activos financieros exigen ahorros previsionales muy superiores a los del pasado. Por ejemplo, para el caso inglés, los inversionistas que a fines de los años noventa adquirían sus propias pensiones con 100.000 libras esterlinas podían obtener un ingreso vitalicio anual de 11.170 libras esterlinas, mientras que con el mismo 
ahorro ahora ganan un ingreso anual de 4.960 libras esterlinas (The Economist, 2016, pág. 25).

Ello también se expresa en la caída de las tasas de interés implícitas en la compra de rentas vitalicias por los pensionados.

De manera complementaria a la rentabilidad obtenida por los fondos ahorrados en las cuentas individuales administradas por las AFP, para analizar la suficiencia de las pensiones deben considerarse las rentas vitalicias que las compañías de seguros están dispuestas a pagar por los fondos ahorrados al momento de la jubilación. Desde 1990 se advierte un claro declive de estas tasas, lo que permite inferir cómo el mercado de seguros ha ido "leyendo" las perspectivas de la rentabilidad de los ahorros. Es preocupante, en ese sentido, la notoria caída de las tasas de interés que pagan las compañías que aseguran una pensión a partir de los fondos acumulados (Rivera, 2014a y 2014b). Esto se advierte claramente en el cuadro IV.6.

\section{Cuadro IV.6}

Chile: tasas de interés medias (implícitas) de rentas vitalicias contratadas en el mercado, a agosto de cada año

(En puntos porcentuales)

\begin{tabular}{lcccccc}
\hline & Vejez & $\begin{array}{c}\text { Vejez } \\
\text { anticipada }\end{array}$ & $\begin{array}{c}\text { Invalidez } \\
\text { total }\end{array}$ & $\begin{array}{c}\text { Invalidez } \\
\text { parcial }\end{array}$ & Sobrevivencia & Media \\
\hline 1998 & 5,83 & 5,67 & 5,63 & 5,51 & 5,48 & 5,68 \\
\hline 2000 & 5,53 & 5,33 & 5,40 & 5,23 & 5,18 & 5,35 \\
\hline 2005 & 3,24 & 3,19 & 3,10 & 3,01 & 2,92 & 3,17 \\
\hline 2010 & 3,26 & 3,33 & 3,28 & 3,06 & 3,27 & 3,28 \\
\hline 2011 & 3,28 & 3,29 & 3,14 & 3,00 & 3,16 & 3,23 \\
\hline 2012 & 3,22 & 3,24 & 3,14 & 3,15 & 3,13 & 3,20 \\
\hline 2013 & 3,02 & 3,05 & 2,94 & 2,76 & 2,96 & 3,00 \\
\hline 2014 & 2,53 & 2,53 & 2,46 & 2,37 & 2,42 & 2,51 \\
\hline 2016 & 2,76 & 2,78 & 2,75 & 2,53 & 2,71 & 2,75 \\
\hline
\end{tabular}

Fuente: Superintendencia de Pensiones [en línea] http://www.spensiones.cl/safpstats/stats/apps/tasas/ tasasRentasVitalicias.php.

Diversos aspectos han gravitado y gravitan en las tasas de reemplazo: las grandes lagunas de cotización; el hecho de que los riesgos financieros se transfieran únicamente a los afiliados y no a las administradoras, que funcionan sin incentivos para maximizar las tasas de reemplazo y no reciben penalización alguna por su caída; el agotamiento de la "edad dorada" de las inversiones en bonos de la deuda pública chilena, que nutrió la rentabilidad inicial del sistema; el marcado descenso de la rentabilidad de los instrumentos financieros debido a la crisis financiera internacional y las regulaciones concomitantes de los mercados financieros; la alta exposición a riesgos financieros, acrecentada por la liberalización de las inversiones 
introducida en 2008 en el marco de la reforma; la inadecuada protección de los fondos de pensiones ante riesgos financieros (por ejemplo, en los casos de las empresas Polar y Cascadas); la baja rentabilidad con que las AFP colocan los recursos en Chile, ya que la cartera de inversión está concentrada en beneficio de unos pocos grupos empresariales y bancos de gran tamaño, y por último, pero no por eso menos importante, las altas comisiones que cobran las AFP por la administración de los fondos de pensiones y que dan origen a ganancias muy elevadas (Rivera, 2010, 2014a y 2014b).

Se ha concluido que las rentabilidades de los fondos de pensiones a lo largo del tiempo no evidencian diferencias significativas que puedan atribuirse a su administración por parte de las diversas AFP, mientras que las comisiones cobradas por estas varían considerablemente. Es decir que los contribuyentes que pagan comisiones más altas no reciben mayores beneficios, escenario en el cual el mayor beneficio estribaría en pagar las más bajas comisiones posibles. Pero aun así, por ejemplo, en mayo de 2016 un $75 \%$ de los afiliados se concentraba en las cuatro AFP que cobraban las comisiones más altas (Lara, López y Morgado, 2016).

En esos términos, la alta rentabilidad de las AFP y empresas conexas es el genuino anverso del sistema de pensiones contributivo, en tanto que la otra cara de la moneda son las bajas tasas de reemplazo: al estar el sistema articulado por el lucro, ambos aspectos son indisociables y deben analizarse en forma conjunta.

La actual rentabilidad de los bancos en Chile, que es alta a escala internacional, se ubica en torno al $18 \%$. Ello es elocuente como punto de referencia respecto de los niveles anuales de rentabilidad de las AFP: se observan altas tasas de rentabilidad tanto en administradoras que reúnen muchos afiliados, como Provida, como en una pequeña, como la AFP Modelo, que por sus características tiene muy bajos costos de operación (véase el cuadro IV.7).

Cuadro IV.7

Chile: rentabilidad anual de las Administradoras de Fondos de Pensiones (AFP), al 31 de diciembre de cada año

(En porcentajes)

\begin{tabular}{lrrrr}
\hline & 2012 & 2013 & 2014 & 2015 \\
\hline Capital & 10,53 & 11,92 & 10,22 & 14,85 \\
\hline Cuprum & 43,81 & 68,8 & 54,95 & 19,75 \\
\hline Habitat & 34,73 & 33,82 & 34,91 & 31,98 \\
\hline Modelo & 211,3 & 95,15 & 145,85 & 101,21 \\
\hline Plan Vital & 22,59 & 13,91 & 15,73 & $-3,6$ \\
\hline Provida & 33,32 & 43,62 & 40,58 & 24,06 \\
\hline Sistema AFP & 26,5 & 31,38 & 29,56 & 22,34 \\
\hline
\end{tabular}

Fuente: Superintendencia de Pensiones. 
Un cálculo reciente relaciona la rentabilidad de las AFP con la exposición al riesgo y concluye que la rentabilidad sobre el patrimonio medio del 25,4\% que las AFP alcanzaron en el período 2006-2015 fue 4,8 veces superior al 5,3\% que sería justificable por su exposición al riesgo de mercado. En términos monetarios, se estima que de los 4.400 millones de dólares obtenidos por la industria en la última década, cerca de 3.500 millones de dólares corresponderían a una ganancia "excesiva“" (López, 2016).

Más aún, el sistema no incentiva la eficiencia: las AFP obtienen una comisión fija y previsible, independiente del beneficio previsional que los cotizantes obtengan con su intermediación. Solo se ven afectadas en cuanto al $1 \%$ de los recursos que deben invertir en los mismos instrumentos del fondo de pensiones que manejan. Esta desconexión entre beneficios previsionales y ganancia reduce los beneficios sociales netos y no estimula la competencia (por ejemplo, disminuye la importancia de reducir los costos e incrementar la eficiencia). Ello se potencia por el hecho de que los ahorrantes, como hemos visto, eligen una AFP y permanecen en ella con un gran desconocimiento de las comisiones efectivas que pagan, sin analizarla en términos comparativos y sin capacidad para efectuar decisiones técnicas fundadas.

Además, debe considerarse que el sistema previsional chileno ha sido muy costoso en términos fiscales y - de no modificarse su fundamentolo seguirá siendo. La creación del sistema fue onerosa, ya que, en tanto reforma sustitutiva, tuvo altos costos de transición: como incentivo al traslado, fueron reconocidas sin tope todas las contribuciones realizadas, ajustadas por inflación y con una tasa de interés (Mesa Lago, 2000). Además, en un sistema que ya ha madurado, dado que un contingente importante de cotizantes tiene lagunas previsionales sustanciales y sufre bajas tasas de reemplazo, se incrementa el número de pensionados que califican para recibir pensiones mínimas, o bien para recibir el aporte previsional solidario, con lo cual se vuelve problemático el efecto de desplazamiento (crowding out) que ejerce respecto de otros objetivos de la política social. En tal sentido, superar el lucro como articulador del sistema de pensiones permitiría un uso más eficiente y equitativo del ahorro para pensiones y disminuiría las presiones para canalizar recursos al pilar solidario de pensiones, precisamente en una época en que deben encararse nuevos riesgos, como las necesidades de cuidado de las personas en ambos extremos de la vida, aspecto que se abordará en el capítulo VI.

Precisamente, el envejecimiento de la población y los nuevos riesgos asociados con la obsolescencia del capital humano, la volatilidad del empleo y las necesidades de cuidado vuelven urgente encarar la visión del bienestar por ciclo de vida, incluso tras la edad activa, en un conjunto más amplio de políticas. 


\section{La AFP estatal como estrategia de cambio gradual por superposición y de transición hacia un sistema contributivo de cuentas individuales sin fines de lucro}

El proyecto de creación de una AFP del Estado forma parte de las iniciativas del segundo gobierno de la Presidenta Bachelet, tendientes a enfrentar los retos de la calidad de las pensiones percibidas por los sectores medios y de mayor vulnerabilidad. Ese fue el motivo por el que se convocó la Comisión Asesora Presidencial sobre el Sistema de Pensiones, cuyas propuestas se sintetizarán en el apartado D.4. El proyecto de una AFP estatal se planteó con el objetivo de aumentar la competencia entre las AFP respecto del nivel de las comisiones que cobran y la calidad del servicio que prestan a los afiliados, e incrementar la cobertura de pensiones de la población que presenta bajos niveles de participación en el sistema, como los trabajadores independientes y los trabajadores en zonas geográficas alejadas de centros urbanos (Bachelet, 2014).

Los sectores vulnerables indudablemente deben ser un foco primordial de las políticas públicas y de las mejoras que se introduzcan en el sistema de pensiones, porque sobre ellos recaen más riesgos ante los que deben actuar los sistemas de protección social. Sin embargo, si los ingresos de algunos de los sectores con escasa participación en el sistema previsional o que viven en zonas alejadas son muy bajos, estos más bien serán protegidos por el pilar solidario, con lo que se desdibuja el sentido del proyecto y se subestima la virtualidad reformista de una AFP estatal.

A nuestro juicio, la creación de una AFP estatal es un planteamiento muy potente, precisamente porque ofrece la posibilidad de impulsar modificaciones de carácter sistémico que pueden beneficiar a todos los ahorrantes previsionales, sin que ello vaya en desmedro de los sectores más pobres y vulnerables. Ese beneficio transversal de mejorar la calidad de las pensiones para todos es precisamente un elemento crucial, que cabe destacar en el discurso comunicativo gubernamental para fortalecer las alianzas y coaliciones políticas de apoyo a la reforma contra el lucro en la protección social, de modo de poder enfrentar la capacidad de veto que, hasta ahora, han demostrado tener los poderosos actores económicos y políticos con intereses en la industria previsional.

Esa virtualidad subyace a la gran oposición que esta iniciativa ha generado en la industria previsional. Los opositores al proyecto de ley de creación de una AFP estatal traen a colación diversos argumentos que, sintetizados por Schmidt-Hebbel, afirman que una AFP estatal no mejoraría las pensiones, ya que "La única forma que ofrezca mayores tasas de rentabilidad y mejores servicios que los de la competencia privada 
es recibiendo subsidios del Estado[...] Esto desplazaría a la competencia privada y, en el límite, terminaría con una gran caja de pensiones estatal, al estilo argentino[...] Tampoco resuelve el problema de lagunas previsionales y de bajas tasas de reemplazo[...] Por lo tanto, no aporta a un mejor sistema de pensiones" (Schmidt-Hebbel, 2014).

Esta falaz argumentación puede objetarse desde numerosos ángulos. Complementariamente al aumento de cobertura que se menciona en la fundamentación del proyecto, la AFP estatal puede cumplir una función crucial respecto de la mejora generalizada de las tasas de reemplazo de las pensiones. Para comprender los efectos sistémicos que puede acarrear esta reforma, nos parece fecundo utilizar la conceptualización sobre cambio institucional gradual que han desarrollado Thelen, Streeck y Mahoney, que se muestra en el diagrama IV.1 y el cuadro IV.1.

Lejos de una reforma por sustitución, la AFP estatal puede mejorar las pensiones por sus efectos sistémicos directos e indirectos, y con ello beneficiar sustancialmente a los sectores medios y a todos los ahorrantes previsionales, que están siendo perjudicados de manera global por el actual sistema. Por su parte, los sectores más pobres serían cubiertos mediante el pilar solidario.

La AFP estatal generaría un cambio gradual por superposición (Mahoney y Thelen, 2009, págs. 14-18; Streeck y Thelen, 2005, págs. 19-23) en la medida en que las reglas básicas no se eliminan - ya que seguirían vigentes las cuentas individuales para el ahorro previsional y su administración por entidades privadas y por una entidad pública, bajo condiciones de libre elección y competencia-, pero ofrece la posibilidad de crear una dinámica que altere la trayectoria por un mecanismo de crecimiento diferencial desde el margen. Ello se logra mediante una nueva regla que consiste en crear una AFP estatal que no se rige por el principio del lucro, a diferencia de la maximización de la ganancia privada que buscan las AFP y empresas conexas, sino que tiene como objetivo maximizar la tasa de reemplazo de las pensiones, a fin de honrar de manera proporcional el esfuerzo de ahorro que las personas plasman en sus cuentas individuales. En la medida en que la AFP tiene como principio y objetivo maximizar la tasa de reemplazo de las pensiones, ello implica una redistribución de recursos hacia las pensiones. A tal fin, las comisiones de esta nueva entidad deben cubrir los costos asociados a una administración eficiente de los recursos sin fines de lucro. La AFP estatal también debería eliminar la comisión de retiro (que representa un 1,25\% del fondo ahorrado) y ampliar, sin exposición a altos riesgos financieros, la cartera de inversiones, para aumentar la ganancia de los fondos que administre. Cuanto mayor sea el contingente de personas que se trasladen a la AFP estatal en razón de estas ventajas, mayor será la capacidad de negociar mejores intereses para las inversiones de los fondos de pensiones que administre. 
Como se observa, a diferencia de lo afirmado por Schmidt-Hebbel, de manera alguna se trataría de subsidiar a la AFP estatal. El efecto de desplazamiento (Streeck y Thelen, 2005, págs. 20 y 24) que ella pueda ejercer respecto de las AFP tradicionales manejadas con criterios de lucro dependerá de su rendimiento efectivo en el marco de la competencia y del efecto de demostración que origine. Ello requerirá, además, importantes esfuerzos comunicativos para abordar los comportamientos inerciales de los cotizantes al sistema AFP y contrapesar la propaganda engañosa que eventualmente otros puedan utilizar. En ese sentido, de ser exitosa en su cometido, puede cumplir un papel de transición hacia un nuevo sistema de cuentas individuales que, como un todo, se articule bajo el principio de velar por la maximización de la seguridad del ingreso en la vejez.

En tal sentido, es fundamental que la AFP estatal sea eficiente en el manejo de los recursos para reducir los gastos administrativos, que las ganancias producto de avances en materia tecnológica se trasladen a la mejora de las pensiones, que los sueldos de sus altos funcionarios y directivos sean acordes a una vocación sin fines de lucro, y que esté sometida a estrictas regulaciones y escrutinios indispensables que controlen situaciones de fraude y abuso.

Como se ha mencionado, muchas personas no ejercen realmente su libertad de elección. En materia de pensiones, los productos son muy complejos. Por las asimetrías que coartan la competencia y la capacidad de elección, la AFP estatal podría concebirse como opción por defecto, es decir, como un dispositivo de afiliación automático y obligatorio para las personas que no realizan elecciones. Este administrador público de cuentas individuales debe funcionar con bajos costos administrativos (Barr, 2013) $y$, por supuesto, no tener fines de lucro. No obstante, se requeriría de una coalición política muy fuerte para que ello fuese viable.

Hemos visto que en la encuesta encargada por la Comisión Asesora Presidencial sobre el Sistema de Pensiones se evidencia una evaluación muy desfavorable del sistema de AFP vigente. Por tanto, resulta interesante considerar que la propuesta de una AFP estatal tiene muy buena acogida en la misma encuesta: ante la pregunta de si se está de acuerdo o en desacuerdo con la propuesta de AFP estatal presentada por el Gobierno, el 79\% de los encuestados que emite una opinión está de acuerdo y las opiniones son más favorables cuanto mayor es el nivel educativo y de ingresos. Cuando se les pregunta si se cambiarían a una AFP estatal, la proporción de personas que lo haría asciende al 69\% (CAPSP, 2015c, págs. 43 y 44).

En términos de consolidar coaliciones políticas favorables a la reforma, es fundamental apuntar a la posibilidad que tiene la AFP de beneficiar a todos los ahorrantes previsionales que quieran afiliarse a ella, cualquiera sea su condición socioeconómica. Pero se trata de un 
elemento que no se comprende inmediatamente ni siquiera por sectores que claramente se verían favorecidos por la reforma, como las clases medias. De nuevo, se advierte la relevancia del discurso "comunicativo" (Schmidt, 2002) a tal efecto. Si el rendimiento de la AFP estatal ejerce un adecuado efecto de demostración, es decir, atrae cotizantes con diversas capacidades de ahorro gracias a la mejora de las tasas de reemplazo, favorecerá la transición hacia un sistema contributivo obligatorio de cuentas individuales no articulado por el lucro.

Dada la estructura de cuentas individuales del actual sistema, que es interesante en lo que respecta a buscar una proporcionalidad entre los beneficios y el esfuerzo de ahorro previsional o poder disponer los ahorros como herencia, en Chile resulta muy relevante analizar el modelo de pensiones sueco, en aras de superar la articulación del sistema basada en el lucro.

Para maximizar la expectativa de un ingreso digno en la vejez y de una relativa homogenización del consumo a lo largo del ciclo de vida, se trata de lograr una adecuación de los beneficios. El ahorro mediante cuentas individuales de las personas dentro del sistema contributivo de pensiones debe tener como objetivo conservar una proporcionalidad entre la capacidad de ahorro de los ciudadanos plasmada en sus contribuciones y las tasas de reemplazo mediante la maximización de estas.

También debería abarcar ciertas funciones de aseguramiento y determinados umbrales redistributivos dentro de las mismas cohortes; por ejemplo, debe eliminarse la discriminación de género en los cálculos actuariales de las pensiones por mayor expectativa de vida de las mujeres. También deben preverse ciertos umbrales redistributivos intergeneracionales, que contemplen amortiguadores ante la exposición a diversos ciclos económicos y a choques financieros.

Este último aspecto se señala actualmente como una posible reforma dentro del sistema sueco e implica diseñar elementos redistributivos que atiendan el objetivo de aseguramiento, con elementos de solidaridad intergeneracional, para que el peso del menor o mayor riesgo no caiga unívocamente en cada cohorte según las diversas coyunturas económicas a las que están expuestas (Barr, 2013). Es la incertidumbre - señeramente destacada por Arrow en la literatura sobre aseguramiento (Arrow, 1963 y 2000) - , en este caso respecto de los ciclos económicos, la que provee una base objetiva a ese diseño y da un fundamento político a una disposición favorable de los contribuyentes.

Debido a los avatares de la vida laboral en un mundo globalizado, con cambios tecnológicos vertiginosos y choques de tipo económico y político, es importante que el sistema de cuentas individuales sea, como hasta ahora, afín a la movilidad laboral, porque está asociado positivamente con la portabilidad. 
Otro elemento de diversificación del riesgo, que existe actualmente en el caso sueco, es la posposición voluntaria total o parcial de la jubilación, pero con ganancias en la tasa de reemplazo (Barr, 2013).

Las adecuaciones paramétricas que se propongan en la actualidad deben resolverse en consonancia con el diseño del nuevo sistema sin fines de lucro. Es decir, desde ya debe transitarse hacia una convergencia de reglas en el cálculo de las pensiones, en los topes, en los índices de corrección y en las tasas de contribuciones, para la que deben estipularse y definirse plazos claros.

Plantear un sistema contributivo de cuentas individuales sin fines de lucro no tiene un ánimo estatista y, dentro de una perspectiva tetradimensional de la democracia (Ferrajoli), lejos está del espíritu del "ogro filantrópico" del que elocuentemente nos advirtiera hace muchos años Octavio Paz, y que figura en las argumentaciones de José Piñera, pero de manera maniquea. Tampoco refleja una simple animadversión respecto de los empresarios o del mercado.

Al fin y al cabo, el sistema contributivo está financiado eminentemente por los contribuyentes y tampoco debería generar compromisos fiscales indebidos por su carácter desvirtuado, que arroja más personas hacia el pilar solidario dada la insuficiencia de sus pensiones. Se trata de que el sistema de pensiones brinde beneficios razonables y proporcionales al esfuerzo de ahorro previsional de las personas durante su vida activa y no ejerza efectos negativos en términos fiscales. En un contexto de creciente esperanza de vida y de promoción de una mayor fecundidad mediante las políticas de cuidado, se trata de mejorar las pensiones en consonancia con las mejoras de productividad de la economía, el incremento de las densidades de cotización en razón de mejores trayectorias laborales y la reducción del incumplimiento contributivo; se trata de aspirar al mejor rendimiento financiero y de reducir la exposición al riesgo; se trata de que las personas adultas mayores gocen de autonomía económica, de que no representen una carga para quienes deban completarles los bajos ingresos y de liberar a las personas activas de ese deber, o al menos reducirles la carga; se trata de articular en Chile un sistema contributivo de cuentas individuales sin fines de lucro para que la esencia del esfuerzo del sistema sea la maximización de las pensiones en aras del bienestar de todos los ciudadanos contribuyentes, desde los más humildes hasta los de más altos ingresos.

Ello exige que se supere la maximización del lucro como articuladora de la combinación público-privada del sistema vigente, ya que la alta rentabilidad de las AFP y empresas conexas y las bajas tasas de reemplazo constituyen el genuino anverso del sistema de pensiones contributivo. Como 
el sistema está articulado por el lucro, ambos aspectos son indisociables y los bajos rendimientos del patrimonio plasmado en las cuentas individuales tienen un carácter sistémico y endémico. Por ello, además de tener un origen espurio, la maduración del sistema contributivo de pensiones ha mostrado los alcances y las restricciones de este, precisamente debido al fundamento de su arquitectura y a que no cumple con el objetivo supremo de brindar a los pensionados ingresos dignos tras su vida laboral activa.

La maduración del sistema y los efectos negativos que tienen las bajas pensiones para los chilenos de todos los grupos de ingreso que cotizan dentro del sistema de AFP crean condiciones favorables para un cambio en el que también se asuman los ajustes paramétricos que se estimen convenientes. Es oportuno plantear acá la línea de razonamiento tratada en el capítulo II, en cuanto a que la experiencia de los Estados de bienestar más desarrollados muestra que la presión "desde abajo" ha sido insuficiente para las reformas solidarias y que los desafortunados se han beneficiado con reformas redistributivas cuando algunos grupos resueltos de las élites también han perseverado para ganar (Baldwin, 2003, pág. 292).

Entendido el concepto "desinstitucionalización" como cambio institucional, nos parecen elocuentes las siguientes reflexiones:

Cuanto menor es la confianza general en la conformidad [con la norma], menor es la probabilidad que los actores asignan a la posibilidad de que otros cooperen y, consecuentemente, menor es el valor de su propia conformidad. Al final, los costos de conservar la norma tendrán que ser asumidos totalmente por aquellos que se benefician de ella, lo cual, en efecto, significa el fin de la norma [...] Cuanto más fuertes son las opiniones sobre resultados injustos, y más débiles las normas de cooperación, mayor es la probabilidad de desinstitucionalización (Avdagic, Rhodes y Visser, 2005, pág. 31).

Por ello, antes de que se profundicen los actuales problemas, se trata de concurrir a un acuerdo político que convierta la maximización de las pensiones en la norma suprema de un sistema contributivo de cuentas individuales sin fines de lucro. Las reformas paramétricas que sean indispensables no bastan, sino que deben analizarse en el marco de la reforma de la arquitectura del sistema. Un ejemplo sería eliminar la discriminación de género que deriva en el uso de tablas de expectativa de vida ajustadas por sexo.

\section{Las propuestas de la Comisión Asesora Presidencial sobre el Sistema de Pensiones}

La Comisión Asesora Presidencial sobre el Sistema de Pensiones no llegó a un consenso acerca de las reformas que requiere este sistema y se registraron tres propuestas globales. Una sola persona sugirió el reemplazo del sistema actual por un sistema de reparto, propuesta que por su escasa 
viabilidad política no se examinará en el presente análisis. A continuación se sintetizan las otras dos propuestas (CAPSP, 2015a).

La propuesta global A plantea partir de la reforma de 2008, con políticas graduales que se refuercen mutuamente y perduren en el tiempo en aras de una mejora de las pensiones y el mantenimiento de las promesas a los futuros pensionados. Se propone fortalecer el sistema de pensiones solidarias aumentando de manera significativa la pensión solidaria y universalizando su cobertura. El aumento se financia mediante impuestos y con una nueva cotización del $2 \%$ de cargo del empleador destinada a un fondo solidario. En cuanto al componente de ahorro, se propone introducir "cambios sustantivos" mediante una nueva contribución del 2\% de cargo del empleador destinada a las cuentas de capitalización individual y la creación de una AFP estatal, con estrictas reglas de gobernanza, y nuevas medidas para reducir las comisiones de las AFP. Además, se propone mejorar la equidad de género, al aunar las contribuciones de las parejas en el sistema año a año, equiparar las edades legales de jubilación entre hombres y mujeres en el tiempo e implementar tablas de mortalidad uniformes por sexo.

Por su parte, la propuesta global B plantea transformar el actual sistema de pensiones solidarias en un seguro social, que pasa a ser la parte central del sistema de pensiones, con financiamiento tripartito, organizado por medio de cuentas ciudadanas de seguridad social (que podrán tener la forma de cuentas nocionales), y mantener tanto la pensión básica solidaria como el componente de capitalización individual para los ingresos más altos de aproximadamente el 50\% de los trabajadores. Se trata de elevar las pensiones de los actuales pensionados al construirse un fondo solidario con aportes de trabajadores, empleadores y recursos del Estado. Se propone, además, universalizar la cobertura de la pensión básica solidaria, excepto para aquellos beneficiarios de muy altos ingresos. El nuevo seguro social se financiaría con la contribución del $10 \%$ de todos los cotizantes, con un tope de 350.000 pesos chilenos, de un $3 \%$ a un $4 \%$ de incremento en la cotización de cargo de los empleadores, y se complementaría con aportes fiscales. El nuevo componente de seguro social permitiría facilitar la inclusión de trabajadores independientes, aliviar las desigualdades de género, mejorar la solidaridad intra e intergeneracional del sistema, diversificar la exposición al riesgo y centralizar la administración de cuentas.

Como se aprecia, por encima de sus diferencias, tanto la propuesta A como la B incrementan los componentes solidarios. En el caso de la primera, se introduce un aporte empresarial a las cotizaciones, se retoma el planteamiento de la AFP estatal, se observa la necesidad de reducir las comisiones de las AFP y se proponen ajustes paramétricos por sexo. 
La propuesta B es un híbrido de un seguro social con la capitalización individual para los sectores de mayores ingresos. Se trata de enunciados potentes sobre posibles reformas que nutrirán una discusión que adquirirá vigor en el próximo tiempo.

\section{E. Individualización del riesgo en un sistema de salud dual con reaseguro público: el caso chileno}

\section{Breve caracterización de algunos rasgos de la lógica dual del sistema de salud y sus efectos}

La lógica dual del sistema de salud chileno es única en el plano internacional: la cotización obligatoria, a cargo exclusivo del trabajador, permite afiliarse al sistema público de salud mediante el FONASA, cuya base de reparto favorece la solidaridad, o a las ISAPRE, que a pesar del carácter obligatorio del aseguramiento, funcionan bajo una lógica de seguro privado asociada al riesgo individual. El FONASA brinda acceso a prestaciones públicas en la llamada modalidad institucional o a prestaciones privadas mediante la modalidad de libre elección, que está sujeta a diversos copagos, y, además de las contribuciones de los afiliados, también se nutre de otros aportes con cargo al presupuesto público. El FONASA y el sector público actúan como un reaseguro global del sistema, ya que están desprovistos de barreras de entrada y hacia ellos migran quienes son desplazados de las ISAPRE por el encarecimiento de los planes o las exclusiones. Al igual que el sistema contributivo de pensiones vigente, se creó en 1980 durante la dictadura militar.

Sabida es la dificultad política inherente a la exclusión explícita de prestaciones por parte del asegurador público en salud. Chile resulta también bastante singular en este ámbito, ya que el FONASA cuenta con un catálogo explícito de prestaciones; esta disposición, polémica por naturaleza, también se vio facilitada por el contexto autoritario de la reforma del gobierno militar. Sin embargo, cabe destacar que desde la década de 1990, el catálogo de prestaciones ha aumentado sustancialmente y ha incluido prestaciones de alto costo que se consolidan con las prestaciones garantizadas. Las Garantías Explícitas en Salud (GES), que entraron en vigor en 2005 tras un complejo proceso de negociaciones políticas, modifican en forma parcial la morfología dual del sistema de salud y comprenden fundamentalmente prestaciones avanzadas y de alto costo. Aunque translucen las restricciones políticas que impidieron una reforma de más envergadura vinculada con tales garantías, constituyen un paso adelante que imprime solidaridad al sistema de salud sin alterar la solidaridad del financiamiento a escala del sistema y de las dos lógicas del aseguramiento. A pesar de su limitada cobertura, representan un avance en la superación de la dualidad del sistema de salud chileno, ya que aseguran el acceso efectivo, uniforme y obligatorio a algunas prestaciones, 
tanto en el sistema público como en el sistema privado de aseguramiento en salud. Para el asegurado del sistema público, se aumenta y garantiza la cobertura efectiva de algunas prestaciones, incrementando la certeza del asegurado en cuanto al logro de las prestaciones, que además están sujetas a cumplirse en condiciones de oportunidad y calidad, condiciones que no se han cumplido cabalmente (asunto no se tratará en esta oportunidad). En el caso de las ISAPRE, estas tienen capacidad de fijar precios de acuerdo con el tipo de prestadores elegidos y las diferencias de calidad y de hotelería, lo que evidentemente estratifica estas prestaciones según la capacidad de pago.

Las GES encarnan ciertas coberturas de salud, con una reglamentación de copagos y de obligaciones. Consideran cuatro elementos: acceso, calidad, protección financiera y oportunidad. El acceso, porque es obligación del FONASA y de las ISAPRE otorgarlo; la calidad, porque los servicios debe ofrecerlos un prestador registrado o acreditado; la oportunidad, porque se fija un plazo máximo para disfrutarlas, y la protección financiera, porque se regulan los copagos y la gratuidad. Se establecen reglas de responsabilidad del Estado en materia sanitaria y los órganos de la administración deben responder por "falta de servicio". Hasta el momento, en Chile no se advierte una judicialización del derecho a la salud en el ámbito de las prestaciones garantizadas, ya que la canalización de los reclamos sigue cauces administrativos. Como se verá en el capítulo V, la judicialización se refiere eminentemente a los precios y las coberturas de los planes de salud de las ISAPRE, que se ajustan por riesgo.

Por otra parte, debido a su naturaleza, que permite un descreme del mercado, la privatización de la salud en Chile ha sido una gran fuente de ganancias. Con estas tasas de rentabilidad, el capital se recupera en un plazo de tres a cuatro años (véase el cuadro IV.8). La disminución de la rentabilidad observada en los últimos años en parte tiene relación con la judicialización contra la selección de riesgo (véase el capítulo V).

Cuadro IV.8

Chile: rentabilidad anual media del sistema de Instituciones de Salud Previsional (ISAPRE) sobre capital y reservas, al 31 de diciembre de cada año

(En puntos porcentuales)

\begin{tabular}{cc}
\hline Año & Puntos porcentuales \\
\hline 2010 & 45,1 \\
\hline 2011 & 59,7 \\
\hline 2012 & 43,6 \\
\hline 2013 & 20,1 \\
\hline 2014 & 18,6 \\
\hline 2015 & 11,1 \\
\hline
\end{tabular}

Fuente: Superintendencia de Salud. 
El sistema público, financiado desde el FONASA, cuenta con un solo plan de salud con dos modalidades de prestación: i) institucional, de carácter gratuito y ii) de libre elección, sujeta a copagos, que se aplica genéricamente a todos sus afiliados. En el caso de las ISAPRE, los planes permiten adecuar la prima y los copagos a los costos individuales esperados y al lucro. Si la contribución no alcanza, se pagan montos adicionales, la denominada cotización voluntaria, y esa brecha es mayor entre los asegurados de menores ingresos y de edades más avanzadas. La dispersión del alza de precios de los planes se regula mediante una banda. De acuerdo a información de la Superintendencia de Salud, a enero de 2014 habría existido un total de 55.830 planes vigentes, de los cuales 11.604 habrían sido comercializados, y que se diferencian por las coberturas financieras ofrecidas para diferentes tipos de prestaciones, así como por los topes de uso y los copagos. La capacidad de elección se ve coartada por tal profusión y, de hecho, las pólizas se concentran en un reducido número de planes (Comisión Asesora Presidencial para el Estudio y Propuesta de un Nuevo Marco Jurídico para el Sistema Privado de Salud, 2014, págs. 21 y 22). Aquí se advierte nuevamente la falacia del consumidor bien informado y lo inconducente para los asegurados de una proliferación de planes de una diversidad superflua o fingida, que son un obstáculo para tomar decisiones fundadas y elevarían infinitamente los costos de transacción, de tiempo y de oportunidad del asegurado que quisiera tomar una decisión.

El carácter de reaseguro del sector público y los subsidios cruzados del sector público al sector privado con fines de lucro se muestran en el perfil diverso de los beneficiarios del FONASA y de las ISAPRE, que se tornará más complejo conforme avance el envejecimiento de la población. Las ISAPRE tienen una baja proporción de población adulta mayor y un alto porcentaje de población en edad económicamente activa, con un marcado predominio del sexo masculino; el FONASA, en tanto, duplica los índices de envejecimiento de las ISAPRE. El índice de dependencia en el FONASA es un 71\% mayor que en las ISAPRE, el índice de masculinidad de las ISAPRE es de 116 hombres por cada 100 mujeres y el porcentaje de personas con discapacidad es mayor en la población del FONASA para prácticamente todas las categorías edad e ingresos. Los beneficiarios del FONASA tienen mayores riesgos de salud por las estructuras de edad y porque no hay barreras para las personas con enfermedades preexistentes. Además, el nivel de ingreso medio de los afiliados es menor que el de las ISAPRE, lo que repercute en el financiamiento del Fondo (Comisión Asesora Presidencial para el Estudio y Propuesta de un Nuevo Marco Jurídico para el Sistema Privado de Salud, 2014, págs. 28 y 31). Esta segmentación hace evidente que la dualidad del sistema está orientada en favor de las ISAPRE y que, al 
concentrarse la población de ingresos más altos en el subsistema privado, el sistema de salud, como un todo, no dispone de las cotizaciones que aportan los sectores de altos ingresos, se pierde la solidaridad directa de ingresos en el interior del sistema y solo se observa la que ocurre a través de los impuestos generales que se ingresan al FONASA (Comisión Asesora Presidencial para el Estudio y Propuesta de un Nuevo Marco Jurídico para el Sistema Privado de Salud, 2014, págs. 47).

Cabe destacar que el alza de los gastos para las ISAPRE abiertas crece, en promedio, un $4,5 \%$ por beneficiario cada año, por sobre el aumento del valor de la unidad de fomento (UF), medida monetaria que se ajusta por la inflación. Esta alza está impulsada tanto por un mayor costo y número de licencias médicas, como por una mayor cantidad de prestaciones que se ofrecen a precios más altos cada año, y en los que tiene una importante gravitación el aumento de los honorarios médicos. Esto implica que la orientación al lucro e indexación de los planes de salud privados ha originado un alza de precios de las prestaciones muy por encima de la inflación. Ello tiene otras consecuencias para el gasto fiscal por los vasos comunicantes, por ejemplo, cuando se adquieren en el sector privado servicios para las prestaciones garantizadas en lugar de ampliar la oferta pública (Comisión Asesora Presidencial para el Estudio y Propuesta de un Nuevo Marco Jurídico para el Sistema Privado de Salud, 2014). Como se verá en el capítulo V, en lo que respecta a la judicialización en torno al alza de las pólizas de las ISAPRE, el Tribunal Constitucional, mediante una disposición sistémica, declaró inconstitucional que las tablas de factores que determinan el costo de los planes de salud de las ISAPRE se definan mediante normas administrativas. Más tarde, por ley también se "aplanaron" las tablas de factores de riesgo. Como consecuencia de las decisiones judiciales, se han creado primas especiales (como la prima Auge), que evolucionan al alza e interactúan con el control de los precios de los planes: su aumento compensa el menor ajuste de los precios de las pólizas que se han determinado por disposiciones judiciales y se convierte en un resquicio para neutralizarlas (Rivera, 2013).

Lamentablemente, hay un aspecto que ha recibido muy poca atención en la discusión que tuvo lugar en Chile sobre la reforma y que, dada su particular relevancia para la protección social en materia de salud, podría ser medular para argumentar contra el lucro como articulador del sistema. Se trata de la importancia de que el Estado de bienestar, en este caso el sistema de salud, actúe como un "banco de ahorros". Como se vio en el capítulo II, muchos de los beneficios que reciben las personas han sido pagados por ellas mismas en otros períodos de su vida (Brittan, 2001) y ello precisamente viabiliza la redistribución intrapersonal a lo largo del ciclo de vida (Falkingham y Hills, 2001). 
En esos términos, la cotización que no cubre gastos efectuados y que, por tanto, puede ser "ahorrada" a escala del sistema coadyuva a su sostenibilidad financiera, mientras que su "uso intertemporal" permite el acceso a prestaciones futuras y, con ello, valida y actualiza una "propiedad" entendida como acceso a prestaciones que, como se ve, en parte han sido financiadas por el propio cotizante en períodos en que se hizo un escaso uso del seguro, debido a la buena salud, a la edad o a las etapas reproductivas individuales. Que el financiamiento del sistema funcione como "banco de ahorros" es fundamental para la solidaridad y la universalidad: no se aporta en función del estado de salud, del sexo, ni de la edad.

En el caso chileno, el fundamento del sistema precisamente impide que funcione como banco de ahorros: el lucro se basa primordialmente en la diferencia entre el precio de la prima y las prestaciones, y los precios y las coberturas de las pólizas se van actualizando según el perfil de riesgo. Cuando los asegurados ya no las pueden pagar, se ven expulsados gracias a la dualidad del sistema: los "buenos riesgos" solventes y que hacen un escaso uso del sistema le generan altas ganancias, junto con los "malos riesgos" solventes, es decir, aquellos beneficiarios cautivos que pagan altas pólizas o altos gastos de bolsillo (copagos, gastos catastróficos); los "malos riesgos" insolventes son expulsados sistemáticamente al sector público, que cumple una función de reaseguro. Es decir, que los asegurados no tienen "capacidad de ahorro" dentro de las ISAPRE, dado que los recursos no utilizados cuando se hace un bajo uso de la póliza, en lugar de constituir un acervo global para el sistema de salud, con fines solidarios, se absorben en el corto plazo bajo la máxima del lucro, y con ello se coarta la intertemporalidad del aseguramiento. En este sentido, el dualismo coarta la redistribución y limita la sostenibilidad del sistema que necesita recibir más recursos fiscales en su función de reaseguro.

El argumento de que el aseguramiento, en tanto "banco de ahorros", se ve socavado por el lucro es importante en una sociedad en que se han debilitado los lazos de solidaridad, porque enfatiza el daño que se hace directamente a los aportes individuales que realizan los cotizantes en tanto coarta el horizonte de mediano y largo plazo en que operan las contribuciones a la seguridad social y puede complementar otros argumentos que apelen a la solidaridad. De manera complementaria, como vimos en el capítulo II, la incertidumbre de los riesgos de salud, en cuanto al momento en que se necesita una atención, sus costos y su duración, provee, por su parte, un fundamento firme para argumentar por la solidaridad, ya que incluso los sectores de buenos ingresos pueden enfrentar gastos catastróficos y, por tanto, en la fragilidad de la naturaleza humana hay un fundamento para la universalidad y la solidaridad del aseguramiento en salud. 


\section{La discusión contemporánea en torno a la reforma del aseguramiento privado y sus impactos globales en el sistema de salud}

Desde hace muchos años, la insatisfacción con el sistema dual de salud ha ido de la mano de varias propuestas de reforma que han sido muy resistidas por las ISAPRE. El diagrama IV.2 es útil para graficar las tensiones políticas en torno a la reforma.

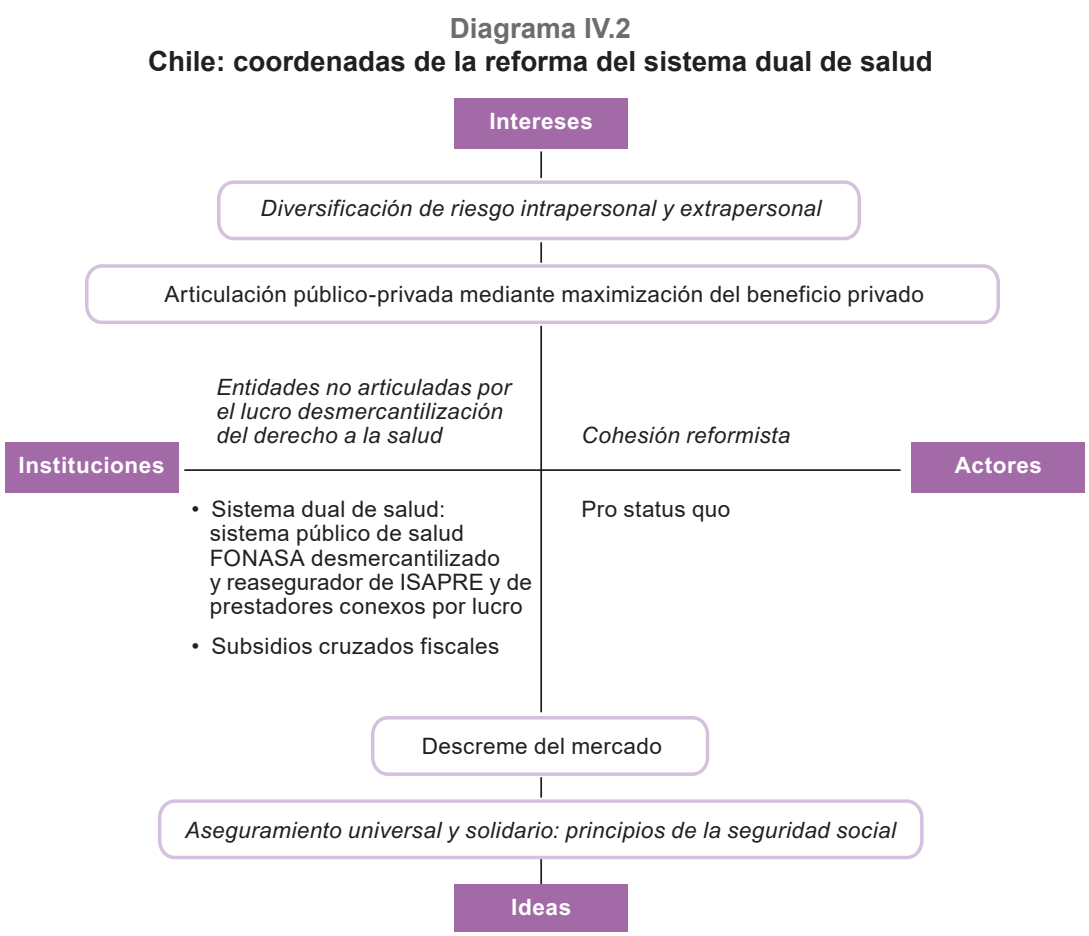

Fuente: Elaboración propia sobre la base de O. Fioretos, T. G. Falleti y A. Sheingate, "Historical institutionalism in political science", Oxford Handbook of Historical Institutionalism, O. Fioretos, T.G. Falleti y A. Sheingate (eds.), Nueva York, Oxford University Press, 2014.

Durante el gobierno del Presidente Piñera, se planteó un Plan Garantizado de Salud (PGS) obligatorio para las ISAPRE, que debía cubrir medicina preventiva, patologías del Plan Auge, cobertura de gastos catastróficos, atenciones de emergencia y la planilla de prestaciones que entrega el FONASA. Cada ISAPRE definiría el costo de ese plan, el Fondo de Compensación Solidario debía permitir a las ISAPRE acoger a los afiliados de mayor costo y se terminaba con las preexistencias y con la tabla de factores de riesgo, que definía el costo del plan en virtud del sexo, la edad y la condición de salud del afiliado. 
Durante el segundo gobierno de la Presidenta Bachelet se convocó una Comisión Asesora Presidencial para que elaborara una propuesta de reforma del régimen de las ISAPRE, que permitiera regular a estas instituciones para terminar con la discriminación por riesgo y selección de asegurados, controlar las alzas de precios y su variabilidad, y regular planes en cuanto a beneficios y copagos. Ello en el marco de una mirada global del financiamiento, del aseguramiento y de los prestadores, desde una perspectiva de la salud como un derecho y reconociendo la necesidad de introducir mayor equidad y solidaridad en el sistema de acuerdo con los principios de la seguridad social.

La Comisión reconoce la necesidad de una perspectiva sistémica y que la reforma del régimen de las ISAPRE afecta al sistema de salud en su conjunto y, por tanto, también al sistema público de salud. De allí que sea necesario plantear el desafío de la modernización y el fortalecimiento del sistema prestador de salud, en particular del sistema público, en cuanto a los recursos humanos, físicos, tecnológicos y financieros requeridos para alcanzar los estándares de calidad. Se consideró indispensable definir y proponer un horizonte de mediano y largo plazo, como visión de futuro para orientar los cambios requeridos en el corto plazo en el sistema privado. En cuanto a la reforma inmediata al sistema privado de salud, es necesario abordar las transformaciones que requiere el régimen de las ISAPRE para superar las principales dificultades que lo alejan de los principios de la seguridad social y adecuar los sistemas público y privado a las importantes modificaciones.

Tampoco en el seno de esta Comisión se logró unanimidad en las recomendaciones. La propuesta mayoritaria propone, en el mediano plazo, un seguro público único y seguros privados de carácter voluntario, suplementario o complementario, mientras que la propuesta alternativa propone un sistema de multiseguros de libre elección entre aseguradores.

La propuesta mayoritaria incluye los siguientes elementos:

- Establecimiento de un plan de seguridad social (PSS) único, universal y estandarizado para todos los habitantes del país, que abarca el listado de beneficios de la modalidad de atención institucional (MAI) del sistema público de salud, las GES, la modalidad libre elección (MLE) del FONASA, la Ley de Urgencia, la Cobertura Adicional para Enfermedades Catastróficas (CAEC) y el Subsidio por Incapacidad Laboral (SIL), el Plan complementario actual de ISAPRE, el Examen de Medicina Preventiva (EMP) y el listado de prestaciones conocido como códigos de la Superintendencia de Salud. El PSS se deberá otorgar sin considerar preexistencias ni afiliados cautivos, dentro del sistema de las ISAPRE. Se deberán 
estudiar las condiciones y los mecanismos que permitan en el futuro viabilizar la movilidad plena de los cotizantes entre las ISAPRE y el FONASA, y podrían considerarse mecanismos y condiciones distintos a la declaración de salud, que impidan que personas de riesgo alto transiten inmediatamente de un sistema a otro.

- Inclusión en el PSS de un sistema de copagos estandarizados, con un gasto anual máximo por copago respecto de la renta de las familias. Se financiará con la cotización obligatoria de seguridad social fijada por ley. Además, las ISAPRE podrán cobrar una prima comunitaria fijada por cada aseguradora, asociada a redes de prestadores, y ofrecer hasta un máximo de tres redes con sus respectivas primas.

- Creación de un Fondo Inter-ISAPRE de compensación de riesgos para permitir la movilidad y el fin de la cautividad y de las preexistencias, e introducir mayor solidaridad al sistema de las ISAPRE. Este se conformará con las cotizaciones de sus afiliados y, descontados los recursos destinados al fondo mancomunado y al fondo para subsidio por incapacidad laboral, redistribuirá a cada ISAPRE una cápita ajustada por el riesgo de sus cotizantes, que considere variables asociadas al costo de la atención de salud, por edad, sexo, condición de salud, zona geográfica y demás. También admite compensaciones ex post mediante una reserva para eventos de mayor costo y baja probabilidad de ocurrencia, no considerados en la fórmula capitada.

- Implementación de un fondo mancomunado universal (FMU) entre el FONASA y las ISAPRE (desde el Fondo Inter-ISAPRE) para romper la segmentación, introducir solidaridad entre los distintos sistemas y financiar prestaciones universales. Se contempla además un aporte directo, progresivo y gradual proveniente de los impuestos generales. El FMU financiará algunas prestaciones universales para los beneficiarios de las ISAPRE y del FONASA, como las asociadas al alto costo (al inicio financiará medicamentos de alto costo de manera universal).

- Para superar los problemas asociados a la obtención de licencias médicas y su subsidio, conformación de un Subsidio por Incapacidad Laboral (SIL), con financiamiento tripartito (Estado, empleadores y trabajadores) y organizado en un Fondo Común de Incapacidad Laboral, que incluye a los asegurados del FONASA y de las ISAPRE y también licencias por accidentes $y$ enfermedades profesionales. 
- El Fondo Común de Incapacidad Laboral debe someterse a una evaluación actuarial periódica e independiente, y la entidad pagadora de los subsidios, tanto de enfermedad como de accidentes laborales y enfermedades profesionales, deberá estar separada de la entidad encargada de controlar y evaluar las licencias para asegurar una mayor transparencia.

- Creación de un plan de seguros complementarios, supervisado por la Superintendencia de Salud conforme a la regulación establecida por ley, que abarcará seguros de largo plazo, vitalicios, con renovaciones periódicas, referidos a mejores coberturas en redes o prestadores más apetecidos por los afiliados y que cubran diferenciales de copagos. Se propone que los prestadores no puedan ofrecerlos directamente.

- Transición entre escenarios contractuales: los actuales afiliados de las ISAPRE podrán cambiarse voluntariamente al nuevo sistema, mientras que los nuevos deberán ingresar en forma directa. Los incrementos de precios delos planes delas personas que opten por mantener su plan vigente serán regulados por la Superintendencia de Salud, al igual que los nuevos planes complementarios.

- En cuanto a la relación entre seguros y prestadores, cada aseguradora comunicaría el conjunto de prestadores acreditados a los que sus usuarios pueden acceder y un mismo prestador puede ofrecer servicios a varias aseguradoras. Para mejorar la utilización de los prestadores disponibles, especialmente en regiones, los asegurados de las ISAPRE podrán acceder a prestadores públicos en condiciones similares a los asegurados del FONASA, es decir, mediante la atención primaria, pero asegurando que no desplacen a los del Fondo.

- Otorgamiento de mayores facultades de regulación a la Superintendencia de Salud, no solo en cuanto a la acreditación, sino también respecto de los contratos. La visión de mayoría reafirma la prohibición de la integración vertical de aseguradores y prestadores que contempla la ley.

- En cuanto a la regulación de precios y su capacidad de reajuste, se trata de eliminar la unilateralidad con que actúan las ISAPRE para readecuar planes y subir los precios, más allá del índice de precios al consumidor (IPC). Se propone que todos los precios sean monitoreados y regulados por la autoridad, de acuerdo con una normativa establecida en la ley. Se contempla definir un mecanismo de evaluación de precios, y la Superintendencia 
de Salud deberá contar con un equipo o consejo de análisis de los precios.

- Fomento de las relaciones contractuales de largo plazo sobre la base de parámetros objetivos, mecanismos de pago y control de costos que eviten cambios unilaterales en las condiciones, con promoción del uso de redes, paquetes quirúrgicos, grupos relacionados de diagnóstico o similares, establecidos por la ley. Desarrollo de sistemas de información con resultados clínicos de prestadores públicos y privados para transparentar la efectividad sanitaria. Codificación común de prestaciones para todo el sector de la salud.

- En cuanto a las nuevas tecnologías médicas, se propone crear una institucionalidad nacional para la evaluación de tecnologías de la salud con el propósito de garantizar el uso de tecnologías que sean seguras, tengan impacto y sean eficientes en función de los costos.

Las principales divergencias entre los integrantes de la Comisión giran en torno a los siguientes puntos planteados por la minoría:

- El Fondo Mancomunado de Salud debe ser exclusivamente para los medicamentos de alto costo. Por ello, en su propuesta, este se denomina Fondo Especial para Medicamentos de Alto Costo (FEMAC), aunque mantiene la idea de mancomunar recursos para beneficiarios del FONASA y las ISAPRE. La principal divergencia se refiere a la definición del funcionamiento del Fondo, que recibe aportes de la cotización para salud y no vuelve a redistribuir las primas ajustadas por riesgo a los aseguradores. Se afirma que en el futuro esto compromete la participación de múltiples aseguradores en la seguridad social y la capacidad de las personas de elegir un sistema de salud dentro de una visión de multiseguros.

- Se plantea que la existencia de una prima comunitaria adicional a la cotización del $7 \%$ para financiar el PSS en las ISAPRE es una discriminación por ingresos. La posición minoritaria sostiene que las ISAPRE deberían otorgar un plan obligatorio por el 7\%, sin prima comunitaria, y que las primas comunitarias deben estar asociadas a planes según las características de las redes de prestadores.

- En cuanto al alcance de la extinción de la declaración de salud, se afirma que esta debería mantenerse para las personas que quieran cambiarse del FONASA a una ISAPRE, para evitar que el nuevo modelo conduzca al desfinanciamiento del sistema 
de las ISAPRE. De acuerdo con esta visión, se produciría un desfinanciamiento entre la prima establecida para el ajuste de riesgo y la tarifa del PSS, debido a la migración hacia las ISAPRE de asegurados del FONASA que tienen enfermedades graves y que se encuentran en listas de espera.

- En cuanto a la integración vertical, por respeto a la libre iniciativa privada y su derecho a organizarse libremente en el marco del ordenamiento jurídico vigente, se aboga por no considerar el tema de la integración vertical en el marco de la propuesta de la Comisión y, por no haberse profundizado en él, se recomienda realizar nuevos estudios en el futuro.

Se observa, por tanto, que la discusión actual gira en torno a nuevos vasos comunicantes dentro del sistema de salud como un todo y al cuestionamiento de su dualidad, funcional hasta ahora a la alta rentabilidad de las ISAPRE y los prestadores relacionados. Un paso radical sería el establecimiento de un plan universal de salud, con consideraciones redistributivas en los copagos, mientras que otro giro radical sería la elevación de la mancomunidad de riesgos dentro del sistema de las ISAPRE.

\section{F. Conflictividad y altos costos de transacción: las trampas de la complejidad del sistema de salud colombiano}

Como vimos en el capítulo II, partiendo de niveles muy bajos, Colombia ha experimentado una aceleración sin par de la cobertura de salud de la población en América Latina, y varios indicadores de salud muestran mejoras. Algunas brechas de desigualdad en esta materia se han reducido y se ha incrementado la protección financiera ante riesgos en materia de salud $^{11}$. Con la reforma radical emprendida en 1993 se pretendió instaurar un sistema de salud que propiciara la competencia tanto en el aseguramiento como en la provisión de servicios, en un marco que propugnaba los principios de solidaridad y universalidad, y la descentralización. A tal fin, se aprendió de la experiencia chilena en cuanto a las exclusiones e inequidades que eran atribuibles a su dualidad y se incorporaron dispositivos orientados a la solidaridad. Se trata de uno de los sistemas de salud más complejos de la región e incluso, en palabras del actual Ministro de Salud y Protección Social de Colombia, resulta difícil de entender (Gaviria, 2015). En este apartado se detallan algunos de sus rasgos, que evidencian tanto la complejidad del sistema como la magnitud de los retos.

Véase un recuento de algunos de los logros en Ministerio de Salud y Protección Social de Colombia (2015). 
Pese a los propósitos originales, la competencia ha encontrado numerosos obstáculos, y algunas características del sistema han originado altos costos de transacción y permitido conductas lesivas al buen uso de los recursos y al logro de la equidad. También se han observado serias carencias en cuanto a la integración y complementariedad de la red de servicios y de los niveles de atención.

Retrospectivamente, destaca como defecto de origen de la alambicada arquitectura del sistema de salud colombiano que el logro de numerosos principios, objetivos y expectativas se cifró en que el modelo operara bajo condiciones de competencia. No se consideró cabalmente la viabilidad intrínseca de la competencia en razón de las singularidades del mercado de la salud, ni las complejidades institucionales y políticas de crear, conservar y expandir condiciones de competencia en los ámbitos pertinentes, ni tampoco los costos financieros y, en general, de transacción que podía acarrear tanto el objetivo de promover la competencia como, en su defecto, la ausencia de competencia en un régimen de mercado.

Originalmente, los beneficios se consolidaron en dos regímenes: i) el contributivo, que se nutre de contribuciones obrero-patronales y ii) el subsidiado, de carácter selectivo para los más pobres, financiado eminentemente con recursos fiscales y un pequeño aporte solidario del régimen contributivo, manejados por las administradoras del régimen subsidiado y con prestaciones mucho más reducidas. La afiliación se establece mediante las aseguradoras públicas y privadas denominadas Entidades Promotoras de Salud (EPS), que reciben un monto fijo por afiliado, llamado Unidad de Pago por Capitación (UPC), y que contratan servicios de salud tanto en la red privada como en la red pública, en las denominadas Instituciones Prestadoras de Salud (IPS). El Fondo de Solidaridad y Garantía, por su parte, debía velar por el equilibrio de los recursos y las condiciones de igualdad del régimen contributivo, mediante un pago per cápita que se ajustaba para evitar la selección de riesgos en las prestaciones. El Fondo tenía cuatro subcuentas - de compensación, de solidaridad, de promoción y de eventos catastróficos y accidentes de tránsito- y debía transferir el 1\% de la cotización de ese régimen al subsidiado, que se sumaba a los impuestos generales de los que este se nutría. Lo que se pretendía era ir hacia un financiamiento de las prestaciones mediante el subsidio a la demanda - es decir, determinado por la demanda efectiva de los asegurados-que reemplazara el subsidio a la oferta, como se denominaba al financiamiento tradicional de prestadores eminentemente públicos y mediante presupuestos históricos. Las disparidades distributivas y la singular oferta territorial de los prestadores imposibilitaron una sustitución total del uno por el otro y no se llegó a definir una proporción deseable. 
En la concepción y trayectoria se observaron tempranamente serias carencias en cuanto a la integración y complementariedad de la red de servicios y los niveles de atención. Por su parte, las funciones de salud pública (que en el inicio quedaron relativamente descuidadas por el modelo, lo que dio origen, por ejemplo, a retrocesos de las vacunaciones) fueron transferidas de manera progresiva a los departamentos y entidades territoriales.

Además de las asimetrías de información inherentes al ámbito de la salud, cabe destacar que la capacidad de elección se ve comprometida por la cantidad de entidades aseguradoras y prestadoras, concentradas territorialmente. En 2013 el sistema abarcaba una amplia red de actores: cerca de 66 EPS, 30.000 IPS y más de 30.000 profesionales independientes. Tal cantidad de entidades, además de obstaculizar la presunta libertad de elección asociada con la competencia, dificultaba al Estado las funciones de acreditación, seguimiento, inspección, vigilancia y control que deben proteger al ciudadano y evidencian estándares laxos. Se ha constatado una gran asimetría, por ejemplo, en la capacidad regulatoria y de gobernanza de las entidades territoriales y de las Secretarías de Salud, especialmente en zonas apartadas, ante las EPS y las IPS. Ello también dificulta la conformación de redes. Algunas han sido intervenidas para buscar una mayor solidez del sistema de aseguramiento y prestación, y se ha vislumbrado la necesidad de depurarlas sobre la base de criterios de calidad, capacidad y responsabilidad financiera (Ministerio de Salud y Protección Social de Colombia, 2013, pág. 75).

Uno de los aspectos más complejos fue la dificultad para llegar a establecer un plan universal de beneficios. El régimen contributivo se regulaba por el Plan Obligatorio de Salud (POS), que explicitaba un listado de beneficios estándar que, esencialmente, retomaba los servicios que estaban disponibles en 1993 en el seguro social, en tanto que el régimen subsidiado se regía por el Plan Obligatorio de Salud Subsidiado (POS-S). Se suponía que ambos deberían converger gradualmente hasta 2001, pero eso no ocurrió. No obstante, se dieron algunos pasos de transición hacia la convergencia, como la eliminación de los planes de beneficios parciales y la introducción de mecanismos directos de pago del régimen subsidiado desde el Gobierno Central en la Ley núm. 1.430. En 2009, la Corte Constitucional intervino para catalizar y acelerar la confluencia, en el marco de una profunda judicialización del derecho a la salud (véase el capítulo V).

La evaluación de algunas experiencias piloto de igualación de los regímenes contributivo y subsidiado ofrece lecciones interesantes en cuanto a las condiciones que posibilitaron avanzar hacia la convergencia, o bien, sobre la tipificación de los problemas y obstáculos. Los éxitos en el 
caso de Barranquilla se atribuyen, por ejemplo, a que se habría contado con un apoyo político y financiero para renovar la red pública y establecer un control riguroso de los diferentes agentes del mercado a fin de garantizar la efectividad en la prestación de servicios y la sostenibilidad financiera del sistema, mientras que en Cartagena se habría actuado de manera improvisada, sin haber reformado la red hospitalaria y sin políticas de control estrictas de los recursos canalizados a las EPS y las IPS. Como elementos indispensables para el éxito se señalan la identificación plena de los usuarios como condición para efectuar su afiliación, el fortalecimiento del primer nivel de atención, la puesta en marcha de políticas de prevención y promoción de la salud, la conveniencia de tener un administrador único de los recursos y garantizar flujos eficientes de recursos dentro del sistema (Castañeda y otros, 2012, págs. 59-61).

En términos más globales, la experiencia colombiana fue destacada durante décadas como un laboratorio de implantación de prestaciones explícitas en salud, en un contexto en el cual la priorización explícita en salud se promovía con denuedo por el Banco Mundial, desde el famoso Informe mundial Invertir en salud, de 1993, y por el Banco Interamericano de Desarrollo (BID) y otras entidades, con el objetivo de manejar las tensiones crecientes entre presiones sobre el gasto y la disponibilidad de recursos (Glassman y Chalkidou, 2012) ${ }^{12}$. Sus defensores afirmaban que "la priorización explícita no puede verse como un ejercicio aislado, desarrollado de manera ad hoc o 'de una sola vez'; por el contrario, debe ser visto como un sistema que implica múltiples pasos que se aplican de manera sistemática en el tiempo y donde confluyen muchos actores con un fin común: mejorar la asignación de los recursos escasos en salud para lograr mejores resultados en términos de equidad, eficiencia y calidad; iii) un número creciente de países le ha prestado especial atención a uno de los pasos fundamentales dentro de este proceso de priorización: la evaluación de las tecnologías sanitarias" (Giedion, Muñoz y Avila, 2012, pág. 7).

Pero, como se verá en el capítulo V sobre la judicialización del derecho a la salud la experiencia demuestra que la priorización explícita difícilmente puede ser un instrumento para lograr esa confluencia de actores, ni una comunidad de intereses en torno a tales objetivos. Más aún, ella puede ser objeto de grandes tensiones, que en Colombia se dirimieron muy profusamente en el terreno judicial, en una dinámica que combinaba tanto conflictos en torno a las prioridades establecidas, como problemas originados por la prestación de los servicios, junto con conductas de riesgo moral por parte de las compañías farmacéuticas y de las EPS que se beneficiaban de los recobros.

12 Véase un análisis de la trayectoria de la discusión y las políticas de priorización explícita, desde un enfoque favorable a esta, en Giedion, Muñoz y Ávila (2012). 
Junto con los altos costos de transacción inherentes a los conflictos en torno a la priorización, esto ha llevado a cuestionar las ventajas de la priorización explícita frente a la priorización implícita que tradicionalmente han efectuado diversos sistemas de salud. Afortunadamente, en el último tiempo se advierte una menor ortodoxia en la literatura sobre las ventajas y desventajas del racionamiento implícito o explícito de las prestaciones de salud, sobre las opciones intermedias y al tratar la complejidad técnica y política que las diversas opciones implican (Giedion, Tristao y Bitrán, 2014).

Dado que el caso colombiano se suponía emblemático de una opción por la priorización explícita de salud, cabe destacar que actualmente se está transitando de una estipulación detallada y rígida de beneficios, como fue la del POS y la del POS-S, y una amplia gama de prestaciones no POS obtenidas al socaire de la judicialización que constituyó una especie de seguro de reembolso paralelo al sistema de aseguramiento que se había construido (Gaviria, 2015), a un racionamiento implícito y al uso de un listado negativo de servicios que no son financiados, en un marco de confluencia de las prestaciones de ambos regímenes.

El fundamento de esta transición reside en la explosión de los reembolsos de la mano de la judicialización que, según afirma el Ministro Gaviria, habría alineado los incentivos de todos los agentes: la industria farmacéutica, los hospitales y clínicas, las mismas compañías aseguradoras, algunas de ellas integradas verticalmente, que vieron en este otro seguro una oportunidad para sus negocios, los médicos, sobre todo los médicos especialistas, y las asociaciones. Conforme a sus palabras, "Todo el mundo participó, voy a decirlo de manera gráfica, de esta fiesta. Era muy fácil que se prescribiera un medicamento. La compañía farmacéutica estaba ganando, muchos de los médicos estaban ganando, hospitales veían en esto, o en la intermediación de precios de medicamentos, un ingreso que no habían previsto y que comenzó a ser importante. Muchas de las compañías aseguradoras veían en este seguro, una forma, a veces, de evadir su responsabilidad, porque simplemente se prescribía el medicamento que no estaba incluido y ellos se ahorraban los medicamentos que ya hacían parte de las inclusiones. Esa alineación de los incentivos perversamente es lo que explica esta explosión, de la mano de vacíos regulatorios respecto de la presión tecnológica en salud que provocan inclusiones desordenadas, sin que se tenga capacidad de discernimiento, sin análisis de costo efectividad y del marco epidemiológico: el mensaje hacia las farmacéuticas y hacia la tecnología médica, básicamente, era que en Colombia se paga todo, que las puertas estaban abiertas a todas las innovaciones a cualquier precio. De allí la necesidad de crear un conjunto de instituciones regulatorias y de crear una construcción legítima del 'no' que fundamente las exclusiones" (Gaviria, 2015). 
Un paso crucial en ese sentido fue la regulación de precios de los medicamentos, introducida en 2013 mediante una metodología que toma como referencia una canasta de precios internacionales. Por otra parte, la Ley Estatutaria núm. 1.751 dio un giro fundamental, que fue avalado por la Corte Constitucional, en términos de definir límites al derecho fundamental a la salud mediante un mecanismo "técnicocientífico, de carácter público, colectivo, participativo y transparente" para evitar que los recursos del sistema de salud financien servicios y tecnologías: i) que tengan un fin primordialmente cosmético o suntuario, ii) de los que se carezca de evidencia sobre su seguridad, eficacia y efectividad clínica, iii) que no estén autorizados para su uso en el país iv) que sean experimentales o tengan que ser prestados en el exterior. En cualquier caso, deberán tenerse en cuenta las excepciones previstas en la jurisprudencia constitucional.

La Corte Constitucional determinó que los límites a la protección del derecho fundamental a la salud deben establecerse primordialmente a partir de exclusiones, cuya definición necesita un nuevo arreglo institucional, que debe desarrollarse en el plazo de dos años, de la mano de un alto componente técnico y garantizando que los pacientes y la comunidad médica incidan sobre las decisiones. Por el momento, se mantienen los arreglos institucionales vigentes, pero en una transición hacia la nueva realidad institucional definida por la Ley Estatutaria núm. 1.751. Por ejemplo, con la actualización del Plan Obligatorio de Salud de 2013 se eliminaron algunas de las inflexibilidades resultantes de una configuración del POS basada en una lista explícita de formas farmacéuticas específicas. El avance progresivo hacia una protección basada más en exclusiones que en inclusiones debe hacerse compatible con otros mandatos y obligaciones avalados también por la Corte Constitucional, como la progresividad en la protección del derecho.

Por su densa raigambre, deben considerarse también algunos aspectos estructurales del sistema de salud que han sido objeto de discusión y en torno a los cuales se planteó en marzo de 2013 (Ministerio de Salud y Protección Social de Colombia, 2013) un proyecto de ley que ambicionaba una reforma profunda para encarar lo que se denominaba "crisis sistémica". Esta iniciativa, sin embargo, no logró aunar los consensos políticos que requería ${ }^{13}$.

El proyecto de ley plantea que la fragmentación del modelo ha deslegitimado al sistema de salud porque incentiva la extracción de rentas por parte de los distintos agentes en demérito de los objetivos de salud de la población, y que el aseguramiento se ha centrado en el manejo

13 En la página web del Ministerio de Salud y Protección Social puede consultarse la trayectoria que ha tenido el proyecto de ley en el Poder Legislativo. 
financiero, por encima de la gestión de los riesgos en salud (Ministerio de Salud y Protección Social de Colombia, 2013, págs. 1-17). Se destaca que los servicios se han orientado hacia prestaciones de alta complejidad, y que la capacidad para realizar políticas preventivas y la resolutividad en los niveles básicos de atención son bajas.

Se constatan, asimismo, diferentes desarreglos microeconómicos en la relación entre los agentes del sistema, que han desembocado en graves problemas en los flujos financieros, altos costos de transacción y ruptura de la mancomunación de riesgos mediante recobros de servicios no incluidos en el plan de beneficios $\operatorname{POS}^{14}$. De allí la limitada legitimidad del sistema en el contexto institucional y de muchos usuarios, debido a que siguen existiendo barreras de acceso de índole geográfica, administrativa y económica.

En zonas aisladas, por ejemplo, los mecanismos de financiamiento incentivan que las EPS y las IPS se beneficien cuando la población afiliada no usa los servicios. En cuanto al sistema hospitalario, en aras de la competencia y debido a una débil habilitación de las IPS, se generaron incentivos para premiar la rentabilidad de los servicios y el uso de alta tecnología, en detrimento de unidades menos rentables o que reciben menores pagos, como pediatría. A fin de obtener el precio más bajo, las EPS compran las atenciones a diferentes IPS, con lo que los pacientes sufren una discontinuidad y fragmentación de la atención y deben enfrentar costos más altos de transporte y una mayor cantidad de tiempo perdido.

Estos problemas, se afirma, acusan una situación de crisis sistémica y el debilitamiento de la capacidad regulatoria del Ministerio de Salud y Protección Social ante la capacidad de presión de diferentes agentes ${ }^{15}$.

Otro problema de discontinuidad y fragmentación de la atención es el cambio que experimentan las personas debido a modificaciones en la inserción laboral, entre los regímenes contributivo y subsidiado, que originan períodos de desprotección. En cuanto al rango de beneficios a los que se tiene acceso, se reconocen los problemas que han acarreado la rigidez y desactualización del POS, que promovieron la extensa judicialización, que se analizará en el capítulo V, y que generó un gasto creciente y sin mayor control.

Para superar la fragmentación y lograr los objetivos de calidad, en el proyecto de ley se proponía redefinir los roles de los distintos agentes,

\footnotetext{
Esto será analizado en detalle en el capítulo V sobre judicialización.

Se aduce que los avances legislativos logrados por medio de la Ley núm. 1.122 de 2007 y la Ley núm. 1.438 de 2011 son soluciones parciales que no han resuelto de manera estructural el problema de la fragmentación y han dejado al propio Ministerio de Salud y Protección Social con una capacidad de rectoría muy limitada y débiles mecanismos regulatorios. Una lectura de la Ley núm. 1.438 evidencia que se proponen una serie de objetivos, sin estipular los instrumentos que deben permitir su consecución.
} 
alinear los incentivos y mecanismos regulatorios, y fortalecer la capacidad de rectoría del Ministerio de Salud y Protección Social sobre el sistema mediante diferentes estrategias:

- Recuperación de la capacidad de rectoría del Gobierno mediante el manejo directo ex ante del aseguramiento social y el control de los recursos y la información, y de las funciones de inspección, vigilancia y control.

- Territorialización regulada del sistema de salud de acuerdo con las características de la población y la oferta disponible de servicios. Esto incluye generar redes integradas de prestadores reguladas por el Ministerio de Salud y Protección Social y los Departamentos. Respecto de los entes territoriales, se contempla la designación de los directores de hospitales y otras funciones de salud pública y habilitación de servicios.

- Mancomunación integral del riesgo en salud mediante la integración de beneficios POS y no POS, bajo la responsabilidad integrada de los agentes del sistema de salud.

- Implantación de mecanismos e incentivos para velar por la calidad de los servicios y por el funcionamiento eficiente del sistema (entre ellos, el pago por desempeño y los resultados en materia de salud).

- Separación entre el financiamiento y la provisión de servicios.

- Limitación de la integración vertical para fortalecer las condiciones de competencia del sector hospitalario; limitación de la integración horizontal en la provisión e intermediación de medicamentos e insumos médicos, como mecanismo de control de precios.

- Integración y aceleración de los flujos financieros entre los diferentes actores del sistema y de estos con el Estado, para reducir los costos de transacción y los costos asociados con la demora del pago de los servicios y de la provisión de insumos requeridos para las prestaciones.

- Estandarización del reporte de información sobre afiliación, recaudo, auditoría y giro de recursos a los prestadores de servicios de salud para integrar la provisión de información con el pago de servicios.

- Implantación de mecanismos e incentivos para velar por la calidad de los servicios y por el funcionamiento eficiente del sistema (entre ellos, el pago por desempeño y resultados en salud). 
Con relación a las fuentes de financiamiento, se señala que en 2012 eran 16 distintas: recursos fiscales y parafiscales, con distintos procesos de recaudo, asignación y flujo, que dificultan el control y el flujo de recursos ${ }^{16}$. Se plantea que la dispersión y multiplicidad de actores en la administración de los recursos genera rigideces en torno a sus fuentes y usos, y ha dado pie a múltiples leyes y decretos para modificar la destinación de algunas de las fuentes financieras, con el fin de cubrir necesidades en otros frentes o mejorar el flujo de recursos del sistema. El incremento de la participación de recursos fiscales en el financiamiento y la igualación de los planes de beneficio entre los regímenes contributivo y subsidiado, ordenado por la Corte Constitucional, justifican la concentración de todas las fuentes de financiamiento en un solo fondo. Se trata de hace frente a la excesiva complejidad de la operación del Fondo de Solidaridad y Garantía (FOSYGA), que maneja cerca de 100 procesos misionales y 30 transversales que podrían reducirse: aproximadamente un $25 \%$ de los macroprocesos se eliminarían y un $8 \%$ se simplificarían. Se ejercería un adecuado control de las recaudaciones y se reducirían los costos asociados a la administración del FOSYGA y a la complejidad que implica que las EPS sean las que recauden las cotizaciones y realicen un sinnúmero de ajustes por traspasos ulteriores a agentes del sistema. El ahorro respecto del sistema de administración y operación vigente se estimaba en torno al $57 \%$, sin considerar los costos de transacción, que disminuirían o desaparecerían por los nuevos sistemas de operación que se plantean en el proyecto de ley.

El proyecto proponía la necesidad de articular el financiamiento y la prestación de servicios mediante un ente especializado en la gestión del riesgo, que esté desprovisto de cualquier manejo sobre la liquidez financiera del sistema y que cumpla funciones de compra de servicios por medio del componente básico de atención. Sin lugar a dudas, la creación de Salud-Mía era la modificación más profunda planteada por el proyecto de ley. Se trataba de una entidad financiera de naturaleza especial, que reemplazaría al FOSYGA y estaría encargada de afiliar, recaudar, administrar y girar los recursos destinados al pago de los servicios de salud. El objetivo es solucionar cuatro problemas: i) la dispersión de las fuentes de financiamiento, ii) las dificultades operativas de la administración del FOSYGA, iii) los altos costos asociados a la administración del FOSYGA y a procesos delegados en las EPS y iv) las dificultades relacionadas con la afiliación, el recaudo y los pagos a prestadores.

Salud-Mía también estaría encargada del recaudo directo y de girar a cada gestor los recursos que le correspondieran, uniendo información

16 En estudios citados en Castañeda y otros (2012, pág. 19) se ha planteado que el laberinto financiero de las cuentas de salud en Colombia muestra cuatro circuitos de recursos que tienden a ser independientes y sin mayor relación entre sí: los dos circuitos del régimen contributivo y del régimen subsidiado, la red pública de las IPS que atienden a los ciudadanos que no están afiliados a ninguno de los dos sistemas y el circuito de la salud pública. 
de afiliación y pagos. Se trataba de superar el complejo y oneroso recaudo de cotizaciones que realizan las EPS ${ }^{17}$. Salud-Mía tendría, además, la responsabilidad de administrar el sistema de información de la seguridad social en salud en materia de afiliados, mediante una única base de datos transaccional, actualizada en línea y en tiempo real (véase el diagrama IV.3).

\section{Salud-Mía: fuentes de los recursos y destinación}

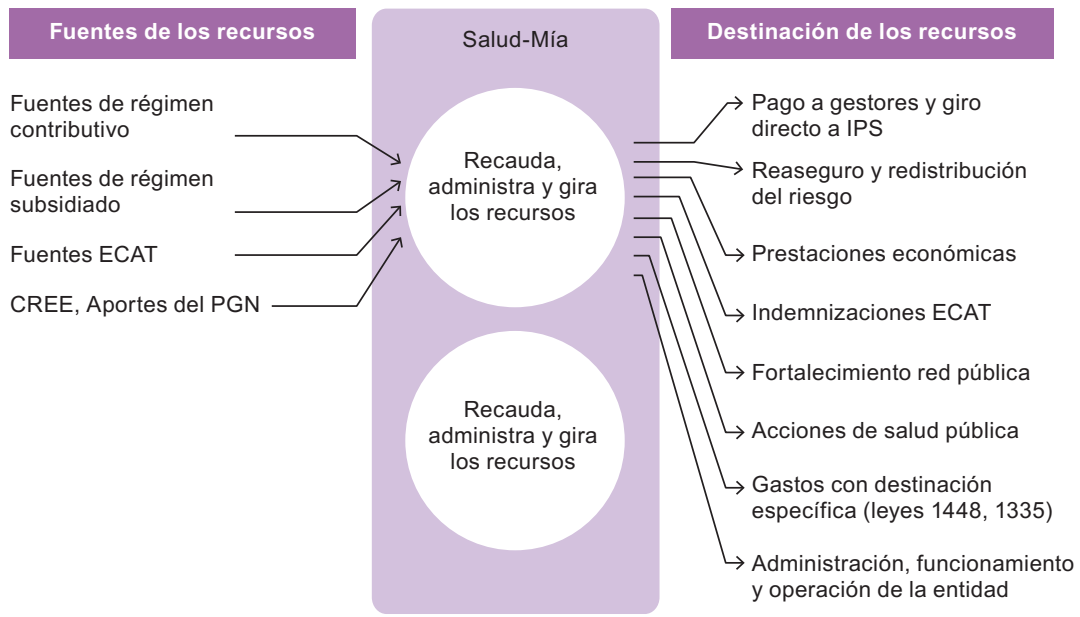

Fuente: Ministerio de Salud y Protección Social.

Si recordamos la discusión conceptual sobre competencia y capacidad de elección planteada al principio, vemos que la experiencia colombiana es muy rica respecto de las complejidades de la competencia y la capacidad de elección. Se observan reducciones del bienestar causadas por altos costos administrativos y de transacción debido a una complejidad excesiva del sistema, y las reformas que se proponen en el proyecto de ley apuntan a acotar la capacidad de selección en aras de optimizarla.

Como no se lograron los acuerdos políticos necesarios para aprobar el proyecto, el Gobierno optó por insertar en el Plan Nacional de Desarrollo 2014-2018 algunos de los principales aspectos contemplados por el proyecto de ley, sobre todo la centralización de recursos financieros en

17 “En un análisis de los últimos cinco años, el Ministerio de Salud y Protección Social, con base en la información suministrada por las EPS, estableció que el costo promedio anual de recaudo de cotizaciones a pesos del año 2011 ascendió a \$55.000 millones, de los cuales $60 \%$ es pagado a los operadores de información de la PILA (\$33.000 millones) y el restante (\$22.000 millones) a entidades financieras, por los convenios que las EPS deben realizar para garantizar el recaudo. Existe diversidad de precios en las tarifas de los operadores de PILA que oscilan entre los \$185 y los $\$ 1.700$ por registro procesado. Una negociación centralizada y no dispersa como lo es hoy, realizada por Salud-Mía, permitiría una importante reducción de costos y manejo de economías de escala" (Ministerio de Salud y Protección Social de Colombia, 2013, pág. 23). 
una nueva entidad, a fin de superar la segmentación vigente, y la supresión del FOSYGA. También se incluyó el fortalecimiento de la regulación de los precios de los medicamentos y de otros insumos de la prestación de salud (Colombia, Gobierno de, 2015a).

Entre las principales reformas aprobadas en ese marco legal se cuenta la unificación de los recursos contributivos y fiscales destinados al financiamiento del Sistema General de Seguridad Social en Salud (SGSSS), bajo la égida de la Entidad Administradora de los Recursos del Sistema General de Seguridad Social en Salud (SGSSS), que se adscribe al Ministerio de Salud y Protección Social (MSPS), con personería jurídica, autonomía administrativa y financiera y patrimonio independiente.

Se estipula que, en ningún caso, la nueva entidad asumirá las funciones asignadas a las EPS, pero debe efectuar el pago de la UPC y demás recursos asociados al aseguramiento obligatorio en salud mediante giros directos a los prestadores de servicios de salud y proveedores de tecnologías en salud, incluso el pago de prestaciones no incluidas en el plan de beneficios que se venían financiando con recursos del FOSYGA. Por su parte, los recursos destinados al régimen subsidiado de salud deberán ser presupuestados y ejecutados por las entidades territoriales. El Gobierno Nacional determinará el régimen de transición en cuanto al inicio de sus funciones para que, una vez que entre en operación, se suprima el FOSYGA.

Por otra parte, en consonancia con las medidas emprendidas para el control de los precios de los medicamentos, se fortalece la capacidad del Ministerio de Salud para efectuar negociaciones centralizadas de precios de medicamentos, insumos y dispositivos. Los precios resultantes de las negociaciones centralizadas serán obligatorios para los proveedores y compradores de medicamentos, insumos y dispositivos de servicios de salud y estos no podrán transar dichos artículos por encima de esos precios. Se estipula que el Gobierno Nacional podrá acudir subsidiariamente a la compra directa de medicamentos, insumos y dispositivos, se fortalece la capacidad en torno a los registros sanitarios de medicamentos y dispositivos médicos, y se regula una tasa para la comercialización de dichos artículos. Cuando así lo delegue el Gobierno Nacional, la Comisión Nacional de Precios de Medicamentos y Dispositivos Médicos será la encargada de definir la metodología y los mecanismos de regulación de precios de medicamentos, así como de regular sus márgenes de distribución y comercialización.

En términos de conceptualización del cambio institucional, se combinan estrategias de superposición en cuanto a controles de precios, con estrategias de sustitución de las reglas de manejo de las exclusiones, y la introducción de nuevas modalidades de financiamiento a cargo de una nueva entidad pública que centraliza su administración. 


\section{Bibliografía}

Abramovich, V. y Ch. Courtis (2006), El umbral de la ciudadanía: el significado de los derechos sociales en el Estado social constitucional, Buenos Aires, Editores del Puerto.

Arrow, K. (2000), "Insurance, risk and resource allocation", Foundations of Insurance Economics. Readings in Economics and Finance, G. Dionne y S. E. Harrington (comps.), Boston, Kluwer Academic Publishers.

(1963), "Uncertainty and the welfare economics of medical care", The American Economic Review, vol. LIII, No 5, diciembre.

Avdagic, S., M. Rhodes y J. Visser (2005), "The emergence and evolution of social pacts: a provisional framework for comparative analysis", European Governance Papers (EUROGOV), N N-05-01, septiembre

Bachelet, M. (2014), “Mensaje de S.E. la Presidenta de la República de Chile, con el que inicia un proyecto de ley que crea una Administradora de Fondos de Pensiones del Estado", Mensaje, $N^{\circ}$ 186-362, Santiago, Ministerio Secretaría General de la Presidencia, 16 de junio.

Baldwin, P. (2003), The Politics of Social Solidarity. Class Bases of the European Welfare State 1875-1975, Cambridge University Press.

Barr, N. (2014), “Designing Pensions: Economic Theory, International Experience and Policy Directions", Presentación ante la Comisión Asesora Presidencial sobre el Sistema de Pensiones, Santiago, agosto.

(2013), The Pension System in Sweden. Report to the Expert Group on Public Economics, Estocolmo, Ministerio de Finanzas. (2001), Economic Theory and the Welfare State, vols. 12 y 3, Cheltenham, The International Library of Critical Writings in Economics, Edward Elgar Publishing. (1993), The Economics of the Welfare State, Stanford, California, Stanford University Press.

Barr, N. y P. Diamond (2008), Reforming Pensions. Principles and Policy Choices, Nueva York, Oxford University Press.

Bertranou, F., E. Calvo y E. Bertranou (2009), "Is Latin America retreating from individual retirement accounts?", Brief, No 9-14, Center for Retirement Research at Boston College, julio.

Blyth, M. (2012), "Paradigms and paradox: the politics of economic ideas in two moments of crisis", Governance: An International Journal of Policy, Administration, and Institutions.

Bonoli, G. (2005a), "The politics of the new social policies: providing coverage against new social risks in mature welfare states", Policy \& Politics, vol. 33, No 3 .

Brittan, S. (2001), "Basic income and the welfare State", Economic Theory and the Welfare State, vol. 2, Cheltenham, Edward Elgar Publishing.

CAPSP (Comisión Asesora Presidencial sobre el Sistema de Pensiones) (2015a), Resumen ejecutivo, Santiago, septiembre. (2015b), Antecedentes de la industria previsional, Santiago, septiembre.

(2015c), La opinión y percepción del sistema de pensiones en Chile, Santiago, septiembre.

Carrin, I.M., K. Xu y D.B. Evans (2013), “Universal coverage: a global consensus", Scaling up Affordable Health Insurance: Staying The Course, A.S. Preker y otros (eds.), Washington, D.C., Banco Mundial. 
Carstensen, M. y V.A. Schmidt (2015), "Power through, over and in ideas: conceptualizing ideational power in discursive institutionalism", Journal of European Public Policy, vol. 23, No 3.

Castañeda, C. y otros (2012), La sostenibilidad financiera del sistema de salud colombiano. Dinámica del gasto y principales retos de cara al futuro, Bogotá", Fedesarrollo.

Castiglioni, R. (2007), "Sistema de pensiones: paradojas, desconfianza y preocupaciones", Tercera Encuesta Nacional de Opinión Pública. Radiografía social, política y económica de Chile, Santiago, Facultad de Ciencias Sociales e Historia, Universidad Diego Portales.

CEPAL (Comisión Económica para América Latina y el Caribe) (2013), Panorama Social de América Latina, 2013 (LC/G.2580), Santiago.

(2012), Panorama Social de América Latina 2012 (LC/G.2557-P), Santiago.

(2010), La hora de la igualdad: brechas por cerrar, caminos por abrir (LC/G.2432 (SES.33/3)), Santiago.

(2007), Cohesión social. Inclusión y sentido de pertenencia en América Latina y el Caribe (LC/G.2335), Santiago.

(2006), La protección social de cara al futuro: acceso, financiamiento y solidaridad, (LC/G.2294(SES.31/3)), Santiago.

(2000), Equidad, desarrollo y ciudadanía (LC/G.2071/Rev.1-P/E), Santiago.

Colombia, Gobierno de (2015a), “Ley 1753 de 9 junio 2015, por la cual se expide el Plan Nacional de Desarrollo 2014-2018 “Todos por un nuevo país'”, Diario Oficial, N 49538, Bogotá.

(2015b), “Ley Estatutaria No. 1751 por medio de la cual se regula el derecho fundamental a la salud y se dictan otras disposiciones", Congreso de la República, 16 de febrero.

(2014), “La Corte Constitucional revisó la constitucionalidad del Proyecto de ley estatutaria 'Por medio del cual se regula el derecho fundamental a la salud y se dictan otras disposiciones'", Comunicado, $\mathrm{N}^{\mathrm{o}} 21,29$ de mayo.

Comisión Asesora Presidencial para el Estudio y Propuesta de un Nuevo Marco Jurídico para el Sistema Privado de Salud) (2014) Estudio y propuesta de un nuevo marco jurídico para el sistema privado de salud, Santiago, 8 de octubre.

Crouch, C. (2007), "How to 'do' post-determinist institutional analysis", SocioEconomic Review, vol. 5.

Cubillos, L. y otros (2012), “Universal health coverage and litigation in Latin America", Journal of Health Organization and Management, vol. 26, N³.

Cutler, D. (2002), "Health care and the public sector", NBER Research Paper, $N^{o}$ 8802, Cambridge, Massachusetts, Oficina Nacional de Investigaciones Económicas (NBER).

Cutler, D. y R. Zeckhauser (2000), "The anatomy of health insurance", Handbook of Health Economics, A.J. Culyer y J.P. Newhouse, vol. 1A, Amsterdam, Elsevier Science Publishers.

Diamond, P. (2001), "A framework for social security analysis", Economic Theory and the Welfare State, Barr, Nicholas (comp.), vols. 12 y 3, Cheltenham, The International Library of Critical Writings in Economics, Edward Elgar Publishing.

Días de Lima, L. (2013), “A coordenação federativa do sistema público de saúde no Brasil", A saúde no Brasil em 2030: prospecção estratégica do sistema de saúde brasileiro: organização e gestão do sistema de saúde, vol. 3, Río de Janeiro, Fundação Oswaldo Cruz (Fiocruz)/Instituto de Investigación Económica Aplicada (IPEA)/Ministerio de Salud/Secretaría de Asuntos Estratégicos de la Presidencia de la República. 
Durán, F. y H. Peña (2011), “Determinantes de las tasas de reemplazo de pensiones de capitalización individual. Escenarios latinoamericanos comparados", serie Seminarios y Conferencias, No 64 (LC/L.3329-P), Santiago, Comisión Económica para América Latina y el Caribe (CEPAL).

Durán, M.A. (ed.) (2012), El trabajo no remunerado en la economía global, Bilbao, Fundación BBVA.

Falkingham, J. y J. Hills (2001), "Redistribution between people or across the life cycle", Economic Theory and the Welfare State, vol. 2, Cheltenham, Edward Elgar Publishing.

Fioretos, O., T. G. Falleti y A. Sheingate (2014), "Historical institutionalism in political science", Oxford Handbook of Historical Institutionalism, O. Fioretos, T.G. Falleti y A. Sheingate (eds.), Nueva York, Oxford University Press.

Ferrajoli, L. (2008), Democracia y garantismo, Madrid, Editorial Trotta.

Gaviria, A. (2015), "Fortalecer la capacidad de discernimiento de los gobiernos: una necesidad para enfrentar la presión tecnológica en salud", Serie de políticas y métodos basados en presentaciones a expertos. Breve 13, Red de Conocimiento sobre Priorización y Planes de Beneficios en Salud del Banco Interamericano de Desarrollo (CRITERIA), diciembre.

Giedion, U., A. L. Muñoz y A. Ávila (2012), “Introducción a la Serie de priorización explicita en salud", Series de notas técnicas sobre procesos de priorización de salud, División de Protección Social y Salud, Banco Interamericano de Desarrollo (BID), enero.

Giedion, U., G. Panopoulou y S. Gómez-Fraga (2009), “Diseño y ajuste de los planes explícitos de beneficios: el caso de Colombia y México", serie Financiamiento del Desarrollo, No 219 (LC/L.3131-P), Santiago, Comisión Económica para América latina y el Caribe (CEPAL), noviembre.

Giedion, U., I. Tristao y R. Bitrán (eds.) (2014), Planes de beneficios en salud de América Latina: una comparación regional, División de Protección Social y Salud, Banco Interamericano de Desarrollo (BID), enero.

Glassman, A. y K. Chalkidou (2012), Priority-Setting in Health Building Institutions for Smarter Public Spending. A Report of the Center for Global Development's Priority-Setting Institutions for Global Health Working Group, Washington, D.C., Centro para el Desarrollo Mundial.

Gómez Sabaini, J.C., O. Cetrángolo y D. Morán (2014), “La evasión contributiva en la protección social de salud y pensiones: un análisis para la Argentina, Colombia y el Perú", serie Políticas Sociales, No 208 (LC/L.3882), Santiago, Comisión Económica para América Latina y el Caribe (CEPAL), agosto.

González-Rossetti, A., T. Chuaqui y C. Espinosa (2000), “Enhancing the Political feasibility of health reform: the Chile Case", LAC Health Sector Reform Initiative, $\mathrm{N}^{\mathrm{o}} 40$, Harvard School of Public Health Data for Decision Making (DDM), junio [en línea] http:/ / www.americas.health-sector-reform.org.

González-Rossetti, A. y T. J. Bossert (2000), “Mejorando la factibilidad política de la reforma en salud: un análisis comparativo de Chile, Colombia y México", LAC Health Sector Reform Initiative, No 36, Harvard School of Public Health Data for Decision Making (DDM), junio [en línea] http://www.americas. health-sector-reform.org.

Hall, P. (2009), "Historical institutionalism in rationalist and sociological perspective", Explaining Institutional Change, Ambiguity, Agency, and Power, J. Mahoney y K. Thelen (eds.), Cambridge University Press. 
Hall, P. y K. Thelen (2009), "Institutional change in varieties of capitalism”, SocioEconomic Review, vol. 7, N 1, Oxford University Press.

Hemerijck, A. (2013), Changing Welfare States, Oxford University Press.

Hirschman, A. (1977), Salida, voz y lealtad, Ciudad de México, Fondo de Cultura Económica.

Hopenhayn, M. y otros (2014), "Pactos sociales para una protección social más inclusiva: experiencias, obstáculos y posibilidades en América Latina", serie Seminarios y Conferencias, No 76 (LC/L.3820), Santiago, Comisión Económica para América Latina y el Caribe (CEPAL).

ICEFI (Instituto Centroamericano de Estudios Fiscales) (2013), "Política fiscal salvadoreña 2007-2013: diagnóstico y condicionantes financieros para la transición política de 2014" [en línea] http:/ / icefi.org/publicaciones/politica-fiscal-salvadorena-2007-2013.

Lara, D., F. López y A. Morgado (2016), “Fondos de pensiones: ¿existe un líder en rentabilidad?", Documento de Investigación, I-315, Santiago, Universidad Alberto Hurtado, julio.

López, F. (2016), “Industria de AFP: ¿Cuánto gana y cuánto debería ganar?”, Revista de Análisis Económico, vol. 31, N² 2, Facultad de Economía y Negocios, Universidad Alberto Hurtado/ Georgetown University.

Mahoney, J. y K. Thelen (2009), "A theory of gradual institutional change”, Explaining Institutional Change, Ambiguity, Agency, and Power, J. Mahoney y K. Thelen (eds.), Cambridge University Press.

Maldonado, C. y A. Palma (2013), “La construcción de pactos y consensos en materia de política social: El caso de la Ley General de Desarrollo Social de México, 2000-2008", serie Politicas Sociales (LC/L.3669), Santiago, Comisión Económica para América Latina y el Caribe (CEPAL), septiembre.

Mesa-Lago, C. (2000), "Estudio comparativo de los costos fiscales en la transición de ocho reformas de pensiones en América Latina", serie Financiamiento del Desarrollo, No 93 (LC/L.1344-P/E), Santiago, Comisión Económica para América Latina y el Caribe (CEPAL), marzo.

Ministerio de Salud y Protección Social de Colombia (2015), Plan Estratégico Sectorial 2014-2018. Sector Administrativo de Salud y Protección Social, noviembre.

(2013), “Exposición de motivos del Proyecto de Ley 'Por el cual se redefine el Sistema General de Seguridad Social en Salud y se dictan otras disposiciones'" [en línea] ttps://www.minsalud.gov.co/Documents/Ley\%20Reforma\%20 a $\% 201 a \% 20$ Salud / Exposicion-Motivos-\%20Proyecto-leyredefinicionsistema-General-SeguridadSocial-Salud\%20pdf.pdf.

OCDE (Organización de Cooperación y Desarrollo Económicos) (2015), Study on Replacement Rates and Other Issues Related to Pension Systems, París, OECD Publishing. (2013), Pensions at a Glance 2013. OECD and G20 Indicators, París, OECD Publishing.

Palier, B. (ed.) (2010), A Long Goodbye to Bismarck? The Politics of Welfare Reform in Continental Europe, Amsterdam, Amsterdam University Press.

Piñera, J. (1991), El cascabel al gato, Santiago, Editorial Zig-Zag.

Porter, D. (1999), Health, Civilization and The State. A History of Public Health from Ancient to Modern Times, Londres, Routledge.

Rivera, E. (2014a), “¿Hacia dónde va la reforma previsional?, Mensaje, Santiago, julio (2014b), "La reforma previsional de 2008 en Chile. Un análisis desde la política pública", Pactos sociales para una protección social más inclusiva: experiencias, obstáculos y posibilidades en América Latina, serie Seminarios y Conferencias, No 76 (LC/L.3820), M. Hopenhayn y otros (eds.), Santiago, Comisión Económica para América Latina y el Caribe (CEPAL). 
(2014c), "La situación del sistema previsional privado al inicio del nuevo gobierno: el debate que viene", Barómetro de política y equidad, $\mathrm{N}^{\circ}$ 8, Santiago, abril.

Rivera, E. (2013), "La herencia de Piñera en AFP y salud: los grandes problemas siguen pendientes", Cae el telón. El último año del gobierno de Sebastián Piñera, Barómetro de Política y Equidad, Santiago, Fundación Equitas/Friedrich Ebert Stiftung. (2010), "El impacto de la crisis financiera global en el sistema chileno de capitalización individual: lecciones respecto de los desafíos regulatorios", Envejecimiento en América Latina. Sistemas de pensiones y protección social integral, A. Prado y A. Sojo (eds.), Libros de la CEPAL, No 110 (LC/G.2475-P), Santiago, Comisión Económica para América Latina y el Caribe (CEPAL), noviembre. (2009), "La reforma previsional a medio camino", inédito.

Schmidt-Hebbel, K. (2014), "El sistema de pensiones en Chile: antecedentes, retos y propuestas de reforma", Presentación ante la Comisión Asesora Presidencial sobre el Sistema de Pensiones, Santiago, agosto.

Schmidt, V. (2011), “Discursive institutionalism: scope, dynamics and philosophical underpinnings", The Argumentative Turn Revised: Public Policy as Communicative Practice, F. Fischer y J. Forester (eds.), Durham, Duke University Press. (2008), "Discursive institutionalism: the explanatory power of ideas and discourse", Annual Review of Political Science, vol. 11. (2002) "Does discourse matter in the politics of Welfare State adjustment?", Comparative Political Studies vol. 35, No 2, Princeton University, julio.

Serrano, C. (2014), "Comentarios generales sobre protección social en América Latina: otros procesos de pacto en América Latina", Pactos sociales para una protección social más inclusiva: experiencias, obstáculos y posibilidades en América Latina, serie Seminarios y Conferencias, No 76 (LC/L.3820), M. Hopenhayn y otros (eds.), Santiago, Comisión Económica para América Latina y el Caribe (CEPAL).

Sojo, A. (2014), "El sistema contributivo de pensiones como locus de rivalidad y de un nuevo pacto social en Chile", serie Seminarios y Conferencias, N 211 (LC/L.3901), Santiago, Comisión Económica para América Latina y el Caribe (CEPAL).

(2011), "De la evanescencia a la mira. El cuidado como eje de políticas y de actores en América Latina", serie Seminarios y Conferencias, No 67 (LC/L.3393), Santiago, Comisión Económica para América Latina y el Caribe (CEPAL). (2003), "Vulnerabilidad social, aseguramiento y diversificación de riesgos en América Latina y el Caribe", Revista de la CEPAL, No 80 (LC/G.2204-P/E), Santiago, Comisión Económica para América Latina y el Caribe (CEPAL). (2001), "Reformas de gestión en salud en América Latina", Revista de la CEPAL, No 74 (LC/G.2135-P), Santiago, Comisión Económica para América Latina y el Caribe (CEPAL), agosto. (1999), "Principios generales y pautas de buenas prácticas en política social. Una propuesta de la CEPAL para la discusión", inédito.

Streeck, W. y K. Thelen (2005), Beyond Continuity. Institutional Change in Advanced Political Economies, Oxford University Press.

The Economist (2016), "Pensions. Fade to grey", 24 de septiembre.

Van de Ven, W. (2013), "Making health insurance affordable: role of risk equalization", Scaling up Affordable Health Insurance: Staying The Course, A.S. Preker y otros (eds.), Washington, D.C., Banco Mundial.

Zweifel, P. (2013), "Theory of social health insurance", Scaling up Affordable Health Insurance: Staying The Course, A.S. Preker y otros (eds.), Washington, D.C., Banco Mundial. 



\section{Capítulo V \\ Claroscuros de la judicialización del derecho a la salud}

\section{Introducción}

En el presente capítulo se aborda, en primer lugar, la relevancia de los derechos sociales, los desafíos para su cumplimiento y la posibilidad de uso de instrumentos jurídicos a tal fin. En segundo término, se analiza la base de los litigios en materia de salud en América Latina y se consideran cuatro aspectos: las disposiciones legales sobre la satisfacción de los derechos sociales, la arquitectura de los sistemas de salud, las políticas de priorización en este ámbito y el acceso a los medicamentos mediante litigio. Las diversas aristas muestran que la judicialización abarca una vasta zona de claroscuros, dado que puede contribuir al ejercicio de los derechos, pero también puede alimentar conductas de riesgo moral por parte de diversos actores. Se evidencia la necesidad de fortalecer la institucionalidad de los sistemas de salud en torno a la satisfacción de este derecho para que no se sobredimensione el recurso a la judicialización, el derecho se ejerza con mayor igualdad, se mejore el uso de los recursos y se combatan los actos de colusión en esta materia.

\section{A. Derechos sociales y judicialización}

Los derechos sociales constituyen un asunto complejo respecto del cual deben precisarse - entre otros aspectos- su alcance, los sujetos deudores, las obligaciones que emanan de su goce, las relaciones entre sujetos titulares de derechos, el establecimiento de prioridades y los 
instrumentos de garantía o de protección pertinentes (Courtis, 2007). Mientras que el goce de los derechos de propiedad y de libertad está protegido por garantías claramente establecidas, los derechos sociales generalmente carecen de un sistema de garantías equiparable en cuanto a su capacidad de regulación y de control, y la adecuación a su naturaleza. Incluso en los Estados de bienestar europeos, el amplio desarrollo de estos derechos ha tenido lugar gracias a la ampliación de la discrecionalidad de los aparatos burocráticos (Ferrajoli, 2002). Esta carencia se transforma en un factor de ineficacia de los derechos sociales: la ausencia de garantías sociales o positivas adecuadas puede conducir a prácticas burocráticas asistencialistas y orientadas a beneficiar a clientelas políticas que son un terreno fértil para la corrupción y las decisiones arbitrarias. De allí que, desde el punto de vista jurídico, las garantías sean prácticas idóneas para asegurar la efectividad de las normas que reconocen los derechos.

Algunos países de la región, como la Argentina, el Brasil, Colombia, el Ecuador y el Estado Plurinacional de Bolivia han incluido en sus Constituciones extensas listas de derechos sociales, políticos, culturales y económicos con referencias a sujetos como las personas mayores y los niños, y bienes de la naturaleza, entre otros ${ }^{1}$. Si bien pueden apreciarse una "inflación de derechos" y la distancia que separa las realidades actuales de las aspiraciones y exigencias de aquellos textos, también es cierto que gracias a ellos en buena medida han podido reivindicarse diversos derechos (Gargarella y Courtis, 2011).

Asimismo, existen disposiciones significativas en materia de política social, como las cartas de derechos de los usuarios, que cobran sentido respecto de las garantías jurídicas que sustentan, o bien las garantías de prestaciones de salud, que conforman una gama diversa de experiencias en la región conforme al derrotero propio de cada sistema de salud, y cuyas restricciones evidencian algunos retos pendientes ${ }^{2}$. En países con sistemas de salud poco desarrollados, con niveles de aseguramiento muy acotados para la población de bajos ingresos y que sufren procesos de transición epidemiológica polarizada, la garantía de prestaciones se ha volcado eminentemente a la atención primaria en salud y a la atención maternoinfantil. En términos relativos, estas prestaciones y su garantía ejercen un efecto muy limitado en lo concerniente a la reorganización global del sistema de salud, pero representan un esfuerzo respecto del punto de partida. En México, por su parte, la garantía de prestaciones del seguro popular se introdujo mediante una reforma que no modifica

Véase un detalle de los derechos explicitados por estas constituciones en Gargarella y Courtis (2011, págs. 330-331).

2 Respecto de las cartas de derechos vigentes en Chile, se ha advertido que constituyen, sobre todo, una protección de derechos liberales con escasa presencia del derecho a las prestaciones (López, 2013). 
la profunda segmentación del sistema de aseguramiento ya que, aunque tiene algunos vínculos con el sistema mediante los prestadores, cuenta con recursos ad hoc en el plano financiero y su cobertura no se refuerza con garantías adicionales. En la región, solo en casos excepcionales las garantías han ido más allá del establecimiento de cierta cobertura a fin de garantizar oportunidades, acceso, protección financiera y calidad. Tal fue el caso de Chile a partir de 2005, donde se incluyeron también prestaciones de alto costo y se dispusieron regulaciones que, al acotar las prácticas de selección adversa de las Instituciones de Salud Previsional (ISAPRE) e incrementar la transparencia de las coberturas, tuvieron efectos positivos respecto de la articulación de la combinación público-privada (Sojo, 2006).

Los derechos sociales fijan estándares imperativos para la sociedad y explicitan situaciones inadmisibles para sus miembros; de allí la relevancia de que estén encarnados en un cuerpo jurídico consistente y operativo. En ese marco, el uso de instrumentos jurídicos puede contribuir a que la sociedad asuma como propios los valores de la solidaridad y la reciprocidad. Las llamadas garantías jurisdiccionales otorgan a los titulares de derechos la capacidad de someter denuncias de incumplimiento de las obligaciones emanadas de esos derechos ante un poder independiente de los sujetos obligados — sean estos públicos o privados - al que, dado el caso, se confieren competencias para forzar el cumplimiento y establecer reparaciones o sanciones ${ }^{3}$. Se trata de garantías secundarias, que entran en juego y cobran sentido cuando los poderes encargados de concretar y hacer efectivos los derechos incumplen con sus obligaciones (Abramovich y Courtis, 2006; Courtis, 2007).

Sin embargo, debido a la naturaleza del ámbito judicial, no debería sobredimensionarse su radio de acción en materia de derechos sociales. La acción contenciosa del recurso judicial y del poder judicial —que insume costos, recursos y tiempo- está acotada por sus características institucionales propias, y por el lugar que el poder judicial ocupa en la división de poderes. Aun cuando ventile intereses colectivos, ella se estructura a partir de una confrontación dialéctica entre dos partes antagónicas - una parte gana y la otra pierde-, diseño que le resta capacidad para abordar la totalidad de los intereses en juego en el conflicto original. Al tener como referente el caso concreto, su alcance se ve restringido, pues difícilmente podrán considerarse todos los elementos y la multiplicidad de factores vinculados. Por tanto, los respectivos poderes políticos son los llamados a tener las atribuciones centrales en materia de

Tradicionalmente, esta función está en manos del poder judicial, aunque pueden existir otras formas de garantía jurisdiccional - como los tribunales administrativos, los tribunales arbitrales, las cortes internacionales $\mathrm{u}$ otras autoridades que administren métodos no judiciales de resolución de conflictos- que deben garantizar la imparcialidad y la independencia respecto de las partes (véase Abramovich y Courtis, 2006, págs. 37-47). 
cumplimiento de los derechos sociales y la formulación de las políticas correlativas, papel que no debe ser suplantado por el poder judicial. El desarrollo de mecanismos de denuncia, consideración y solución de los incumplimientos es relevante, pero debe enmarcarse en el diseño y el perfeccionamiento de los mecanismos de responsabilidad política y jurídica, y en el debate sobre la rendición de cuentas de los poderes políticos. En tal sentido, debe aspirarse a la menor judicialización posible del disfrute de los derechos, estén estos garantizados o no (Abramovich y Courtis, 2006, pág. 249; CEPAL, 2007).

Esta temática alude a la complejidad de "traducir" algunos reclamos y aspiraciones al lenguaje liberal de los derechos, ya que la idea de derechos puede tender a simplificar en extremo lo que es demasiado complejo, sugiriéndose respuestas eminentemente jurídicas para atender problemas que fundamentalmente no son de carácter jurídico, promover la judicialización de cuestiones que merecen una atención y un tipo de soluciones que son primordialmente extrajudiciales y tender a individualizar reclamos que son principalmente colectivos (Gargarella, 2014, pág. 323).

Por otra parte, debe tenerse presente la manera en que la introducción de los derechos sociales influye en la expansión o limitación de los diversos poderes del Estado al aumentar las facultades del poder judicial, y cómo, a su vez, esta reorganización del poder puede favorecer o bloquear la potencialidad de los derechos sociales. Es así que se ha señalado que las fuerzas progresivas adoptan una posición paradójica: transfieren facultades adicionales a la rama del poder más alejada de la elección y el control populares, o, en términos jeffersonianos, a la rama del poder menos republicana de todas (Gargarella, 2014, pág. 251).

Tanto las fuerzas que impulsan el litigio en materia de salud como sus diversos efectos se relacionan estrechamente con la naturaleza del sistema de salud y de los sistemas legales (Gloppen, 2011, pág. 19). Desde el punto de vista analítico, la judicialización ha sido vinculada con modelos de financiamiento mediante impuestos o con modelos de carácter contributivo y mixto (Flood y Gross, 2014). Sin embargo, por sí solo el tipo de financiamiento no determina la manera en que se organiza el aseguramiento ni la gama de políticas disponibles (Kutzin, 2008). En América Latina, el litigio desempeña un papel importante en el ámbito de la salud no solo en el caso de los sistemas eminentemente contributivos, por ejemplo, el de Costa Rica, Chile y Colombia, sino también en los sistemas financiados en gran parte con impuestos, como el del Brasil. Por ende, más allá del modelo de financiamiento, lo decisivo es la arquitectura de los sistemas de protección social.

Otro aspecto crucial que debe abordarse al analizar la experiencia en la región se refiere a la "temporalidad". Para comprender plenamente el 
cambio institucional en este ámbito no solo importan los efectos causales de la oportunidad y las secuencias de las reformas. A fin de entender la variabilidad de la adopción de nuevas normas o de reformas, es indispensable reflexionar acerca del posible efecto causal de la duración, el ritmo y la aceleración de las transformaciones, porque la duración y el horizonte temporal de los eventos pueden repercutir en los costos, y la velocidad del cambio puede afectar la naturaleza del aprendizaje y el carácter de la deliberación. Por su parte, el grado de aceleración del cambio tiene relevancia para identificar qué tipo de mecanismos se activan a tal efecto (Fioretos, Falleti y Sheingate, 2016).

Dado el estrecho vínculo existente entre la judicialización y el carácter de los sistemas de salud, reviste importancia la temporalidad en la cual se dan procesos interrelacionados, por ejemplo, la formas en que el litigio se pone en marcha; la persistencia y tenacidad para llevarlo adelante; el propósito de las transformaciones que se experimentan y su escala; las estrategias mediante las que se aborda la judicialización, y las transformaciones de los sistemas a las que puede dar lugar. Si se abordan estas transformaciones desde su arista temporal, es posible dar cuenta de un ingente acervo de experiencias que permiten extraer importantes enseñanzas para la región.

Resulta difícil precisar los efectos globales de la judicialización en la equidad de los sistemas de salud en cuanto a su arquitectura y financiamiento, dada la presencia de muchos otros elementos que también intervienen (Mæstad, Rakner y Motta Ferraz, 2011). Respecto de los grupos desfavorecidos, las experiencias de los países muestran una gama muy variada de resultados: en algunos casos han acarreado cambios sistémicos beneficiosos, como en la Argentina, el Brasil, Colombia y Costa Rica, mientras que en otros se han exacerbado las desigualdades en la prestación de servicios (incluso en esos mismos países) (ibídem, págs. 299 y 301; Uprimny y Durán, 2014). Los efectos cuantificables se relacionan más directamente con variables sustitutas (proxies) de la caracterización socioeconómica de los litigantes y la relación costo-eficacia de los tratamientos o medicamentos aprobados. En este sentido, las demandas individuales parecen favorecer a quienes tienen más recursos y acceden con mayor facilidad a los tribunales de justicia y a los abogados, mientras que las resoluciones de carácter estructural relacionadas con las inequidades de los sistemas son las que ejercen los efectos más positivos desde el punto de vista de la igualdad (Yamin y Gloppen, 2011; Uprimny y Durán, 2014). Se constata un conocimiento endeble de la condición económica del litigante, elemento que resalta la necesidad de que el criterio de incapacidad económica, sujeto a escrutinio, deba ser más utilizado (Uprimny y Durán, 2014).

Por otra parte, se ha señalado la importancia de la "razonabilidad" de la tensión entre los derechos a escala individual y los derechos a escala 
social. Así, el caso colombiano ha sido interpretado como un paradigma del riesgo de prestar excesiva atención a los derechos individuales, lo que llevó al Gobierno a perder poder de negociación ante las compañías farmacéuticas y diversos prestadores en lo concerniente a la fijación de precios (Flood y Gross, 2014). Los derechos a escala individual son más susceptibles de defenderse en un litigio en ciertas circunstancias que llevan a un proceso social de construcción del reclamo que implica nombrar el derecho, establecer un responsable y reivindicar el derecho; se trata de la sucesión naming, blaming, claiming, acuñada por Felstiner, Abel y Sarat (1980), en que agentes interesados en la ganancia (abogados y compañías farmacéuticas, por ejemplo) pueden buscar que se supere la "apatía ante la queja", a fin de transformarla en un reclamo.

\section{B. Raíces y bases del litigio en América Latina}

Los antecedentes de los conflictos son tan problemáticos e interesantes como los litigios que, en última instancia, pueden emerger (Felstiner, Abel y Sarat, 1980)

Desde una perspectiva institucional, las pautas y la estructuración del litigio condensan la acumulación de acciones que fueron realizadas a escala individual (Felstiner, Abel y Sarat, 1980, pág. 649). En América Latina, el poder judicial se ha visto arrastrado a un protagonismo inédito en esta materia, que expresa tensiones y conflictos entre demandas individuales de sujetos de derecho respecto de la gama de prestaciones fijada por el Estado o del acceso efectivo a ellas. Se ha originado una activa jurisprudencia que interpreta y protege los derechos sociales, $\mathrm{y}$ que en varias ocasiones ha forzado al poder ejecutivo y al legislativo a redefinir sus políticas, mediante el fortalecimiento de dinámicas de judicialización de derechos. También surgen inquietantes claroscuros cuando se repara en la forma en que agentes aseguradores, prestadores o compañías farmacéuticas se han visto beneficiados, de manera esporádica o recurrente, por ciertos fallos. Las lecciones que pueden extraerse de las experiencias concretas respecto de los alcances, características y límites de la judicialización advierten sobre la inconveniencia de alabar sin más reparo la judicialización de los derechos.

\section{Disposiciones jurídicas sobre la satisfacción de los derechos sociales}

El alcance y los rasgos que asume la judicialización en cada país dependen de las disposiciones jurídicas vigentes sobre la satisfacción de los derechos sociales, ya que estos patrones institucionales acotan las opciones disponibles. 
En Costa Rica y Colombia, el acceso es relativamente fácil en comparación con lo que ocurre en la Argentina y el Brasil (Gloppen, 2011, pág. 20).

La Constitución Política de Colombia de 1991 estableció por primera vez una extensa gama de disposiciones que versan sobre la salud como un derecho y atribuyó al legislador amplias facultades para desarrollar el sistema de salud, las condiciones de acceso a los servicios, la ampliación progresiva de la cobertura y las reglas para la participación de los particulares en la prestación de servicios de salud. Para salvaguardar los derechos fundamentales, estableció la acción de tutela, que permite su "protección inmediata", siempre que los derechos "resulten vulnerados o amenazados por la acción o la omisión de cualquier autoridad pública", recurso que puede ser presentado ante los jueces por cualquier persona, sin necesidad de patrocinio letrado, en cualquier momento y lugar (Gobierno de Colombia, 2015, pág. 26). El procedimiento es "preferente y sumario" y se caracteriza por su informalidad: en diez días debe resolverse la primera instancia y el fallo puede ser impugnado. Si bien se requiere que el afectado no disponga de otro medio de defensa judicial, la regla se exceptúa cuando se utiliza como mecanismo transitorio para evitar un perjuicio irremediable. Otro instrumento importante de expansión de los servicios ha sido la creación de comités técnicos y científicos, que se transformaron en órganos de resolución de conflictos sobre servicios no comprendidos en el Plan Obligatorio de Salud (POS) pero ordenados por los médicos tratantes, y que eran financiados con cargo al Fondo de Solidaridad y Garantía (FOSYGA) (Uprimny y Durán, 2014, págs. 8 y 11).

La elevada judicialización del derecho a la salud desatada tempranamente en Colombia sirvió de aprendizaje a otros que querían evitarla: por ejemplo, cuando en Chile se diseñaron las prestaciones garantizadas del Plan de Acceso Universal con Garantías Explícitas (Plan AUGE), el asunto fue objeto de un análisis concreto. A tal efecto, se planteó la necesidad de crear instancias administrativas dentro del propio sistema de salud que respondieran a la denegación de derechos y que comprendiesen al Ministerio de Salud, al Fondo Nacional de Salud (FONASA) y a la Superintendencia de Salud, para que el recurso judicial solo se interpusiese una vez agotadas tales instancias (Sandoval, 2008). Ello, junto con un marco social de alta tolerancia a la priorización - como ha sido el caso de las prestaciones del seguro solidario de salud del FONASA-, posiblemente explica que en Chile se haya ejercido una judicialización restringida en lo concerniente al Plan AUGE. Como se verá a continuación, en este país la judicialización irrumpe en torno al alza de los planes de salud de las ISAPRE sin mayores disposiciones legales que hayan reforzado previamente la capacidad de litigio. 


\section{Arquitectura de los sistemas de protección social en materia de salud y la judicialización}

Para captar adecuadamente los efectos de la judicialización, deben considerarse tanto su frecuencia como su base casuística o estructural y la temporalidad dentro de la cual se da. Mientras que la orientación casuística no busca una aplicación genérica del fallo, el enfoque estructural hace referencia a características del sistema que subyacen al litigio y que, por tanto, permite extraer las causales aplicables a otros casos. Se ha afirmado que los tribunales son más propensos a intervenir mediante resoluciones individuales y que se muestran más renuentes a considerar asuntos de política más amplios, particularmente aquellos de carácter estructural (Flood y Gross, 2014).

La naturaleza del litigio puede analizarse en varios planos: ¿qué buscan los litigantes?, ¿qué tipo de prestaciones exigen?, ¿cuál es su alcance —individual, colectivo, de interés público-?, ¿las prestaciones están cubiertas o no?, ¿su acceso se ve obstaculizado por la implementación de las políticas? En la dimensión legal, se atribuye importancia a los argumentos fácticos con que se litiga (Gloppen, 2011, pág. 32).

La reiterada judicialización a causa de un mismo patrón o tipo de servicio pone de manifiesto la incapacidad para resolver el acceso equitativo a ellos mediante bases más estructurales (Mæstad, Rakner y Motta Ferraz, 2011, pág. 297). Conforme los mecanismos del litigio devienen rutinarios, los argumentos factuales se tornan cada vez más endebles y disminuye la capacidad de indagar en las razones estructurales que subyacen a los reclamos. Cuando el litigio deviene masivo o recurrente e inercial, se convierte casi en una precondición de acceso a determinados servicios, y la identificación de las causas subyacentes al problema por parte de las autoridades de salud y reguladoras competentes y el emprender soluciones estructurales se postergan (Uprimny y Durán, 2014, pág. 41). Como afirmó una autoridad judicial, en Colombia la rutinización ejerció un efecto tenaz en la manera en que se toman las decisiones y afectó el formato de las resoluciones judiciales. Debido a que otras entidades del poder público no cumplen el papel protagónico de supervisión y vigilancia, la rama judicial se congestiona y el litigio masivo siempre va "en busca de lo mismo", por ejemplo, de prestaciones incluidas en los planes obligatorios. Además, las demandas o tutelas se presentan con un formato predeterminado: los escritos se realizan mediante plantillas, que se llenan cambiando el nombre de la persona y del medicamento y recurriendo a líneas jurisprudenciales predefinidas. Asimismo, faltan pruebas respecto de la capacidad de pago, que se traslada a la entidad ejecutora del fallo. Mientras el juez se dedica a los asuntos que 
le competen en los procesos ordinarios, delega en los niveles inferiores las decisiones de tutela, que llegan a ser resueltas hasta por practicantes universitarios (Zapata Pérez, 2013) ${ }^{4}$.

Se ha planteado como hipótesis que la naturaleza y el volumen de la judicialización se relacionan con la organización de los sistemas de salud: cuanto más universales y públicos y, en principio, abiertos a toda la población, habría menos litigios; cuanto más fragmentados y basados en mecanismos de competencia y con un financiamiento o una prestación predominantemente privados, mayor sería la judicialización (Gloppen, 2011, pág. 19). Por otra parte, se ha señalado en forma crítica que los jueces no necesariamente toman en consideración los posibles efectos universales de sus fallos, ni los costos a ellos vinculados (Yamin, 2011, pág. 368).

Si bien el litigio puede tener causas estructurales, en las más variadas experiencias latinoamericanas se ha llevado adelante sobre todo a escala individual y con un alcance también individual: en la región, entre el $97 \%$ y el $99 \%$ de los casos son individuales (Mæstad, Rakner y Motta Ferraz, 2011, pág. 282). Si esto se vincula a las características de los sistemas de salud, se observa el desafío que representa para los jueces el imperativo de desentrañar los problemas sistémicos que emergen de los casos individuales para actuar sobre sus efectos agregados mediante sentencias que consoliden la modificación de elementos de carácter estructural pertinentes y que se alejen de las soluciones atomizadas e individuales ${ }^{5}$. Este objetivo es ajeno a un proceso de mera rutinización que, por el contrario, se caracteriza por aceptar un fundamento factual generalmente débil respecto de la prestación pretendida y de escasa información acerca de las características socioeconómicas y de salud del demandante. Como se verá, precisamente la tensión entre el origen estructural del litigio y el enfoque individualista del tratamiento de las demandas subyace a lecciones cruciales que pueden extraerse en la región.

4 Los audios de las exposiciones y debates del taller Equidad en Salud y Judicialización del Derecho a la Salud en Colombia: Balance de Dos Décadas y Perspectivas ante la Reforma en Marcha pueden consultarse [en línea] en http://dds.cepal.org/proteccionsocial/pacto-social/ actividades-2013-07-taller-judicializacion-salud-colombia.

5 En el ámbito de la sociología del derecho se ha subrayado la relevancia de las soluciones estructurales en la judicialización, en contraposición a las soluciones particulares que no resuelven los problemas de fondo y que pueden ser promovidas por los abogados: los tribunales de justicia pueden transformar las controversias mediante la individualización de los recursos que cabría interponer. Algunas de las víctimas lesionadas por un producto defectuoso tal vez quieran obligar al fabricante a modificar su proceso de producción, pero como en las causas por daños en que no hay dolo los tribunales otorgan solo una indemnización monetaria en concepto de daños y perjuicios, incluso lo que para las víctimas sería un resultado aceptable pasa de ser un bien colectivo (seguridad) y se transforma en un enriquecimiento individual, transformación alentada en gran medida por el interés de los abogados por la creación de un fondo de donde cobrar sus honorarios (Felstiner, Abel y Sarat, 1980, p. 652). 
En este sentido, resulta interesante analizar la experiencia de Chile, donde, pese a las aludidas previsiones administrativas para acotar el ejercicio del litigio, este irrumpió desde otro ángulo. En el capítulo IV se hizo referencia a la lógica dual del sistema de salud chileno, inédita en el plano internacional, ya que la cotización obligatoria a cargo exclusivo del trabajador le permite afiliarse al sistema público de salud mediante el Fondo Nacional de Salud (FONASA), que favorece la solidaridad, o mediante las ISAPRE que, pese al carácter obligatorio de las contribuciones, funcionan con una lógica de seguro privado, en que se asocian las primas al riesgo individual y se produce el descreme del mercado. Precisamente esta dualidad explica el grueso de los litigios en el país, orientados a impugnar la selección de riesgos y la discriminación por género y edad que ejercen las ISAPRE mediante los precios de las pólizas. Por medio de sus abogados, los afiliados que desean mantenerse en el sistema privado pagando la misma prima han presentado ante la Corte de Apelaciones y la Corte Suprema recursos de protección contra las alzas unilaterales de las entidades aseguradoras privadas. Estos órganos acogieron los recursos al estimar que las alzas eran arbitrarias, habida cuenta de que la salud es un servicio público, que puede ser prestado por el sector privado siempre y cuando los contratos de salud se ajusten al estándar constitucional.

Estos fallos pueden calificarse de estructurales debido a que abordan la selección de riesgo que ejercen las ISAPRE en función del fundamento de la dualidad del sistema de salud, al referirse a uno de los instrumentos principales mediante el que se realiza la selección: el aumento de las primas en función del riesgo. Existe un problema estructural y global subyacente en el sistema, que se expresa en demandas particulares y que se canaliza hacia el poder judicial dentro de una perspectiva de la salud como servicio público. Cabe resaltar que, afortunadamente, la reacción estructural del poder judicial ante los reclamos por el aumento del precio de los planes de salud fue muy temprana, por lo que se liberó del agobio asociado con la resolución eminentemente casuística y se develaron meridianamente rasgos adversos al aseguramiento, inherentes a la arquitectura dual del sistema de salud y que, por diversas constelaciones políticas favorables a las ISAPRE, no habían sido reconocidos cabalmente.

La judicialización se inició en 2007 con 737 causas, cifra que en 2013 alcanzó su nivel más elevado de 150.000 causas, entre las que se incluyeron los recursos contra el aumento de precios de base y los aumentos de precios por Garantías Explícitas en Salud (GES). En 2014, el 60\% de las causas tramitadas ante la Corte de Apelaciones de Santiago correspondió a recursos de protección de beneficiarios de las ISAPRE, que cuadruplican con creces los provenientes de la justicia civil, que se ubicaron en segundo lugar. Casi la totalidad de los fallos favorecieron a los demandantes 
(Comisión Asesora Presidencial para el Estudio y Propuesta de un Nuevo Marco Jurídico para el Sistema Privado de Salud, 2014, pág. 55).

En Chile, el Tribunal Constitucional declaró inconstitucional que las tablas de factores que determinan el costo de los planes de salud de las ISAPRE se definan mediante normas administrativas y objetó los numerales 1, 2, 3 y 4 del inciso tercero del artículo 38 de la Ley núm. 18.933 sobre Instituciones de Salud Previsional relativos a la estructura de la tabla de factores. En ese sentido, las modificaciones al plan base de salud deben ser excepcionales y aplicarse en forma restringida para evitar abusos. Asimismo, las ISAPRE deben demostrar de manera cabal, pormenorizada, racional y verificable los motivos que justifican el alza de los precios (Comisión Asesora Presidencial para el Estudio y Propuesta de un Nuevo Marco Jurídico para el Sistema Privado de Salud, 2014).

Pese a la marcada tendencia a la disminución de los montos, el incentivo de los abogados está en las cuantiosas costas que las ISAPRE han debido pagar: en 2007 promediaron los 433.705 pesos, mientras que en 2008 rondaron los 351.074 pesos y en 2009 bajaron a 229.315 pesos. En la actualidad, si se toman en cuenta todas las Cortes de Apelaciones del país, el promedio supera los 150.000 pesos, y en Santiago es de 130.000 pesos. En 2013, los importes a favor de los abogados alcanzaron los 8.000 millones de pesos (Comisión Asesora Presidencial para el Estudio y Propuesta de un Nuevo Marco Jurídico para el Sistema Privado de Salud, 2014).

La extensa judicialización fue uno de los elementos analizados en el seno de la Comisión Asesora Presidencial para el Estudio y Propuesta de un Nuevo Marco Jurídico para el Sistema Privado de Salud, órgano creado recientemente que podría catalizar reformas que impugnen la dualidad del sistema de salud. La propuesta de mayoría de esta Comisión planteó conformar en el mediano plazo un seguro público único, un fondo único de salud y seguros privados complementarios vitalicios regulados. Como medida transitoria, propuso un plan de seguridad social único, universal y estandarizado, con un listado de prestaciones explícitas que se consolidarían a partir de diversos beneficios existentes y con bonificaciones máximas según un arancel. Además de las cotizaciones, las ISAPRE podrían cobrar una prima comunitaria asociada con una red de prestadores y sujeta a competencia. En tal sentido, la introducción de un plan de seguridad social único, universal y estandarizado crearía las condiciones para no tener que recurrir contra la selección de riesgo. Por su parte, el dictamen de minoría de la Comisión propuso un modelo de seguro social de salud basado en multiseguros y postuló que la fórmula de reajuste se calculara de manera independiente de las ISAPRE y que se legislara respecto de los reajustes de la prima comunitaria (Comisión Asesora Presidencial para el Estudio y Propuesta de un Nuevo Marco Jurídico para el Sistema Privado de Salud, 2014). 
Contrasta esto con la judicialización ocurrida en Colombia, donde adquirió un carácter inercial y rutinario durante un largo tiempo, acicateada sobre todo por las tutelas de salud. El aprendizaje y los debates acerca de los efectos positivos y negativos fueron lentos e inhibieron la creación de nuevas normas y ajustes o reformas orientados a solucionar la vulneración de los derechos fundamentales y las ganancias privadas indebidas producto de la judicialización.

En Colombia, la trayectoria cuantitativa de la tutela en materia de salud puede ser vista como un proceso de tres etapas. Una inaugural, en que el litigio no fue masivo, pero en la que se decidieron los casos pioneros y se adoptaron los "hitos jurisprudenciales" que crearon las condiciones para su masificación, seguida de una "fase de explosión", al socaire del sistema de salud adoptado por la Ley núm. 100 de 1993, cuando el litigio se consolidó, se masificó y representó una proporción cada vez más significativa de las tutelas, y, en tercer lugar, una "fase de racionalización" a partir de 2009, cuando se adoptaron medidas para contener la judicialización masiva y generalizada en materia de salud, que desde entonces empezó a disminuir. Entre los derechos invocados con mayor frecuencia, el de petición, usado sobre todo para acceder a pensiones, pasó al primer puesto (Rodríguez Garavito, 2012, págs. 511-519; Uprimny y Durán, 2014, págs. 18-19).

La relación entre el activismo judicial y las características del sistema de salud es también evidente en este caso, dado que la frecuencia y las modalidades del patrón de litigio guardan un nexo estrecho con el diseño original del sistema de salud, que distingue el subsistema contributivo (POS) del subsidiado (no POS), y que a raíz de la dinámica sectorial no llegaron a converger. También se relaciona con la ineficacia de los mecanismos administrativos para canalizar adecuadamente conflictos surgidos de la prestación de los servicios de salud. Por encima de los aspectos administrativos, se pone de manifiesto también la acción incipiente de los entes reguladores, supervisores y fiscalizadores en lo relativo a las coberturas, la priorización y las exclusiones.

Por ejemplo, la Superintendencia de Salud, que, además de las funciones de control de la actuación de los aseguradores y los prestadores de servicios, por ley puede ejercer funciones jurisdiccionales respecto de la cobertura de los procedimientos, las actividades y las intervenciones del plan obligatorio de salud cuando la negativa por parte de las entidades promotoras de salud y entidades asimiladas ponga en riesgo o amenace la salud del usuario. También puede actuar respecto de las prestaciones excluidas del Plan de Beneficios en Salud que no sean pertinentes para atender las condiciones particulares del individuo. Temáticamente, tales facultades coinciden con el objeto de la tutela en salud, pero la Corte 
Constitucional de Colombia ha señalado que ellas no desplazan al juez de tutela en forma automática en la decisión de casos concretos, si bien algunas sentencias han considerado que la jurisdicción de esta entidad debe aplicarse como mecanismo principal de protección del derecho a la salud. Sin embargo, la Superintendencia de Salud ha ejercido estas facultades en escasas ocasiones (Uprimny y Durán, 2014). En 2011, tal vez para descongestionar la carga de tutela, se reforzaron las funciones jurisdiccionales de la Superintendencia de Salud, de modo que pueda acudirse a ella con causas de carácter judicial cuya segunda instancia es un tribunal. Afortunadamente, la figura es poco conocida, pues, de lo contrario, no se estaría en capacidad de responder. Por su parte, en la Sentencia T-760 de 2008 se dieron órdenes de seguimiento y control a la Superintendencia de Salud que la obligaron a prestar una atención sistemática y rigurosa a los cambios estructurales del sistema de salud. Aunque ello a veces haya resulta abrumador para la institución, ha tenido algunos efectos muy positivos, por ejemplo, con la elaboración de un ranking de las entidades promotoras de salud (EPS) en función de su mal cumplimiento contribuyó a crear una cultura de la calidad (Morales, 2013).

De allí que se haya planteado que la judicialización en Colombia se origina en una combinación singular de fallas profundas y persistentes del sistema de salud, de un poder judicial particularmente accesible y proactivo en la protección de los derechos sociales, y de actores de la sociedad civil que han recurrido en forma masiva a los tribunales para resolver conflictos sobre el derecho a la salud (Rodríguez Garavito, 2012, pág. 510). Entre las fallas profundas y persistentes del sistema de salud se han señalado el incumplimiento de la función de control y vigilancia por parte del Estado, la falta de actualización del POS, la negativa de las EPS a suministrar algunas prestaciones incluidas en el plan de beneficios y el aprovechamiento del sistema de recobros por parte de actores como las EPS, las farmacéuticas y sectores venales de la administración pública (Rodríguez Garavito, 2012, pág. 554). Ante la inexistencia de mecanismos administrativos eficaces de resolución de las peticiones y reclamos de los ciudadanos, situación que perpetúa las insatisfactorias respuestas prejudiciales del sistema de salud, se ha propuesto que las instituciones de salud sean las que tramiten eminentemente los conflictos judicializados mediante instancias de decisión expeditas, con criterio técnico especializado y en sintonía con las obligaciones que derivan del derecho a la salud, en tanto que las intervenciones del poder judicial deben promover condiciones estructurales de carácter procedimental del sistema de salud y profundizar las aproximaciones estructurales de la jurisprudencia, de manera similar a lo establecido en la Sentencia T-760 de 2008, a fin de evitar las desventajas de la aproximación casuística (Rodríguez Garavito, 2012, págs. 511, 530, 544 y 546). Más allá del fortalecimiento de los mecanismos administrativos prejudiciales de solución de conflictos para 
tornarlos más expeditos, eficaces y justos (Rodríguez Garavito, 2012, pág. 545), el reto se relaciona también con el fortalecimiento de entes que ejerzan funciones de supervisión y de regulación relacionadas con las coberturas y con las exclusiones. Por ejemplo, una Superintendencia de Salud que prevalezca ante la acción de tutela caracterizada como subsidiaria o residual (Uprimny y Durán, 2014, pág. 10).

En contraste con la expedita reacción estructural por parte de los jueces en Chile, las soluciones estructurales en Colombia resultaron tardías ante la explosión del litigio, bajo el dictum del enfoque individual y casuístico de los reclamos, pese al estrecho vínculo entre la judicialización y las características del sistema de salud. Este rezago permitió que el litigio se instaurara como vía privilegiada para resolver el incumplimiento de los derechos y originó una gran congestión judicial y una rutinización extrema del litigio. Al no considerarse las razones sistémicas subyacentes, se retardó el emprendimiento de reformas cruciales del sector de la salud $\mathrm{y}$ el fortalecimiento de tareas regulatorias que inciden sobre el disfrute de los derechos; asimismo, se postergó el objetivo de abordar el desvirtuado usufructo de las resoluciones judiciales por parte de privados.

La inflexión más contundente provino de la legendaria Sentencia T-760 de 2008 que, a partir de una selección de los conflictos de tutela más recurrentes, identificó fallas de regulación, exigió actualizar los contenidos del POS y avanzar hacia la unificación de los beneficios de los regímenes contributivo y subsidiado. En una comparación internacional, esta sentencia ha sido considerada la tentativa más profunda por parte de un Tribunal Supremo de afectar las políticas de salud del país (Mæstad, Rakner y Motta Ferraz, 2011, pág. 208). Además de consagrar la salud como un derecho fundamental susceptible de ser tutelado autónomamente, la Corte Constitucional de Colombia con ese fallo expidió órdenes dirigidas a los actores relevantes del sector de la salud para que atendieran en plazos perentorios las fallas estructurales que subyacen a la judicialización del derecho a la salud (Rodríguez Garavito, 2012, pág. 518).

Es decir, que el patrón de litigio en Colombia, tanto en cuanto a su frecuencia como a sus modalidades, tuvo un nexo estrecho con el diseño original del sistema de salud, con el fracaso de la convergencia de los subsistemas POS y no POS, con la rigidez de la estructuración del Plan Obligatorio de Salud (sobre todo respecto de los medicamentos) y con mecanismos administrativos que no canalizan adecuadamente los conflictos surgidos en la prestación de los servicios de salud. Por ello, la Sentencia T-760 de 2008 identifica fallas de regulación y exige actualizar los contenidos del POS y avanzar hacia la unificación de los beneficios. Como se analizó en el capítulo IV sobre las combinaciones público-privadas en disputa, en la actualidad en el caso colombiano se plantea la necesidad de una mejor articulación territorial del sistema de salud, la acción de 
un administrador único de los recursos con capacidad de sanción y el fortalecimiento de la atención primaria. Estos aspectos, que se revelan fundamentales para el acceso adecuado a los servicios, contribuirían también a reducir la judicialización del derecho a la salud.

Como se aprecia, si bien el litigio puede no referirse explícitamente a la estructura del sistema, tiene la capacidad de modificarlo según el tipo de análisis que realice la justicia. En tal sentido, lo determinante no es tanto el tipo de litigio como la comprensión "estructural" por parte de la justicia (Cubillos y otros, 2012, pág. 398). Más aún, cuando no se abordan de manera correcta las raíces estructurales del litigio, pueden producirse distorsiones e incentivos que resultan negativos desde el punto de vista social, como los recobros de medicamentos mediante tutelas o disposiciones de los comités técnicos y científicos, en el caso de Colombia. Estos recobros por separado tenían incentivos negativos inherentes, ya que generaban rentas adicionales para los prestadores (EPS) en detrimento del FOSYGA, que debía pagarlos (Uprimny y Durán, 2014, págs. 25-29). Durante años, ello permitió postergar la flexibilización de algunas fórmulas farmacéuticas rígidas del POS, no enfrentar el poder de cabildeo (lobby) de los médicos y de la industria farmacéutica en cuanto a la prescripción de medicamentos o a sus sobreprecios, y fue caldo de cultivo para la rutinización que agobió al poder judicial y a las entidades sectoriales ad hoc.

Además, una enseñanza crucial es que las soluciones colectivas o estructurales, que trascienden los casos concretos, ofrecen un potencial mayor respecto de las individualizadas para arrancar de raíz las desigualdades a la hora de proteger el derecho a la salud (Uprimny y Durán, 2014).

Para el país y para los organismos competentes del sistema de salud, la búsqueda de soluciones estructurales implica mejorar la arquitectura del sistema y formular mejores políticas, así como lograr sistemas de salud vigorosos, más equitativos y eficientes, y capaces de responder mejor a las demandas ciudadanas. Por ahora, se ha catalizado la búsqueda de cambios dentro del sector: la confluencia de beneficios, la aspiración de tener un comprador único — reforma que apenas comienza a concretarse- y el fortalecimiento de la capacidad regulatoria respecto de la industria farmacéutica (por ejemplo, mediante el establecimiento en 2014 de controles de precios para una serie de medicamentos).

\section{La priorización en salud}

De la mano de combinaciones público-privadas que nacieron en el marco de reformas privatizadoras, en América Latina se fortalecieron los planteamientos de priorización. Los recursos son siempre escasos y los sistemas más diversos ejercen tradicionalmente formas de racionamiento 
que, por ejemplo, dan lugar a las listas de espera. Por su parte, el racionamiento explícito ha sido una práctica idiosincrática arraigada en Chile, mediante el catálogo de prestaciones que estructura el aseguramiento solidario del FONASA o mediante el descreme del mercado que practican las ISAPRE, ya que pese a tratarse de contribuciones obligatorias, las pólizas se ajustan al riesgo individual y se pactan en valores constantes en unidades de fomento (UF), por lo que aumentan todos los meses en función de la inflación.

En materia de priorización, en el clásico Informe sobre el Desarrollo Mundial 1993 (Banco Mundial, 1993), se postuló que los gobiernos debían concentrarse en compensar las fallas de mercado y en financiar servicios que beneficiaran, sobre todo, a los pobres. En tal sentido, debía reducirse el gasto en el nivel terciario de salud y en intervenciones especializadas. Con los recursos públicos debían financiarse tanto una serie de intervenciones públicas orientadas a las enfermedades contagiosas con altas externalidades y a ciertas políticas de prevención, como un conjunto esencial de intervenciones clínicas que asegurara una mejor salud a los pobres y cuya composición y amplitud se determinara a escala nacional de acuerdo con las condiciones epidemiológicas, las preferencias locales y los ingresos. Más allá de la intervención en materia de salud pública y en estas medidas esenciales, respecto de las demás "intervenciones clínicas" los gobiernos debían promover la diversidad y la competencia en la provisión de servicios, fomentar el aseguramiento social o privado con regulaciones de acceso y de contención de costos, acreditar estas instituciones, y diseminar información acerca de su desempeño (Banco Mundial, 1993, pág. 5).

Como se ha señalado respecto de diversos postulados análogos del Banco Mundial, la propuesta es paradigmática en cuanto al reduccionismo en política social, que circunscribe la responsabilidad pública en materia de protección social a políticas focalizadas en los pobres mediante redes de protección, y que promueve el aseguramiento individual, desestimando el principio de solidaridad en un régimen de aseguramiento social, o aceptando solo en el margen mancomunaciones de riesgo mediante contribuciones obligatorias (Sojo, 2003, pág. 138). De este modo se advierte un fundamento más global de la priorización mediante listas de prestaciones explícitas.

En tanto el informe inviste a la taxativa propuesta de una suerte de autoridad, resulta sugerente analizarla aplicando el enfoque de "poder en las ideas" (power in ideas) (Carstensen y Schmidt, 2016). Valiéndonos de la jerga de ese enfoque, el conjunto esencial de prestaciones clínicas y su anverso - la exclusión- constituían un "concepto-instrumento" del Banco Mundial que, dada su capacidad de implantarse institucionalmente, pretendía instaurar una hegemonía y una autoridad sobre la validez o invalidez de planteamientos acerca 
de la gama de prestaciones disponibles en materia de salud, y de las políticas concomitantes insertas dentro de una arquitectura del sistema de salud. Para ello, por un lado limitaba el ámbito de alternativas consideradas aceptables y, así, las coberturas horizontales (quiénes) y verticales (qué), al igual que el medio (cómo); por otro lado, servía de orientación a los actores públicos y de fuente de justificación y de legitimidad para las medidas que se emprendieran en la materia. En estos términos, la fundamentación explícita en tanto "poder en las ideas" se instauró en algunos países bajo la rúbrica de la priorización y adquirió, en consecuencia, un arraigo institucional, mientras que en otros países no se implantó y actuó como un referente que conviene tener en cuenta o que en épocas de austeridad y ajustes pende como la espada de Damocles.

La idea de priorización se ha vinculado a sistemas de salud de la región que se rigen por el aseguramiento contributivo (Flood y Gross, 2014), pero ello no se aplica en sentido estricto, pues no existe en algunos sistemas de aseguramiento, como el de Costa Rica. Sin embargo, del análisis de estos autores cabe retomar el planteamiento de que cuando los sistemas de aseguramiento operan mediante contratos entre el asegurador y el individuo donde se especifica una lista de bienes y servicios que debe cubrirse, ello provee una base idónea para el litigio. Es decir que la propia estructura del sistema de salud, dado el énfasis en un conjunto de beneficios definido, brinda condiciones favorables para la judicialización.

Según Arrow, la diversificación de riesgos es "la esencia del aseguramiento" (Arrow, 2000, pág. 220). Los seguros obligatorios suelen adoptar una perspectiva de largo plazo, ya que, al establecer garantías generales, los individuos no son reclasificados si sus riesgos se incrementan (Arrow, 1963, pág. 904). Además, el establecimiento en términos más genéricos de la cobertura de riesgos es lo que permite romper la identidad entre prima y riesgo individual e incluir algunos riesgos que normalmente no serían cubiertos por seguros individuales de mercado (Barr, 1993, págs. 123-128 y 308). Por el contrario, los contratos anuales que varían de acuerdo con el estatus de salud observable (por ejemplo, mediante la denominada calificación de la experiencia (experience rating), que considera nuevos cuadros de morbilidad o enfermedades preexistentes) impiden el aseguramiento intertemporal, es decir, el derecho a comprar coberturas futuras de salud a costos medios aun cuando la enfermedad sobrevenga hoy (Cutler y Zeckhauser, 2000, pág. 564). Así, la lógica de la diversificación de riesgos puede desvirtuarse en parte cuando las coberturas se establecen en términos menos genéricos y el sistema de protección social se expone a tensiones estructurales que pueden canalizarse mediante el litigio. 
De allí que el activismo judicial haya sido explicado, de manera pertinente, en razón de la limitada capacidad para diseñar conjuntos de beneficios justos y sólidos, y para establecer prioridades en materia de salud (Cubillos y otros, 2012). Por ello, los tribunales considerarían que las ineficiencias administrativas y los procesos de priorización en salud coartan la protección del acceso de las personas en el ámbito de la salud y violan este derecho, y se convierten en sus garantes y supervisores (Iunes y otros, 2012). El siguiente diagrama resulta útil pues permite observar el propósito de la litigación, y en él se distingue si se refiere a beneficios establecidos o excluidos y se da por sentado el acceso a la litigación. Se han introducido ciertos ajustes a la versión original: por su connotación reduccionista, por ejemplo, no se utiliza el término "esencial" del diagrama original para referirse a la lista oficial de servicios estipulados en el plan de beneficios.

\section{Diagrama V.1 \\ Litigación para acceder a beneficios de salud}

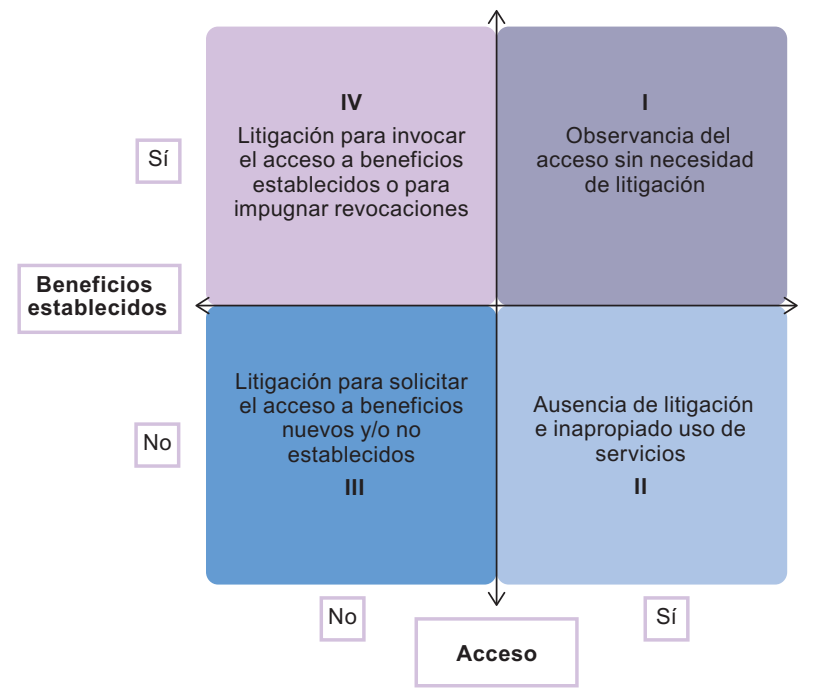

Fuente: L. Cubillos y otros, "Universal health coverage and litigation in Latin America", Journal of Health Organization and Management, vol. 26, №3, Bingley, Emerald Group Publishing, 2012.

Nota: Se modificó la casilla IV para incluir las revocaciones y se reemplazó el término "esencial" utilizado originalmente para referirse a la lista oficial de beneficios o a los beneficios que se establecerán.

En la región se han analizado cambios en el consumo de las prestaciones garantizadas en los distintos planes de beneficios, pero se ha estudiado muy poco lo que acontece con el gasto, el acceso y el consumo de prestaciones de salud excluidas de las listas priorizadas. Es crucial conocer la proporción del gasto dirigida a atenciones priorizadas y no priorizadas, 
así como sus respectivos efectos tanto en el caso de prestaciones priorizadas y cuyo acceso estaba restringido por límites en la oferta pública, como de prestaciones no priorizadas. Asimismo, deben analizarse sus efectos globales en la equidad del acceso a las prestaciones, en términos de la cobertura horizontal (beneficiarios) y vertical (prestaciones).

El establecimiento de prioridades admite algunas variaciones: las exclusiones pueden ser explícitas o implícitas respecto de servicios que no se incluyen en los listados de prestaciones y ambas se dan en un marco dinámico ya que, como resultado de la investigación científica y de la dinámica del mercado, surgen diversas prestaciones y servicios que podrían ser incluidos.

Cabe considerar que la priorización involucra una serie de aspectos complejos: razones argumentativas y significativas que tomen en cuenta el derecho a la salud y la manera en que deben imponerse los límites, así como la raigambre institucional de aquel derecho y el territorio en el cual puede ejercerse. Otros aspectos son los principios conforme a los cuales se desarrolla y aplica el alcance de las prestaciones; los criterios sustantivos y procedimentales con que se define la cobertura; el carácter de las reglas que determinan las inclusiones y las exclusiones; las instituciones y los actores que participan en la priorización; los criterios de clasificación de los servicios en cuanto a su eficacia clínica; su carácter indispensable o suntuario; el vínculo con los objetivos terapéuticos; las ambigüedades inherentes a las definiciones y los límites de las prestaciones que, por esencia, revisten suma complejidad; los mecanismos para definir las exclusiones; los criterios para contemplar las excepciones; las disposiciones de financiamiento y las reglas respecto de los servicios no priorizados; y los criterios para las revisiones y las actualizaciones del proceso de priorización?

Dado que la exclusión de determinadas prestaciones puede impugnarse mediante la judicialización, ello torna porosas las barreras infranqueables erigidas por la priorización que, en esos términos, resultarán inocuas e ineficaces ante una práctica de judicialización que, a su vez, puede entrañar altos costos, tener en ocasiones un sustento técnico cuestionable y no ser equitativa. Por ende, es menester tomar en consideración las prestaciones no priorizadas, pues constituyen un potencial objeto de litigio.

En el caso de las prestaciones priorizadas obligatorias de las Garantías Explícitas en Salud (GES) del Plan AUGE, un análisis de una muestra bastante acotada de problemas de salud en Chile no permitió observar un desplazamiento de las prestaciones no priorizadas, aunque se detectó un mayor crecimiento del gasto de las GES, sobre todo en el nivel secundario y terciario. No obstante, dadas las restricciones de la información consultada, el estudio no permitió extraer conclusiones taxativas al respecto (Debrott, Bitrán y Rebolledo, 2014).

7 Estas dimensiones generales se establecieron a partir del matizado análisis en el que Uprimny y Durán examinaron los desafíos de las reformas del sistema de salud colombiano a la luz de la judicialización (Uprimny y Durán, 2014, págs. 52-56). 
De allí la importancia de que la exclusión de determinadas prestaciones goce de una alta legitimidad y de que no constituya una determinación cerrada, sino el producto de procesos deliberativos y participativos. Su motivación debe ser transparente, tener como criterio la justicia y la equidad, y respaldarse con una carga argumentativa en consonancia con razones constitucionales significativas. Por ello, debe precisarse el alcance de los principios conforme a los cuales se deben formular y aplicar las exclusiones, los criterios sustantivos y procedimentales con que debería definirse la cobertura y, más concretamente, los límites del derecho a la salud y cómo deberían imponerse. Además, las decisiones para enfrentar el litigio deberían abordarse de manera más explícita y con fundamentaciones claras y, sobre todo, relevantes cuando la solución impone alguna restricción. En lugar de una rigidez indebida en cuanto a los derechos de los usuarios, se ha propuesto que las exclusiones tengan un carácter prima facie, es decir, que no impliquen una prohibición absoluta de acceso a la prestación, sino que su acceso merezca una especial deferencia judicial, porque la exclusión sería producto de un procedimiento transparente y participativo que, en principio, debe ser respetado por los jueces. Para superar la dicotomía de incluir lo litigado en la cobertura o de imponer barreras infranqueables al litigio, se proponen opciones intermedias que permitirían focalizar mejor la protección y relegar la imposición de barreras para los casos excepcionales claramente justificados, al tiempo que se mantiene algún grado de flexibilidad. Deviene indispensable también considerar las opciones para financiar las prestaciones que se brinden en razón del litigio. Se razona que los listados de servicios deben tener un fundamento legal perdurable: en el caso de Colombia se ha recomendado su inclusión en los proyectos de nuevas leyes ordinarias y estatutarias en materia de salud (Uprimny y Durán, 2014, págs. 54-56 y 63).

Dada la finitud de los recursos y los principios y criterios con que todo sistema de salud se organiza — equidad, solidaridad, universalidad o, por el contrario, individualización del riesgo-, hay diversas formas de racionalizar y racionar las prestaciones o de establecer límites de hecho. La complejidad descrita puede llevar a cuestionar las ventajas de los racionamientos explícitos y pone sobre el tapete la inocuidad de imponer barreras presuntamente infranqueables, pero que al impugnarse en los tribunales pueden originar nuevas normas aún ignotas.

\section{Litigio y acceso a medicamentos}

En varios países latinoamericanos donde la judicialización es recurrente, llama la atención la preponderancia de este recurso para tener acceso a medicamentos. Algunos litigios han tenido efectos sistémicos favorables, pero en otros casos existen evidencias de la presión ejercida por compañías 
farmacéuticas en algunos médicos, a cuyas prescripciones de medicamentos caros se tuvo acceso mediante fallos judiciales, prescripciones que han acarreado gastos cuantiosos en el presupuesto de salud o bien revelaron una eficacia dudosa (Mæstad, Rakner y Motta Ferraz, 2011, pág. 286). Ya se aludió al recobro de algunos medicamentos en Colombia que, a pesar de no ser costosos, generaban por la vía judicial rentas adicionales para los prestadores en detrimento del FOSYGA y ganancias para la industria por medio de sobreprecios (Uprimny y Durán, 2014, págs. 25-29).

Tras una comparación internacional realizada hace algunos años, se llegó a la inquietante conclusión de que la mayoría de los medicamentos obtenidos mediante litigación en el Brasil, Costa Rica y Colombia parecían tener una baja eficacia en función de los costos y, en ocasiones, extremadamente baja; en el estudio también se señalaron algunas excepciones a esta relación entre la eficacia y el costo (Mæstad, Rakner y Motta Ferraz, 2011, pág. 295).

La Constitución Política de Costa Rica no especifica el derecho a la salud. La Sala Constitucional de la Corte Suprema de Justicia, conocida como Sala IV, ha asumido un protagonismo creciente en el litigio en este ámbito, centrado en los medicamentos, muy por encima de los reclamos relacionados con formas de discriminación, listas de espera por especialidades e intervenciones quirúrgicas. Un fallo de 1997 favorable al uso de antirretrovirales para pacientes con VIH y SIDA tuvo efectos muy positivos en términos del desarrollo del derecho a la salud: Costa Rica es actualmente el país con el mayor grado de cobertura para estos pacientes, cuyas tasas de morbilidad han disminuido notablemente. Aquel fallo constituyó un punto de inflexión en cuanto al uso del recurso judicial por parte de pacientes con enfermedades crónicas para acceder a medicamentos de alto costo que les habían sido denegados por la seguridad social, recurso que experimentó un crecimiento acelerado a partir de 2002 en sintonía con el acortamiento de los plazos de resolución de las causas, que alrededor del $60 \%$ de las veces se resuelven favorablemente (Norheim y Wilson, 2014).

A partir de ciertos parámetros en la literatura especializada acerca de la eficacia de los medicamentos, se analizaron 37 fallos favorables de 2008 seleccionados aleatoriamente, a fin de indagar en la calidad técnica de las sentencias de la Sala IV de Costa Rica. Las conclusiones fueron preocupantes: solo un 2,7\% correspondían a fármacos clasificados como de alta prioridad, mientras que el $27 \%$ pertenecían a la segunda categoría; el $48,6 \%$, a la tercera, y el 21,6\% eran experimentales. En otras palabras, más del $70 \%$ de los fármacos eran de baja prioridad y solo tres de los medicamentos correspondían a la lista de fármacos esenciales de la Organización Mundial de la Salud (OMS), situación que, debido a la competencia por los recursos, tendría además efectos adversos en términos 
de equidad. En el seno de la Caja Costarricense del Seguro Social (CCSS) se alega que algunas decisiones de la Sala IV en esta materia han conducido a un uso inadecuado de recursos escasos y se alerta respecto de conductas corruptas por parte de abogados inescrupulosos y médicos que favorecen a compañías farmacéuticas (Norheim y Wilson, 2014).

Cabe destacar que en colaboración con las principales entidades a cargo de la salud, la Sala Constitucional firmó en mayo de 2014 un Plan de cooperación técnica con la Colaboración Cochrane, que pretende facilitar un diálogo especializado respecto de la equidad, la eficiencia, el diseño y la implementación de políticas públicas relacionadas con la priorización, la ley y la judicialización de la salud. Gracias a este plan, la Sala IV tendrá acceso a las amplias bases de datos médicos de Colaboración Cochrane y se capacitará al personal en el uso de información médica especializada con el objeto de consolidar una base técnica relativa a las decisiones. Si bien esta búsqueda de fundamentos técnicos para las decisiones judiciales resulta interesante y loable, queda abierta una interrogante: ¿se estará incurriendo, a pesar del fundamento técnico, en una suplantación indebida del poder político del sector de la salud en lo que respecta a las políticas sobre el financiamiento solidario y público de los medicamentos?

En el Brasil, la creciente utilización del litigio se relaciona tanto con los efectos de racionamiento (filas y listas de espera) como con la fijación de prioridades (medicamentos excluidos de las listas de prestaciones). A manera de ejemplo, en un estudio sobre Belo Horizonte se muestra la importancia relativa de los medicamentos. De 1998 a 2009, casi la mitad de los reclamos se entablaron por medicamentos que no figuraban en las listas del Sistema Único de Salud (SUS) por motivos relacionados con la eficacia en función de los costos. Las prescripciones de medicamentos mayoritariamente provenían de médicos que trabajaban para el SUS, pero otras eran de médicos de seguros privados, cuyos beneficiarios obtenían financiamiento público para esas prestaciones gracias a los fallos judiciales. Un $90 \%$ de las sentencias eran favorables y otorgaban coberturas totales o parciales. A escala municipal, los gastos en medicamentos en Belo Horizonte pasaron del 6,2\% del total en 2007 al 93,6\% en 2009 y, si se analiza la concentración del gasto, se observa cierta influencia de los fallos judiciales (Gonçalves Menicucchi y Machado, 2010).

Por su parte, debido a la proporción, la masividad y las características de los reclamos por medicamentos, puede aducirse que se trató de un esfuerzo desproporcionado para el sistema judicial colombiano, que revela el efecto de incentivos negativos para que los aseguradores se beneficien del litigio mediante el FOSYGA y la colusión de empresas farmacéuticas y médicos en torno a la prescripción de determinados medicamentos (Uprimny y Durán, 2014, pág. 46). Las tutelas por servicios incluidos en el Plan Obligatorio de 
Salud representan un alto porcentaje de litigios en materia de salud que, en proporción, han variado a lo largo del tiempo y a veces han sido incluso mayoritarias. El total acumulado de 1999 a 2011 evidencia que las tutelas por medicamentos han predominado respecto de las correspondientes a cirugías y tratamientos. El Ministerio de Salud constató que el 88,6\% de las moléculas de medicamentos cubiertos por el POS fueron financiadas como prestaciones excluidas de la cobertura debido al uso de variaciones farmacéuticas. A causa de su rigidez, la estructura del POS ofrecía un incentivo perverso en ese sentido, pues especificaba las concentraciones y fórmulas farmacéuticas cubiertas. Así, de los 442 principios activos del POS, existían al menos en 372 casos otras concentraciones o formas farmacéuticas no cubiertas, lo que incentivaba que se reclamaran y tramitaran como prestaciones no POS. Hay un caso que resulta lamentable por su ponderación dentro del litigio y el agobio judicial al que contribuye: se trata del acetaminofén en gotas, que solo estaba incluido como jarabe, estipulación que carece de todo fundamento técnico, y que representa también el caso de varios otros medicamentos de bajo costo y de aplicación en cuadros simples de morbilidad. Como se trata de un servicio no POS, podía recobrarse de manera separada, mientras que el jarabe se cargaba a la Unidad de Pago por Capitación (UPC). Esto favoreció tanto a las aseguradoras, porque el recobro se hace por un porcentaje mayor al estipulado en el POS, que es adicional a los recursos por capitación que se reciben, como a las compañías farmacéuticas, porque, además, su reembolso a menudo se hacía por valores superiores a los precios de mercado (Uprimny y Durán, 2014, págs. 22-25). A diferencia de los medicamentos caros, estos recobros por prestaciones de poco valor suponen también altos costos de transacción, por lo que el costo de la acción jurídica llega a ser mayor que el de la prestación.

A su vez, entre los medicamentos no POS que son objeto de reclamo se encuentran prestaciones más costosas. El Ministerio de Salud y Protección Social constató que la mayoría de los medicamentos recobrados mediante litigio correspondían en 2013 a los clasificados como innovaciones para enfermedades no transmisibles, cuya incidencia no ha crecido en tal proporción. En cuanto al control del mercado, 18 de los 20 principios activos más recobrados eran versiones de marcas que controlaban más del 30\% del mercado; 16 a una marca que dominaba más del $50 \%$ del mercado y en el caso de 6 productos, una sola acaparaba la totalidad del mercado. Ciertas marcas farmacéuticas claramente predominaban entre los 50 medicamentos más recobrados. El litigio creció de la mano del lanzamiento de medicamentos de alto costo, sobre todo los biotecnológicos, situación que se evidencia en los exorbitantes desembolsos para tales medicamentos, pese a los pocos casos tratados en el país por enfermedades relacionadas. Ello condujo en 2013 a restablecer el control de precios sobre medicamentos y a estipular topes de recobro (Uprimny y Durán, 2014, págs. 26-30). 
En este marco resulta interesante que, desde la perspectiva de los jueces, se plantee que el poder judicial se ha visto congestionado debido a que otras ramas del poder público carecen de un papel protagónico que les permita supervisar y vigilar las fisuras del sistema y la acción de los particulares que actúan bajo la lógica del mercado, o que se arguya que la reacción ocurre demasiado tarde. Entre las áreas de intervención, cabe mencionar el elevado precio de los medicamentos y las ganancias de las empresas farmacéuticas; los vicios de enriquecimiento de sujetos que propician el incremento de tutelas al "incentivar" a los médicos a prescribir medicamentos fuera del POS que serán denegados para que mediante tutelas se cobren al FOSYGA fuera de la UPC; y los recobros del $100 \%$ de parte de las entidades promotoras de salud (EPS). También se ha mostrado sorpresa ante el hecho de que la inflexibilidad de los planes obligatorios haya propiciado el recobro de medicamentos que, en esencia, están cubiertos por la UPC (Zapata Pérez, 2013).

\section{Bibliografía}

Abramovich, V. y C. Courtis (2006), El umbral de la ciudadanía. El significado de los derechos sociales en el Estado social constitucional, Buenos Aires, Editores del Puerto.

Arrow, K. (2000) "Insurance, risk and resource allocation", Foundations of Insurance Economics. Readings in Economics and Finance, G. Dionne y S. E. Harrington (comps.), Boston, Kluwer Academic Publishers.

(1963), "Uncertainty and the Welfare economics of medical care", The American Economic Review, vol. LIII, N 5, diciembre. Banco Mundial (1993), Informe sobre el Desarrollo Mundial 1993. Invertir en salud, Washington, D.C.

Barcellos (de), A. P. (2014), "Sanitation rights, public law litigation, and inequality: a case study from Brazil", Health and Human Rights Journal, vol. 16, № 2, Cambridge, Harvard University Press.

Barr, N. (1993), The Economics of the Welfare State, Stanford, Stanford University Press.

Cabal, L., M. Arango y V. Montoya (2014), "Striking a balance: conscientious objection and reproductive health care from the Colombian perspective", Health and Human Rights Journal, vol. 16, № 2, Cambridge, Harvard University Press.

Carstensen, M. y V. A. Schmidt (2016), "Power through, over and in ideas: conceptualizing ideational power in discursive institutionalism", Journal of European Public Policy, vol. 23, No 3, Taylor and Francis Group.

CEPAL (Comisión Económica para América Latina y el Caribe) (2007), Cohesión social: inclusión y sentido de pertenencia en América Latina y el Caribe (LC/G.2335), Santiago.

Colombia, Gobierno de (2015), Constitución Política de Colombia, Bogotá, Corte Constitucional [en línea] http://www.corteconstitucional.gov.co/inicio/ Constitucion\%20politica\%20de\%20Colombia\%20-\%202015.pdf.

Comisión Asesora Presidencial para el Estudio y Propuesta de un Nuevo Marco Jurídico para el Sistema Privado de Salud (2014), Informe. Estudio y propuesta de un nuevo marco jurídico para el sistema privado de salud, Santiago, octubre. 
Courtis, C. (2007), "Los derechos sociales en perspectiva: la cara jurídica de la política social", Desempeño económico y política social en América Latina y el Caribe: los retos de la equidad, el desarrollo y la ciudadanía, A. Sojo y A. Uthoff (comps.), Ciudad de México, Comisión Económica para América Latina y el Caribe (CEPAL)/Facultad Latinoamericana de Ciencias Sociales (FLACSO).

Cubillos L. y otros (2012), "Universal health coverage and litigation in Latin America", Journal of Health Organization and Management, vol. 26, N³, Bingley, Emerald Group Publishing.

Cutler, D. y R. Zeckhauser (2000), "The anatomy of health insurance”, Handbook of Health Economics, vol. 1A, A.J. Culyer y J.P. Newhouse, Amsterdam, Elsevier Science Publishers.

Debrott, D., R. Bitrán y C. Rebolledo (2014), “Procesos de priorización en salud y prestaciones no priorizadas ni explícitas. La evolución de algunas prestaciones trazadoras en Chile", serie Políticas Sociales, N 201 (LC/L.3853), Santiago, Comisión Económica para América Latina y el Caribe (CEPAL).

Felstiner, W. L. F., R. L. Abel y A. Sarat (1980), “The emergence and transformation of disputes: naming, blaming, claiming...", Law \& Society Review, vol. 15, $\mathrm{N}^{\mathrm{o}} 3 / 4$, Nueva Jersey, Wiley.

Ferrajoli, L. (2002), Derechos y garantías: la ley del más débil, Madrid, Editorial Trotta.

Fioretos, O., T. G. Falleti y A. Sheingate (2016), “Historical institutionalism in political science", Oxford Handbook of Historical Institutionalism, Oxford University Press.

Flood, C. M. y A. Gross (2014), "Litigating the right to health: what can we learn from a comparative law and health care systems approach", Health and Human Rights Journal, vol. 16, N 2, Cambridge, Harvard University Press.

Gargarella, R. (2014), La sala de máquinas de la Constitución. Dos siglos de constitucionalismo en América Latina (1810-2010), Buenos Aires, Katz Editores.

Gargarella, R. y C. Courtis (2011), "El nuevo constitucionalismo latinoamericano: promesas e interrogantes", Sentido de pertenencia en sociedades fragmentadas: América Latina desde una perspectiva global, M. Hopenhayn y A. Sojo (comps.), Buenos Aires, Siglo XXI/Comisión Económica para América Latina y el Caribe (CEPAL).

Gaviria, A. (2013), Presentación sobre el Proyecto de reforma en curso y su significado para la judicialización del derecho a la salud en el Taller Equidad en Salud y Judicialización del Derecho a la Salud en Colombia: Balance de Dos Décadas y Perspectivas ante la Reforma en Marcha, Bogotá, 21 de agosto.

Gloppen, S. (2011), "Litigating health rights: framing the analysis", Litigating Health Rights. Can Courts Bring More Justice to Health?, A.E. Yamin y S. Gloppen, Cambridge, Harvard University Press.

Gonçalves Menicucci, T. M. y J. A. Machado (2010), “Judicialization of health policy in the definition of access to public goods: individual rights versus collective rights", Brazilian Political Science Review, vol. 4, No 1, São Paulo, Asociación Brasileña de Ciencia Política.

Iunes, R., L. Cubillos y M. L. Escobar (2012), “Universal health coverage and litigation in Latin America", En breve, N ${ }^{\circ} 178$, Washington, D.C., Banco Mundial, julio.

Kutzin, J. (2008), "Health financing policy: a guide for decision-makers", Health Financing Policy Paper, $\mathrm{N}^{\mathrm{o}}$ 2008/1, Copenhague, Oficina Regional de la Organización Mundial de la Salud (OMS) para Europa.

López, D. E. (2013), “Comentarios desde una perspectiva académica”, presentación en el Taller Equidad en Salud y Judicialización del Derecho a la Salud en Colombia: Balance de Dos Décadas y Perspectivas ante la Reforma en Marcha, Bogotá, 21 de agosto. 
Mæstad, O., L. Rakner y O. Motta Ferraz (2011), "Assessing the impact of health rights litigation: a comparative analysis of Argentina, Brazil, Colombia, Costa Rica, India and South Africa", Litigating Health Rights. Can Courts Bring More Justice to Health?, A. E. Yamin y S. Gloppen, Cambridge, Harvard University Press.

Morales, G. (2013), "La visión del supervisor del sistema", presentación en el taller Equidad en Salud y Judicialización del Derecho a la Salud en Colombia: Balance de Dos Décadas, y Perspectivas ante la Reforma en Marcha, Bogotá, 21 de agosto.

Norheim, O. F. y B. M. Wilson (2014), "Health rights litigation and access to medicines: priority classification of successful cases from Costa Rica's constitutional chamber of the Supreme Court", Health and Human Rights Journal, vol. 16, N 2, Cambridge, Harvard University Press.

Osorio Estrada, M. E. (2013), “La óptica de las organizaciones sociales que han dado seguimiento al litigio y participado ante la Corte Constitucional", presentación en el Taller Equidad en Salud y Judicialización del Derecho a la Salud en Colombia: Balance de Dos Décadas y Perspectivas ante la Reforma en Marcha, Bogotá, 21 de agosto.

Rodríguez Garavito, C. (2012), “La judicialización de la salud: síntomas, diagnóstico y prescripciones", La salud en Colombia: logros, retos y recomendaciones, Ó. Bernal y C. Gutiérrez (eds.), Bogotá, Universidad de los Andes.

Ruiz, F. (2013), "Comentarios desde la perspectiva de quienes tienen a su cargo la implementación del sistema", presentación en el Taller Equidad en Salud y Judicialización del Derecho a la Salud en Colombia: Balance de Dos Décadas y Perspectivas ante la Reforma en Marcha, Bogotá, 21 de agosto.

Sandoval, H. (2008), Intervención en el Seminario Internacional Desigualdad Socioeconómica y el Derecho a la Salud en América Latina y el Caribe en una Perspectiva Internacional, Santiago, Comisión Económica para América Latina y el Caribe (CEPAL), noviembre.

Sojo, A. (2006), “La garantía de prestaciones en salud en América Latina. Equidad y reorganización de los cuasimercados a inicios del milenio", serie Estudios y Perspectivas, N ${ }^{o} 4$ (LC/L.2484-P), Ciudad de México, Sede Subregional de la CEPAL en México, febrero.

(2003), "Vulnerabilidad social, aseguramiento y diversificación de riesgos en América Latina y el Caribe", Revista de la CEPAL, N 80 (LC/G.2204-P/E), Santiago, Comisión Económica para América Latina y el Caribe (CEPAL).

Uprimny, R. y J. Durán (2014), “Equidad y protección judicial del derecho a la salud en Colombia", serie Politicas Sociales, No 197 (LC.L.3829), Santiago, Comisión Económica para América Latina y el Caribe (CEPAL), mayo.

Yamin, A. E. (2011), "Power, suffering and courts: reflections on promoting health rights through judicialization", Litigating Health Rights. Can Courts Bring More Justice to Health?, A. E. Yamin y S. Gloppen, Cambridge, Harvard University Press.

Yamin, A. E. y S. Gloppen (2011), Litigating Health Rights. Can Courts Bring More Justice to Health?, Cambridge, Harvard University Press.

Zapata Pérez, A. M. (2013), "Comentarios desde la perspectiva de los jueces", presentación en el Taller Equidad en Salud y Judicialización del Derecho a la Salud en Colombia: Balance de Dos Décadas y Perspectivas ante la Reforma en Marcha, Bogotá, 21 de agosto. 


\section{Capítulo VI \\ El fundamento del cuidado como pilar de la protección social ${ }^{1}$}

\section{Introducción}

En 1987, en su libro The Second Stage, Betty Friedan afirmaba "hoy el problema que no tiene nombre es cómo compaginar el trabajo, el amor, la casa y los niños". Con el transcurso del tiempo y en varias latitudes, este malabarismo — que abarca cada vez más el cuidado de las personas mayores dependientes y frágiles - ha adquirido denominaciones diversas.

Todas las personas necesitan de cuidado a lo largo de la vida. Si las necesidades universales que el término "cuidado" designa — con cierta ambigüedad - no se vieran satisfechas, la sociedad no podría reproducirse; de allí que algunos lo conciban como un bien público (Gornick y Meyers, 2009, pág. 6). Sin embargo, su cumplimiento ha sido considerado una responsabilidad eminentemente privada. Además, existen diferentes grupos afectados por la manera en que se provee el cuidado que no tienen una comunidad de intereses, ya que perciben los propios como desvinculados $\mathrm{o}$, incluso, contrapuestos.

Para convertir al cuidado en otro pilar de la protección social y de las políticas públicas en un marco de derechos (CEPAL, 2007, pág. 136) y para propiciar una constelación de intereses y la interacción entre diferentes actores afines a esas reivindicaciones, es esencial ahondar en una gama de

Gran parte de este capítulo se basa en Sojo (2011), pero incluye actualizaciones y complementos en varias áreas. 
fundamentos éticos y empíricos que subviertan las visiones convencionales en la materia. Dada la intersección entre familia, comunidad, Estado y mercado inherente a la provisión de cuidado, es necesario también apelar a las visiones de los ciudadanos: como los grupos sociales que enfrentan riesgos relativos a la capacidad de brindar cuidado son muy heterogéneos, esa visión es interesante por su virtual capacidad aglutinadora de diversos actores sociales que podrían reconocerse en las reivindicaciones y generar acuerdos movilizadores. En la línea del institucionalismo discursivo ${ }^{2}$ y a partir de ciertas características de la región y de experiencias internacionales eminentemente europeas y estadounidenses ${ }^{3}$, en este capítulo se procura sistematizar distintos fundamentos e interacciones de las políticas de cuidado de la infancia y de las personas mayores con el objeto de mostrar los beneficios de que el cuidado sea un marco para las políticas públicas, que aúne y sintonice esfuerzos dentro del piélago institucional que pueda corresponderle en los diversos países ${ }^{4}$. En este sentido, diverge de otros capítulos del libro enfocados en el análisis específico de políticas, ya que no se analizan o evalúan las políticas de cuidado puestas en marcha en la región en el último decenio ${ }^{5}$.

Las políticas públicas en el ámbito del cuidado implican nuevos equilibrios en las interrelaciones entre el Estado, el mercado y la familia, y tal vez apunten a muy diversos objetivos que, con el transcurso del tiempo,

Respecto del cambio institucional, el institucionalismo discursivo reconoce que las instituciones se reconceptualizan y transforman también debido a la acción de las ideas, tanto por el contenido sustantivo de estas como por el proceso interactivo del discurso. La coordinación política, la comunicación y la deliberación que subyacen a la acción pública tienen una dimensión discursiva (Schmidt, 2008 y 2009).

3 No debe entenderse que la mención positiva o negativa de diversas experiencias internacionales a lo largo del texto avala o rechaza de manera general las políticas sociales o de otro tipo instrumentadas por determinados países. Estas menciones son concretas y abordan aspectos particulares y específicos.

4 Cabe señalar varios recortes implícitos del análisis. Se centra en el fundamento del cuidado y tiene en perspectiva, sobre todo, la prestación misma de cuidado en términos privados o formales, y solo tangencialmente otros aspectos que también resultan cruciales e indispensables y que deben concatenarse con las políticas de cuidado; por ejemplo, los instrumentos que la tornan viable en el seno familiar o que abren opciones de conciliación laboral para las mujeres, que son las principales encargadas del cuidado. Entre ellos, pueden mencionarse las licencias posnatales, los mecanismos de conciliación entre el trabajo y la familia instrumentados por las empresas o mediante reglamentaciones del mercado laboral, y la sintonización de horarios entre el trabajo y los servicios formales de cuidado. Dentro de la gama de políticas, la Organización de Cooperación y Desarrollo Económicos (OCDE) ha señalado, por ejemplo, cómo las licencias posnatales pueden repercutir en el involucramiento en el cuidado dentro de las familias y, por ende, en la equidad de género (OCDE, 2012).

5 Los estudios sobre las políticas y necesidades de cuidado en América Latina experimentaron un auge en el último quinquenio. Véanse CEPAL (2013), Calderón Magaña (2013), Gascón y Redondo (2014), Aguirre y Ferrari (2014) y Rico y Robles (2016). También puede consultarse un sinnúmero de trabajos publicados por la División de Desarrollo Social y por la División de Asuntos de Género de la Comisión Económica para América Latina y el Caribe (CEPAL), que en general se enfocan en el plano nacional. 
podrían beneficiarse de una retroalimentación positiva ${ }^{6}$. Entre los posibles objetivos destacan los siguientes: dar un salto en el fortalecimiento de las destrezas y las capacidades infantiles mediante intervenciones tempranas que son críticas para el desarrollo cognitivo y pueden disminuir las desigualdades sociales; velar por el bienestar de las personas mayores vulnerables y dependientes mediante una gama de intervenciones que provean cuidado y fomenten su actividad y autonomía, y actúen contra su aislamiento social; potenciar las opciones vitales de los familiares encargados del cuidado; estrechar las brechas de oportunidades entre mujeres y hombres; contribuir a ampliar las posibilidades de empleo de las mujeres y así generar externalidades positivas para la creación de empleo y la capacidad productiva; disminuir la pobreza y la vulnerabilidad de los hogares ante este flagelo, fortaleciendo la capacidad de las mujeres de menores ingresos para buscar trabajo de mejor calidad; coadyuvar a lograr un rejuvenecimiento de la población que refleje el libre ejercicio del derecho a la maternidad y la paternidad de las personas mediante la eliminación de los obstáculos que impiden conciliar la vida familiar y laboral, de modo favorable para la sociedad; y favorecer la sostenibilidad del financiamiento de la protección social. El análisis presentado en este trabajo se estructura en torno a estos objetivos y sus interacciones.

Estas políticas resultan afines al desarrollo de los derechos económicos y sociales, derechos ciudadanos que se encarnan, entre varios otros, en los derechos de las mujeres, de los niños y de las personas mayores, y en el ejercicio de los derechos reproductivos de las mujeres y los hombres que, en conjunto, pueden presentar externalidades muy valiosas para el desarrollo económico de los países. De allí que sorprenda la miopía prevaleciente en las políticas públicas formuladas en la mayoría de los países de la región.

Según las prelaciones y su virtual incidencia práctica, pueden existir tensiones o conflictos entre los potenciales objetivos. Por ejemplo, si se hace hincapié en las externalidades futuras de una inversión actual en la niñez mirando a los niños como los ciudadanos del mañana, podría desvirtuarse el enfoque y restarse vigor a la importancia que reviste la calidad del presente que vive la infancia, es decir, a la infancia per se y al bienestar de los niños hoy y ahora, y a ellos como individuos contemporáneos de los adultos. Análogo sería el caso si se acentuara de forma unilateral la necesidad de elevar la fecundidad, sugiriendo la conveniencia de tener niños debido a que son el futuro de la sociedad, una suerte de bien común. Al hacer de la niñez un ícono respecto de otras funcionalidades, el enfoque adquiere una perspectiva instrumental respecto del mundo adulto, lo que termina eclipsando en parte a la infancia (Leira y Saraceno, 2008, pág. 9; Lister, 2008).

La distinción y la especificidad de estos objetivos interrelacionables se vieron favorecidas por la asesoría técnica que la autora del presente libro brindó al gobierno de la Presidenta Chinchilla Miranda en Costa Rica. 
Del mismo modo, enfatizar solo la lógica de los sujetos de cuidado puede ocultar la perspectiva de los cuidadores, que en general son mujeres, y de su problemática, que abarca, por ejemplo, la obligación de brindar cuidados que recae sobre ellas, las tensiones concomitantes y los menores recursos con que cuentan a lo largo del ciclo vital debido a las ubicuas asimetrías de género. En cuanto a los sujetos que brindan cuidados, cabe reflexionar sobre las circunstancias y condiciones en las que la prestación social de cuidados puede efectivamente contribuir a ampliar sus opciones vitales y su bienestar, lo que remite a numerosos aspectos conexos, como la necesidad y capacidad de generar empleo decente y de buena calidad.

Los énfasis y la precedencia de los objetivos dan lugar a constelaciones de políticas de cuidado que evolucionan con el transcurso del tiempo. Por ejemplo, incluso en los países nórdicos, la provisión de servicios de cuidado para infantes tuvo como primer fundamento la lucha contra la pobreza mediante el empleo femenino; luego, al ampliarse el empleo, se expandieron los servicios (Bonoli, 2007, pág. 8).

Como se postulará, precisamente velar por la calidad y la pertinencia de las prestaciones permite conservar los respectivos énfasis en función de los sujetos y encarar eventuales instrumentalizaciones (Plantenga y otros, 2008, pág. 42). De allí que la preocupación por la calidad de los servicios, así como su reglamentación y control resulten decisivos a la hora de renovar las políticas sociales.

Para tender un puente con la temática global del libro, el capítulo concluye con una reflexión acerca del financiamiento del cuidado desde la perspectiva de la protección social y del aseguramiento.

\title{
A. Algunas aristas del cuidado y de la interdependencia entre la familia, el Estado y el mercado en su provisión
}

\begin{abstract}
"Sumadas a la globalización y a los cambiantes balances de las economías mundiales, las dos fuerzas que han tenido mayor impacto en los Estados de bienestar y específicamente en las condiciones de sus contratos (sociales) intergeneracionales implícitos, a saber, el envejecimiento de la población y el incremento de la participación de la mujer en la fuerza laboral, tienen también un efecto en los contratos familiares intergeneracionales." Saraceno (2008a)
\end{abstract}

El cuidado proporciona tanto subsistencia como bienestar y desarrollo. Abarca la indispensable provisión cotidiana de bienestar físico, afectivo y 
emocional a lo largo de todo el ciclo vital de las personas. A ello puede agregarse que comprende la estimulación de los fundamentos cognitivos en la infancia y la búsqueda - en la medida de lo posible- de la conservación de las capacidades y la autodeterminación en el caso de las personas frágiles de edad avanzada. La manutención requiere producir y gestionar bienes, recursos, servicios y actividades que hagan viable la alimentación; velar por la salud e higiene personal; y experimentar procesos de desarrollo y de aprendizaje cognitivos y sociales. En el seno de la familia, estas tareas involucran simultaneidad de papeles y responsabilidades, espacios y ciclos que, para ser captados en su totalidad, exigen tomar en cuenta conceptos como los de dirección y gestión, no fácilmente traducibles en estimaciones de tiempo, intensidad o esfuerzo (Durán, 2003 y 2012)

La población dependiente no puede proveerse de manera autónoma las funciones de bienestar mencionadas, por lo que requiere de atención externa. El grado de dependencia varía según la edad del dependiente, su nivel de vulnerabilidad y su estado de salud. Durán distingue cinco categorías sociales principales del trabajo no remunerado realizado en el seno familiar: los niños, los enfermos, las personas de edad, los sobreocupados en la producción para el mercado y los autoconsumidores. En gran medida, las tres primeras comparten su calidad de "insolventes": no pueden pagar a precio de mercado el trabajo de asistencia y precisan que alguien - el Estado por medio de los servicios públicos, los familiares, los amigos, los voluntarios u otro grupo social- satisfaga estas necesidades. Por su parte, los "sobreocupados" venden su tiempo en el mercado y, cuando el precio diferencial de su ingreso es elevado respecto del precio del cuidado, pueden optar por comprarlo. La mayor parte de las personas de ingresos medios y bajos, sobre todo las mujeres, deben proveerse su propio cuidado y el de su familia, porque su nivel de salarios, la cantidad de trabajo que venden al mercado y otros componentes culturales no les permite adquirirlo. Según la misma autora, si las identidades de género sufrieran una transformación profunda, solo una categoría demandante de cuidados sería susceptible de una merma: quienes están exentos o liberados de su propio cuidado a raíz de dichas asimetrías, que generalmente son hombres (Durán, 2003 y 2012).

El cuidado puede proporcionarse de manera no remunerada por medio de familiares, delegarse de forma remunerada o gratuita en personas ajenas a la familia, o brindarse de manera formal mediante instituciones. Cuando se delega de forma remunerada o gratuita en personas o instituciones, ello no significa una simple sustitución o eliminación del trabajo o esfuerzo que antes estaba en juego: para que sea viable, se

Véase un análisis más profundo del concepto de cuidado en CEPAL, 2013, págs. 117-129. 
requieren diversas tareas de coordinación, de carácter organizativo y otras, que suelen estar a cargo de quien delega (Saraceno, 2011a). Estas tareas pueden ser más numerosas, ocupar lapsos más prolongados o resultar más difíciles de realizar cuanto menor sea la calidad de los servicios y de la infraestructura conexa, por ejemplo, de los medios de transporte, dados los mayores desplazamientos que la delegación puede entrañar. La delegación guarda un vínculo estrecho con la conciliación entre trabajo y familia, por ejemplo, respecto de la sintonía entre los horarios laborales y los horarios de los centros de cuidado, las continuidades o discontinuidades entre períodos posnatales y el acceso a servicios de cuidado.

Las necesidades de cuidado son irreductibles. Monetarizados o no, entran en juego enormes recursos y es falaz creer que su movilización es menor cuando se encaran eminentemente dentro de la familia (Esping-Andersen, 2009a). De allí la relevancia de medir la contribución del trabajo no remunerado a la economía ${ }^{8}$. Respecto de estas mediciones, se producen desajustes en la demanda y la oferta a escala social, así como tensiones personales y familiares que se traducen en situaciones de carencia o intensifican el volumen de trabajo de los colectivos que tienen menor capacidad social y política para lograr una redistribución del esfuerzo colectivo (Durán, 2003).

En un mundo globalizado, estos desajustes han dado lugar, entre otros fenómenos, al surgimiento de "cadenas globales de cuidado": a raíz de la creciente migración femenina, se transfieren tareas de cuidado de hogares de los países de origen a hogares de los países receptores, y así surgen "familias transnacionales", en que la maternidad se ejerce a distancia y se reasignan tareas de cuidado en las familias de origen'. Ello reviste vital importancia en América Latina y el Caribe, tanto por la fuerte emigración hacia países desarrollados, por ejemplo, España (Cerrutti y Maguid, 2010), como entre algunos países de la región (Arriagada y Todaro, 2011; Arriagada y Moreno, 2011). Aunque ha menguado a lo largo del tiempo, también cabe tener presente que en América Latina y el Caribe un mecanismo de ajuste vital entre la demanda y la oferta de cuidado aún es el servicio doméstico remunerado.

En América Latina, el empleo en el sector del cuidado representa entre un $5 \%$ y un $10 \%$ del empleo total, según el país ${ }^{10}$. En la última década,

8 Véanse, por ejemplo, las diversas contribuciones de María Ángeles Durán Heras en esta materia, entre las que destaca la obra publicada en 2012, donde se presenta un análisis minucioso. Véanse también García Díez (2012), y Durán Heras y Milosavjevic (2012).

9 En países como El Salvador y otras naciones de Centroamérica, se han vinculado a la formación de pandillas juveniles violentas, como las maras, las tensiones inherentes a la provisión de cuidados en un contexto migratorio, sea cuando la familia nuclear permanece fuera o cuando se disgrega, junto con otros procesos de adaptación y de discriminación en el país receptor y la falta de oportunidades para los jóvenes en el país de origen.

10 Se opta por considerar trabajadores remunerados del cuidado a aquellos que prestan servicios a otras personas dependientes para su supervivencia o desarrollo personal, cuando estos implican 
la proporción de ocupados en este sector se mantuvo relativamente estable. No existe una relación significativa entre el nivel de bienestar económico de los países o la participación laboral de las mujeres y la magnitud del empleo en el sector del cuidado. Las tres cuartas partes de los trabajadores de este ámbito pertenecen al servicio doméstico de los hogares, mientras que la cuarta parte restante se desempeña en otras áreas, como la educación y la salud. Las condiciones laborales de los trabajadores remunerados del sector del cuidado son muy heterogéneas. En su gran mayoría, las trabajadoras del servicio doméstico son asalariadas que se desempeñan en el sector privado, mientras que, en el caso del resto de los cuidadores, el sector público reviste una importancia significativa. Esta estructura ocupacional de los trabajadores del cuidado contrasta con la del resto de los ocupados, ámbito en que el trabajo independiente cobra mayor relevancia. Los trabajadores remunerados - en especial las trabajadoras del servicio doméstico- gozan de una menor protección social, trabajan en promedio menos horas semanales y cumplen más trabajo a tiempo parcial que el resto de los ocupados. Las brechas salariales por hora —ajustadas según las características de los trabajadoresmuestran una penalización considerable del servicio doméstico en la gran mayoría de los países. Las condiciones de los trabajadores del cuidado en el sector de la educación no evidencian un patrón general, mientras que los cuidadores de la salud gozan de una prima salarial en comparación con el resto de los ocupados de características similares (CEPAL, 2013).

En América Latina, incluso los estratos más pobres destinan recursos para contratar servicios de cuidado en el mercado, y resulta muy significativo que, como una proporción del gasto total de los hogares, el gasto de los hogares pobres se aproxime mucho al de los que no lo son. Es decir, que resalta la inelasticidad de este gasto como proporción del gasto total de los hogares, incluso entre los sectores más desposeídos de la población. Ello alerta sobre la irreductibilidad del cuidado, pues evidencia que todos los hogares, incluidos los pobres, adoptan estrategias que combinan el trabajo no remunerado de cuidado realizado dentro del hogar o por familiares, o el acceso a servicios públicos, con la contratación formal e informal de mano de obra remunerada (véase el gráfico VI.1) ${ }^{11}$.

Otro hallazgo significativo, que también se observa en el gráfico VI.1 para algunos países, remite a las urgencias en la materia que afectan a

una relación directa entre el cuidador y el cuidado (CEPAL, 2013, pág. 137).

11 Dependiendo de la disponibilidad y la desagregación de los datos de las encuestas de ingresos y gastos de algunos países latinoamericanos que permitieron un análisis comparativo, se contabilizaron como gastos en cuidado los servicios asociados a diversas actividades del empleo doméstico (por ejemplo, aseadores, cocineras y lavanderas), la atención de niñeras y cuidadoras, la educación preescolar, el cuidado domiciliario y no domiciliario de enfermos, los servicios de centros y hogares para personas de edad o con discapacidades, la gimnasia y terapia correctivas, y otros servicios de rehabilitación similares. 
las mujeres jefas de hogares: pese a sus menores ingresos y a su mayor vulnerabilidad, en el caso de los hogares a su cargo que son pobres, se destina a tal efecto una proporción de recursos igual a la de los hogares de jefatura masculina; $y$, en el caso de los hogares no pobres, el monto incluso sobrepasa el sufragado por los que tienen jefatura masculina. Ello muestra la imperiosa necesidad de contratar apoyos remunerados para realizar las tareas de cuidado.

\section{Gráfico VI.1}

Bolivia (Estado Plurinacional de), México, Nicaragua y Perú: gasto en cuidado como proporción del gasto total de los hogares y como monto promedio, hogares pobres y no pobres, por sexo del jefe de hogar, alrededor de $2005^{a}$

(En porcentajes y dólares PPA de 2005)

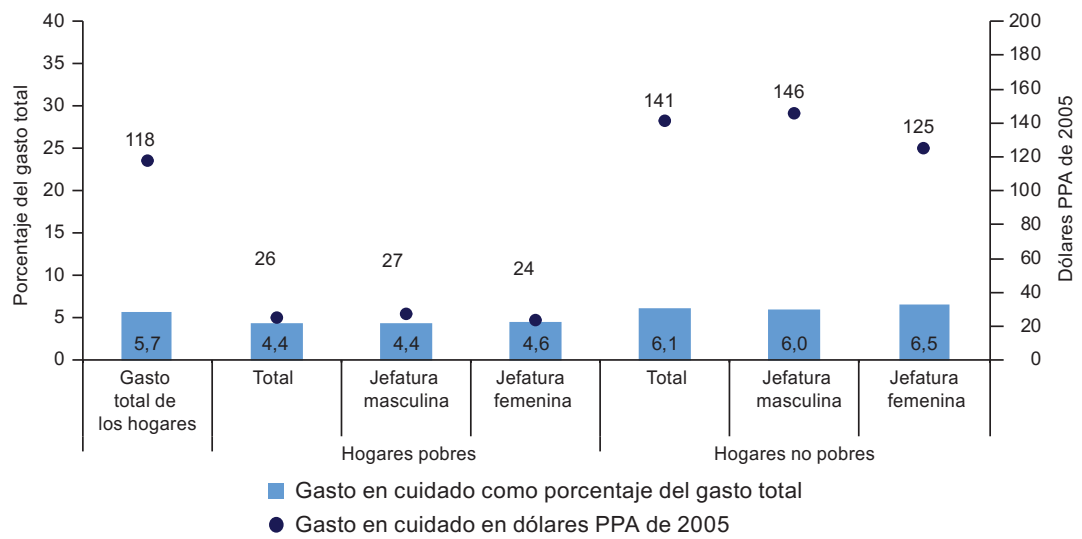

Fuente: Comisión Económica para América Latina y el Caribe (CEPAL), Panorama Social de América Latina 2012 (LC/G.2557-P), Santiago, 2013, sobre la base de tabulaciones especiales de las encuestas de ingresos y gastos de los respectivos países.

a Solo se tomaron en cuenta hogares que efectuaron gastos en materia de cuidado.

Por su parte, como es de esperar, la desigualdad de ingresos se expresa con claridad en la magnitud del gasto en cuidados en términos absolutos, que incide también en su calidad. Conforme aumenta el ingreso disponible, se incrementa el gasto para servicios de cuidado (véase el gráfico VI.2). La magnitud de la desigualdad varía de país a país.

Otras desigualdades del gasto de los hogares en cuidado remiten directamente a la temática de género, tanto por el lado de los ingresos, como de la capacidad y necesidad de contratar servicios de cuidado remunerados. Los hogares encabezados por mujeres gastan proporcionalmente más que los encabezados por hombres, aunque en términos absolutos los hogares encabezados por hombres, mayormente biparentales, gastan en promedio un 16\% más que aquellos con una mujer jefa de hogar, que en su mayoría son monoparentales (CEPAL, 2013). 


\section{Gráfico VI.2}

América Latina (14 países): gasto en cuidado como proporción del gasto total de los hogares y como monto promedio, por quintiles de ingreso per cápita de los hogares, alrededor de $2005^{a}$

(En porcentajes y dólares PPA de 2005)

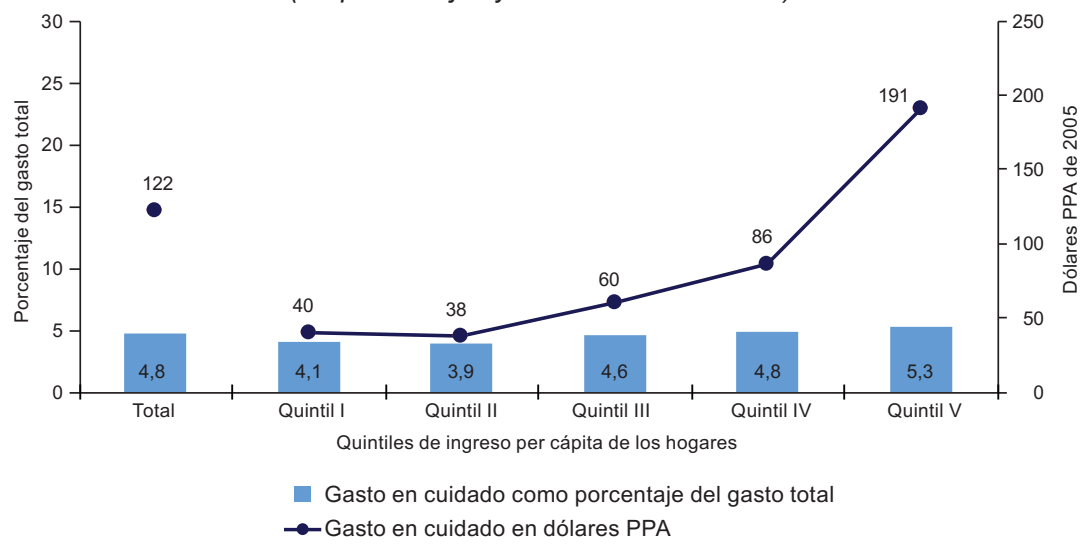

Fuente: Comisión Económica para América Latina y el Caribe (CEPAL), Panorama Social de América Latina 2012 (LC/G.2557-P), Santiago, 2013, sobre la base de tabulaciones especiales de las encuestas de ingresos y gastos de los respectivos países.

a Solo se tomaron en cuenta hogares que efectuaron gastos en materia de cuidado.

Resulta interesante analizar el gasto según la composición del hogar y las asimetrías de género que se expresan en las responsabilidades de cuidado. El patrón de hogares con y sin niños menores de 5 años muestra que las necesidades de los niños de esta franja etaria son cubiertas de manera sustancial por medio de proveedores no remunerados, sea la madre, otros parientes - en general las abuelas - o vecinas. Cuando la madre trabaja, se produce una clara inflexión: se gasta más en cuidado remunerado, en términos absolutos y como proporción del gasto (CEPAL, 2013, págs. 187 y 188). Por su especificidad, es importante indagar también en el cuidado de las personas mayores frágiles y dependientes. Como variable sustituta (proxy), se ha analizado el gasto en cuidado de los hogares con adultos de 75 años o más (véase el gráfico VI.3). A todas luces, los gastos en cuidado remunerado de los hogares con personas mayores son más elevados, tanto en términos absolutos como relativos. Si esta situación se contrasta con el cuidado de niños menores de 5 años, puede especularse que, en parte, tal vez se deba a que se cuenta con menores apoyos intergeneracionales e intrafamiliares, y a que la complejidad de los cuidados es mucho mayor debido a los cuadros de morbilidad y las discapacidades en juego, o también porque en la biografía familiar la persona mayor está en una etapa de transición: pasa de prestar esta solidaridad -implícita en el cuidado no remunerado a la infancia- a ser sujeto de cuidado. Sin embargo, cabe tomar un recaudo adicional: como se 
ha señalado, es habitual que las mujeres de edad avanzada deban asumir el papel de cuidadoras principales de sus esposos, lo que incluso puede acelerar su propia vulnerabilidad (Valenzuela, 2010, págs. 267 y 268).

\section{Gráfico VI.3}

América Latina (14 países): gasto en cuidado como proporción del gasto total de los hogares y como monto medio en el mes de referencia de cada encuesta según presencia de adultos de 75 años o más, alrededor de $2005^{a}$ (En porcentajes y dólares PPA de 2005)

A. En porcentajes del gasto total

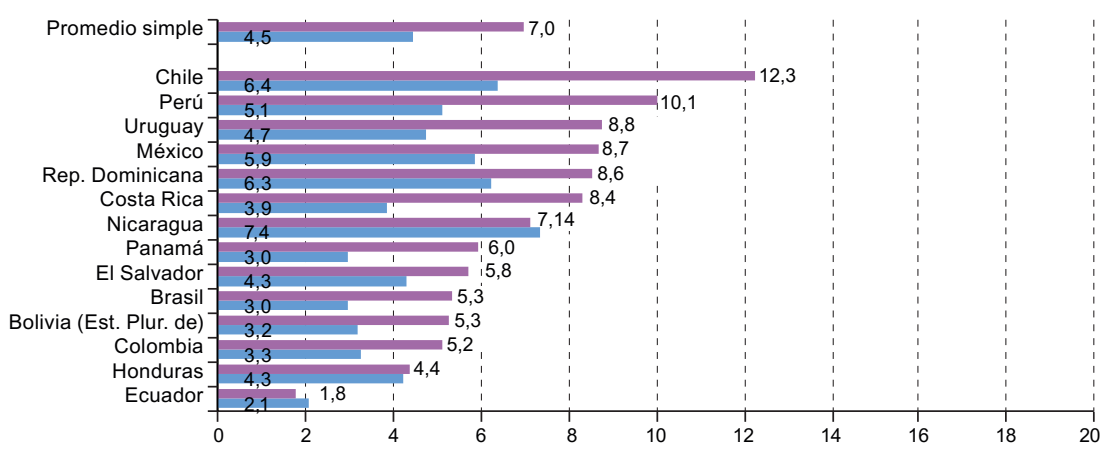

B. En dólares PPA de 2005

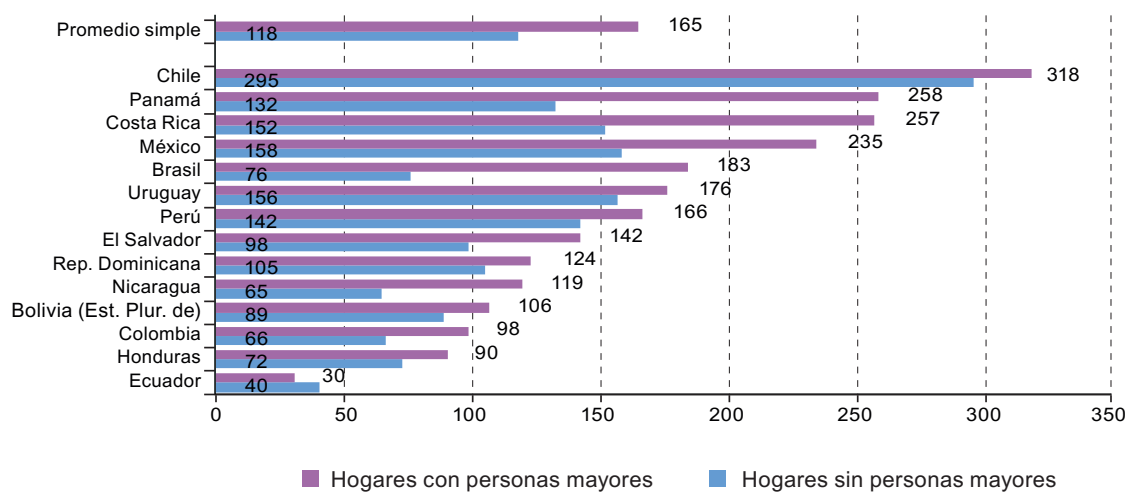

Fuente: Comisión Económica para América Latina y el Caribe (CEPAL), Panorama Social de América Latina 2012 (LC/G.2557-P), Santiago, 2013, sobre la base de tabulaciones especiales de las encuestas de ingresos y gastos de los respectivos países.

a Solo se tomaron en cuenta hogares que efectuaron gastos en materia de cuidado.

Respecto de la provisión privada o pública de cuidado, cabe recordar que el Estado, el mercado y la familia conforman un haz interdependiente, en cuyo marco se produce y se distribuye el bienestar de las personas. La comunidad también puede cumplir un papel complementario de las funciones familiares - mediante un intercambio de reciprocidades en el 
plano personal — o de las funciones públicas —en el caso de organizaciones voluntarias y filantrópicas-. Han proliferado tipologías sobre regímenes de bienestar cuyo potencial analítico y heurístico, y cuyo valor agregado a veces resultan cuestionables; en este campo, al igual que con toda categorización, la parsimonia puede erigirse como una virtud (Kohli y Albertini, 2008, pág. 39; Draibe y Riesco, 2006, pág. 43). Por ello, para entender la dinámica del cuidado nos atenemos a considerar tres procesos planteados originalmente por Esping-Andersen (1999), que son determinantes de la combinación entre la inserción laboral y la vida familiar ${ }^{12}$. Cuando el Estado garantiza a las personas derechos que son independientes de su participación en el mercado, este proceso se denomina "desmercantilización", ya que debilita los vínculos monetarios del bienestar. Por su parte, cuando el bienestar de los individuos depende sobre todo de los sistemas familiares de cuidado y de protección, se denomina "familismo". En las antípodas, los procesos de "desfamilismo" se refieren al grado en que merma la dependencia de las personas respecto de su familia, sea porque aumenta su capacidad de control de recursos económicos o porque se incrementa la oferta de servicios - por ejemplo, en el ámbito del cuidado - que independientes de las reciprocidades familiares o conyugales (Draibe y Riesco, 2006; Esping-Andersen y Myles, 2007).

La desmercantilización se expresa en sistemas de protección social, y en bienes y servicios de carácter público del ámbito de la salud, la educación, las pensiones y otros. En el caso de la protección social, implica un financiamiento solidario mediante sistemas contributivos o con cargo a impuestos generales ${ }^{13}$. Trascendiendo la perspectiva de que el cuidado es una responsabilidad estrictamente individual o familiar, considerar la provisión social de las tareas del ámbito del cuidado en tanto fuente de derechos sociales implica que los sistemas de protección social, educativos y de otra índole abarquen la economía del cuidado y la infraestructura de servicios concomitante para las diversas franjas etarias, lo que implica financiar, articular y regular una red de instancias públicas, privadas y mixtas que provean los servicios necesarios para atender la demanda de cuidado de la sociedad. Dado el carácter indispensable para la sociedad y la responsabilidad social, se requiere promover condiciones laborales equitativas para las mujeres y los hombres, que compatibilicen las actividades productivas con el derecho y con la obligación del cuidado, de la mano de políticas estatales y la responsabilidad social de las empresas, de cambios en la regulación de la esfera productiva y en la organización laboral, y de otras políticas públicas (CEPAL, 2007, pág. 126). En el

12 Desde tal perspectiva, es posible incluso considerar que el mercado y el Estado constituyen un injerto junto con determinados tipos de familia, que, a su vez, contribuyen a transformar en el largo plazo (Kohli y Albertini, 2008, pág. 39).

13 Como se ha señalado en otra oportunidad, la desmercantilización capta la perspectiva de derechos. Véanse más detalles acerca de los derechos económicos, sociales y culturales, y su vínculo con la cohesión y la protección sociales en CEPAL, 2007, págs. 28-32 y 129-132. 
diagrama VI.1 se condensa la combinación de la estructura doméstica con la arquitectura de los sistemas de protección social.

\section{Diagrama VI.1}

\section{Caracterización de los modelos de cuidado según la cobertura pública y el reparto de la carga doméstica}
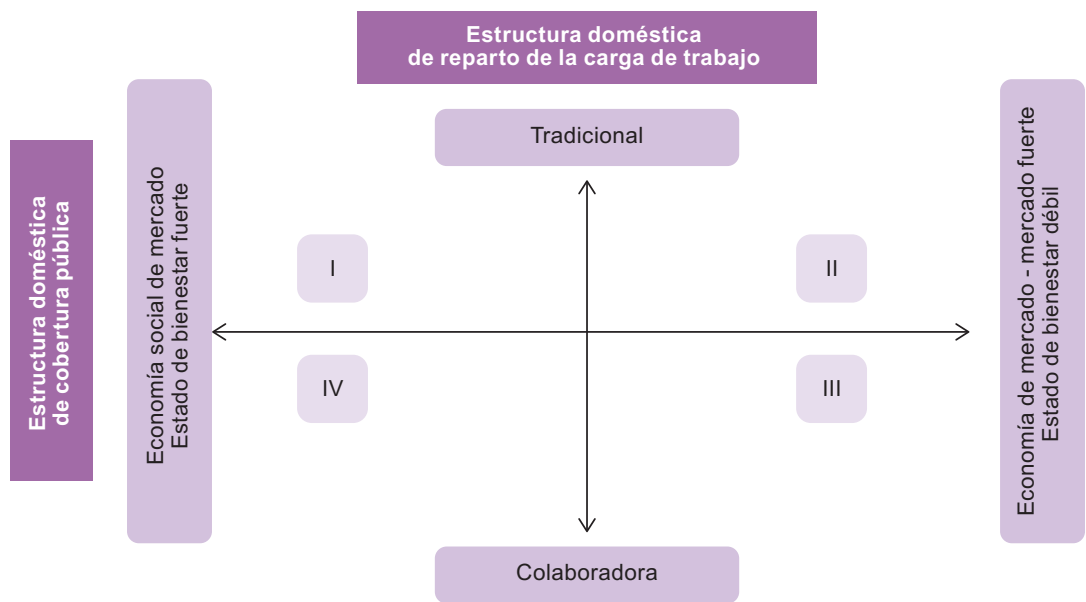

Fuente: S. García Díez, "Childcare in Europe. A reflection on the present economic approach", Documento de Trabajo, Nº 3/2012, Bilbao, Fundación BBVA, 2012.

Tras la división del trabajo social entre las familias y la sociedad, y tras la división del trabajo a escala familiar entre la obtención de ingresos y las tareas de cuidado, subyace un contrato de género implícito (Saraceno, 2008a, pág. 2). Asimismo, como la revolución en las relaciones de género y las transformaciones experimentadas por las familias no han ido de la mano de respuestas políticas adecuadas, la política social de corte "familista" paradójicamente se ha ido convirtiendo en un anatema para la formación de la familia: el descenso de la fecundidad y el incremento de personas adultas que no tienen niños - particularmente en el caso de las mujeres con mayores niveles de educación - se relacionan claramente con la ausencia de provisión de servicios de cuidado para niños y otros dependientes. En países como Italia y España la ausencia de estos servicios reprime el empleo femenino o la fecundidad, en especial entre las mujeres menos educadas, lo que origina desequilibrios sociales que combinan una tasa de fecundidad excepcionalmente baja con la merma del empleo femenino. Así, la imposibilidad de conciliar la maternidad con el empleo provoca una oposición entre la maternidad y la paternidad, por un lado, y el logro de empleo, autonomía económica y mayores ingresos, por el otro. En el plano social, ello se traduce en uno de dos escenarios subóptimos: un equilibrio con baja fecundidad y falta de niños o un equilibrio con bajos ingresos y acotado nivel de empleo (Esping-Andersen, 2009a y 2009b, págs. 80 y 81). 
Dado que la familia constituye una piedra angular de la sociedad, es un imperativo y un reto fundamental brindarle apoyo. A causa de la paradoja mencionada, la esencia de una política de familia eficaz consiste en maximizar las capacidades de las familias mediante procesos de "desfamilismo", particularmente en el ámbito del cuidado (EspingAndersen, 2009, págs. 9 y 81).

Las políticas públicas pueden poner el énfasis en dos áreas: realizar transferencias monetarias a quienes necesitan cuidados, ya sea directamente a ellos o a sus cuidadores, o proveer los respectivos servicios. Esto llama la atención sobre la necesidad de analizar las interrelaciones entre las transferencias monetarias y la provisión de los servicios (Daly y Lewis, 2000, pág. 296) y sobre la pertinencia de establecer normas y controles no solo para los servicios prestados por el sector público, sino también para los contratados con las transferencias.

A partir de la experiencia europea y más allá de las transferencias monetarias, se ha resaltado la importancia de la prestación de servicios y sus externalidades positivas respecto del empleo femenino, el alza de la fecundidad y la reducción de la pobreza (Fagnani y Math, 2008, pág. 74; Knijn y Ostner, 2008, pág. 99; Abrahamson, 2007, pág. 59). La Organización de Cooperación y Desarrollo Económicos (OCDE) ha reconocido este efecto, en función del cual propone mejorar las prestaciones de servicios de carácter universal (OCDE, 2012).

La complejidad del cuidado inhibe o dificulta la posibilidad de plantear y establecer de forma general y para diversos ámbitos del cuidado (en términos conceptuales y, sobre todo, en términos políticos) aquello que para las personas debe o puede resultar delegable o indelegable, sea de manera formal o informal. La frontera entre lo delegable y lo indelegable en esta materia es una línea móvil y dinámica relacionada con valores, tradiciones, asimetrías sociales como las de género, y circunstancias personales y familiares sometidas a distintos procesos de cambio y expresadas mediante diversas opciones y formas de vida. Pero con bastante certeza puede afirmarse que los costos asociados a los servicios restringen la capacidad privada para delegar y que, si la calidad de las opciones de provisión social del cuidado es buena, ello incentiva una mayor disposición a delegar en opciones que resultan deseables.

Sin embargo, ya sea en el marco de la familia o fuera de ella, el cuidado se define y se fundamenta en determinados tipos de relaciones y abarca dimensiones éticas de obligación y responsabilidad. En el seno de la familia, su carácter a la vez obligatorio y desinteresado le otorga una dimensión moral y emocional: no representa estrictamente una obligación jurídica establecida por la ley o sancionada por las normas relativas a los derechos - por ejemplo, de la infancia- o a la obligación de prestar 
asistencia o ayuda, o una mera obligación económica. Involucra también sentimientos y emociones que se expresan en el ámbito familiar, al tiempo que contribuye a construirlos y mantenerlos (Daly y Lewis, 2000) $)^{14 .}$

El derecho a una vida libre de violencia favorece el buen ejercicio del cuidado. En tal sentido, también se requiere promover relaciones familiares respetuosas entre todos los integrantes del núcleo familiar; desterrar el abuso y la violencia doméstica en sus diversas expresiones; y emprender iniciativas que propicien cambios culturales y la flexibilidad en cuanto a los papeles que cada uno debe cumplir en el hogar y que fomenten la conciencia acerca de la provisión del cuidado como un derecho y como un deber en el ámbito privado y social.

Pero en pro de reconocer las dimensiones sociales del cuidado, el discurso que subraya, entre otros aspectos, las dificultades de la conciliación entre la familia y el trabajo, los costos involucrados y la doble jornada laboral, corre el peligro de contribuir a desvanecer las dimensiones de afecto, placer, enriquecimiento personal, creatividad, aprendizaje de la inversión emocional y autoconocimiento que también entran en juego en el cuidado (Leira y Saraceno, 2008, págs. 8 y 9). Proveerlo tampoco llega a ser solo una mera obligación jurídica establecida por ley en términos de la obligación de prestar asistencia o ayuda, o una obligación económica. Incluso fuera del marco familiar, el cuidado está signado por la relación de servicio, de asistencia y de preocupación por los otros; además, se realiza cara a cara entre personas y genera lazos de proximidad (Batthyány, 2010).

Debido a que el cuidado involucra afecto y emociones, y a que contribuye a construirlas y mantenerlas, el perfil de estas políticas requiere tomar en cuenta las etapas de la vida y los lazos intergeneracionales. A la hora de reconocer y apoyar estas necesidades en una sociedad en acelerada transformación, cabe abordar precisamente algunos de estos aspectos en los modelos de prestación social del cuidado e incorporarlos a los criterios, parámetros y estándares relativos a la calidad de las prestaciones. La calidad resalta que los servicios públicos de cuidado representan políticas específicas e independientes que tienen como beneficiarios directos a los niños o a las personas mayores $u$ otros sujetos, y que no cumplen meramente una simple función secundaria respecto de otros objetivos, como la mejor inserción de la mujer en el mercado laboral, el aumento de la fecundidad o la reducción de la pobreza. En este sentido, una estrategia nacional efectiva de cuidado está llamada a ponderar una pluralidad de objetivos (Plantenga y otros, 2008, pág. 42).

No por formar parte de las políticas públicas, las relaciones de cuidado serán vistas como un mero deber o costo social o individual que desconoce

14 En ese artículo las autoras sistematizan la evolución de dicho concepto. 
su otra cara: el involucramiento emocional, la realización, el placer, la creatividad y el aprendizaje mutuo que van de su mano (Leira y Saraceno, 2008, pág. 9; Batthyány, 2010). Aunque los valores normativos relativos a las obligaciones y los sentimientos de afecto y reciprocidad pueden reforzarse mutuamente, cabe reconocer que no tienen la misma lógica ni operan en el mismo nivel. Por ende, alguien puede proveer cuidados en razón de un sentimiento de obligación normativa, aun cuando el afecto esté ausente y las relaciones personales sean malas (Saraceno, 2008a, pág. 12).

La ampliación del espacio social del cuidado no tiene como objetivo desplazar las labores hacia la sociedad, o menoscabar el efecto y la solidaridad interpersonal que están en juego. Las relaciones familiares y de afecto son indispensables y en muchas dimensiones el cuidado que se da en su marco es y será irreemplazable y fundamental para el desarrollo de las personas y de su psiquismo. Se trata precisamente de complementarlas, de apoyarlas y, por cierto, de intervenir en situaciones de abandono.

Se ha debatido acerca del impacto que las disposiciones públicas en el ámbito del cuidado pueden tener en la solidaridad intergeneracional dentro de las familias. La polémica se ha dirimido recurriendo al efecto del desplazamiento negativo (crowding-out) - hipótesis que presupone que los Estados de bienestar generosos suplantan la solidaridad intergeneracional privada que se vería debilitada- y en las antípodas, el efecto del desplazamiento positivo (crowding-in), que remite a una relación armoniosa $\mathrm{o}$, al menos, de confluencia y complementariedad con la solidaridad privada intergeneracional que mantendría su fortaleza. En la mayoría de los estudios europeos se demuestra un efecto favorable en cuanto a que las relaciones interfamiliares relacionadas con el apoyo y la solidaridad permanecen fuertes. Más bien parece modificarse o desplazarse la naturaleza del apoyo y de las normas que lo fundamentan - responsabilidad, reciprocidad, dependencia, independencia, interdependencia, intimidad, condicionalidad e incondicionalidad, entre otras-, lo que hace aflorar la relevancia de la calidad de las relaciones y de la reciprocidad en términos sociológicos, en el marco de diversos recursos y oportunidades disponibles y del monto de los servicios y las transferencias públicas orientados al cuidado (Saraceno, 2008a, págs. 10-14; Künemund, 2008, págs. 110-113; Sarasa y Billingsley, 2008, pág. 142; Keck, 2008; Grundy, 2010, pág. 6). Las políticas públicas que abordan estas dimensiones no tienen como objeto suplantar o sustituir las relaciones interpersonales de cuidado, sino buscar nuevos equilibrios de apoyo a las personas que reciben cuidados y a sus cuidadores, en el marco de diversas formas de corresponsabilidad que sustentan las políticas y que, ante la crisis del apoyo informal, procuran lograr la convergencia del apoyo formal e informal (Sojo, 2010). 
Dada la naturaleza del cuidado, la relación entre su provisión privada y pública debe analizarse como entretejida, como una combinación más que como una disyuntiva. Por eso se afirma que los límites entre el cuidado formal e informal en ningún caso son claros o fijos, sino que circundan un vasto territorio de cooperación, conflicto y negociación permanente, cuyos límites por naturaleza son cambiantes y disputados por razones ideológicas y políticas (Sipilä, Anttonen y Baldock, 2003, pág. 2).

En el caso de los niños, la madre y el padre -o solo uno de ellos en las familias uniparentales- combinan el cuidado formal e informal, que se complementan de acuerdo al costo de los servicios y su disponibilidad, a las características de la red informal de apoyo (abuelos, parientes, amigos y vecinos) y a la cantidad de niños (OCDE, 2012). En el caso de las personas de edad vulnerables, hay evidencias de mejora de las relaciones familiares y de relaciones más balanceadas cuando los cuidadores - eminentemente mujeres - se sienten apoyados y experimentan menos agobio ${ }^{15}$. Se observan relaciones inter e intrageneracionales más equilibradas; por ejemplo, relaciones caracterizadas por un mayor grado de negociación y equilibrio entre los potenciales cuidadores, así como vínculos intrafamiliares más fuertes.

En lo atingente al reparto de la carga de trabajo dentro de la familia, se ha comprobado que actualmente en Europa la estructura colaborativa tiene efectos favorables en la fecundidad. Por ejemplo, en los países nórdicos el involucramiento activo del padre en la crianza del primer hijo favorece claramente el nacimiento de un segundo (OCDE, 2012). En los países con mayor provisión pública destacan las menores desigualdades de género en el cuidado familiar, con mayor participación masculina (Keck, 2008, págs. 149, 158 y 164). Por ejemplo, en el caso de Suecia, donde las políticas públicas apuntalan fuertemente la conciliación entre familia y trabajo, y propician tasas de natalidad adecuadas y la participación de la mujer en el mercado laboral, en los estudios más recientes sobre las normas y expectativas asociadas a la maternidad y paternidad, se señala que se espera tanto una plena participación en el cuidado y educación de sus hijos (involved parenthood), como la realización de una actividad laboral remunerada por parte de hombres y mujeres; se afirma que la idea de una paternidad activa, en la que los varones asumen parte de las tareas de cuidado de los niños así como de otras tareas domésticas, ha alcanzado un estatus hegemónico, sin importar la clase social o la proveniencia cultural (García Díez, 2012). Por otra parte, en lo concerniente al cuidado de las personas de edad, experiencias como la de Dinamarca muestran que los daneses cuidan de los mayores vulnerables con una frecuencia inusual, a pesar de que el Estado provee una completa gama de servicios formales de cuidado (Esping-Andersen,

Véanse más detalles acerca de las personas cuidadoras en Costa Rica y aspectos relativos al agobio en UCR/CONAPAM (2008, págs. 92-97). 
2009a, pág. 163). Otros estudios permiten confirmar la integración de las responsabilidades públicas y familiares en Europa (OCDE, 2012).

Cabe reconocer que, cuando estos servicios son efectivos, la interdependencia, el afecto, las reciprocidades y la solidaridad de los grupos etarios de la sociedad ocurren de manera simultánea y consecutiva, y se plasman en una cadena de cuidado a lo largo de la vida de las personas ${ }^{16}$. Cuando las familias comprenden tres o, incluso, cuatro generaciones, las personas pueden ocupar al mismo tiempo las posiciones de padres, abuelos e hijos. Así, el cuidado fluye "hacia arriba" y "hacia abajo", por lo que tanto los más pequeños como las personas mayores frágiles son los principales beneficiarios, y las generaciones intermedias actúan como el principal proveedor (Leira y Saraceno, 2008, pág. 6).

Por consiguiente, en los términos de Saraceno, las relaciones intergeneracionales en la sociedad y la familia están en el corazón de la continuidad y del cambio de los sistemas sociales y familiares. Los regímenes de parentesco y los diferentes tipos de Estados de bienestar interactúan y moldean el contexto cultural, normativo y práctico en el cual se desarrollan las relaciones intergeneracionales. Por ello, los Estados de bienestar también pueden analizarse como un tipo de contrato público entre generaciones, que corre paralelo a los contratos intergeneracionales privados entre familias y parientes. Así, las políticas de bienestar en gran medida no solo encarnan obligaciones entre generaciones - por ejemplo, la escuela y los sistemas de pensiones - sino que regulan obligaciones dentro de generaciones en el seno de las familias, como en el caso de las medidas que conciernen a la maternidad, los permisos posnatales y los beneficios para los niños. Pensadas las políticas en estos términos, las dos fuerzas que más impacto han tenido en los contratos intergeneracionales implícitos en el Estado de bienestar son precisamente el envejecimiento de la población y la mayor inserción de la mujer en el mercado laboral (Saraceno, 2008a, págs. 2 y 3).

Debido a la interdependencia e interconexión entre las generaciones, resulta indispensable abordar en conjunto las políticas de cuidado relativas a la infancia y a las personas mayores (Hagestad, 2008). Por tanto, es oportuno actuar desde la política pública sobre algunos de los eslabones que atienden a las dos puntas de la vida, ya que en razón de la interdependencia de la cadena de cuidado se producen efectos recíprocos entre las redes de la infancia y de las personas mayores, que trascienden

16 El adjetivo "efectivo" se utiliza para explicar que estas redes tal vez sean inexistentes, por ejemplo en casos de abandono, o estén entreveradas con situaciones de abuso o violencia, dado que, dentro de la microfísica del poder, la proximidad en el seno de cualquier identidad social puede resultar cruenta, verse plagada de fisuras y abusos, y destrizar los lazos más íntimos de confianza y afecto (Sojo, 2011). 
los efectos directos que beneficiarán a ambos grupos etarios y a sus cuidadores en el seno familiar.

En los países desarrollados, de la sociedad industrial a la posindustrial, los riesgos sociales variaron de manera apreciable ${ }^{17}$. En la posguerra, el Estado de bienestar brindaba protección ante las carencias de ingreso en el mercado laboral, sea por enfermedad, invalidez, vejez o falta de empleo, mediante prestaciones otorgadas al hombre jefe de hogar y con una perspectiva de relaciones familiares estables. Pero tras la industrialización, la precariedad del empleo, el desempleo prolongado, la pobreza, el carácter monoparental de los hogares y la dificultad de conciliar el trabajo con la vida familiar se transformaron en riesgos sociales. Es interesante subrayar que en los países nórdicos el Estado de bienestar estuvo fundado, desde un principio, en condicionalidades y en el vínculo entre trabajo y bienestar, y que desde los años setenta las políticas públicas fueron precursoras, puesto que encararon el cuidado con una vocación universal. Estas naciones y algunas anglófonas fueron las primeras en ingresar a la era posindustrial, seguidas unos diez años después por otros países de Europa continental y, más tarde, por países del sur de Europa (Castles, 2009, pág. 10; Bonoli, 2007; Leira y Saraceno, 2008; Abrahamson, 2011).

Las políticas del cuidado tienen importantes dimensiones transversales, por lo que han de integrarse con las políticas educativas, las sanitarias y las relativas a las pensiones. Deben coordinarse con las políticas de empleo (conciliación), urbanismo y vivienda (accesos, ubicación de servicios, remodelación de viviendas), transporte (escolar, de personas con discapacidades), fiscales (desgravaciones por atención a dependientes, planes de pensiones, seguros de dependencia) y ocio (vacaciones, programaciones especiales). Dada la criticidad de las políticas orientadas a fomentar un envejecimiento sano o a lograr una mayor coordinación de los servicios de salud, es crucial el carácter de los sistemas de salud. El mercado de aseguramiento y de prestación de servicios de salud discrimina claramente a las personas mayores mediante precios y exclusiones; de allí, la relevancia de contar con sistemas universales y solidarios, y de encarar la transición epidemiológica con un fuerte énfasis también en políticas de prevención y rehabilitación. En la región, ello deviene más complejo debido a la transición epidemiológica polarizada de aquellos países que tienen sistemas de salud excluyentes y poco desarrollados (Sojo, 2010).

El desarrollo institucional de los sistemas de protección social y de los sistemas educativos a los que debe vincularse el cuidado en los diversos países de la región reviste tal grado de diversidad —al igual que las constelaciones de actores que inciden sobre las políticas públicas-

El término "posindustrial" se utiliza con el sentido propuesto por Ha-Joong Chang para describir una menor proporción de empleo industrial resultante de una mayor productividad del sector (Lane, Chang y Bhagwati, 2011). 
que resulta improcedente postular de manera general una morfología de la institucionalidad del cuidado y de sus engranajes. Por el carácter transversal del cuidado, esta institucionalidad puede operar al inicio sobre todo mediante interfaces asociadas con los sistemas de protección social y de educación, a fin de alcanzar de manera progresiva un perfil más singular por medio de servicios nuevos asociados, o conforme se redefinan servicios antiguos o sus objetivos adquieran más peso en las políticas sectoriales y tengan lugar cambios jurídicos concomitantes que le den mayor asidero y la protejan de los vaivenes políticos ${ }^{18}$. Puede afirmarse con certeza que es indispensable un fuerte asidero sectorial ${ }^{19}$.

Por último, pero no por ello menos importante, desde la región más desigual del planeta cabe resaltar que las reciprocidades asociadas a los vínculos verticales intergeneracionales privados entre familias y parientes - a lo largo del ciclo vital y de generaciones - cristaliza las desigualdades sociales y agrega nuevas inequidades que, en buena parte, son idiosincráticas y dependen de la biografía individual dentro del contexto social, en cuanto a los recursos disponibles interconectados y a la calidad, densidad e intensidad de los vínculos privados (Saraceno, 2008a, pág. 4; Kohli y Albertini, 2008, pág. 41; Sarasa y Billingsley, 2008, pág. 143). Al tornar la provisión y la calidad del cuidado menos dependientes de las desiguales posiciones sociales de las personas, las políticas públicas de cuidado pueden romper algunos círculos viciosos. Conforme su cobertura devino más amplia, más redistributivos han sido sus efectos en Europa (Sarasa y Billingsley, 2008, pág. 140).

\section{B. El cuidado desde la perspectiva de la equidad de género y sus conexidades con el bienestar}

Es pertinaz la eficacia del dispositivo de asimetría de género que escinde dos esferas - la pública y la privada- y adscribe a la mujer lo doméstico como esfera natural de actividades. La esfera privada se refiere a la reproducción de los seres humanos en términos individuales, y en el ámbito doméstico se realizan tareas educativas, procesos de socialización y funciones reproductoras materiales. Pero conforme a este dispositivo, en términos simbólicos lo privado y lo doméstico se perciben como lugares privilegiados de la individualidad y de lo personal, en contraposición a lo público, entendido como terreno de la política. Se trata de una contraposición eficaz que valora lo público como resultado de las interacciones sociales, mientras que aísla la domesticidad de la política rodeándola de un halo de

18 Sin brindar aún una respuesta clara, Midaglia ha formulado una pregunta pertinente acerca de la necesidad de diferenciar analítica, política e institucionalmente qué prestaciones deben formar parte del cuidado y cuáles pueden contribuir a él sin constituir prestaciones exclusivas de ese ámbito (véase Rico, 2011, pág. 119).

19 Cabe extraer enseñanzas de las lecciones negativas que dejaron las políticas destinadas a luchar contra la pobreza desvinculadas de los aspectos sectoriales (Sojo, 2007). 
naturalidad y atribuye un misticismo a presuntas características femeninas que serían también de orden natural (Sojo, 1985).

A pesar de todos los avances en los derechos y la situación de las mujeres, en la mayoría de las latitudes diversos marcos políticos siguen convirtiendo la aptitud biológica de la maternidad en una fuente de asimetrías de género, y la mistificación se amplía al ámbito del cuidado. Este es realizado por el colectivo de mujeres sin remuneración y pese a ser un bien esencial, que, al ser remunerado, supone un elevado costo económico que pocas unidades familiares pueden asumir, goza en general de un escaso reconocimiento social (Díaz Fernández y Llorente Marrón, 2011; Soria Batista y otros, 2008). Por ello, los orígenes del término "cuidado" se remontan a la conceptualización de la condición de las mujeres y derivaron recientemente en el análisis del Estado de bienestar y de la institucionalidad que rige la organización sectorial del cuidado y del tipo de políticas subyacentes (Daly y Lewis, 2000, pág. 286).

En muchos países, las mujeres se han incorporado al empleo sin que los hombres hayan asumido su parte en el desempeño de las labores domésticas y las funciones de cuidado, y sin un adecuado apoyo social en esta materia. Como el tiempo dedicado al trabajo remunerado limita seriamente la oferta de cuidado, ante la ausencia de cambios se genera una situación polarizada: algunas mujeres asumen el trabajo doméstico y las tareas de cuidado casi en solitario e, incluso, deben retirarse del empleo para desempeñar estas tareas, mientras que otro grupo renuncia a la maternidad y contribuye así al descalabro de los indicadores de fecundidad, tal como se observa en Europa (Díaz Fernández y Llorente Marrón, 2011), y otras adoptan una postura intermedia y terminan afrontando el malabarismo al que hizo alusión Friedan (1987).

Ante la mengua de la hegemonía del proveedor masculino, la crisis del papel convencional del ama de casa (housewifery) y las veloces transformaciones de las estructuras familiares, los países tal vez deban hacer frente en mayor o menor grado a una crisis en este ámbito. En las sociedades posindustriales, la igualdad de género requiere cimentar una nueva arquitectura del bienestar donde las mujeres ocupen un lugar protagónico, lo que implica un nuevo equilibrio entre los hogares y la economía que va de la mano del auge de la economía de servicios (Esping-Andersen, 2002, págs. 68 y 69) y del apoyo público en esta materia. A continuación, se describe el contexto en que ello ocurre en la región, donde consolidar un Estado de bienestar constituye todavía una asignatura pendiente en varios países y en muchas esferas. Es posible que la búsqueda de nuevos equilibrios en las interrelaciones entre el Estado, el mercado y la familia se beneficie de la retroalimentación de los diversos objetivos que pueden tener las políticas públicas en el ámbito del cuidado. 


\section{Los radicales cambios de las estructuras familiares en la región}

La evolución de la carga de cuidado y de su estructura y de la capacidad de atenderla guarda un nexo estrecho con la dinámica de las familias. En la actualidad, hay menos familias extensas; las nucleares se han reducido; han disminuido las nucleares biparentales con hijos; y crecieron las monoparentales a cargo de mujeres, así como los hogares no familiares. En un mayor número de familias, el padre y la madre están insertos en el mercado laboral. Una menor cantidad de dependientes reduce la carga del cuidado, pero también disminuyen los adultos a cargo (Arriagada, 2007). Debido a la evolución demográfica, la mayoría de las familias transitan la etapa de expansión y consolidación, es decir que ya no tendrán más hijos.

En los países más diversos, la carga de cuidado en el seno de los hogares continúa eminentemente en manos de las mujeres (véase el gráfico VI.4). Aunque de manera rudimentaria — sobre todo si se toman en cuenta las prevenciones de Durán y las actuales características de estos instrumentos-, las encuestas sobre el uso del tiempo permiten captar ciertas dimensiones. En términos económicos y de cuidado, la etapa con presencia de hijos dependientes menores de 18 años es compleja, como también aquella con personas mayores dependientes y frágiles.

\section{Gráfico VI.4}

Ecuador, Guatemala, México y Uruguay: horas diarias de trabajo no remunerado, por sexo y tipo de familia

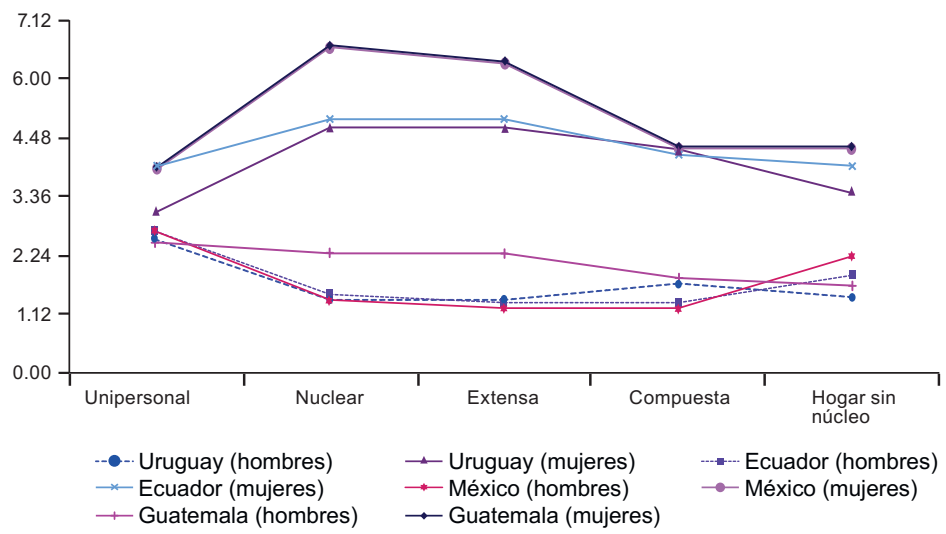

Fuente: A. Espejo, F. Filgueira y M. N. Rico, "Familias latinoamericanas: organización del trabajo no remunerado y de cuidado", Documentos de Proyectos (LC/W.354), Santiago, Comisión Económica para América Latina y el Caribe (CEPAL), 2010.

Nota: Las encuestas de hogares utilizadas son las de México (2002), Guatemala (2006), el Ecuador (2007) y el Uruguay (2007). 
Como unidad de análisis y variable sustituta, no debe confundirse "hogar" con "familia". En el ámbito que se aborda en este trabajo no hay total correspondencia, ya que las responsabilidades y obligaciones familiares pueden estar en manos de miembros que no comparten el hogar (Jelin, 2007, pág. 96; Durán Heras, 2012; Saraceno, 2008b), lo que precisamente forma parte de las cadenas de solidaridad intergeneracionales. Pero como la convivencia cotidiana facilita la satisfacción del cuidado, la disminución del número de miembros convivientes y la mayor participación de la mujer en el mercado laboral evidencian una mayor concentración de estas tareas y una compresión del tiempo disponible para efectuarlas en la esfera privada. Esta tarea resulta compleja debido a las singularidades de la población infantil y de las personas de edad frágiles y vulnerables. Si se toma prestada la terminología de Durán, podría afirmarse que la mayor inserción laboral de las mujeres trae aparejado que algunas pueden optar por comprar trabajo de atención, lo que aumenta la necesidad de autoconsumo de trabajo en familias con menos integrantes e incrementa las presiones hacia la conciliación. Debido al menor tamaño de las familias y al mayor número de personas que viven solas, se dificulta la situación de algunas personas mayores vulnerables.

\section{Los cambios de la fecundidad, ¿revelarán maternidades y paternidades constreñidas?}

Si se toman en consideración las trayectorias vitales, el vínculo entre la participación laboral de la mujer y la fecundidad resulta ser una variable determinada por el balance entre el trabajo y la familia, que tiene una connotación de género, pues las mujeres lo enfrentan como una disyuntiva. Si no se apoya la conciliación entre estas esferas, la fecundidad decrece, al tiempo que se acrecientan sus costos de oportunidad. Los países con políticas de igualdad de género que han impulsado medidas de conciliación y de apoyo a las familias exhiben tasas de fecundidad moderadamente bajas o más altas, y una mayor participación femenina en el mercado laboral. A escala social, ello propicia el crecimiento económico y así, mediante impuestos y contribuciones, las mujeres contribuyen a financiar la protección social (McDonald, 2010). Hay otros elementos de la política pública que inciden en las tasas de fecundidad. En algunos países de la OCDE, como la República de Corea y el Japón, cuando los costos de la educación están en gran parte a cargo de las familias, ello también parece impedir a las personas tener el número de hijos deseados (OCDE, 2012).

Algunas encuestas europeas recientes muestran que las mujeres disminuyen o interrumpen su actividad laboral al tener hijos, signo claro de que las sociedades aún no encuentran formas para conciliar la vida laboral y familiar, y de las resistencias sociales a los cambios genuinos ocurridos en los roles de género al incrementarse la inserción de las mujeres en el mercado 
laboral o al modificarse las estructuras familiares. Las políticas de familia no han promovido adecuadamente el trabajo de las mujeres y la conciliación. A ello se suma la complejidad de que las responsabilidades domésticas son también una esfera de afecto y cuidado. Mientras que esta compatibilidad debería estar organizada a escala social, la coordinación de ambas esferas aún suele darse a nivel individual, sobre todo de las mujeres. Los países donde los horarios sociales están mejor estructurados, en particular los países nórdicos, y donde los sistemas públicos contribuyen a la conciliación mediante el cuidado de los niños son aquellos en los que los encuestados expresan tener menores dificultades. También se revela la importancia de que las empresas presten más atención a dispositivos flexibles que proporcionen a los trabajadores cierta autonomía para compatibilizar estas esferas y demuestren sensibilidad ante el deseo de conciliar la vida laboral y la vida familiar (Davoine y Meda, 2008; OCDE, 2012).

Por tanto, incluso en los países desarrollados la miopía respecto de las tensiones entre trabajo y familia ha acarreado serios problemas. Las dificultades para conciliar estos ámbitos en forma armónica llevan a las mujeres a sacrificar oportunidades laborales, o a que las personas pospongan tener hijos, tengan menos de los que desearían o renuncien a tenerlos. Para contrarrestar la disminución del número de personas en edad activa, debe impulsarse el empleo de las mujeres y eliminar las barreras que obstaculizan su inserción en el mercado laboral, en especial respecto del cuidado de la infancia. Las políticas de países como Suecia - que propiciaron que tanto las madres como los padres puedan mantener relaciones laborales - lograron elevar las tasas de empleo y de natalidad (Adema, Huerta y Queisser, 2010).

$\mathrm{Si}$ se desea profundizar en el efecto que el género ejerce en la fecundidad, es importante conocer el grado de implicación de las mujeres en la actividad económica, los roles de los hombres y las mujeres en el hogar y en la educación de los hijos, y los espacios de decisión en el seno de la familia, por ejemplo, respecto de la gestión de los ingresos. En Europa, las encuestas sobre generaciones y género constituyen encuestas de género de última generación, ya que permiten indagar el vínculo entre los comportamientos demográficos y las relaciones de género: abarcan representaciones acerca de la familia, así como información sobre los roles en las tareas familiares y el mercado laboral, y sobre la autonomía económica, la toma de decisiones y la gestión de los recursos (Zavala de Cosío, 2010). Por ejemplo, al analizar la probabilidad de nacimiento del primer hijo, se ha visto que cuanto mayor es la igualdad en la división de las tareas domésticas y la gestión de los ingresos económicos, menor es la fecundidad, lo que se atribuye a la mayor importancia que revisten los costos indirectos asociados con que las mujeres trabajen fuera del hogar o con que los hombres se involucren en la vida familiar (Zavala de Cosío, 2010). 
Los análisis de los países de la OCDE permiten concluir que, a diferencia de hace 30 años, los países con las tasas de empleo femenino más elevadas también son los de mayor fecundidad, lo que demuestra que las políticas de conciliación entre trabajo y responsabilidades de cuidado resultan eficaces para cerrar la brecha entre la fecundidad deseada y efectiva. Estas abarcan una gama diversa en cuanto al carácter de las prestaciones, la continuidad a lo largo del ciclo de vida de los niños, y su estabilidad y permanencia. A tal efecto, las transferencias monetarias tienen una repercusión más modesta, a menos que sean de mayor monto. Los permisos posnatales para los hombres parecen afectar la ocurrencia de los nacimientos, pero dependen de las tasas de reemplazo de los ingresos normales. La amplia cobertura y el acceso a establecimientos formales de buena calidad para el cuidado de los niños parecen ser los factores cruciales de las diferentes tasas de natalidad registradas en los países, al igual que la permanencia de las políticas. Otros factores destacados son la flexibilidad en los horarios laborales y las posibilidades de adquirir servicios en razón de los ingresos femeninos (OCDE, 2012). De allí que, respecto del tamaño de las familias, tales aspectos sean más explicativos que los niveles de educación, que influyen en la posposición de los nacimientos. En circunstancias de conciliación favorables, las mujeres más educadas "recuperan" a mayor edad el diferencial de fecundidad (OCDE, 2012).

Aunque la región no cuenta con encuestas demográficas específicas que den cuenta de esta situación, las dificultades para conciliar el trabajo y la familia pueden coartar las decisiones relativas a la fecundidad. Tal como se plantea respecto de Costa Rica, el imperativo de la maternidad temprana claramente se ha transformado y las cohortes más jóvenes la posponen. Conforme aumenta la proporción de mujeres entre 25 y 29 años que no han tenido hijos, se pone sobre el tapete si ello puede traducirse en una tendencia a no tener hijos, por una decisión voluntaria o debido a un decrecimiento de la fecundidad relacionado con la edad. Esta proporción claramente es más alta entre las mujeres con estudios superiores. Más allá de los profundos cambios culturales y normativos relacionados con la maternidad que ello esté mostrando, surge la pregunta: ¿cómo influyen en estas decisiones las restricciones económicas, la percepción de una creciente inseguridad económica o de una mayor inestabilidad de las relaciones de pareja, y las oportunidades laborales que compiten con la maternidad (Rosero-Bixby, Castro-Martín y Martín-García, 2009).

En lo concerniente al efecto que los ciclos económicos ejercen en la fecundidad, en un estudio de 18 países de América Latina que abarcó tres décadas se demostró que durante períodos recesivos las tasas de fecundidad fueron más bajas o que la maternidad se pospuso, mientras que los períodos de crecimiento resultaron favorables, sobre todo para las mujeres con mayor educación. El nivel educativo de las mujeres demostró 
tener un papel significativo y una asociación negativa tanto respecto del primer nacimiento como del segundo, lo que tal vez evidencie las limitadas opciones disponibles para el cuidado de los niños y los costos asociados, al igual que las condiciones adversas para su inserción en el mercado laboral relacionadas con la maternidad, que conducen a su posposición. Por su parte, los períodos de auge económico tienen un efecto positivo en la fecundidad, tanto entre quienes gozan de un mayor nivel educativo como entre quienes tienen un menor nivel de formación, aunque en el caso de las mujeres con más educación (nivel postsecundario) no se observa este efecto respecto del primer nacimiento. Entre las mujeres más educadas, los coeficientes relativos al segundo y tercer nacimiento son positivos y significativos. Si se tiene en cuenta la distribución muy inequitativa de los frutos del desarrollo en América Latina, no resulta sorpresivo que la fecundidad se vea afectada también de manera desigual (Adsera y Menéndez, 2011): una prueba más de la ubicuidad de este fenómeno en la región. A continuación, se exponen algunas conexidades entre las cuestiones de género y el bienestar familiar que hacen visible la necesidad de encarar el cuidado.

\section{Empleo femenino, asimetrías de género e incidencia de la pobreza}

En los países de la OCDE, la vulnerabilidad de las familias se asocia con la incapacidad de conciliar el empleo con la maternidad y la paternidad (OCDE, 2012). En nuestra región, cuando las mujeres trabajan es aún más difícil equilibrar la participación en el mercado laboral con los compromisos familiares. Entre otros aspectos, ello se refleja en una menor disposición para ingresar al mercado laboral, sobre todo entre las mujeres con baja escolaridad. La mujer tiene mayor representación en el sector informal, lo que pone de manifiesto que la conciliación es un problema al que se hace frente con una inserción precaria y flexible. Es incluso más grave cuando los hogares están a cargo exclusivamente de mujeres, tendencia que ha aumentado en algunos países y que es causal de pobreza. Para una gran parte de las mujeres pobres y de los sectores medios, los malabares se traducen en una gran escasez de tiempo y ausencia de espacios de recreación, o bien las mujeres se ven forzadas a desaprovechar sus logros educativos y a renunciar a oportunidades laborales o profesionales para poder llevar a cabo estas labores. Cuando cuentan con servicios de cuidado solo quienes pueden solventarlos, se refuerzan las desigualdades sociales en circunstancias en que la calidad de estos servicios tiene un estrecho vínculo con su costo.

La miopía impide reconocer cuán auspiciosa resulta la inserción laboral de las mujeres, tanto para ellas mismas como para la sociedad en general. La posibilidad de tener ingresos propios constituye una base crucial para la autonomía personal y para avanzar hacia una mayor equidad de género. Cuando ellas se integran al mercado laboral, la pobreza de los hogares y de la 
infancia experimenta una merma notable que varía según el tipo de inserción laboral. Lamentablemente, en el mercado laboral aún prevalecen algunas formas de discriminación, por ejemplo, cuando las mujeres perciben menores ingresos o pueden transitar carreras laborales dispares pese a tener niveles de educación y experiencia análogos o superiores a los de los hombres. Aunque en las últimas dos décadas las brechas de ingreso por género se contrajeron sobre todo en los estratos más jóvenes, persiste una gran inequidad que no se condice con los logros educativos femeninos.

La falta de ingresos propios o de autonomía económica constituye un indicador destacado para caracterizar las desigualdades de género. La marcada merma de la proporción de mujeres sin ingresos propios en la última década — que en 2002 alcanzaba el 42\%, mientras que la de los hombres llegaba al 15\% - se debe en particular a su mayor incorporación al mercado laboral y a que suelen ser las beneficiarias directas de programas de transferencias monetarias tendientes a superar la pobreza. La posibilidad de que ellas gocen de independencia y autonomía económica está determinada fundamentalmente por sus posibilidades de acceder a un trabajo decente y por el cierre de las brechas de género que caracterizan el mercado de trabajo en términos de tasas de participación, desempleo y ocupación; nivel de ingresos; y acceso a jubilaciones y pensiones (CEPAL, 2016, pág. 27).

Los cambios recientes han sido significativos, pero persisten desigualdades muy marcadas. La mayor presencia femenina en el mercado laboral, medida tanto por la tasa de participación laboral como por el índice de empleo, es una de las modificaciones más relevantes. Entre 2002 y 2012 se acortaron las brechas de participación y de empleo: en 2002 la tasa media ponderada de participación femenina de 18 países de América Latina equivalía al 63\% de la tasa masculina y en 2012 se elevó al 67\%. A su vez, la tasa de empleo de las mujeres, que en 2002 equivalía al $61 \%$ de la masculina, en 2012 se elevó al 65\% (CEPAL, 2014). Sin embargo, la brecha de participación entre hombres y mujeres continúa siendo muy significativa (CEPAL, 2014, pág. 176).

Por otra parte, en todos los países analizados las remuneraciones mensuales medias de las mujeres son inferiores a las de los hombres, al igual que en las distintas categorías ocupacionales. Las brechas exhiben una variación notoria entre los países: mientras que en el Estado Plurinacional de Bolivia y el Perú el ingreso mensual medio de los hombres supera el de las mujeres en más de un 50\%, en El Salvador, Honduras y Panamá esta diferencia es inferior al 10\% (CEPAL, 2014, pág. 193).

El aumento de las tasas de participación y empleo estuvo acompañado de un incremento significativo de su aporte al volumen total de ingresos de sus hogares, que en muchos casos les permite no caer en la pobreza o salir de esa situación. Se ha calculado que el aporte de las 
mujeres a la ampliación de la clase media varía, según los países de la región, entre el 3\% y el 9\%, siendo el efecto mayor en los rangos medio y bajo de los sectores medios (Arriagada y Sojo, 2012).

En el Panorama Social de América Latina 2014 se simularon los niveles de desigualdad de ingresos y de pobreza que se alcanzarían en 18 países de la región si se cerrara la brecha de participación y de ingresos entre los hombres y las mujeres. Si se desvaneciera esta diferencia, el ingreso medio de los hogares aumentaría entre el 3\% y el $4 \%$ en la Argentina, el Brasil, Colombia, México y el Uruguay, mientras que superaría el 10\% en El Salvador, Honduras, Nicaragua y el Perú. Los países donde la brecha es mayor son los que obtendrían las mayores ganancias en términos de ingresos medios. Además, la nivelación contraería la desigualdad entre 1 y 4 puntos porcentuales según el coeficiente de Gini (CEPAL, 2014, pág. 203).

Por su parte, si se eliminara la brecha de ingresos entre hombres y mujeres, la pobreza se reduciría sustancialmente en países como el Estado Plurinacional de Bolivia (menos 14 puntos porcentuales); Colombia (menos 9 puntos porcentuales); y el Ecuador, Nicaragua y el Perú (menos 8 puntos porcentuales). Como en estos países un porcentaje muy alto de las mujeres están ocupadas pero sin remuneración, los cambios resultan muy significativos cuando se presupone que recibirían un ingreso similar al que perciben los hombres con el mismo nivel educativo y experiencia laboral. En ese caso, el coeficiente de Gini bajaría entre 2 y 9 puntos porcentuales (CEPAL, 2014, págs. 205 y 206).

El hecho de que las familias con dependientes menores sufran más pobreza (Sojo, 2011) evidencia la necesidad de contar con políticas conciliatorias entre el mundo laboral y familiar, y políticas de cuidado. Es crucial concatenar los diferentes objetivos del cuidado, así como tener en mente su importancia para la inserción de las mujeres en el mercado laboral y velar por la continuidad de la cadena de apoyo a la infancia, sin dejar de lado a las personas mayores dependientes.

La experiencia europea muestra que las discontinuidades entre el momento en que termina el permiso por paternidad o maternidad y da inicio el período de apoyo para el cuidado infantil representan un serio obstáculo para la conciliación entre la vida laboral y familiar (Adema, Huerta y Queisser, 2010) ${ }^{20}$.

20 Por ejemplo, en Alemania, país caracterizado por una muy baja cobertura de la atención preescolar y una tasa de natalidad muy baja, una vez que el niño ha cumplido el primer año de vida, se interrumpen las transferencias estatales a los hogares, que tienen que buscar una respuesta económica a la nueva situación. A partir de este momento son las familias quienes deben afrontar la situación con sus propios recursos, por lo que los hogares experimentan una clara reducción de los ingresos disponibles que afecta su nivel de consumo. Una posible solución es que la madre decida prolongar la baja por maternidad hasta que el niño cumpla los tres años, período que no se financia mediante ayudas públicas, salvo en raras ocasiones (García Díez, 2012). 


\section{Otra arista de la transición demográfica y su interrelación con el género y el cuidado: el financiamiento sostenible de la educación y de la protección social}

Dependiendo de los avances específicos en la esperanza de vida y las trayectorias en materia de fecundidad, los países de la región se sitúan en diferentes etapas de la transición demográfica. Vista como un todo, la transición demográfica de la región ha sido la más acelerada del planeta. Entre 2005 y 2015, los menores de 15 años disminuyeron en términos absolutos y aumentaron las edades centrales, así como, aunque en menor cuantía, los mayores de 60 años. Entre 2035 y 2045, todos los grupos quinquenales menores de 60 años sufrirán una merma absoluta, mientras que los mayores de 60 años aumentarán notablemente. Para entonces, Cuba será el único país latinoamericano que experimentará una contracción de todos los grupos etarios. Según las proyecciones, se extenderá la esperanza de vida, decrecerá la población joven, y habrá más enfermos crónicos y una mayor proporción de mujeres entre las personas mayores (CEPAL, 2009). Así se irán modificando las necesidades de cuidado de los diferentes grupos etarios (véase el gráfico VI.5).

Los países con menores presiones de crecimiento de la infancia tendrán la posibilidad de mejorar la calidad del sistema educativo y saldar la gran deuda pendiente en materia de cobertura preescolar si reconocen la necesidad de ampliar la provisión social de las labores de cuidado. En esta etapa en que crece la población adulta - con la capacidad de insertarse en el mercado laboral y de contribuir al financiamiento solidario de las labores de cuidado dentro de un sistema de protección social - y en que las presiones del envejecimiento aún no son desmesuradas, pueden prepararse mejor para encarar las crecientes necesidades que tendrán las personas mayores vulnerables. Las ventanas de oportunidad (el llamado bono demográfico) pueden aprovecharse para actuar en el campo del cuidado e incidir en las trayectorias demográficas futuras a fin de impedir un envejecimiento excesivo producto de tasas de fecundidad demasiado bajas en la edad adulta ${ }^{21}$.

21 Por otro lado, ciertamente se requieren políticas contra el embarazo precoz y, en general, no deseado de las adolescentes, que compromete su desarrollo futuro al agudizar las tensiones entre la crianza y la propia inserción educativa o laboral. Ello implica acciones en el ámbito educativo e intervenciones dirigidas a ampliar el control que las personas ejercen en su trayectoria reproductiva, factor que también cabe tener presente en el caso de las transferencias monetarias para madres solteras a fin de no crear incentivos perversos. Las transferencias por hijo destinadas a las familias pueden desvirtuarse en algunos contextos, como en algunas comunidades indígenas de México, donde a raíz de los usos y costumbres se promueven los matrimonios adolescentes, que se benefician de transferencias monetarias basadas en el número de hijos. 


\section{Gráfico VI.5 \\ América Latina y el Caribe: unidades de demanda de cuidado en los países conforme al avance de su transición demográfica, 2011}

(En unidades de cuidado según la escala de Madrid) ${ }^{a}$

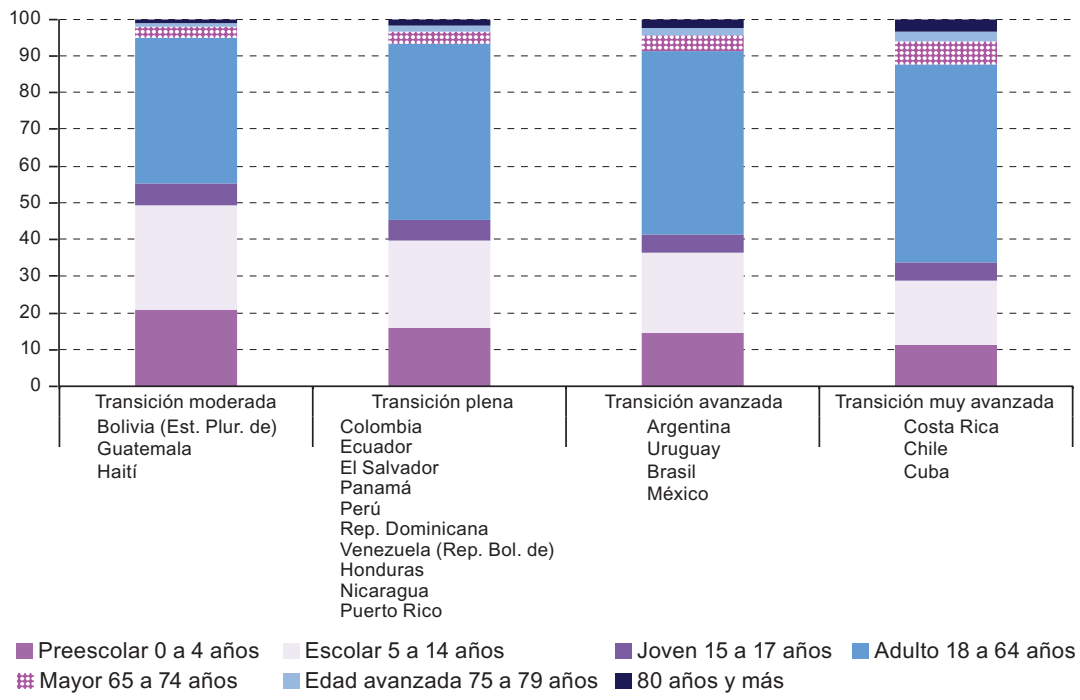

Fuente: Comisión Económica para América Latina y el Caribe (CEPAL), sobre la base de proyecciones de población del Centro Latinoamericano y Caribeño de Demografía (CELADE)-División de Población de la CEPAL para el período 1950-2025.

En la escala de Madrid, las unidades de demanda de cuidado se miden por grupos etarios desde un punto de vista colectivo, es decir que las personas del mismo grupo satisfacen las necesidades del conjunto. El valor 1 corresponde a quienes pueden autosatisfacer todas sus necesidades de cuidado, mientras que el 2 se asigna a aquellos individuos cuyo cuidado permanente no puede ser proporcionado por el mismo grupo. Los ponderadores son: 2 para el grupo de 0 a 4 años; 1,5, para el grupo de 5 a 14; 1,2 para el de 15 a 17; 1 de 18 a 64; 1,2 de 65 a 74; 1,7 de 75 a 79, y 2 a partir de 80 . Habiendo utilizado estos ponderadores con la estructura demográfica de los países, la distribución del cuidado hacia distintos grupos etarios se expresa en porcentajes.

Si los países no aprovechan las etapas más favorables de sus transiciones demográficas, las deudas sociales en materia de infancia seguirán postergadas y se acrecentarán las relativas a las personas mayores. Asimismo, surgirán mayores restricciones de financiamiento conforme se estrecha la franja etaria capaz de insertarse en el mercado laboral y de efectuar aportes al financiamiento fiscal y a la protección social, lo que exacerbará un círculo vicioso en países ya muy desiguales. El hecho de que los países nórdicos hayan podido enfrentar mejor los denominados nuevos riesgos sociales surgidos de la incapacidad de combinar las labores de cuidado y el trabajo remunerado se atribuye al momento en el que se adoptaron estas políticas: cuando el grado de envejecimiento y los compromisos en materia de pensiones originaban menos presiones y menor competencia del lado del financiamiento de las pensiones en comparación con otros países europeos con Estados de bienestar más maduros y concebidos conforme al modelo del sostén de familia (breadwinner) masculino (Bonoli, 2007). 
También es pertinente situar la temática del cuidado en la perspectiva del financiamiento de la protección social. Tal como se analizó en otros capítulos, en el caso de los sistemas de pensiones, estos pueden tener objetivos múltiples que abarcan el emparejamiento del consumo a lo largo de la vida, la función de aseguramiento, el combate a la pobreza y la redistribución del ingreso, entre otros factores, los que pueden balancearse y ponderarse de diferentes maneras. Para lograr un financiamiento sostenido de las pensiones, resultan cruciales tanto el grado de envejecimiento de la población como la oferta de trabajo. En este marco deben resaltarse dos aspectos capitales relacionados con el cuidado: la menor participación laboral de la mujer o bien sus discontinuidades en la inserción laboral, y los efectos en las bajas tasas de fecundidad (Barr y Diamond, 2008, págs. 130132). Estos elementos ejercen un efecto adverso en el financiamiento de la protección social y los ingresos de las mujeres en concepto de pensiones, y, en el caso de las pensiones de capitalización individual, se exacerban las brechas de género (Durán Valverde y Pena, 2011).

Debido al proceso de envejecimiento en la región, el financiamiento de los sistemas de protección social recaerá cada vez más en cohortes jóvenes o adultas más reducidas; por ende, la producción del sistema económico reviste importancia fundamental para la capacidad de financiamiento de la protección social (Barr y Diamond, 2008, págs. 104, 130, 132, 143, 144, 149 y 150). Por ello, es esencial elevar la productividad invirtiendo en el capital humano desde la primera infancia; incrementar la participación femenina con miras a ampliar la base del financiamiento de la protección social; y acrecentar la productividad de los recursos del sistema económico y las políticas sociales, por ejemplo, para disminuir los costos en el caso de la salud. Asimismo, es menester propiciar procesos de rejuvenecimiento de la población - que no son de corto plazo-, de modo que en el mediano plazo den lugar a nuevos equilibrios en el financiamiento de la protección social, en su sostenibilidad y en sus posibilidades de expansión. En ese sentido, una mayor provisión social del cuidado potencia elementos que pueden contrarrestar los efectos que el envejecimiento tiene en la sostenibilidad del financiamiento de la protección social.

\section{La polarización cognitiva y el cuidado en la primera infancia: ¿tiempo ganado, perdido o recuperado?}

Hemos observado que diferentes aspectos de la primera infancia, como la estimulación cognitiva y la crianza parental, permiten predecir diferentes aspectos relativos a la capacidad neurocognitiva en años posteriores de la infancia, por ejemplo, las capacidades lingüísticas y la memoria.

Hackman, Farah y Meaney (2010) 
Si la infraestructura social para el cuidado de la infancia proveyera eminentemente servicios a madres y padres que trabajan, a fin de incrementar la participación de la mujer en el mercado laboral y de contribuir al desarrollo económico y a la sostenibilidad del Estado de bienestar, ello por sí solo tendría un sentido, sobre todo instrumental, respecto de los sujetos de cuidado. De allí las críticas a distorsiones de la perspectiva de la política social que, al deslindar el futuro de los niños de su actual ser como contemporáneos de los adultos con necesidades específicas, instrumentalizan su devenir como un determinado tipo de adulto que resulta funcional a las necesidades del mercado laboral o a necesidades de otra índole (Lister, 2008, pág. 387).

Hacer hincapié tanto en la calidad como la universalidad de la provisión de los servicios evidencia que los objetivos trascienden la mera noción de que son necesarios para las madres que desean insertarse en el mercado laboral o para permitir la conciliación entre la familia y el trabajo, y la perspectiva de los rendimientos futuros de esta inversión (Jenson, 2008, pág. 364). Es que están en juego el contenido y el sentido mismo del cuidado respecto de sus beneficiarios directos. De allí, la relevancia de brindar servicios de cuidado de alta calidad para la niñez y las personas mayores (Plantenga y otros, 2008, pág. 42), en consonancia con los derechos y necesidades de ambos grupos etarios. En tanto ámbito colectivo de recursos, debe aspirarse a que su calidad enriquezca la experiencia cognitiva y las relaciones de los niños y que refuerce la búsqueda de igualdad de oportunidades. Así se reconoce de manera global el valor de las tareas de cuidado, el espacio social y el tiempo que a ello se destinan, y se amplía notablemente el espectro de sujetos sociales a cargo (Saraceno, 2009).

Una importante faceta del cuidado de la infancia remite a las desigualdades sociales. En el caso de las familias vulnerables y de bajos ingresos y niveles educativos, a causa del agobio socioeconómico, la diversidad de tareas que deben cumplirse en el ámbito familiar $\mathrm{y}$ las circunstancias en que tienen lugar (y que abarcan la vivienda, infraestructura básica y equipamiento doméstico, entre otros factores), los adultos pueden y suelen dedicar menos tiempo exclusivo a los niños, no saben de la necesidad de actividades expresas de estimulación de su desarrollo o desconocen técnicas adecuadas a tal efecto. En el caso de las clases medias-bajas que aspiran a elevar su estatus social, son también intensas las presiones para reducir el tiempo destinado al cuidado y encauzarlo al trabajo remunerado.

Por el contrario, en el otro extremo de la distribución educativa, las familias con niveles más altos incluso incrementaron en las últimas décadas su dedicación a las actividades de estimulación y recreación de 
sus hijos, por lo que se presencia un fenómeno nada trivial: la potenciación de la brecha social de la estimulación cognitiva y no cognitiva que los niños reciben en la primera infancia ${ }^{22}$. Por otra parte, si las mujeres con un nivel educativo superior son quienes posponen la maternidad, se refuerza un mayor traspaso ulterior de destrezas a sus hijos. Por todo ello, el recrudecimiento de la pobreza infantil, la desigualdad social y las brechas del tiempo exclusivo dedicado a los niños según los diversos niveles de educación de los padres y madres sugieren la acción de efectos combinados (Esping-Andersen, 2008), que trazan un círculo vicioso que las políticas públicas deben romper, e imponen desafíos en cuanto a la deseable interrelación de estas intervenciones.

Debe apostarse a reducir la dispersión o la polarización de las capacidades cognitivas de las personas, actuando con vigor desde la primera infancia. La experiencia internacional muestra que es viable aspirar a una mayor equidad cognitiva fundada en el logro de altos promedios; es decir, que la merma de la polarización cognitiva no debe realizarse a expensas de los estándares en juego (Esping-Andersen y Myles, 2007). En lugar de emprender búsquedas tardías del tiempo perdido a partir de la escuela primaria, es menester reforzar las experiencias positivas tempranas que darán muchos frutos en el futuro.

Como punto de partida, debe destacarse que las experiencias tempranas de la infancia sientan las bases del aprendizaje humano. La ausencia de una intervención decidida respecto de esas diferencias tempranas orientada a minimizar el impacto futuro de estas desigualdades en las oportunidades dificulta ulteriormente crear condiciones de paridad entre niños y niñas de diferentes condiciones socioeconómicas, o tratar de igualar o nivelar los cimientos del aprendizaje (Weisleder, 2010a) ${ }^{23}$.

Los fundamentos cognitivos cruciales, que determinarán las capacidades, las habilidades y las motivaciones, se establecen muy al inicio de la primera infancia: las experiencias de esta etapa de la vida tienen efectos profundos y duraderos en el funcionamiento de los sistemas neurocognitivos, como los relacionados con la visión, el lenguaje, la atención

22 En los países desarrollados, entre los hombres con altos niveles educativos aumentó de manera considerable en las últimas décadas el tiempo que dedican exclusivamente a sus hijos: se duplicó en los Estados Unidos y en Dinamarca, por ejemplo, y se triplicó en el Reino Unido. Entre las mujeres, también se incrementó el tiempo de dedicación exclusiva a los niños, pero en este caso, a expensas de su tiempo de ocio. Esping-Andersen atribuye en parte a la capacidad negociadora de las mujeres las causas de este mayor tiempo dedicado por los hombres: conforme crece el ingreso femenino, también lo hace su capacidad negociadora. Así se destaca la importancia también indirecta para el desarrollo infantil que revisten las políticas destinadas a favorecer el empleo femenino y la elevación de sus ingresos (Esping-Andersen, 2008 y 2009; Bonke y EspingAndersen, 2007).

23 Si se desea consultar hitos en la discusión internacional sobre la etapa preescolar de la educación y los marcos jurídicos que se han elaborado, véase Programa Estado de la Nación (2011). 
y la memoria. Las diferencias socioeconómicas de las habilidades cognitivas $\mathrm{y}$ verbales se remontan a experiencias muy tempranas adquiridas mucho antes de ingresar a la escuela (Hart y Risley, 1995; Fuller y otros, 2009; Weisleder, 2010a).

Ya desde el vientre materno, el ambiente ejerce una profunda influencia en el desarrollo cerebral, que no se detiene con el nacimiento, sino que continúa a lo largo de la infancia y de la adolescencia, y se adentra en la edad adulta. Las experiencias cumplen un rol excepcional en la conformación de diferentes sistemas cerebrales neurocognitivos y circuitos neurales. Durante los períodos o fases de "desarrollo delicado" (sensitive periods), el cerebro es al mismo tiempo en extremo plástico y vulnerable, y muchas de estas fases acontecen durante los primeros cinco años de vida. Por ende, asemejan una espada de dos filos: si el ambiente es estimulante, los sistemas neurales maduran y optimizan su arquitectura, pero si es adverso, las secuelas negativas serán duraderas y persistirán en el largo plazo (Weisleder, 2010a; Knudsen y otros, 2006; Hackman, Farah y Meaney, 2010; Knudsen, 2004).

Algunas investigaciones llevadas a cabo en países desarrollados permiten concluir que algunas desventajas cognitivas de los hijos de familias de bajos ingresos se asocian con su limitado acceso a materiales y actividades de aprendizaje; con formas de disciplina rígidas e incongruentes, o con un restringido involucramiento positivo en el cuidado resultante de las dificultades socioeconómicas; con una menguada comunicación verbal de parte de los padres; y con una exposición muy limitada al lenguaje en el seno familiar. Situaciones que ocurren precisamente en etapas en que el desarrollo del vocabulario tiene enormes ventajas, por ejemplo, para el posterior aprendizaje de la lectura. En un estudio señero, Hart y Risley (1995) mostraron que a los tres años de edad, niñas y niños de familias profesionales ya habían escuchado 30 millones más de palabras que quienes provenían de familias dependientes de ayudas sociales (welfare families), y que estas diferencias de experiencia se reflejaban en su lenguaje y habilidades cognitivas. Por tanto, incluso cuando los infantes de bajos ingresos reciban una buena educación a partir de la escuela primaria y aprendan al mismo ritmo que sus pares de mayores ingresos, resulta difícil compensar el tiempo perdido y con frecuencia es una tarea imposible (Hart y Risley, 1995; Duncan, Brooks-Gunn y Klebanov, 1994; McLoyd, 1998; Ramey y Ramey, 2004; Nisbett, 2009) ${ }^{24}$.

Una buena experiencia preescolar en términos del desarrollo cognitivo, el desarrollo del lenguaje y las aptitudes socioemocionales que influyen en los logros académicos ejerce efectos positivos en la 24 Véanse las conclusiones de estudios sobre Costa Rica en Programa Estado de la Nación, 2011,
págs. 92-96. 
transición hacia la educación formal. En las antípodas, el fracaso escolar precoz conduce a comportamientos disruptivos por falta de concentración e, incluso, al abandono escolar, con lo cual se alcanzan menores niveles educativos, que pesan sobre el bienestar futuro de estos alumnos (Shonkoff y Phillips, 2000; Weisleder, 2010b) y que también traen aparejadas repercusiones negativas en el ámbito social.

En los Estados Unidos, centros infantiles de calidad y servicios preescolares de carácter público para poblaciones con desventajas socioeconómicas han logrado incrementar los rendimientos escolares y las tasas futuras de graduación del nivel secundario, éxitos que se han traducido en incrementos salariales y en menores índices delictuales. En tal sentido, los programas preescolares exitosos representan grandes ganancias para la inversión pública, pues producen ahorros asociados con una menor criminalidad y preparan a las futuras generaciones para una exitosa inserción escolar y laboral. Por su parte, las intervenciones dirigidas a mejorar las prácticas de cuidado de las madres y los padres han mostrado efectos beneficiosos en sus interacciones con sus hijas e hijos y en sus logros (Heckman, 2008; Landry y otros, 2008; Weisleder, 2010a).

En Europa, la inclusión de los servicios de cuidado de niños en el sistema de educación formal se considera un factor que contribuye a mejorar la calidad de estos servicios, porque eleva los requerimientos pedagógicos y demanda personal más calificado. Sin embargo, en la medida en que esta exigencia puede desacelerar la adopción de estas políticas, pues acarrea mayores costos, esta decisión debe analizarse de manera coherente y situarse en el marco de los requerimientos de calidad (Comisión Europea, 2009, págs. 9 y 63).

Las perspectivas sobre el nivel preescolar se han centrado en dos tradiciones: la de la sicología social — que veía los años preescolares como un tiempo en el cual centrarse en objetivos amplios de desarrollo, sin un foco específico en la preparación para la escuela - y la de la educación temprana -que enfatizaba la promoción de habilidades sociales y académicas que facilitaran esta transición hacia la escolaridad-. Al advertir sobre la interacción entre desarrollo y aprendizaje, cabe nutrirse de ambas tradiciones, para que el cuidado de la primera infancia encauzado por la educación preescolar impulse una amplia gama de comportamientos y de habilidades que fomenten el desarrollo socioemocional y que faciliten la transición hacia la escuela. Por lo tanto, las políticas de cuidado encaran la pregunta acerca de las destrezas que deben cultivarse en los primeros años de vida ${ }^{25}$.

Entre los factores asociados con transiciones dificultosas hacia el sistema escolar, los maestros e investigadores identifican debilidades

25 Los siguientes tres párrafos y su bibliografía se basan en Weisleder (2010b). 
académicas, como aptitudes sociales débiles, problemas de autocontrol, y dificultades para seguir instrucciones y para realizar trabajos en forma independiente y en grupo (Rimm-Kaufman, Pianta y Cox, 2000; Princeton University/The Brookings Institution, 2005). Varias competencias lingüísticas y cognitivas - como la adquisición de vocabulario, la fluidez y la comprensión del lenguaje oral, la familiaridad con el alfabeto y con los libros, y destrezas aritméticas elementales - representan componentes importantes de la preparación para la escuela. En particular, el conocimiento de palabras - el vocabulario del lenguaje oral- desempeña un papel crítico en los futuros logros relativos a la lectura (Dickinson, McCabe y Essex, 2006). Por consiguiente, la participación en actividades de alfabetización, como la lectura de libros en grupo, provee a los niños de una base crítica para el desarrollo del lenguaje y alimenta procesos orientados a la alfabetización (Rodríguez y otros, 2009).

Cabe abordar la pertinencia de las prácticas pedagógicas desde el punto de vista del desarrollo infantil. La Asociación Internacional de Lectura (AIL), conjuntamente con la Asociación estadounidense para la educación de los niños pequeños (National Association for the Education of Young Children (NAEYC)), propone involucrar a los niños y niñas en el aprendizaje conducente a la alfabetización mediante experiencias significativas e importantes. Para llegar a transformarse en buenos lectores, deben desarrollar un lenguaje rico y una base conceptual de conocimientos, así como un vocabulario amplio y profundo, y habilidades de razonamiento verbal. También precisan aptitudes relacionadas con la comprensión de los códigos; es decir que deben ser capaces de entender que las palabras utilizadas en el habla se componen de elementos más pequeños de lenguaje (conciencia fonológica), que las letras representan esos sonidos (el principio del alfabeto) y que existen correspondencias sistemáticas entre los sonidos y la ortografía. Para desarrollar e hilvanar estas ideas, los niños pequeños no deben estar aislados: necesitan tener muchas oportunidades colectivas para adquirirlas de manera interactiva. El significado - no las letras ni los sonidos- es el motivo que conduce, moviliza y dispone las experiencias tempranas del niño hacia el logro de la escritura. Por lo tanto, en coordinación e interacción con experiencias significativas, deben adquirir aptitudes, como el conocimiento del alfabeto, que revisten importancia crucial para el proceso de alfabetización (Neuman, Copple y Bredekamp, 2000). Desde esta perspectiva, si los adultos captan los intereses de los niños y apoyan su aprendizaje mediante experiencias significativas y ricas en contenidos, ellos también podrán jugar un papel protagónico en la alfabetización (Neuman y Roskos, 1997).

Las experiencias ricas en contenidos y en lenguaje, que revisten significancia para la alfabetización, permiten a los niños comprender integradamente ideas que conectan nuevos conocimientos y destrezas con 
los ya adquiridos. Abarcan aspectos, como tiempo, materiales y recursos, que desarrollan de manera activa el lenguaje y el conocimiento conceptual; acceso a una amplia variedad de recursos destinados a la lectura y la escritura; participación individual y en grupos de diversos tamaños (grandes y pequeños); diferentes niveles de guía acordes con las necesidades individuales de los pequeños; y oportunidades para el aprendizaje sostenido y exhaustivo, incluidas las actividades lúdicas y las que sustentan el aprendizaje y el desarrollo socioemocional (Weisleder, 2010b).

Los engranajes de una red de cuidado que culminan en el preescolar requieren que las experiencias de aprendizaje, las competencias, los conocimientos, las destrezas y las capacidades adquiridas antes de esta etapa guarden pertinencia con este y exigen que la etapa preescolar resulte pertinente respecto de la enseñanza primaria. Así, la etapa asociada con el cuidado representa un paso inicial y adicional de la progresión educativa, que va desde las experiencias más tempranas de aprendizaje a experiencias más complejas. La socialización temprana y la educación preescolar deben buscar una sintonía creciente con el proceso formal de escolarización posterior. Si se aspira a lograr un equilibrio entre las metas de desarrollo generales y las metas cognitivas específicas $\mathrm{y}$, dado que el sistema educativo constituye un continuo, la experiencia preescolar y la etapa previa no deberían constituir etapas disociadas o divorciadas.

La asistencia al preescolar tiene externalidades muy favorables respecto de los logros futuros de los estudiantes. En un análisis de los factores asociados a los logros de los estudiantes en las pruebas del Segundo Estudio Regional Comparativo y Explicativo (SERCE) de 2006, que abarcaron 16 países de la región, se muestra que el rendimiento escolar en la primaria se ve favorecido por la asistencia al nivel preescolar ${ }^{26}$. En términos del cuidado, también reviste significado otro resultado: el grado en que la familia ha participado en la educación del niño, incluso antes de la etapa escolar - medida por una variable sustituta que considera la frecuencia con que se realizan dentro de la familia ciertas actividades relacionadas con la educación del estudiante y la escuela-, refleja un gran peso en las mejoras del aprendizaje (Treviño y otros, 2010). Ambos aspectos dan cuenta de las restricciones con que lidian las escuelas para revertir las desventajas del aprendizaje de quienes provienen de hogares vulnerables.

Los efectos favorables que la etapa preescolar ejerce en la adolescencia se han cuantificado a escala internacional. Por ejemplo, las pruebas del Programa para la Evaluación Internacional de Alumnos (PISA)

26 Las pruebas conocidas como SERCE, impartidas en 2006 en 16 países de América Latina y el Caribe y en el estado de Nuevo León en México, miden el desempeño de los estudiantes de primaria en áreas como la matemática, la lectura y las ciencias, y permiten identificar algunos elementos de la escuela, del aula y del contexto que repercuten en tal rendimiento. 
evidencian que haber asistido al preescolar eleva notablemente los logros académicos en la adolescencia. Así, los logros relacionados con las matemáticas aumentan, por ejemplo, un $10 \%$ en Dinamarca, lo que modifica el valor explicativo de otras variables importantes, como el acceso a libros en el hogar o el nivel educativo de la madre. En los Estados Unidos, Alemania y el Reino Unido, las mediciones del rendimiento de la misma prueba muestran efectos positivos entre quienes recibieron más de un año de educación preescolar en comparación con quienes no asistieron a este nivel (Esping-Andersen, 2008 y 2009).

Medidos con variables sustitutas (proxies) similares a las usadas por Esping-Andersen para países desarrollados, también en América Latina y el Caribe los resultados obtenidos por los adolescentes en las pruebas PISA de matemática y lectura muestran el efecto positivo de la asistencia al preescolar por más de un año, incluso en el caso de los estratos más privilegiados. Mucho más que el estatus ocupacional de los padres o tutores del estudiante, es relevante la incidencia positiva tanto del preescolar como de otros factores muy relacionados con el clima educacional del hogar, como la presencia de libros y otros recursos pedagógicos (Sojo, 2011).

\section{El cuidado de las personas mayores}

En el otro extremo de la vida y en el seno de familias cada vez más pequeñas, se acrecienta en la región la población mayor dependiente que recibe fundamentalmente cuidados de sus familiares inmediatos, casi exclusivamente de las mujeres. Otras personas mayores carecen del apoyo que necesitan. Las redes de cuidado formales son aún muy limitadas en las distintas formas que son pertinentes, como centros diurnos, entidades especializadas en grados de dependencia altos, residencias, o actividades recreativas plenas de sentido para la persona mayor.

El cuidado de las personas mayores pone sobre el tapete las asignaturas pendientes en la región en materia de protección social, tanto por el lado de los sistemas de salud como de los ingresos relacionados con las pensiones, que permiten adquirir en el mercado algunos servicios de cuidado. Este aspecto del cuidado tiene múltiples entrelazamientos. La capacidad de las familias o de la persona de edad para comprar servicios de cuidado o remodelar la vivienda a fin de encarar discapacidades o velar por la seguridad física guarda una relación estrecha con los ingresos de la familia y de la persona mayor, lo que remite a las trayectorias laborales previas, así como a los sistemas contributivos y no contributivos de pensiones y a las restricciones de las pensiones de capitalización individual, ámbito donde emergen también graves asimetrías de género. En lo atinente a la infraestructura social básica, exige modificaciones 
de los accesos, los transportes, los servicios y otros factores debido a las discapacidades que se incrementan con la edad.

Dada la criticidad de las políticas orientadas a fomentar un envejecimiento sano o a lograr una mayor coordinación de los servicios de salud, el carácter de los sistemas de salud reviste importancia fundamental. Puesto que el mercado del aseguramiento y de la prestación privada de servicios de salud discrimina claramente a las personas mayores mediante precios y exclusiones, para promover de manera anticipada una vejez lo más sana posible y programas de rehabilitación, son cruciales los sistemas de salud universales y solidarios y las políticas de prevención que se llevan adelante en etapas anteriores de la vida ${ }^{27}$. Esta meta resulta muy difícil de alcanzar en los países de la región con sistemas de salud muy excluyentes y poco desarrollados, pero es complejo incluso en los países latinoamericanos que tienen sistemas de salud más avanzados, debido a la estratificación del aseguramiento, la provisión no universal de los servicios y la débil solidaridad de su financiamiento. Esta situación también se debe a las frágiles políticas de prevención y tratamiento de enfermedades crónicas que requieren adoptar sistemas de referencia y contrarreferencia eficaces y ágiles, incrementar el nivel resolutivo de la red de atención y avanzar en la formación de recursos humanos, técnicos y profesionales adecuados para acelerar la transición demográfica y epidemiológica ${ }^{28}$. En términos de personas mayores, los sistemas de salud, en coordinación con otras políticas, deben tratar de prevenir la dependencia, de postergarla y de promover que se reduzca al mínimo en el marco de una vejez lo más saludable posible.

Teniendo presente este contexto indispensable, cabe mencionar una cara de la moneda del cuidado que en la actualidad reviste vital relevancia tanto en los sistemas familistas como en los desmercantilizados. Cuando las personas mayores gozan de salud e independencia para sus actividades, actúan como importantes cuidadores de sus nietos y nietas y facilitan la conciliación entre la vida laboral y familiar de sus propios hijos e hijas (Saraceno, 2008b). Cuando las mujeres se insertan en el mercado laboral en países con políticas públicas eminentemente familistas, las familias muchas veces dependen en forma casi exclusiva de este apoyo, lo que tiene implicaciones profundas en el tiempo de descanso o de recreación que las abuelas requerirían en esta etapa de la

$27 \quad$ Véase en Grundy (2010) el estrecho nexo entre las políticas de cuidado y el sistema de salud del Reino Unido, que es universal y solidario.

28 En Chile, por su sistema dual, el sistema público es un reaseguro del sistema privado. Tal como analizamos en el capítulo IV, en esta etapa de la vida quienes no pueden pagar los altos precios de las pólizas en el sistema privado se ven compelidos a migrar a FONASA, tras décadas de haber costeado pólizas a las ISAPRE mediante sus contribuciones. Esta selección de riesgo es una fuente esencial de las ganancias del sistema privado y son claros los subsidios cruzados que se encauzan del financiamiento público al sistema de salud como un todo, erigidos en parte sobre la lógica del reaseguro. 
vida y, tal vez, para la calidad y estabilidad de la inserción laboral femenina. Pero en estas etapas, las personas transitan hacia la otra cara de la moneda: el debilitamiento de las condiciones físicas, producto de su envejecimiento, acarrea el abandono de tareas que antes realizaban en forma cotidiana para toda la familia o para sí mismas. Algunas de estas tareas dejan de hacerse, porque nadie las asume, y muchas otras se transfieren en mayor o menor medida a familiares, amigos, vecinos, servicios públicos, instituciones, empresas, voluntarios o empleados domésticos. Cuando las realizan personas diferentes de quien las disfruta, se convierten en un trabajo, ya sea remunerado o no remunerado, o, cuando menos, en una donación del tiempo propio, y la calidad de estas labores depende de los recursos de cuidado disponibles. El aseo personal es un buen ejemplo de esta transformación: puede suprimirse o reducirse en gran medida respecto de los estándares medios de una sociedad, o bien mantenerse en un nivel alto de calidad, aun en los casos más desfavorables (incontinencia), cuando se dispone de recursos de cuidado adecuados (Durán Heras, 2012).

A fin de satisfacer necesidades básicas, de autocuidado y emocionales, las personas mayores dependientes y vulnerables requieren apoyos diversos en sus actividades cotidianas. Ello implica acceso a recursos económicos, como ingresos, alojamiento, comida, vestimenta o servicios. Puede abarcar apoyos para la alimentación y el aseo personal; la realización de acciones instrumentales necesarias para relacionarse con los demás y lograr otras metas, como el uso de medios de transporte, realizar quehaceres domésticos, compras o tener acceso a información útil; satisfacer necesidades emocionales y afectivas relacionadas con compañía, empatía, reconocimiento y escucha; satisfacer necesidades de salud integral, de carácter preventivo o curativo; y participar en actividades de recreación al aire libre, deportes, clubes, grupos de lectura o baile, entre otras (CONAPAM, 2010).

Precisamente cuando se incrementa el número de personas que requieren asistencia, los cambios en los patrones de interacción entre las familias y la convivencia despiertan preocupaciones en Europa acerca de la provisión familiar del apoyo. Aunque la corresidencia ha declinado, el contacto regular y el apoyo en las tareas domésticas siguen siendo característicos de la vida familiar en Europa. Más limitado es el apoyo recibido por quienes no tienen hijos y por los hombres divorciados con escaso contacto con sus hijos. Las encuestas evidencian que los familiares cercanos, sobre todo las esposas e hijas, son quienes asumen el cuidado (Grundy, 2010; Poggio, 2008; Saraceno, 2008b; Keck, 2008; Durán Heras, 2012). Aunque los familiares no convivientes no desempeñan un papel de proveedores de servicios tan intenso y sustitutorio como los convivientes, su importancia no puede pasarse por alto, en especial en las actividades no sometidas a horarios ni presencia física (Durán Heras, 2012). 
Desde la política pública, el apoyo al cuidado de la persona mayor se orienta en primer término directamente a la persona mayor dependiente y vulnerable. Pero indirectamente beneficia a sus cuidadores en el seno de las familias, en particular a las mujeres, que casi libradas a sí mismas enfrentan muchas veces grandes sobrecargas de funciones y agobio, al atender diversas funciones en el seno familiar y el mundo laboral, sobre todo cuando las personas mayores tienen profundos grados de dependencia. En este contexto, por ejemplo, se habla de la "generación sándwich", conformada por mujeres que transfieren cuidados y tiempo tanto "hacia abajo", es decir, hacia sus descendientes, como "hacia arriba", es decir, hacia las personas mayores vulnerables (Saraceno, 2008a, pág. 10; Durán Heras, 2012).

Se estima que una cuarta parte de las mujeres británicas de 85 años o más no pueden bañarse sin ser asistidas y que la mitad sufre al menos una restricción que le dificulta la movilidad. Incluso en algunos estudios donde se estiman tasas decrecientes de minusvalía, se concluye que experimentará un incremento notable el número de personas con restricciones para realizar actividades cotidianas, como tomar un baño, comer o vestirse (Grundy, 2010). Por ejemplo, según datos de 2005 correspondientes a Costa Rica, se aprecia que 7 de cada 10 personas de 65 años o más no presentaban ninguna dificultad para realizar actividades cotidianas, pero 3 de cada 10 sufrían al menos una; además, el grado de dependencia aumentaba considerablemente con la edad y la mayor dependencia se observaba a partir de los 82 años (Sauma, 2011, pág. 17). Asimismo, hay que considerar que el deterioro de la salud en edades avanzadas no suele seguir un curso gradual, sino que a menudo se ve precipitado por episodios agudos de enfermedad, por accidentes o traumas como un duelo, y es incierto el grado en que puede revertirse (Grundy, 2010). Otro aspecto específico es el padecimiento de enfermedades muy inhabilitantes, como la enfermedad de Alzheimer y ciertos grados de artritis, que exigen cuidados permanentes, intensos y especializados.

El cuidado requerido por enfermedades crónicas y discapacitantes entraña una tarea absorbente que consume ingentes recursos de tiempo y tiene una incidencia mucho mayor que las enfermedades episódicas y breves para las que la legislación y los convenios sindicales europeos en general tienen previstos mecanismos automáticos de cobertura. Por ejemplo, en España se contemplan días de permiso por enfermedad de un familiar, en tanto que para las dolencias crónicas no existe una cobertura automática, si bien casi el $10 \%$ de los adultos cuidan a diario a personas enfermas o discapacitadas. Las mujeres que prestan cuidados cotidianos a personas con discapacidades son el doble que los varones en la misma situación. En ese país, a la inversa de lo que sucede con el cuidado de los niños, los familiares de personas con un estatus socioeconómico más elevado son quienes prestan menos cuidados cotidianos a enfermos y discapacitados. En proporción, los familiares de estos grupos que asumen estas tareas pertenecen en mayor 
medida a los niveles socioeconómicos más bajos, dato muy relevante para las políticas sanitarias y sociales (Durán Heras, 2012). Es decir que emerge una polarización socioeconómica del cuidado de las personas mayores relacionada con los ingresos propios y los de sus familias.

El costo de la provisión de los servicios de cuidado y de su indispensable ampliación también constituye una preocupación esencial en Europa. Ello alude a la necesidad de establecer también círculos virtuosos en el otro extremo de la vida en el ámbito del cuidado, y de fomentar - en el mediano y largo plazo- procesos de rejuvenecimiento de la población (aspecto que se abordó someramente), al igual que políticas que promuevan el envejecimiento saludable y la mejor coordinación de los servicios brindados a esta población, así como la interacción de las intervenciones preventivas y las de rehabilitación (Grundy, 2010).

Debido al aumento de la esperanza de vida en la región, los cuidados más especializados que deben proveerse a esta franja etaria han aumentado y continuarán en ascenso. Además, los cuidadores de personas mayores muy dependientes - casi siempre mujeres- enfrentan a menudo un agobio que puede generar ansiedad y tensión, afectar gravemente su salud física y emocional, y ejercer efectos adversos en las características del cuidado ${ }^{29}$. En el caso de las esposas que asumen el papel de cuidadora principal, muchas son personas necesitadas de cuidados y que, al realizar esas tareas sin apoyo, incluso aceleran su propio proceso de envejecimiento (Valenzuela, 2010). Claramente se requiere de la acción del Estado, en conjunto con las familias, las comunidades y el mercado, a fin de crear, regular, reglamentar y supervisar las alianzas público-privadas.

En Europa, ya adentrado el siglo XX, incluso en los países nórdicos la "institucionalización" de las personas de edad representó más bien una suerte de asistencia social precaria para personas mayores pobres e indigentes. Tras la Segunda Guerra Mundial, la población europea, en general, y las personas mayores, en particular, experimentaron notables saltos en su bienestar ${ }^{30}$ y en la mayoría de los países la institucionalización

29 "Según estudios, las personas cuidadoras con mayor riesgo de presentar sobrecarga de funciones son las hijas e hijos con una edad promedio de 45 años, debido a los múltiples roles que deben desempeñar en esta etapa de sus vidas, lo que puede generar conflictos familiares y crisis" (UCR/CONAPAM, 2008).

30 Respecto de los países nórdicos, la evolución de la pobreza en los últimos 20 años muestra que las expectativas de eliminar este flagelo mediante el sistema de bienestar se han visto frustradas, pero que su incidencia es baja en comparación con la mayoría de los demás países del mundo. Es interesante señalar que, en términos de ingreso, esta se concentra entre las personas mayores solteras y los jóvenes sin hijos. El sistema de pensiones y el cuidado de las personas de edad mediante los servicios municipales y los sistemas regionales de atención de la salud han reducido la pobreza entre la población mayor, en tanto que la amplia cobertura de las políticas para las familias tuvo el mismo efecto en el caso de las familias con niños. Son los escandinavos pobres quienes reciben asistencia social mediante transferencias (Abrahamson, 2007, págs. 60-62). 
fue objeto de un escrutinio desde varios ángulos ${ }^{31}$. Prima la idea de que fundamentalmente debe orientarse a las personas mayores con altos grados de dependencia y con deterioro severo de la salud. Se ha dado un giro progresivo desde los servicios residenciales hacia los servicios de permanencia en el domicilio, y se ha diversificado la gama de servicios, varios de ellos de apoyo a los cuidados dentro del hogar. También se han instaurado nuevas formas de domicilio; por ejemplo, en Inglaterra se ofrecen viviendas colectivas a las personas de edad, con la presencia de una persona supervisora residente o de supervisores comunitarios. De allí que numerosas reflexiones y polémicas giren en torno al diseño y la ejecución de una amplia gama de servicios diversificados de apoyo al cuidado en el seno del hogar de la persona mayor y en instituciones de cuidado diurno cotidiano, donde ellas no residen. Como la provisión del cuidado suele ser una interacción entre familias, comunidades, Estados y mercados, la diversificación y la variación de los servicios emergen como variable de importancia (Grundy, 2010; Sundström, 2010; Martínez Rodríguez, 2010a y 2010b; Rodríguez Rodríguez, 2010).

Los procesos de enfermedad que surgen durante la vejez pueden ocasionar condiciones diversas de dependencia física, social y mental, que se deben tomar en cuenta para el diseño de la oferta de servicios. Esta debe tener diversos niveles de complejidad a fin de dar una respuesta diferenciada, ya que la realidad social no es uniforme. Existen necesidades diversas y cambiantes, estilos y preferencias personales variados, familias y situaciones distintas, territorios diferentes, entre otros elementos, los que tornan imprescindible elaborar respuestas heterogéneas y ofrecer una gama de recursos flexibles, adaptados a las personas y a sus comunidades. Las experiencias nacionales muestran que se requiere un proceso de maduración de los servicios en el curso del tiempo. En varios casos los gobiernos subnacionales surgen como entidades fundamentales en la ejecución de las políticas de cuidado, muchas veces en estrecha asociación con organizaciones privadas filantrópicas y con fines de lucro (Sojo, 2010).

Se pone de relieve la necesidad de apostar — pero no de manera retórica- por un modelo orientado a las personas y su bienestar cotidiano, pero que no tome en cuenta solo sus necesidades y características, sino también sus derechos, preferencias y deseos. Para lograr una sintonía con las preferencias y el bienestar subjetivo de las personas, resulta vital el concepto de calidad de vida como aspecto central y determinante a la hora de definir el modelo de intervención de los servicios de atención personal. En la actualidad, las políticas europeas están muy marcadas por el modelo del envejecimiento activo en los ámbitos de la salud, la seguridad y la participación ${ }^{32}$.

\footnotetext{
31 Si se desea consultar la trayectoria europea y española y los consensos internacionales, véanse Rodríguez Rodríguez (2010) y Martínez Rodríguez (2010a).

32 Véase CEPAL, 2013, págs. 117-129.
} 
Se toma como punto de partida que las personas en situación de dependencia son especialmente vulnerables a recibir un trato que no respete su dignidad. De allí que el trato digno deba traducirse en aspectos muy concretos de la atención cotidiana a los que debe prestarse especial atención, como: i) la protección y garantía de la intimidad y la privacidad; ii) la protección de la propia identidad y el cuidado de la imagen personal; iii) el objetivo de evitar los sentimientos de exclusión; iv) el respeto de la vejez, y v) el hecho de demostrar respeto y apoyo hacia el desarrollo de proyectos propios (Rodríguez Rodríguez, 2010).

La perspectiva de los derechos de las personas mayores ha calado mucho. De allí el planteamiento de que la atención personal de las personas adultas frágiles y en situación de dependencia demande prestaciones en sintonía con las preferencias y el bienestar subjetivo de las personas, y de que el modelo que sustente el cuidado se oriente a las personas y a su bienestar cotidiano y no solo hacia sus necesidades y características. O bien la importancia del concepto de calidad de vida, como aspecto central y determinante a la hora de definir el modelo de intervención de los servicios de atención personal, con una doble indicación: la técnica y la ética. Es así como la llamada garantía de derechos comprende la atención personalizada desde la autodeterminación y la vida independiente; el objetivo de velar por la intimidad y la confidencialidad; la integración de lo terapéutico en lo cotidiano y significativo; y la participación voluntaria de las familias y la organización, al servicio de las personas (Martínez Rodríguez, 2010a y 2010b).

Las lecciones de la experiencia histórica europea a lo largo del siglo XX y las ideas del envejecimiento activo promovidas por la Organización Mundial de la Salud (OMS) se plasman en el modelo de envejecimiento activo en el ámbito territorial de la Unión Europea, de la que se derivan las siguientes líneas de acción (Martínez Rodríguez, 2010a)

- Apuesta por servicios de atención personal para apoyar la permanencia en casa y en el entorno habitual de vida;

- Prevención de la dependencia (aparición e incremento) mediante actuaciones dirigidas al fomento de la actividad, así como al control de otros factores de riesgo (accidentes, patologías, entre otros);

33 En el caso de Costa Rica, el Consejo Nacional de la Persona Adulta Mayor (CONAPAM, 2010) recoge y adopta principios muy semejantes: atención integral (acceso a servicios que les aseguren mayores niveles de bienestar), realización personal (oportunidad para desarrollar plenamente su potencial, sus capacidades y habilidades de acuerdo con sus preferencias personales), independencia (mantener su independencia mediante el equilibrio entre el bienestar físico, intelectual, social, emocional, mental y espiritual que les permita desenvolverse por sí mismas), igualdad de oportunidades (no ser discriminadas en ninguna situación por razones de edad), dignidad (derecho a vivir con dignidad y seguridad, ser tratadas con respeto y consideración, y verse libres de explotaciones y de malos tratos, físicos o mentales), participación (derecho a participar en la vida social, económica, política, educativa, cultural, deportiva y recreacional del país) y permanencia en el núcleo familiar y comunitario (derecho a permanecer integradas a su familia y a la comunidad, participando activamente en las decisiones que afectan su bienestar). 
- Lucha contra la discriminación por razón de edad (ageism), fomento de la inclusión y participación social y del empoderamiento de las personas mayores;

- Autodeterminación de las personas con discapacidad o dependencia, incluyendo a las personas con deterioro cognitivo y demencia;

- Modelos de cuidados de larga duración (modelos no institucionales, coordinación de servicios sociales y sanitarios);

- Calidad de la atención con dignidad (calidad de vida y derechos);

- Nuevas tecnologías para la promoción de la vida independiente y de la autonomía (productos de apoyo y tecnologías de la información y las comunicaciones (TIC));

- Cualificación y capacitación de los profesionales, y

- Apoyo/capacitación de las familias cuidadoras.

A pesar de que los servicios de cuidado se introdujeron en España con cierto rezago respecto de otros países y de que todavía se les destinan pocos recursos, es notable la sistematización de lecciones y de buenas prácticas sobre el camino recorrido y que pueden tomarse en cuenta en nuestra región (Rodríguez Rodríguez, 2006 y 2010; Martínez Rodríguez, 2010a y 2010b), como enseñanzas y criterios para promover un cuidado digno ${ }^{34}$.

Rodríguez Rodríguez ha distinguido ocho principios que deben orientar las intervenciones, de los que se derivan los criterios técnicos que deben conducir las interacciones profesionales (véase el diagrama VI.2). Los principios "hacen referencia a las personas a las que se dirigen los programas y al respeto de su dignidad y de sus derechos, cualquiera sea su situación de discapacidad o dependencia a cualquier edad. Estos sientan la filosofía de la intervención y colocan a la persona en el centro de la atención. En consecuencia, la persona y sus derechos pasan a constituir el eje alrededor del cual deben girar tanto el sistema organizativo como el saber profesional y las intervenciones que se desarrollen. Los criterios, que han de estar impregnados de valores éticos en todo el proceso de intervención, constituyen la metodología que hará posible el cumplimiento de los principios" (Rodríguez Rodríguez, 2010). "Por tanto, principios y criterios se reclaman recíprocamente. Los criterios tienen que ver con una correcta praxis profesional, con la calidad de los programas y con la idoneidad de

34 AquísetuvieronencuentalosinteresantesaportesdeRodríguezRodríguezydeMartínezRodríguez. Respecto de la experiencia española, véase Consejo Superior de Investigaciones Científicas(CSIC), "Documentación. Informes PM" [en línea] http://envejecimiento.csic.es/documentacion/ estudiosyresultados/informes/pm-index.html. 
los apoyos que se determinen para hacer posible el cumplimiento de los principios sustentadores" (Rodríguez Rodríguez, 2006).

Estos ocho principios destacados son: la autonomía, la participación, la integralidad, la individualidad, la integración social, la independencia, la continuidad de los cuidados y la dignidad, y se vinculan con criterios relativos a la calidad de los servicios (véase el diagrama VI.2). Por ejemplo, el principio de autonomía establece que los profesionales de los centros de atención social deben promover y respetar las decisiones de las personas usuarias.

\section{Diagrama VI.2}

\section{Principios y criterios para fundamentar un modelo de atención centrado en la persona mayor}
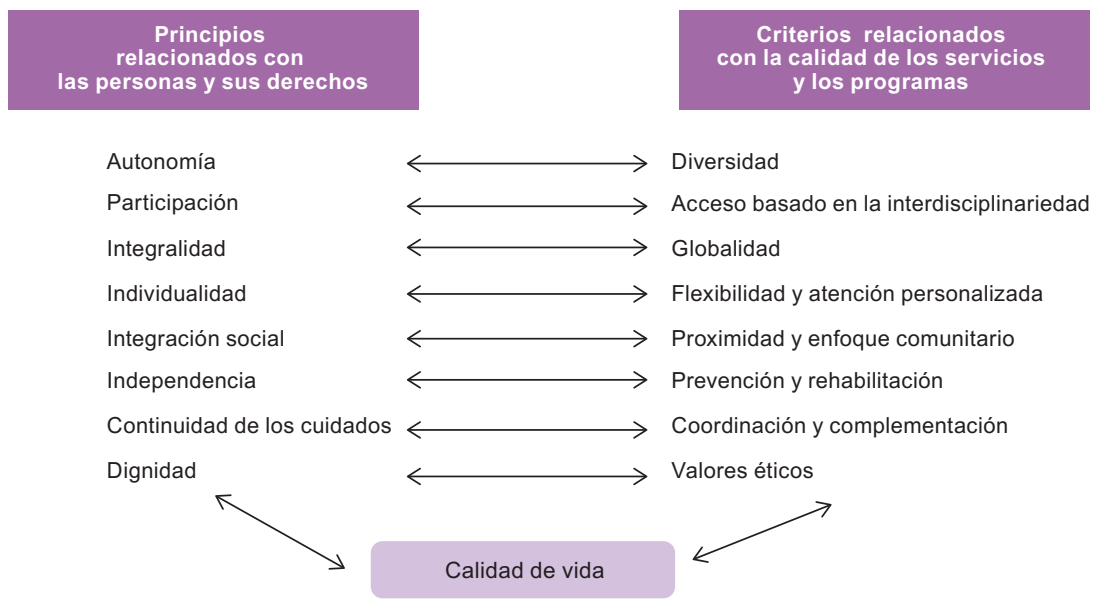

Fuente: P. Rodríguez Rodríguez, "El sistema de servicios sociales español y las necesidades derivadas de la atención a la dependencia", Documento de Trabajo, № 87/2006, Madrid, Fundación Alternativas, 2006.

Como la autonomía personal consiste en la capacidad de tomar decisiones y controlar la propia vida, ciertamente no es una noción opuesta a la dependencia: el término contrario a la autonomía es más bien la heteronomía. De hecho, una persona en situación de dependencia puede y debe ser lo más autónoma posible, de donde se desprenden los postulados en torno al concepto de autodeterminación como capacidad y como derecho. En tanto que capacidad, la autodeterminación se refiere a su ejercicio directo por las propias personas y al conjunto de habilidades que cada cual tiene para hacer sus propias elecciones, tomar sus decisiones y responsabilizarse de las consecuencias, facultad que se adquiere mediante su ejercicio y el aprendizaje que proviene de uno mismo y de la interacción social. En tanto que derecho, la autodeterminación alude a la garantía de que las personas, al margen de sus capacidades, puedan desarrollar y controlar proyectos vitales basados en su identidad personal. En el caso de personas mayores 
con grave afectación, el ejercicio del derecho de la autodeterminación puede ser indirecto, es decir mediado por otros y por medio de los apoyos necesarios (Martínez Rodríguez, 2010b). La autonomía como principio implica un esfuerzo permanente de apoyo a la autoestima de la persona con dependencia y el respeto absoluto de su dignidad personal y del ejercicio de su voluntad para que pueda - si no ha perdido la totalidad de sus facultades mentales- decidir libremente sobre su vida en aspectos accesorios o importantes, como sus opiniones, sus anhelos, el respeto por su intimidad, el estímulo de su capacidad de decisión y de la creatividad, entre otros.

Para minimizar el debilitamiento o la pérdida de las funciones de las personas dependientes y frágiles, es preciso ayudarlas a afrontar sus dificultades, estimulándolas y realizando con ellas actividades para las que aún conserven la capacidad, o, en el caso de aquellas actividades que no puedan realizar por sí mismas, ayudándolas a llevarlas a cabo con el grado de colaboración que necesiten y con la máxima delicadeza posible, y respetando sus deseos (Martínez Rodríguez, 2010b).

Por su parte, la planificación centrada en la persona es una metodología facilitadora para que la propia persona con discapacidad, en situación de fragilidad o dependencia, sobre la base de su historia, capacidades y deseos, planifique las metas que quiere alcanzar para mejorar su vida. Para ello tal vez sea necesario, si la persona presenta una grave afectación, posibilitar el ejercicio de la autodeterminación en forma indirecta, mediada por otros, ofreciéndole un grupo social de referencia así como los apoyos precisos. Este método busca dar un poder efectivo, garantizando su autodeterminación y partiendo de varios presupuestos básicos: la atención individualizada debe ser el valor central de los servicios que apoyen a las personas; al partir de sus derechos, el foco se sitúa en sus capacidades, preferencias y elecciones, y los apoyos que precisan para ello cobran una importancia extrema; si la persona con discapacidad o dependencia grave mantiene relaciones de interdependencia con su red social próxima, su familia y amigos son esenciales y cumplen un papel clave en el ejercicio de la autodeterminación y en el desarrollo de su proyecto vital; la planificación centrada en la persona se entiende como un proceso continuo donde la escucha y el aprendizaje modulan los cursos de acción. Por ende, se trata de un proceso flexible y abierto al cambio, que debe adaptarse a las diferentes necesidades, deseos y aspiraciones de las personas en las diferentes etapas y circunstancias de la vida (Martínez Rodríguez, 2010b).

Un aspecto fundamental es que las actividades de cuidado, incluso las de carácter recreativo, estén plenas de sentido (Martínez Rodríguez, 2010a). De la misma forma en que el cuidado en la primera infancia debe encararse seriamente, por todo el desarrollo cognitivo y emocional que está en juego, en el caso de las personas mayores se debe conservar al 
máximo sus capacidades, con pleno respeto de sus derechos. Para el ser humano, esta puede ser una etapa de creatividad y disfrute, en lugar de verse condenado a vegetar.

\section{E. El financiamiento del cuidado desde la perspectiva de la protección social y el aseguramiento ${ }^{35}$}

El financiamiento de las políticas de cuidado debe apuntar a que la satisfacción de las necesidades de cuidado de las personas dependientes no esté determinada solo por la provisión de cuidados brindados en el seno familiar, o por la capacidad individual para pagar los servicios, ya que en el plano social ambos ámbitos evidencian grandes desigualdades.

Por este motivo, debe plantearse el financiamiento mediante impuestos generales, cuyo efecto redistributivo esté claramente determinado por la presión fiscal, la estructura tributaria, y el monto y origen de los recursos destinados a tal efecto. Pero también es pertinente analizarlo en términos del aseguramiento dentro del marco de los sistemas de protección social, con el deseo de que se convierta en uno de sus pilares. Ello representa un cambio profundo de óptica respecto de los principios del Estado de bienestar, ya que en sus orígenes el aseguramiento se concibió solo en relación con el trabajo asalariado, y los asuntos de género y familia se tomaban en cuenta en la medida en que afectaran la oferta de trabajo del proveedor masculino.

La solidaridad del financiamiento redistributivo y la universalidad plasmada en el acceso abierto a los servicios se fundamentan en la necesidad de diversificar los riesgos asociados y en la aspiración a prestar servicios de calidad creciente. Con un fundamento análoga al del aseguramiento en materia de salud planteado en el capítulo II, es importante prever el aseguramiento del cuidado de largo plazo, dado el carácter fortuito de algunos eventos que pueden exacerbar la dependencia y la imprevisibilidad del nivel de dependencia que las personas mayores tendrán que enfrentar, más allá de las medidas preventivas y del autocuidado que quizás hayan adoptado a lo largo de su vida para aminorarla, o de las diversas condiciones socioeconómicas de que hayan podido disfrutar. Con respecto al cuidado de los niños, no se trata de un evento imprevisible sino deseado, relacionado con la necesidad de intervenir en esta fase del desarrollo. En este caso, los riesgos están asociados con el acceso a los servicios, mientras que, en el caso de los eventos indeseados, el riesgo es doble: el acontecimiento del evento y la capacidad de encararlo.

35 En esta sección se reproducen algunas ideas planteadas en CEPAL, 2013, págs. 242-244. Como puede verse, más allá de su especificidad en cuanto al cuidado, se vinculan con las reflexiones acerca del aseguramiento desarrolladas en el segundo capítulo del presente libro. 
La capacidad de pago para acceder a los servicios de cuidado constituye un factor crítico en el caso de los sectores pobres, pero puede también serlo para los sectores medios, y la gravedad de ciertas situaciones de dependencia sufridas por uno mismo o por miembros del hogar incluso puede acarrear un empobrecimiento. Por ello, no es aconsejable concentrarse solo en los sectores pobres.

Hay que tomar en consideración tanto la probabilidad de necesitar cuidado, como la distribución de las diferentes duraciones e intensidades de los episodios en que este se necesite, que resultan inciertas (Barr, 2010, págs. 6-8), y también son inciertos los costos que puede conllevar la prestación de cuidado. Esto torna recomendable el financiamiento obligatorio, y la necesidad de diferenciar riesgos supone incluir gente joven en el aseguramiento (Barr, 2010, pág. 8), como en el caso del aseguramiento de la salud. Así se expresan la solidaridad intergeneracional y la nivelación del consumo de las personas a lo largo de su vida mediante el ahorro que representan las contribuciones efectuadas cuando jóvenes a este sistema de aseguramiento. Por lo tanto, se trata de combinar formas de aseguramiento del cuidado con el acceso a los servicios.

Es muy importante velar por la sostenibilidad del sistema social de cuidados, es decir, por la solvencia financiera de su financiamiento, y así lograr un apoyo político y público. En estos términos, cabe considerar que el sistema puede verse afectado al menos por tres factores: i) la percepción sobre su justeza y valor respecto de los costos de su financiamiento; ii) aunque sea un término relativo, la capacidad de financiarse, es decir, condecirse con la disposición social a pagar por sus beneficios, y iii) la capacidad del sistema de adaptarse a distintas circunstancias para mantener su solvencia (Fernández y Forder, 2012, págs. 347 y 348).

Dada la incertidumbre respecto de la trayectoria futura de los niveles de dependencia, del requerimiento de apoyos de cuidado de largo plazo, del momento en que estos serán necesarios y por cuánto tiempo, y de su costo a precios de mercado, plantear beneficios de carácter universal en este ámbito representa una solución eficiente e igualitaria. No obstante, establecer un derecho universal a beneficios de cuidado de largo plazo y a la provisión social de cuidado no imposibilita introducir medidas selectivas específicas para ampliar la gama de servicios o el monto de las prestaciones para quienes sufren algunas necesidades muy severas, $\mathrm{o}$, en el caso de las personas con menores niveles de dependencia, que se contemplen aportes diferenciados según su capacidad de pago (Colombo y Mercier, 2012, pág. 327).

Cabe tener presente que, debido a los ciclos económicos, la prosperidad puede divergir de una generación a otra a lo largo del tiempo y así también puede variar la contribución a los costos de las etapas de 
dependencia en materia de cuidado y el acceso efectivo a los beneficios que la política pública establece. También pueden variar las tasas de dependencia demográfica, es decir la relación entre el número de individuos en edades activas e inactivas. Las reformas de las políticas públicas pueden modificar los beneficios y causar conflictos intergeneracionales (Colombo y Mercier, 2012; Colombo y otros, 2011, pág. 12). Esta problemática se asemeja a la del financiamiento y los beneficios de los sistemas de pensiones (Barr y Diamond, 2008), que, con los ajustes del caso, puede alimentar esta reflexión. La experiencia internacional demuestra que el criterio de financiamiento del cuidado de largo plazo a menudo es semejante al que se aplica en la protección social en materia de salud, es decir, por medio de impuestos generales o contribuciones a la seguridad social (Colombo y Mercier, 2012, pág. 328).

En el caso de América Latina y el Caribe, la desigualdad que expresan los sistemas de protección social de pensiones y de salud es tan extrema y tan complejas son sus reformas, que el financiamiento del cuidado de largo plazo no debe alinearse con las formas de seguridad social preexistentes. Debe asentarse en el principio de iguales oportunidades de cuidado, lo que implica una arquitectura basada en la solidaridad y la universalidad, nutrida con impuestos generales y con formas de aseguramiento solidarias, de carácter contributivo y no contributivo. En cuanto al funcionamiento de la red así financiada, es preciso establecer interacciones efectivas entre los servicios pertinentes para la prestación de cuidado (salud y asistencia social) y la red de prestadores de la protección social existente, con regulaciones que impidan el "descreme del mercado" y velen por la calidad, teniendo en cuenta la universalidad encarnada en el principio de igualdad de oportunidades de cuidado.

\section{Bibliografía}

Abrahamson, P. (2011), "El sentido de pertenencia en el contexto del Estado de bienestar europeo", Sentido de pertenencia en sociedades fragmentadas: América Latina desde una perspectiva global, M. Hopenhayn y A. Sojo (comps.), Buenos Aires, Siglo XXI/Comisión Económica para América Latina y el Caribe (CEPAL). (2007), "El modelo nórdico de protección social y sus efectos en la cohesión social", Cohesión social en América Latina y el Caribe: una revisión perentoria de algunas de sus dimensiones (LC/W.120), A. Sojo y A. Uthoff (eds.), Santiago, Comisión Económica para América Latina y el Caribe (CEPAL) [en línea] http:/ / repositorio.cepal.org/bitstream/handle/11362/3548/1/S2007025_es.pdf.

Adema, W., M. C. Huerta y M. Queisser (2010), "Conciliar los compromisos de trabajo y familia en países de la OCDE", Envejecimiento en América Latina. Sistemas de pensiones y protección social integral (LC/G.2475-P), A. Prado y A. Sojo (eds.), Santiago, Comisión Económica para América Latina y el Caribe (CEPAL).

Adsera, A. y A. Menéndez (2011), "Fertility changes in Latin America in the context of economic uncertainty", Population Studies, vol. 65, N 1, Abigndon, Routledge. 
Aguirre, R. (ed.) (2009), Las bases invisibles del bienestar social. El trabajo no remunerado en Uruguay, Montevideo, Fondo de Desarrollo de las Naciones Unidas para la Mujer (UNIFEM).

Aguirre, R. y F. Ferrari (2014), “La construcción del sistema de cuidados en el Uruguay. En busca de consensos para una protección social más igualitaria", serie Políticas Sociales, No 192 (LC/L.3805), Santiago, Comisión Económica para América Latina y el Caribe (CEPAL) / Agencia Alemana de Cooperación Internacional (GIZ).

AIL/NAEYC (Asociación Internacional de Lectura/National Association for the Education of Young Children) (1998), "Learning to read and write: developmentally appropriate practices for young children", Young Children, vol. 53, $\mathrm{N}^{\mathrm{o}}$ 4, Washington, D.C.

Anttonen, A., J. Baldock y J. Sipilä (eds.) (2003), The Young, the Old and the State. Social Care Systems in Five Industrial Nations, Cheltenham, Edward Elgar Publishing.

Arriagada, I. (coord.) (2007), Familias y políticas públicas en América Latina. Una historia de desencuentros (LC/G.2345-P), Santiago, Comisión Económica para América Latina y el Caribe (CEPAL) [en línea] http:/ / repositorio.cepal.org/bitstream/ handle/11362/2504/S0700488_es.pdf.

Arriagada, I. y A. Sojo (2012), “Las clases medias en América Latina: algunas conjeturas desde la perspectiva de género", Pensamiento Iberoamericano, $\mathrm{N}^{\circ} 10$, Madrid, Agencia Española de Cooperación Internacional para el Desarrollo (AECID)/Fundación Carolina [en línea] https://www.fundacioncarolina.es/ wp-content/uploads/2014/07/Pensamientolbero10.pdf.

Arriagada, I. y M. Moreno (2011), “La constitución de cadenas globales de cuidado y las condiciones laborales de las trabajadoras peruanas en Chile", Mujeres inmigrantes en Chile. ¿Mano de obra o trabajadoras con derechos?, C. Stefoni (ed.), Santiago, Universidad Alberto Hurtado.

Arriagada, I. y R. Todaro (2011), Cadenas globales de cuidados: el papel de las migrantes peruanas en la provisión de cuidados en Chile, Santiago, Entidad de las Naciones Unidas para la Igualdad de Género y el Empoderamiento de las Mujeres (ONU-Mujeres).

Astelarra, J. (coord.) (2007), “Género y cohesión social”, Documento de Trabajo, No 16, Madrid,Fundación Carolina, octubre[enlínea]https:/ / www.fundacioncarolina.es/ wp-content/uploads/2014/08/DT16.pdf.

Barr, N. (2010), "Long-term care: a suitable case for social insurance", Social Policy and Administration, vol. 44, $\mathrm{N}^{\mathrm{o}}$ 4, Nueva York, Wiley Blackwell [en línea] http: / / eprints.lse.ac.uk/28942/.

Barr, N. y P. Diamond (2008), Reforming Pensions. Principles and Policy Choices, Nueva York, Oxford University Press.

Batthyány, K. (2010), "Envejecimiento, cuidados y género en América Latina", ponencia presentada en el seminario internacional Experiencias Internacionales y Propuestas para Consolidar la Red Nacional de Cuido de las Personas mayores en Costa Rica, San José, 22 y 23 de noviembre.

Bonke, J. y G. Esping-Andersen (2007), "Parental investments in children: how educational homogamy and bargaining affect time allocation", Barcelona, Universidad Pompeu Fabra.

Bonoli, G. (2007), "Time matters: postindustrialisation, new social risks and welfare state adaptation in advanced industrial democracies", Comparative Political Studies, vol. 40, No 5, Thousand Oaks, SAGE Publishing. 
(2005), "The politics of the new social policies: providing coverage against new social risks in mature welfare states", Policy $\mathcal{E}$ Politics, vol. 33, No 3 , Bristol, Policy Press.

Calderón Magaña, C. (coord.) (2013), “Redistribuir el cuidado: el desafío de las políticas", Cuadernos de la CEPAL, N 101 (LC/G.2568-P), Santiago, Comisión Económica para América Latina y el Caribe (CEPAL).

Castles, F. (2009), "Patterns of state expenditure in Europe and America", United in Diversity? Comparing Social Models in Europe and America, J. Alber y N. Gilbert (eds.), Nueva York, Oxford University Press.

CEPAL (Comisión Económica para América Latina y el Caribe) (2016), Desarrollo social inclusivo: una nueva generación de políticas para superar la pobreza y reducir la desigualdad en América Latina y el Caribe (LC.L/4056/Rev.1), Santiago.

(2014), Panorama Social de América Latina, 2014 (LC/G.2635-P), Santiago.

(2013), Panorama Social de América Latina, 2012 (LC/G.2557-P), Santiago.

(2009), Panorama Social de América Latina, 2009 (LC/G.2423-P), Santiago.

(2007), Cohesión social: inclusión y sentido de pertenencia en América Latina y el Caribe (LC/G.2335/Rev.1), Santiago.

(2006), La protección social de cara al futuro: acceso, financiamiento y solidaridad (LC/G.2294(SES.31/3)), Santiago.

Cerrutti, M. y A. Maguid (2010), “Familias divididas y cadenas globales de cuidado: la migración sudamericana a España", serie Políticas Sociales, No 163 (LC/L.3239-P), Santiago, Comisión Económica para América Latina y el Caribe (CEPAL).

Colombo, F. y J. Mercier (2012), "Help wanted? Fair and sustainable financing of long-term Care Services", Applied Economic Perspectives and Policy, vol. 34, No 2, Nueva York, Oxford University Press.

Colombo, F. y otros (2011), Help Wanted? Providing and Paying for Long-Term Care, París, Organización de Cooperación y Desarrollo Económicos (OCDE).

Comisión Europea (2009), The Provision of Childcare Services. A Comparative Review of 30 European Countries, J. Plantenga y C. Remery (coords.), Bruselas.

CONAPAM (Consejo Nacional de la Persona Adulta Mayor) (2010), "Marco conceptual para orientar el uso de recursos económicos asignados y transferidos a las organizaciones de naturaleza jurídica privada que atienden a personas adultas mayores", San José, inédito.

(2006), Plan Estratégico Nacional para la Atención de la Persona Adulta Mayor: 2006-2012, San José.

Daly, M. (2000), “A fine balance. Women's labor market participation in international comparison", Welfare and Work in the Open Economy Volume II: Diverse Responses to Common Challenges in Twelve Countries, F. W. Scharpf y V. A. Schmidt, Nueva York, Oxford University Press.

Daly, M. y J. Lewis (2000), "The concept of social care and the analysis of contemporary welfare states", British Journal of Sociology, vol. 51, N² 2, Londres, Wiley Blackwell.

Davoine, L. y D. Meda (2008), "Importance and meaning of work in Europe: a French singularity", Document de travail, $\mathrm{N}^{\mathrm{o}}$ 96-2, Noisy-Le-Grand, Centre d'études de l'emploi (CEE).

Díaz Fernández, M. y M. Llorente Marrón (2011), Estimaciones de la demanda mundial de cuidado, 2010-2050. Una aproximación econométrica, Bilbao, Fundación BBVA. 
Dickinson, D. K., A. McCabe y M. A. Essex (2006), “A window of opportunity we must open to all: the case for high-quality support for language and literacy", Handbook of early literacy research, vol. II, D. K. Dickinson y S. B. Neuman (eds.), Nueva York, Guilford Press.

Domínguez Serrano, M. (2012), "Unpaid care work in Africa”, Documento de Trabajo, $N^{\circ}$ 6/2012, Bilbao, Fundación BBVA.

Draibe, S. y M. Riesco (2006), “Estado de bienestar, desarrollo económico y ciudadanía: algunas lecciones de la literatura contemporánea", serie Estudios y Perspectivas, N 55 (LC/L.2601-P), Ciudad de México, sede subregional de la CEPAL en México.

Duncan, G. J., J. Brooks-Gunn y P. K. Klebanov (1994), “Economic deprivation and early childhood development", Child Development, vol. 65, No 2, Ann Arbor, Society for Research in Child Development.

Durán Heras, M. A. (2012), El trabajo no remunerado en la economía global, Bilbao, Fundación BBVA.

(2003), "El trabajo no remunerado y las familias", ponencia presentada en la Consulta técnica sobre contabilización de la producción no remunerada de servicios de salud en el hogar, Washington, D.C., 4 y 5 de diciembre.

Durán Heras, M. A. y V. Milosavjevic (2012), "Unpaid work, time use surveys and care demand forecasting in Latin America", Documento de Trabajo, No 7/2012, Bilbao, Fundación BBVA.

Durán Valverde, F. y H. Pena (2011), “Determinantes de las tasas de reemplazo de pensiones de capitalización individual: escenarios latinoamericanos comparados", serie Seminarios y conferencias, No 64 (LC/L.3329-P), Santiago, Comisión Económica para América Latina y el Caribe (CEPAL).

Education, Audiovisual and Culture Executive Agency (2009), Tackling Social and Cultural Inequalities through Early Childhood Education and Care in Europe, Bruselas.

Espejo, A., F. Filgueira y M. N. Rico (2010), “Familias latinoamericanas: organización del trabajo no remunerado y de cuidado", Documentos de Proyectos (LC/W.354), Santiago, Comisión Económica para América Latina y el Caribe (CEPAL).

Esping-Andersen, G. (2009a), The Incomplete Revolution. Adapting to Women's New Roles, Cambridge, Polity Press.

(2009b), "Families and the Revolution in Women's Roles", The Incomplete Revolution. Adapting to Women's New Roles, Cambridge, Polity Press.

(2008), "Equal opportunities in an increasingly hostile world", Trois Lectures, $\mathrm{N}^{\mathrm{o}}$ II, París, College de France [en línea] http://citeseerx.ist.psu.edu/ viewdoc / download?doi=10.1.1.317.9623\&rep=rep1\&type=pdf.

(2002), "A new gender contract", Why We Need a New Welfare State?, G. Esping-Andersen y otros, Oxford, Oxford University Press.

(1999), Social Foundations of Postindustrial Economies, Nueva York, Oxford University Press.

Esping-Andersen, G. y J. Myles (2007), "The welfare state and redistribution", inédito [en línea] https:/ / www.researchgate.net/publication/255583959_The_ Welfare_State_and_Redistribution.

Esping-Andersen, G. y otros (2013), "Couple specialization in multiple equilibria", European Sociological Review, vol. 29, N 6, Oxford, Oxford University Press.

Fagnani, J. y A. Math (2008), "Policy packages for families with children in 11 European countries: multiple approaches", Comparative Social Research, vol. 25, A. Leira y C. Saraceno (eds.), Bingley, Emerald Group Publishing Limited. 
Fernández, J. L. y J. Forder (2012), “Reforming long-term care funding arrangements in England: international lessons", Applied Economic Perspectives and Policy, vol. 34, N ${ }^{\circ} 2$, Nueva York, Oxford University Press.

Friedan, B. (1987), The Second Stage, Nueva York, Summit Books.

Fuller, B. y otros (2009) "The health and cognitive growth of Latino toddlers: at risk or immigrant paradox?", Maternal and Child Health Journal, vol. 13, N 6, Springer International Publishing, [en línea] http://www.ncbi.nlm.nih.gov/ pmc/articles/PMC2759448/.

García Díez, S. (2012), "Childcare in Europe. A reflection on the present economic approach", Documento de Trabajo, N 3/2012, Bilbao, Fundación BBVA.

Gascón, S. y N. Redondo (2014), "Calidad de los servicios de largo plazo para personas mayores con dependencia", serie Políticas Sociales, No 207 (LC/L.3875), Santiago, Comisión Económica para América Latina y el Caribe (CEPAL).

Gil Calvo, E. (2011), "Sin autonomía", El País, Madrid, 17 de abril.

Gornick, J. y M. Meyers (2009), "Institutions that support gender equality in parenthood and employment", Gender Equality. Transforming Family Divisions of Labor, J. Gornick y M. Meyers (eds.), Londres, Verso.

Grundy, E. (2010), "The care of older people in the United Kingdom: problems, provision and policy", documento preparado para el seminario internacional Experiencias Internacionales y Propuestas para Consolidar la Red Nacional de Cuido de las Personas mayores en Costa Rica, San José, 22 y 23 de noviembre [en línea] http:/ /dds.cepal.org/eventos/presentaciones/2010/1122/Grundy.pdf.

Hackman, D. A., M. J. Farah y M. J. Meaney (2010), “Socioeconomic status and the brain: mechanistic insights from human and animal research", Nature Reviews Neuroscience, vol. 11, No 9, Londres, Macmillan Publishers [en línea] http:/ / www.ncbi.nlm.nih.gov/pubmed/20725096.

Hagestad, G. O. (2008), "The book-ends: emerging perspectives on children and old people", Families, Ageing and Social Policy. Intergenerational Solidarity in European Welfare States, C. Saraceno (ed.), Northampton, Edward Elgar Publishing.

Hart, B. y T. R. Risley (1995), Meaningful Differences in the Everyday Experience of Young American Children, Baltimore, Brookes Publishing.

Haskins, R. y otros (2005), School Readiness: Closing Racial and Ethnic Gaps Affairs, vol. $15, N^{o} 1$, The Future of Children, Princeton University/The Brookings Institution.

Heckman, J. J. (2008), "Schools, skills, and synapses", IZA Discussion Paper, N 3515, Bonn, Institute for the Study of Labor (IZA).

Jelin, E. (2007), "Las familias latinoamericanas en el marco de las transformaciones globales", Familias y políticas públicas en América Latina. Una historia de desencuentros (LC/G.2345-P), I. Arriagada (coord.), Santiago, Comisión Económica para América Latina y el Caribe (CEPAL).

Jenson, J. (2008), "Children, new social risks and policy change: a lego ${ }^{\mathrm{TM}}$ future?", Comparative Social Research, vol. 25, A. Leira y C. Saraceno (eds.), Bingley, Emerald Group Publishing Limited.

Keck, W. (2008), "The relationship between children and their frail elderly parents in different care regimes", Families, Ageing and Social Policy. Intergenerational Solidarity in European Welfare States, C. Saraceno (ed.), Northampton, Edward Elgar Publishing.

Knijn, T. e I. Ostner (2008), "The 'meaning' of children in Dutch and German family policy", Comparative Social Research, vol. 25, A. Leira y C. Saraceno (eds.), Bingley, Emerald Group Publishing Limited. 
Knudsen, E.I. (2004), "Sensitive periods in the development of the brain and behavior", Journal of Cognitive Neuroscience, vol. 16, $\mathrm{N}^{\mathrm{o}}$ 8, Cambridge, Massachusetts Institute of Technology.

Knudsen, E.I. y otros (2006), “Economic, neurobiological, and behavioral perspectives on building America's future workforce", Proceedings of the National Academy of Sciences of the United States of America (PNAS), vol. 103, $\mathrm{N}^{\mathrm{o}} 27$, Washington, D.C., NationalAcademy of Sciences [en línea] www.pnas.org/ cgi/doi/10.1073/pnas.0600888103.

Künemund, H. (2008), "Intergenerational relations within the family and the state", Families, Ageing and Social Policy. Intergenerational Solidarity in European Welfare States, C. Saraceno (ed.), Northampton, Edward Elgar Publishing.

Kohli, M. y M. Albertini (2008), "The family as a source of support for adult children's own family projects: European varieties", Families, Ageing and Social Policy. Intergenerational Solidarity in European Welfare States, C. Saraceno (ed.), Northampton, Edward Elgar Publishing.

Landry, S. H. y otros (2008), "A responsive parenting intervention: the optimal timing across early childhood for impacting maternal behaviors and child outcomes", Developmental Psychology, vol. 44, N 5, Washington, D.C., American Psychological Association.

Lane, P., H.J. Chang y J. Bhagwati (2011), “The Economist.com debate: manufacturing" [en línea] http://www.columbia.edu/ jb38/papers/pdf/The_Economist_com_ Debate_Manufacturing.pdf.

Leira, A. y C. Saraceno (eds.) (2008), “Childhood: changing contexts", Comparative Social Research, vol. 25, Bingley, Emerald Group Publishing Limited.

Lister, R. (2008), "Investing in children and childhood: a new welfare policy paradigm and its implications", Comparative Social Research, vol. 25, A. Leira y C. Saraceno (eds.), Bingley, Emerald Group Publishing Limited.

Martínez Rodríguez, T. (2010a), "Los servicios formales de atención a las personas mayores. Situación actual, avances y experiencias significativas en los países desarrollados", documento preparado para el seminario internacional Experiencias Internacionales y Propuestas para Consolidar la Red Nacional de Cuido de las Personas mayores en Costa Rica, San José, 22 y 23 de noviembre [en línea] http://dds.cepal.org/eventos/presentaciones/2010/1122/TeresaMartinez.pdf. (2010b), "Las buenas prácticas en la atención a las personas adultas en situación de dependencia", Madrid, Informes Portal Mayores, $N^{\circ}$ 98, Madrid, Consejo Superior de Investigaciones Científicas (CSIC) [en línea] http:/ / www.imsersomayores.csic.es/documentos/documentos/martinezpracticas-01.pdf.

McDonald, P. (2010), "Macro and micro perspectives on the interrelationship between women's employment and fertility", presentación realizada en el IV Congreso de la Asociación Latinoamericana de Población (ALAP): Condiciones y Transformaciones Culturales, Factores Económicos y Tendencias Demográficas en Latinoamérica, La Habana, 16-19 de noviembre.

McLoyd, V.C. (1998), "Socioeconomic disadvantage and child development", American Psychologist, vol. 53, N², Washington, D.C., American Psychological Association.

Nelson III, C. A. y otros (2007), "Cognitive recovery in socially deprived young children: the Bucharest Early Intervention Project", Science, vol. 318, No 5858, Nueva York, American Association for the Advancement of Science. 
Neuman, S. B. y K. Roskos (1997), "Literacy knowledge in practice: contexts of participation for young writers and readers", Reading Research Quarterly, vol. 32, $\mathrm{N}^{\mathrm{o}}$ 1, Newark, International Literacy Association (ILA).

Neuman, S. B., C. Copple y S. Bredekamp (2000), Learning to Read and Write. Developmentally Appropriate Practices for Young Children, Washington, D.C., National Association for the Education of Young Children (NAEYC).

Nisbett, R.E. (2009), Intelligence and How to Get It: Why Schools and Cultures Count, Nueva York, W.W. Norton \& Company.

OCDE (Organización de Cooperación y Desarrollo Económicos) (2012), Haciendo lo mejor para las familias, Santiago, Corporación de Investigación, Estudio y DesarrollodelaSeguridadSocial(CIEDESS) [en línea] http:/ / www.oecd-ilibrary. org/social-issues-migration-health / haciendo-lo-mejor-para-las-familias_ 9789264190474-es. (2009), Doing Better for Children, París.

(2005a), Informe PISA 2003. Aprender para el mundo del mañana, Madrid, Editorial Santillana.

(2005b), Long-term Care for Older People, París.

(2002), Conocimientos y aptitudes para la vida. Primeros resultados del Programa Internacional de Evaluación de Estudiantes (PISA) 2000 de la OCDE, Ciudad de México, Editorial Santillana.

OIT/PNUD (Organización Internacional del Trabajo/Programa de las Naciones Unidas para el Desarrollo) (2009), Trabajo y familia: hacia nuevas formas de conciliación con corresponsabilidad social, Santiago.

Plantenga, J. y otros (2008), “Childcare services in 25 European Union member states: the Barcelona targets revisited", Comparative Social Research, vol. 25, A. Leira y C. Saraceno (eds.), Bingley, Emerald Group Publishing Limited.

Poggio, T. (2008), "La proprietà della casa nella stratificazione sociale”, Meridiana, N 62.

Prado, A. y A. Sojo (eds.) (2010), Envejecimiento en América Latina. Sistemas de pensiones y protección social integral (LC/G.2475), Santiago, Comisión Económica para América Latina y el Caribe (CEPAL).

Programa Estado de la Nación (2011), Tercer Informe Estado de la Educación, San José.

Ramey, C. y S. Ramey (2004), "Early Intervention, Intelligence and Academic Achievement: Empirical Evidence for Successful Outcomes" [en línea] http: / / www.cdl.org/wp-content/uploads/2014/02/Early-InterventionIntelligence-and-Academic-Achievement. pdf.

Rico, M.N. y C. Robles (2016), "Politicas de cuidado en América Latina. Forjando la igualdad", serie Asuntos de Género, No 140, (LC/L.4226), Santiago, Comisión Económica para América Latina y el Caribe (CEPAL).

Rico, M.N. y C. Maldonado Valera (eds.) (2011), “Las familias latinoamericanas interrogadas. Hacia la articulación del diagnóstico, la legislación y las políticas", serie Seminarios y conferencias, $N^{\circ} 61$ (LC/L.3296-P), Santiago, Comisión Económica para América Latina y el Caribe (CEPAL).

Rico, M. N. (coord.) (2011), “El desafío de un sistema nacional de cuidados para el Uruguay", serie Seminarios y Conferencias, No 66 (LC/L.3359), Santiago, Comisión Económica para América Latina y el Caribe (CEPAL).

Rimm-Kaufman, S. E., R. C. Pianta y M. J. Cox (2000), “Teachers' judgments of problems in the transition to kindergarten", Early Childhood Research Quarterly, vol. 15, No 2, Amsterdam, Elsevier. 
Rodríguez, E.T. y otros (2009), “The formative role of home literacy experiences across the first three years of life in children from low-income families", Journal of Applied Developmental Psychology, vol. 30, N 6, Amsterdam, Elsevier.

Rodríguez Enríquez, C., N. Giosa Zuazúa y D. Nieva (2009), “El costo de las políticas ausentes. Las implicancias económicas y sociales de la carencia de acciones de conciliación en América Latina", Organización Internacional del Trabajo (OIT), inédito.

Rodríguez Rodríguez,P. (2010), “La atención integral centrada en la persona. Principios y criterios que fundamentan un modelo de intervención en discapacidad, envejecimiento y dependencia", Informes Portal Mayores, No 106, Madrid, Consejo Superior de Investigaciones Científicas (CSIC) [en línea] http:/ / envejecimiento. csic.es/documentos/documentos/pilar-atencion-01.pdf.

(2006), "El sistema de servicios sociales español y las necesidades derivadas de la atención a la dependencia", Documento de Trabajo, No 87/2006, Madrid, Fundación Alternativas.

Román, I. y N. Morales (2010), “Demanda potencial de cuido infantil según estructura de los hogares: el caso de Costa Rica", San José, Programa Estado de la Nación/Instituto Nacional de las Mujeres (INAMU).

Rosero-Bixby, L., T. Castro-Martín y T. Martín-García (2009), “Is Latin America starting to retreat from early and universal childbearing?", Demographic Research, vol. 20, Rostock [en línea] http://www.demographic-research.org/ Volumes/Vol20/9/.

Saraceno, C. (2011a), "Beyond care. The persistent invisibility of unpaid family work", Sociologica, No 1/2011, Bolonia, Società Editrice il Mulino.

(2011b), "Work-family balance across Europe: a too narrow focus in policy practices and discourses", Challenge Europe, N ${ }^{\circ}$ 21, Bruselas, European Policy Centre. (2009), "Bisogni e responsabilità di cura. Non solo una questione di genere", Turín,Universidad deTurín [en línea]http:/ / www.centrounesco.to.it/media/ letio-magistralissaraceno.pdf.

(2008a), "Introduction: intergenerational relations in families. A micro-macro perspective", Families, Ageing and Social Policy. Intergenerational Solidarity in European Welfare States, Northampton, Edward Elgar Publishing. (ed.) (2008b), Families, Ageing and Social Policy. Intergenerational Solidarity in European Welfare States, Northampton, Edward Elgar Publishing.

Sarasa, S. y S. Billingsley (2008), "Personal and household caregiving from adult children to parents and social stratification", Families, Ageing and Social Policy. Intergenerational Solidarity in European Welfare States, C. Saraceno (ed.), Northampton, Edward Elgar Publishing.

Sauma, P. (2011), “Elementos para la consolidación de la Red Nacional de Cuido de las Personas mayores en Costa Rica", serie Seminarios y Conferencias, No 63 (LC/L.3323-P), Santiago, Comisión Económica para América Latina y el Caribe (CEPAL).

Schmidt, V. A. (2009), "Putting the political back into political economy by bringing the state back in yet again", World Politics, vol. 61, N 3, Cambridge University Press. (2008), "Bringing ideas and discourse back into the explanation of change in varieties of capitalism and welfare states", Working Paper, $\mathrm{N}^{\mathrm{o}} 2$, Brighton, Universidad de Sussex.

Sen, A. (2000), Development as Freedom, Nueva York, Anchor Books. 
Shonkoff, J. P. y D. A. Phillips (eds.) (2000), From Neurons to Neighborhoods. The Science of Early Childhood Development, Washington, D.C., National Academy Press.

Sipilä, J., A. Anttonen y J. Baldock (2003), “The importance of social care”, The Young, the Old and the State. Social Care Systems in Five Industrial Nations, Cheltenham, Edward Elgar Publishing.

Sojo, A. (2011), "De la evanescencia a la mira. El cuidado como eje de políticas y de actores en América Latina", serie Seminarios y Conferencias, No 67 (LC/L.3393), Santiago, Comisión Económica para América Latina y el Caribe (CEPAL).

(2010) "Conclusiones del seminario", presentación realizada en el seminario internacional Experiencias Internacionales y Propuestas para Consolidar la Red Nacional de Cuido de las Personas mayores en Costa Rica, San José, 22y 23 denoviembre[enlínea]http:/ / dds.cepal.org/eventos/presentaciones / 2010/1122/ AnaSojo-conclusiones.pdf.

(2007), "La trayectoria del vínculo entre políticas selectivas contra la pobreza y políticas sectoriales", Revista CEPAL, N 97 (LC/G.2333-P), Santiago, Comisión Económica para América Latina y el Caribe (CEPAL).

(1985), Mujer y politica. Ensayo sobre el feminismo y el sujeto popular, San José, Departamento Ecuménico de Investigaciones (DEI).

Soria Batista, A. y otros (2008), "Envelhecimento e dependência: desafios para a organização da proteção social", Coleção Previdência Social, vol. 28, Brasilia, Ministerio de Previsión Social.

Sundström, G. (2010), "Swedish old-age care: traditions, challenges, and experiences", documento preparado para el seminario internacional Experiencias Internacionales y Propuestas para Consolidar la Red Nacional de Cuido de las Personas mayores en Costa Rica, San José, 22 y 23 de noviembre [en línea] http:/ /dds.cepal.org/eventos/presentaciones/2010/1122/GSundstrom.pdf.

Treviño, E. y otros (2010), Factores asociados al logro cognitivo de los estudiantes de América Latina y el Caribe, Santiago, Organización de las Naciones Unidas para la Educación, la Ciencia y la Cultura (UNESCO)/Laboratorio Latinoamericano de Evaluación de la Calidad de la Educación (LLECE).

UCR/CONAPAM (Universidad de Costa Rica/Consejo Nacional de la Persona Adulta Mayor) (2008), I Informe estado de situación de la persona adulta mayor en Costa Rica, X. Fernández y A. Robles (coords.), San José.

UNICEF/UNIPRIN (Fondo de las Naciones Unidas para la Infancia/Unión de Instituciones Privadas de Atención a la Niñez y la Adolescencia) (1999), Factores que favorecen la calidad en la atención a la niñez, San José.

Valenzuela, M.E. (2010), “Trabajo y responsabilidades familiares en el contexto del envejecimiento: ¿quién se encarga del cuidado?", Envejecimiento en América Latina: sistemas de pensiones y protección social integral (LC/G.2475), A. Prado y A. Sojo (eds.), Santiago, Comisión Económica para América Latina y el Caribe (CEPAL).

Weisleder, A. (2010a), “The importance of investing in early education”, inédito. (2010b), "Developmentally appropriate practice in preschool education", inédito.

Zavala de Cosío, M. E. (2010), "Familias y relaciones de género en América Latina. Perspectivas internacionales y el caso de México", presentación realizada en el IV Congreso de la Asociación Latinoamericana de Población (ALAP): Condiciones y Transformaciones Culturales, Factores Económicos y Tendencias Demográficas en Latinoamérica, La Habana, 16-19 de noviembre. 



\section{Publicaciones recientes de la CEPAL ECLAC recent publications}

\section{www.cepal.org/publicaciones}

\section{Informes periódicos / Annual reports}

También disponibles para años anteriores / Issues for previous years also available

- Estudio Económico de América Latina y el Caribe 2016, 236 p. Economic Survey of Latin America and the Caribbean 2016, 232 p.

- La Inversión Extranjera Directa en América Latina y el Caribe 2016, 170 p. Foreign Direct Investment in Latin America and the Caribbean 2016, 164 p.

- Anuario Estadístico de América Latina y el Caribe 2016 / Statistical Yearbook for Latin America and the Caribbean 2016, 132 p.

- Balance Preliminar de las Economías de América Latina y el Caribe 2016, 132 p. Preliminary Overview of the Economies of Latin America and the Caribbean 2016, 124 p.

- Panorama Social de América Latina 2015, 226 p. Social Panorama of Latin America 2015, 222 p.

- Panorama de la Inserción Internacional de América Latina y el Caribe 2016, 174 p. Latin America and the Caribbean in the World Economy 2015, 170 p.

\section{Libros y documentos institucionales / Institutional books and documents}

- ECLAC Thinking. Selected Texts (1948-1998), 2016, 520 p.

- La matriz de la desigualdad en América Latina, 2016, 96 p. The social inequality matrix in Latin America, 2016, 94 p.

- Autonomía de las mujeres e igualdad en la agenda de desarrollo sostenible, 2016, 184 p. Equality and women's autonomy in the sustainable development agenda, 2016, 168 p. Autonomia das mulheres e igualdade na agenda de desenvolvimento sustentável. Síntese, 2016, $106 p$.

- La Unión Europea y América Latina y el Caribe ante la Agenda 2030 para el Desarrollo Sostenible: el gran impulso ambiental, 2016, $112 p$.

The European Union and Latin America and the Caribbean vis-à-vis the 2030 Agenda for Sustainable Development: The environmental big push, 2016, 112 p.

- Horizontes 2030: la igualdad en el centro del desarrollo sostenible, 2016, 176 p. Horizons 2030: Equality at the centre of sustainable development, 2016, 174 p. Horizontes 2030: a igualdade no centro do desenvolvimento sustentável, 2016, 176 p.

- 40 años de agenda regional de género, 2016, 130 p. 40 years of the regional gender agenda, 2016,128 $p$.

- La nueva revolución digital: de la Internet del consumo a la Internet de la producción, 2016, 100 p. The new digital revolution: From the consumer Internet to the industrial Internet, 2016, 100 p.

- Panorama fiscal de América Latina y el Caribe 2016: las finanzas públicas ante el desafío de conciliar austeridad con crecimiento e igualdad, 2016, 90 p.

Fiscal Panorama of Latin America and the Caribbean 2016: Public finances and the challenge of reconciling austerity with growth and equality, 2016, 86 p. 
- Reflexiones sobre el desarrollo en América Latina y el Caribe: conferencias magistrales 2015, 2016, $74 \mathrm{p}$.

- La nueva revolución digital: de la Internet del consumo a la Internet de la producción, 2015, 98 p. The new digital revolution: From the consumer Internet to the industrial Internet, 2015, 98 p.

- Pactos para la igualdad: hacia un futuro sostenible, 2014, $340 \mathrm{p}$.

Covenants for Equality: Towards a sustainable future, 2014, 330 p.

\section{Libros de la CEPAL / ECLAC books}

141 Brechas y transformaciones: la evolución del empleo agropecuario en América Latina, Jürgen Weller (ed.), 2016, $274 \mathrm{p}$.

140 Protección y formación: instituciones para mejorar la inserción laboral en América Latina y Asia, Alberto Isgut, Jürgen Weller (eds.), 2016, 428 p.

Protection and training: Institutions for improving workforce integration in Latin America and Asia, Alberto Isgut, Jürgen Weller (eds.), 2016, 428 p.

139 Hacia una nueva gobernanza de los recursos naturales en América Latina y el Caribe, Hugo Altomonte, Ricardo J. Sánchez, 2016, 256 p.

138 Estructura productiva y política macroeconómica: enfoques heterodoxos desde América Latina, Alicia Bárcena, Antonio Prado, Martín Abeles (eds.), 2015, 282 p.

137 Juventud: realidades y retos para un desarrollo con igualdad, Daniela Trucco, Heidi Ullmann (eds.), 2015, $282 \mathrm{p}$.

136 Instrumentos de protección social: caminos latinoamericanos hacia la universalización, Simone Cecchini, Fernando Filgueira, Rodrigo Martínez, Cecilia Rossel (eds.), 2015, 510 p.

\section{Páginas Selectas de la CEPAL / ECLAC Select Pages}

- Planificación y prospectiva para la construcción de futuro en América Latina y el Caribe. Textos seleccionados 2013-2016, Jorge Máttar y Mauricio Cuervo (comps.), 2016, 222 p.

- Desarrollo inclusivo en América Latina. Textos seleccionados 2009-2016, Ricardo Infante (comp.), 2016, 294 p.

- Globalización, integración y comercio inclusivo en América Latina. Textos seleccionados 2010-2014, Osvaldo Rosales (comp.), 2015, 326 p.

- El desafío de la sostenibilidad ambiental en América Latina y el Caribe. Textos seleccionados 2012-2014, Carlos de Miguel, Marcia Tavares (comps.), 2015, 148 p.

\section{Copublicaciones / Co-publications}

- El imperativo de la igualdad, Alicia Bárcena, Antonio Prado, CEPAL/Siglo Veintiuno, Argentina, 2016, $244 \mathrm{p}$.

- Gobernanza global y desarrollo: nuevos desafíos y prioridades de la cooperación internacional, José Antonio Ocampo (ed.), CEPAL/Siglo Veintiuno, Argentina, 2015, 286 p.

- Decentralization and Reform in Latin America: Improving Intergovernmental Relations, Giorgio Brosio and Juan Pablo Jiménez (eds.), ECLAC/Edward Elgar Publishing, United Kingdom, 2012, 450 p.

- Sentido de pertenencia en sociedades fragmentadas: América Latina desde una perspectiva global, Martín Hopenhayn y Ana Sojo (comps.), CEPAL/Siglo Veintiuno, Argentina, 2011, 350 p. 


\section{Coediciones / Co-editions}

- Perspectivas económicas de América Latina 2017: Juventud, Competencias y Emprendimiento, 2016, 338 p. Latin American Economic Outlook 2017: Youth, Skills and Entrepreneurship, 2016, 314 p.

- Desarrollo e integración en América Latina, 2016, 314 p.

- Hacia un desarrollo inclusivo: el caso del Uruguay, 2016, 174 p.

- Perspectivas de la agricultura y del desarrollo rural en las Américas: una mirada hacia América Latina y el Caribe 2015-2016, CEPAL/FAO/IICA, 2015, 212 p.

\section{Documentos de proyecto / Project documents}

- El cambio tecnológico y el nuevo contexto del empleo: tendencias generales y en América Latina, Sebastian Krull, 2016, 48 p.

- Cambio climático, políticas públicas y demanda de energía y gasolinas en América Latina: un meta-análisis, Luis Miguel Galindo, Joseluis Samaniego, Jimy Ferrer, José Eduardo Alatorre, Orlando Reyes, 2016, 68 p.

- Estado de la banda ancha en América Latina y el Caribe 2016, 2016, 46 p.

\section{Cuadernos estadísticos de la CEPAL}

44 Las cuentas de los hogares y el bienestar en América Latina. Más allá del PIB, 2016.

43 Estadísticas económicas de América Latina y el Caribe: Aspectos metodológicos y resultados del cambio de año base de 2005 a 2010

\section{Series de la CEPAL / ECLAC Series}

Asuntos de Género / Comercio Internacional / Desarrollo Productivo / Desarrollo Territorial / Estudios Estadísticos / Estudios y Perspectivas (Bogotá, Brasilia, Buenos Aires, México, Montevideo) / Studies and Perspectives (The Caribbean, Washington) / Financiamiento del Desarrollo / Gestión Pública / Informes y Estudios Especiales / Macroeconomía del Desarrollo / Medio Ambiente y Desarrollo / Población y Desarrollo / Política Fiscal / Políticas Sociales / Recursos Naturales e Infraestructura / Seminarios y Conferencias.

\section{Manuales de la CEPAL}

4 Territorio e igualdad: planificación del desarrollo con perspectiva de género, 2016, 84 p.

3 Manual de formación regional para la implementación de la resolución 1325 (2000) del Consejo de Seguridad de las Naciones Unidas relativa a las mujeres, la paz y la seguridad, María Cristina Benavente R., Marcela Donadio, Pamela Villalobos, 2016, 126 p.

2 Guía general para la gestión de residuos sólidos domiciliarios, Estefani Rondón Toro, Marcel Szantó Narea, Juan Francisco Pacheco, Eduardo Contreras, Alejandro Gálvez, 2016, 212 p.

\section{Revista CEPAL / CEPAL Review}

La Revista se inició en 1976, con el propósito de contribuir al examen de los problemas del desarrollo socioeconómico de la región. La Revista CEPAL se publica en español e inglés tres veces por año.

CEPAL Review first appeared in 1976, its aim being to make a contribution to the study of the economic and social development problems of the region. CEPAL Review is published in Spanish and English versions three times a year. 


\title{
Observatorio demográfico / Demographic Observatory
}

Edición bilingüe (español e inglés) que proporciona información estadística actualizada, referente a estimaciones y proyecciones de población de los países de América Latina y el Caribe. Desde 2013 el Observatorio aparece una vez al año.

Bilingual publication (Spanish and English) proving up-to-date estimates and projections of the populations of the Latin American and Caribbean countries. Since 2013, the Observatory appears once a year.

\section{Notas de población}

Revista especializada que publica artículos e informes acerca de las investigaciones más recientes sobre la dinámica demográfica en la región. También incluye información sobre actividades científicas y profesionales en el campo de población. La revista se publica desde 1973 y aparece dos veces al año, en junio y diciembre.

Specialized journal which publishes articles and reports on recent studies of demographic dynamics in the region. Also includes information on scientific and professional activities in the field of population. Published since 1973, the journal appears twice a year in June and December.

\section{Las publicaciones de la CEPAL están disponibles en: ECLAC publications are available at: www.cepal.org/publicaciones}

También se pueden adquirir a través de: They can also be ordered through: www.un.org/publications

\author{
United Nations Publications \\ PO Box 960 \\ Herndon, VA 20172 \\ USA
}

Tel. (1-888)254-4286

Fax (1-800)338-4550

Contacto / Contact. publications@un.org Pedidos / Orders: order@un.org 


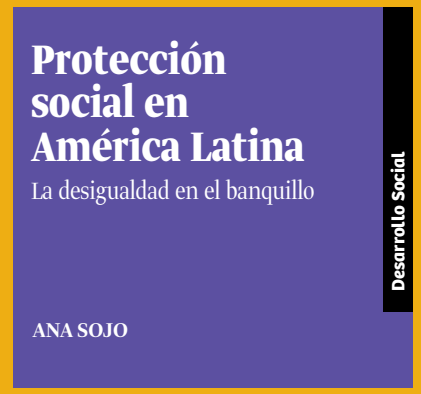

En América Latina los sistemas de protección social adolecen de profundas segmentaciones y desigualdades, y varios de ellos enfrentan graves crisis de legitimidad como consecuencia de promesas incumplidas.

Para emprender reformas que permitan encarar la complejidad de los sistemas existentes, fortalecer su ethos redistributivo y solidario y mejorar la calidad de los servicios es indispensable forjar amplias coaliciones políticas.

En este libro se tratan los avances y desafíos de los sistemas de pensiones y salud, y se razona acerca de la necesidad de que el cuidado sea un nuevo pilar de la protección social dada su gama de objetivos cruciales.

Se indaga en sistemas de protección social fragmentados y poco equitativos y, a partir de ello, se abordan e hilvanan de manera recursiva los diversos enfoques sobre la protección social y sus efectos; además, se fundamentan los principios de universalidad y solidaridad y se hace un contrapunto con el aseguramiento de mercado.

Asimismo, se estudian las coberturas para reconstruir un mosaico de las desigualdades asociadas con el mercado laboral y con la morfología de los sistemas. Se examina el efecto negativo que el aseguramiento guiado por el lucro en materia de salud y pensiones ha tenido en la desigualdad y el bienestar social. Por último, se analiza la judicialización del derecho a la salud y, al respecto, se pone de manifiesto la existencia de una vasta zona de claroscuros. 